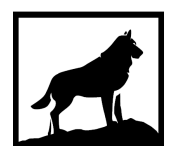

Michigan Technological

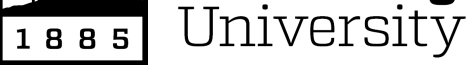

Michigan Technological University Digital Commons @ Michigan Tech

\title{
OPTIMIZATION AND COMPARISON OF OVER-EXPANDED AND OTHER HIGH EFFICIENCY FOUR-STROKE SPARK-IGNITED BOOSTED ENGINES
}

Zhuyong Yang

Michigan Technological University, zhuyongy@mtu.edu

Copyright 2019 Zhuyong Yang

\section{Recommended Citation}

Yang, Zhuyong, "OPTIMIZATION AND COMPARISON OF OVER-EXPANDED AND OTHER HIGH EFFICIENCY FOUR-STROKE SPARK-IGNITED BOOSTED ENGINES", Open Access Dissertation, Michigan Technological University, 2019.

https://doi.org/10.37099/mtu.dc.etdr/940

Follow this and additional works at: https://digitalcommons.mtu.edu/etdr

Part of the Applied Mechanics Commons, Energy Systems Commons, and the Heat Transfer, Combustion Commons 
OPTIMIZATION AND COMPARISON OF OVER-EXPANDED AND OTHER HIGH EFFICIENCY FOUR-STROKE SPARK-IGNITED BOOSTED ENGINES

By

Zhuyong Yang

\begin{abstract}
A DISSERTATION
Submitted in partial fulfillment of the requirements for the degree of DOCTOR OF PHILOSOPHY

In Mechanical Engineering - Engineering Mechanics
\end{abstract}

MICHIGAN TECHNOLOGICAL UNIVERSITY

2019

C 2019 Zhuyong Yang 
This dissertation has been approved in partial fulfillment of the requirements for the Degree of DOCTOR OF PHILOSOPHY in Mechanical Engineering - Engineering Mechanics.

Department of Mechanical Engineering - Engineering Mechanics

Dissertation Advisor: Jeffrey D. Naber

Committee Member: $\quad$ Scott A. Miers

Committee Member: Jeremy J. Worm

Committee Member: Kuilin Zhang

Department Chair: $\quad$ William W. Predebon 


\section{Table of Contents}

$1 \quad$ Introduction

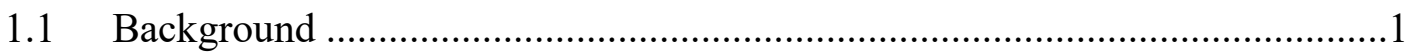

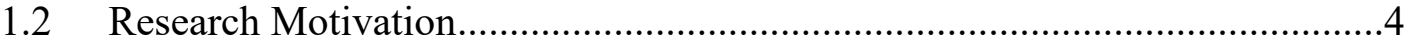

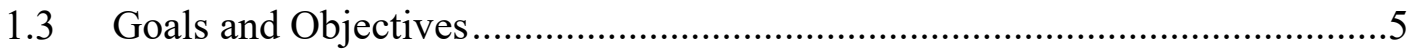

1.4 Introduction to over-expanded cycle and over-expanded cycle engine ...........6

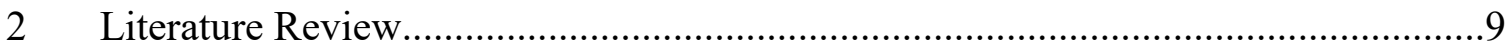

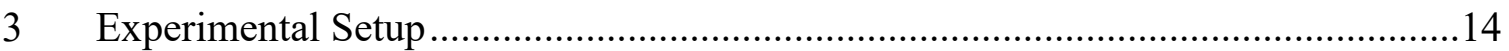

3.1 Tested Engine Specification .....................................................................14

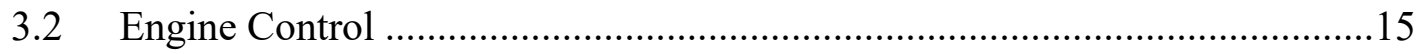

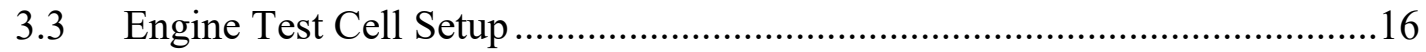

3.4 Definition of Experiments .......................................................................19

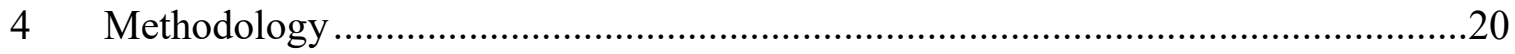

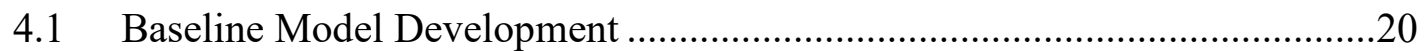

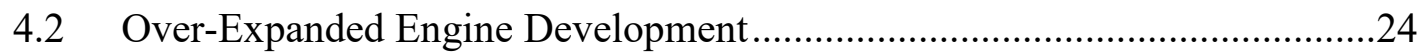

4.3 High Compression Engine Development ........................................................

4.4 Optimization of Simulation Results ..............................................................

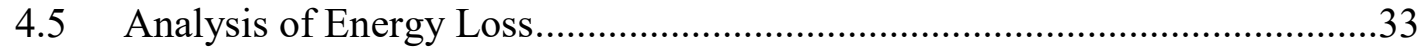

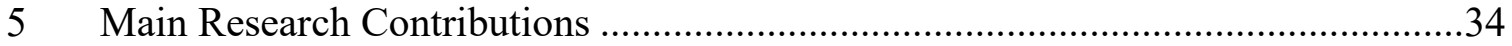

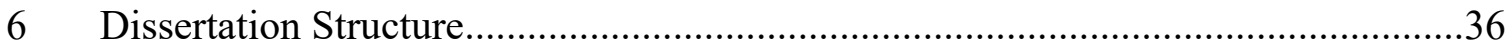

7 Investigation and Optimization of Multi-Link Over-Expanded Engine at Light Load Conditions.

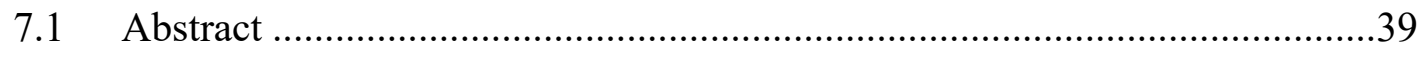

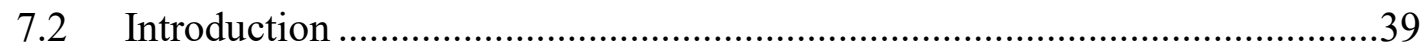

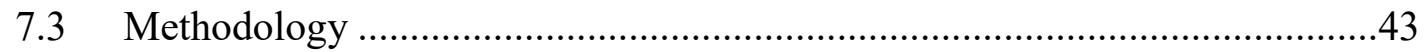

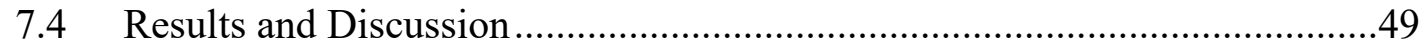




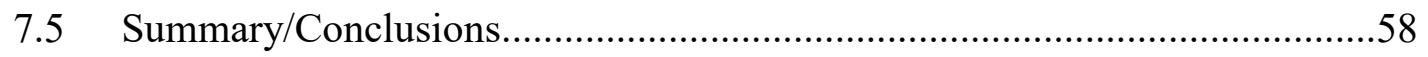

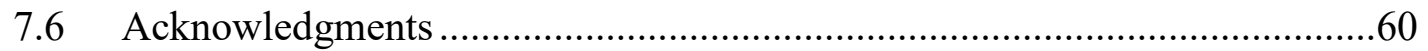

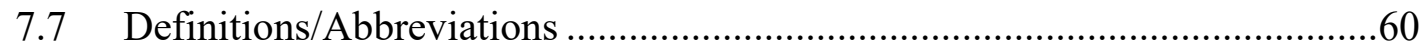

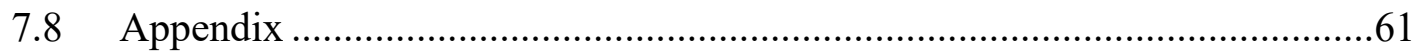

8 Investigation of High Load Operation of Spark-Ignited Over-Expanded Atkinson

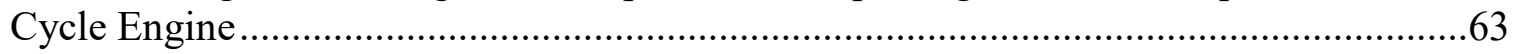

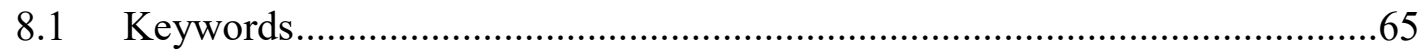

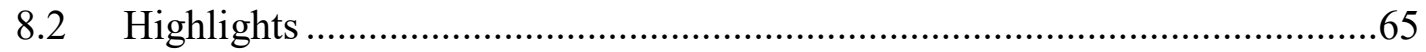

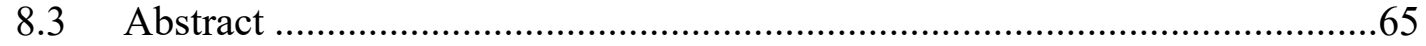

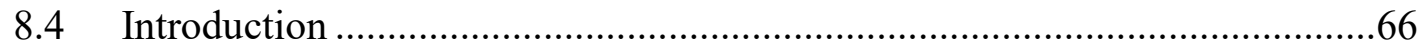

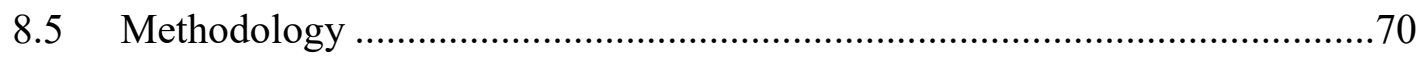

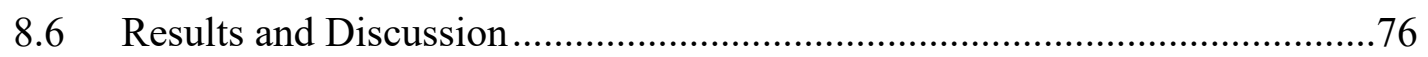

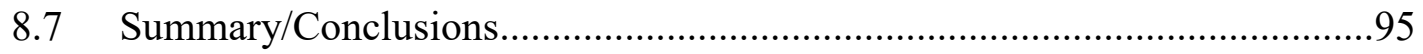

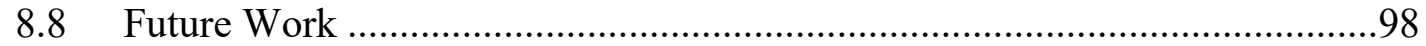

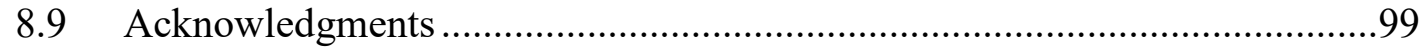

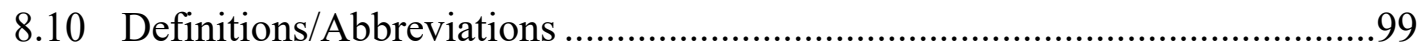

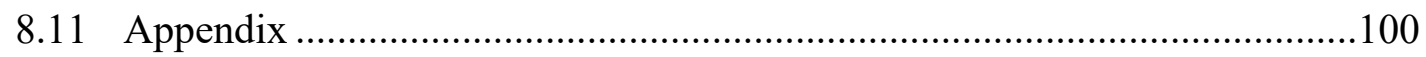

9 Comparing Methods for Improving Efficiency for Spark-Ignited Engines - Multilink Mechanical Over-Expansion to High Compression Ratio with LIVC ......................104

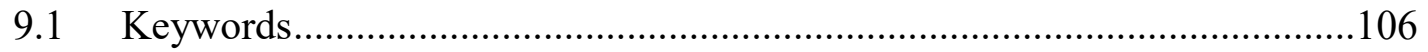

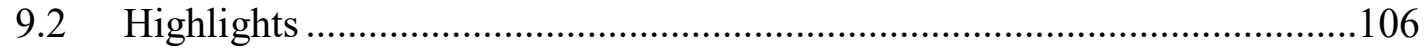

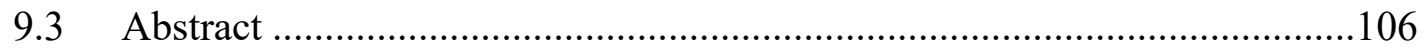

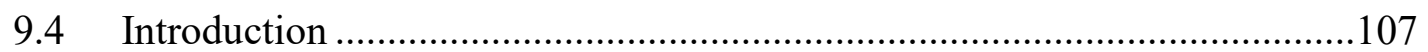

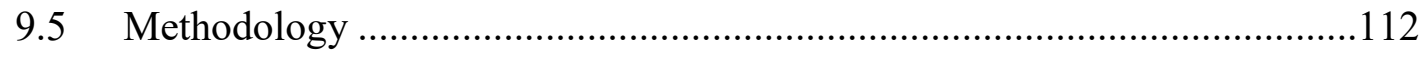

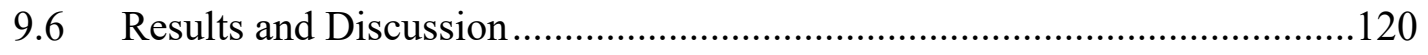

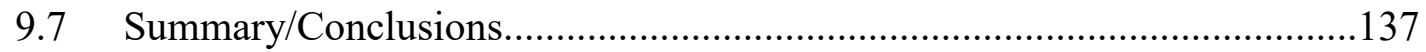

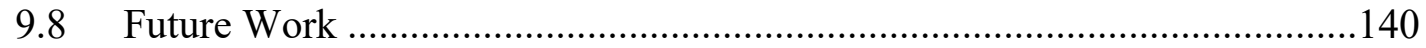

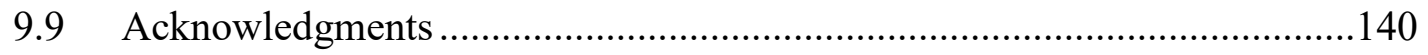

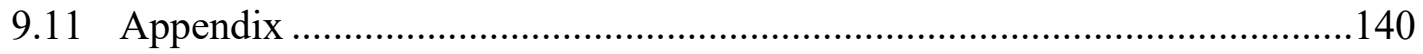




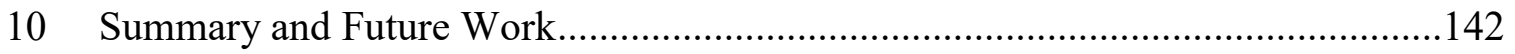

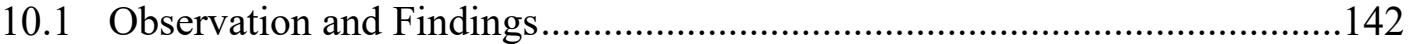

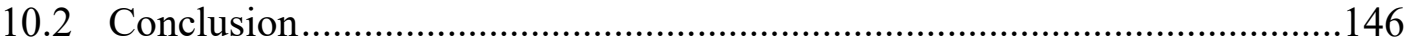

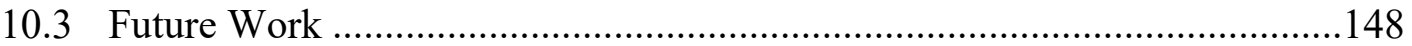

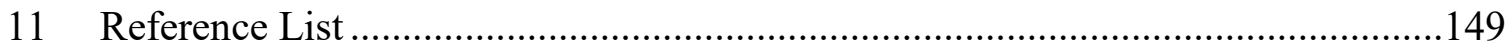

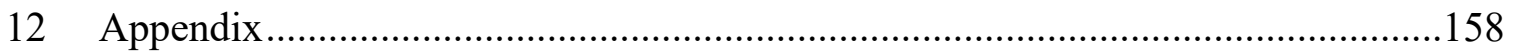




\section{List of figures}

Figure 1.1 Pressure-volume diagram for the ideal cycle of (1) Otto-cycle, (2) Overexpanded cycle, and (3) Atkinson cycle

Figure 3.1 GM LNF engine on quick disconnect engine cart.........................................14

Figure 3.2 LNF baseline valve lift as a function of crank angle location..........................15

Figure 3.3 ETAS - engine calibration tool box.................................................................16

Figure 3.4 Dynamometer in APS Labs test cell \#2 ………...........................................17

Figure 3.5. EPC Encoder Model 260 ............................................................................17

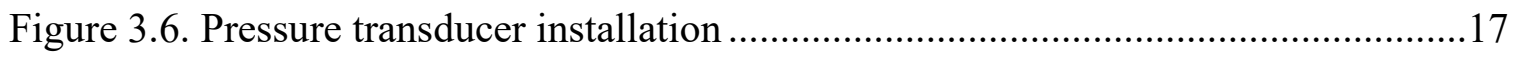

Figure 3.7. National Instruments PXI chassis...............................................................18

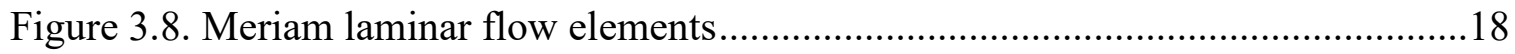

Figure 3.9. Micro Motion 1700....................................................................................18

Figure 3.10. Wiring of Micro Motion 1700 ………………...........................................18

Figure 4.1 Combustion chamber in CAD model ..........................................................20

Figure 4.2 GT-Suite generated mesh of combustion chamber .........................................20

Figure 4.3 Induction times as a function of unburned zone temperature..........................21

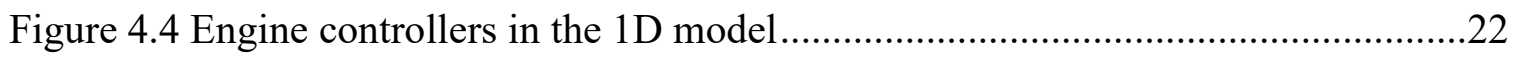

Figure 4.5 Schematic of multi-link over-expanded mechanism .......................................24

Figure 4.6 Piston location as a function of crank angle, baseline engine, and over-expanded

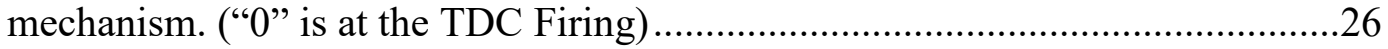

Figure 4.7 In-cylinder volume as a function of crank angle, baseline, and over-expanded

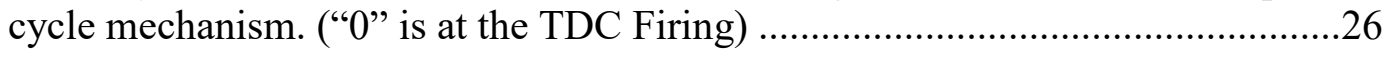

Figure 4.8 Volume and valve list as a function of crank angle of over-expanded engine.29

Figure 4.9 Gross work and pumping work of over-expanded engine in a $\log \mathrm{P}-\log \mathrm{V} / \mathrm{V}_{\max }$ diagram $\left(\mathrm{V}_{\max }\right.$ is the maximum in-cylinder volume at the end of intake stroke)...29

Figure 4.10 Indicated work breakdown of over-expanded engine .29 
Figure 4.11. Development of the multi-link mechanism and implementation in GTSuite

Figure 4.12. Valve lift of LIVC and non-LIVC of high compression engine ..................31

Figure 4.13 Cam timing sweep of IMOP and EMOP for over-expanded engine, light load

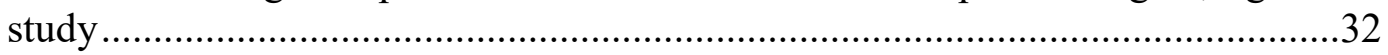

Figure 4.14 Cam timing sweep of IMOP and EMOP for over-expanded engine, high load study......

Figure 4.15 Cam timing sweep of IMOP and EMOP, the comparison study between high compression engine and multi-link over-expanded engine.

Figure 4.16 Energy loss calculation flow chart 33

Figure 7.1. Schematic of the Atkinson mechanism .46

Figure 7.2. Single-Cylinder Version of Atkinson Mechanism at Crank TDC, Output from GT-Suite. 46

Figure 7.3 Piston location as a function of crank angle comparison between baseline and Atkinson mechanism. (“0” mean at TDC Firing) .46

Figure 7.4. Spark timing sweep of baseline and Atkinson engine at 1750rpm, 10.3bar IMEPnet 47

Figure 7.5. Volume, valve lift as a function of crank angle of Atkinson engine .48

Figure 7.6. Log PV of baseline and adjusted Atkinson Engine at 1750rpm, 10.3bar IMEPnet 48

Figure 7.7. Definition of the gross loop and pumping loop in an Atkinson cycle .49

Figure 7.8. Net indicated efficiency of baseline and Atkinson engine at 2500rpm, 4 to $12 \mathrm{bar}$ IMEPnet .50

Figure 7.9. Net indicated efficiency break down at 2500rpm, 4 to 12 bar IMEPnet..........51

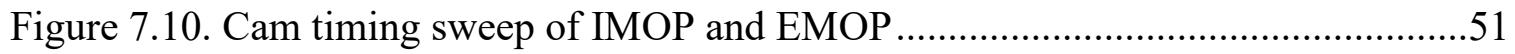

Figure 7.11. Residual gas fraction of intake and exhaust cam timing sweep at 1300rpm, 3.3bar IMEPnet. .54

Figure 7.12. Burn duration 10\%-90\% of intake and exhaust cam timing sweep at 1300rpm, 3.3bar IMEPnet. 
Figure 7.13. PMEP of intake and exhaust cam timing sweep at 1300rpm, 3.3bar IMEPnet

Figure 7.14. OE indicated Efficiency of intake and exhaust cam timing sweep at 1300rpm, 3.3bar IMEPnet.

Figure 7.15. Net indicated Efficiency of intake and exhaust cam timing sweep at 1300rpm, 3.3bar IMEPnet.

Figure 7.16. Log PV diagram of optimized baseline and Atkinson engine at 1300rpm, 3.3bar IMEPnet.

Figure 7.17. Residual gas fraction of intake and exhaust cam timing sweep at 1750rpm, 10.3bar IMEPnet.

Figure 7.18. Burn duration 10\%-90\% of intake and exhaust cam timing sweep at 1750rpm, 10.3bar IMEPnet.

Figure 7.19. PMEP of intake and exhaust cam timing sweep at 1750rpm 10.3bar, IMEPnet

Figure 7.20. OE indicated efficiency of intake and exhaust cam timing sweep at 1750rpm, 10.3bar IMEPnet.

Figure 7.21. Net indicated efficiency of intake and exhaust cam timing sweep at 1750rpm, 10.3bar IMEPnet.

Figure 7.22. Log PV diagram of optimized baseline and Atkinson engine at 1750rpm, 10.3bar IMEPnet. .56

Figure 7.23. Net indicated efficiency of optimized baseline, non-adjusted Atkinson cycle, and optimized Atkinson cycle engine, at 1300rpm, 3.3bar IMEPnet and 1750rpm, 10.3bar IMEPnet .58

Figure 7.24. Unburned fuel mass fraction at knock onset of intake and exhaust cam timing sweep at 1750rpm, 10.3bar IMEPnet,baseline.

Figure 7.25. Piston speed as a function of crank angle comparison between baseline and Atkinson mechanism. ("0" mean at TDC Firing).

Figure 8.1. $\log \mathrm{P}-\mathrm{Log} \mathrm{V} / \mathrm{V}_{\max }$ of Atkinson cycle split by non-over-expansion and overexpansion ( $\mathrm{V}_{\max }$ is the maximum in-cylinder volume during intake stroke)

Figure 8.2 Induction time as a function of unburned zone temperature .71

Figure 8.3. Schematic of the Atkinson cycle engine multi-link mechanism .73 
Figure 8.4. Piston movement as a function of crank angle of baseline and Atkinson cycle mechanism. (" 0 " of $x$-axis is at crank angle of TDC Firing) ...................................74

Figure 8.5. In-cylinder volume as a function of crank angle of baseline and Atkinson mechanism. (" 0 " of $\mathrm{x}$-axis is at crank angle of TDC Firing) .................................74

Figure 8.6. In-cylinder volume and valve lift of exhaust and intake cam as a function of crank angle of Atkinson cycle engine .76

Figure 8.7. Gross loop and pumping loop in an Atkinson cycle $\log \mathrm{P}-\log \mathrm{V} / \mathrm{V}_{\max }\left(\mathrm{V}_{\max }\right.$ is the maximum in-cylinder volume during intake stroke) .77

Figure 8.8. Intake and exhaust cam timing sweep for optimization .................................78

Figure 8.9. Baseline engine net indicated efficiency at 1500rpm 13bar IMEPnet ............79

Figure 8.10. Atkinson cycle engine net indicated efficiency at 1500rpm 13bar IMEPnet 79

Figure 8.11. Baseline engine net indicated efficiency at 3500rpm 20bar IMEPnet ..........79

Figure 8.12. Atkinson cycle engine net indicated efficiency at 3500rpm 20bar IMEPnet 79

Figure 8.13. $\log \mathrm{P}-\log \mathrm{V} / \mathrm{V}_{\max }$ of baseline and Atkinson cycle engine for knock propensity investigation, at 1500rpm 13bar IMEPnet, CA50 $=14.8^{\circ} \mathrm{aTDC}\left(\mathrm{V}_{\max }\right.$ is the maximum in-cylinder volume during intake stroke). .81

Figure 8.14. Unburned zone temperature of baseline and Atkinson cycle engine vs. normalized volume, at 1500rpm 13bar IMEPnet, CA50 $=14.8^{\circ} \mathrm{aTDC}\left(\mathrm{V}_{\max }\right.$ is the maximum in-cylinder volume during intake stroke) .81

Figure 8.15. Piston speed as a function of crank angle of baseline and Atkinson cycle engine at $1500 \mathrm{rpm} 13 \mathrm{bar}$ IMEPnet, CA50 $=14.8^{\circ}$ aTDC .82

Figure 8.16. Overall $\tau$ ratio (baseline and Atkinson cycle engine) at 1500rpm, 13 bar IMEPnet, $\mathrm{CA} 50=14.8^{\circ} \mathrm{aTDC}$

Figure 8.17. $\log \mathrm{P}-\log \mathrm{V} / \mathrm{V}_{\max }$ of baseline and Atkinson cycle engine at 1500rpm 13bar IMEPnet, knock limited spark timing, optimized cam timing $\left(\mathrm{V}_{\max }\right.$ is the maximum in-cylinder volume during intake stroke) .83

Figure 8.18. Net indicated efficiency of baseline and Atkinson cycle engine at 1500rpm, 13bar IMEPnet, optimized cam timing. .84

Figure 8.19. Flow chart of energy loss calculation .85

Figure 8.20. Energy loss of baseline and Atkinson cycle engine at 1500rpm, 13 bar IMEPnet, optimized cam timing . .86 
Figure 8.21. Net indicated efficiency of baseline and Atkinson cycle engine at 3500rpm,

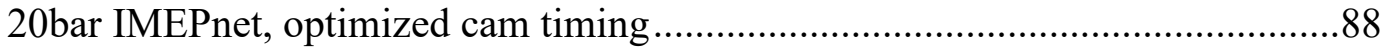

Figure 8.22. Efficiency loss of baseline and Atkinson cycle engine at 3500rpm, 20 bar IMEPnet, optimized cam timing..... .88

Figure 8.23. $\log \mathrm{T}-\log \mathrm{V} / \mathrm{V}_{\max }$ of power stroke at 3500rpm 20bar IMEPnet, at same combustion phasing, cam timing, and Lambda $\left(\mathrm{V}_{\max }\right.$ is the maximum in-cylinder volume during intake stroke) .89

Figure 8.24. $\log \mathrm{P}-\log \mathrm{V} / \mathrm{V}_{\max }$ diagram of baseline and Atkinson cycle engine at 3500 rpm 20bar IMEPnet, knock limited spark timing, cam timing optimized ( $\mathrm{V}_{\max }$ is the maximum in-cylinder volume during intake stroke) .90

Figure 8.25. Turbine power normalized by fuel-in power of baseline and Atkinson cycle engine, at 1500rpm, 13bar IMEPnet and 3500rpm, 20bar IMEPnet .91

Figure 8.26. OE gross work, late blowdown, and OE pumping highlighted in $\log \mathrm{P}-\log$ $\mathrm{V} / \mathrm{V}_{\max }$ diagram of Atkinson cycle engine at 1500rpm 13bar IMEPnet and 3500rpm 20bar IMEPnet with late expansion and OE pumping.. .92

Figure 8.27. Normalized energy difference of Atkinson cycle engine late blowdown, pumping loss, and over-expansion indicated efficiency (3500rpm 20bar IMEPnet 1500rpm 13bar IMEPnet) .93

Figure 8.28. Summary of the optimized baseline and Atkinson cycle engine net indicated efficiency at optimized at 1500rpm, 13bar IMEPnet and 3500rpm, 20bar IMEPnet .94

Figure 8.29. Baseline engine trapping ratio at 1500rpm 13bar IMEPnet 101

Figure 8.30. Atkinson cycle engine trapping ratio at 1500rpm 13bar IMEPnet. 101

Figure 8.31. Baseline engine trapping ratio at 3500rpm 20bar IMEPnet 101

Figure 8.32. Atkinson cycle engine trapping ratio at 3500rpm 20bar IMEPnet. 101

Figure 8.33. Baseline engine CA50 at 1500rpm 13bar IMEPnet 101

Figure 8.34. Atkinson cycle engine CA50 at 1500rpm 13bar IMEPnet .101

Figure 8.35. Baseline engine CA50 at 3500rpm 20bar IMEPnet .102

Figure 8.36. Atkinson cycle engine CA50 at 3500rpm 20bar IMEPnet 102

Figure 8.37. Baseline engine PMEP at 1500rpm 13bar IMEPnet (Positive value represents boost condition) 102 
Figure 8.38. Atkinson cycle engine PMEP at 3500rpm 20bar IMEPnet 102

Figure 8.39. Baseline engine PMEP at 3500rpm 20bar IMEPnet .102

Figure 8.40. Atkinson cycle engine PMEP at 1500rpm 13bar IMEPnet .102

Figure 8.41. Baseline engine OE indicated efficiency at 3500rpm 20bar IMEPnet .103

Figure 8.42. Atkinson cycle engine OE indicated efficiency at 3500rpm 20bar IMEPnet 103

Figure 9.1. Log V/Vmax diagram of Atkinson cycle highlighted with the portion of nonover-expansion and over-expansion (Vmax is the maximum in-cylinder volume at the end of the intake stroke). .110

Figure 9.2. Schematic of the Atkinson mechanism .113

Figure 9.3. Piston location as a function of crank angle, baseline, and Atkinson mechanism. (" 0 " is at the TDC Firing) .114

Figure 9.4. In-cylinder volume as a function of crank angle, baseline, and Atkinson mechanism. (" 0 " is at the TDC Firing). .114

Figure 9.5. Volume, valve lift as a function of crank angle of Atkinson cycle engine ...116

Figure 9.6. Induction time $(\tau 1, \tau 2, \tau 3$, and $\tau)$ as a function of unburned zone temperature at 1500rpm 13bar IMEPnet, optimized condition... 119

Figure 9.7. Indicated work of Atkinson cycle breakdown .121

Figure 9.8. Gross loop and pumping loop in an Atkinson cycle Log P - Log V/Vmax diagram (Vmax is the maximum in-cylinder volume at the end of intake stroke) .121

Figure 9.9. Intake and Exhaust Cam Timing Sweep for Optimization 123

Figure 9.10. Valve lift of Non-LIVC and LIVC condition of HC engine at 1300rpm 3.3bar IMEPnet .123

Figure 9.11. Net indicated efficiency as a function of IVC and EMOP, baseline engine, HC engine, and Atkinson cycle engine at 1300rpm 3.3bar IMEPnet .124

Figure 9.12. RGF as a function of IVC and EMOP, baseline engine, HC engine, and Atkinson cycle engine at 1300rpm 3.3bar IMEPnet. .124 
Figure 9.13. Log PV diagram of baseline engine, $\mathrm{HC}$ engine, and Atkinson cycle engine at 1300rpm 3.3bar IMEPnet, knock limited spark timing, cam timing optimized (Vmax is the maximum in-cylinder volume at the end of intake stroke). .126

Figure 9.14. Net indicated efficiency of baseline engine, $\mathrm{HC}$ engine, and Atkinson cycle engine at 1300rpm, 3.3bar IMEPnet .................................................................126

Figure 9.15. Flow chart of energy loss calculation........................................................127

Figure 9.16. Efficiency losses of baseline engine, $\mathrm{HC}$ engine, and Atkinson cycle engine at 1300rpm, 3.3 bar IMEPnet. 128

Figure 9.17 Heat transfer loss of baseline engine, $\mathrm{HC}$ engine, and Atkinson cycle engine at 1300rpm, 3.3 bar IMEPnet. 128

Figure 9.18. Net indicated efficiency as a function of IVC and EMOP, baseline engine, HC engine, and Atkinson cycle engine at 1500rpm 13bar IMEPnet 129

Figure 9.19. Residual gas fraction as a function of IVC and EMOP, baseline engine, HC engine, and Atkinson cycle engine at 1500rpm 13bar IMEPnet 129

Figure 9.20. Log PV diagram of baseline engine, $\mathrm{HC}$ engine, and Atkinson cycle engine at 1500rpm 13bar IMEPnet, knock limited spark timing, cam timing optimized (Vmax is the maximum in-cylinder volume at the end of intake stroke) 130

Figure 9.21. Net indicated efficiency of baseline engine, $\mathrm{HC}$ engine, and Atkinson cycle engine at $1500 \mathrm{rpm}, 13 \mathrm{bar}$ IMEPnet. 131

Figure 9.22. Efficiency losses of baseline engine, $\mathrm{HC}$ engine, and Atkinson cycle engine at 1500rpm, 13bar IMEPnet. 132

Figure 9.23 Heat transfer loss of baseline engine, $\mathrm{HC}$ engine, and Atkinson cycle engine at 1500rpm, 13bar IMEPnet.

Figure 9.24. Net indicated efficiency as a function of IVC and EMOP, baseline engine, HC engine, and Atkinson cycle engine at 2500rpm 10bar IMEPnet 133

Figure 9.25. Log PV diagram of baseline engine, $\mathrm{HC}$ engine, and Atkinson cycle engine at 2500rpm 10bar IMEPnet, cam timing optimized (Vmax is the maximum incylinder volume at the end of intake stroke). 134

Figure 9.26. Net indicated efficiency of baseline engine, $\mathrm{HC}$ engine, and Atkinson cycle engine at 2500rpm, 10bar IMEPnet. .135

Figure 9.27. Efficiency losses of baseline engine, $\mathrm{HC}$ engine, and Atkinson cycle engine at 2500rpm, 10 bar IMEPnet .136 
Figure 9.28 Heat transfer loss of baseline engine, $\mathrm{HC}$ engine, and Atkinson cycle engine at 2500rpm, 10 bar IMEPnet

Figure 9.29. Net indicated efficiency of optimized baseline engine, optimized HC engine, and optimized Atkinson cycle engine, at 1300rpm, 3.3bar IMEPnet, 1500rpm, 13bar IMEPnet, and 2500rpm 10bar IMEPnet

Figure 10.1. Residual gas fraction of intake and exhaust cam timing sweep at 1300rpm, 3.3bar IMEPnet [68] 142

Figure 10.2. OE indicated Efficiency of intake and exhaust cam timing sweep at 1300rpm, 3.3bar IMEPnet [68] 142

Figure 10.3. PMEP of intake and exhaust cam timing sweep at 1300rpm, 3.3bar IMEPnet $[68]$

Figure 10.4. OE indicated efficiency of intake and exhaust cam timing sweep at 1750rpm, 10.3bar IMEPnet [68] 143

Figure 10.5. Net indicated efficiency of intake and exhaust cam timing sweep at 1750rpm, 10.3bar IMEPnet [68] 143

Figure 10.6 Net indicated efficiency of optimized baseline, Non-adjusted Atkinson cycle, and optimized Atkinson cycle engine, at 1300rpm, 3.3bar IMEPnet and 1750rpm, 10.3bar IMEPnet [68] 143

Figure 10.7. Piston speed as a function of crank angle of baseline and Atkinson cycle engine at $1500 \mathrm{rpm} 13 \mathrm{bar}$ IMEPnet, CA50 $=14.8^{\circ}$ aTDC 144

Figure 10.8. Overall $\tau$ ratio (baseline and Atkinson cycle engine) at 1500rpm, 13 bar IMEPnet, CA50 $=14.8^{\circ}$ aTDC .144

Figure 10.9. Summary of the optimized baseline and Atkinson cycle engine net indicated efficiency at optimized at 1500rpm, 13bar IMEPnet and 3500rpm, 20bar IMEPnet 145 


\section{List of tables}

Table 1.1 Ideal cycle efficiency (constant volume combustion) at different CR and ER ...7

Table 2.1 Literature Review of over-expanded engine study ...........................................11

Table 3.1 Geometric Specification of GM LNF Engine.....................................................14

Table 3.2 GM LNF baseline camshaft specification at the parked position .......................15

Table 3.3 Test matrix of experimental study ................................................................19

Table 4.1 Controller Summary …………………………………………………....22

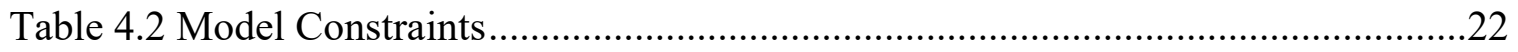

Table 4.3 Baseline engine calibration at selected operating conditions ...........................23

Table 4.4 Design variable of over-expanded mechanism.................................................24

Table 4.5 Geometric specifications of designed mechanisms ..........................................27

Table 4.6 Crank angle offset and stroke duration of designed over-expanded

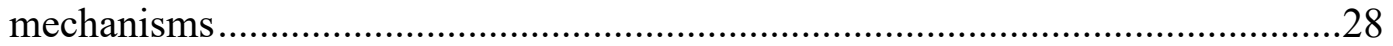

Table 4.7 Geometric specification of baseline engine and high compression engine ........31

Table 7.1 Literature review summary of Atkinson cycle engine study .............................41

Table 7.2. Baseline engine specifications .....................................................................43

Table 7.3. Valve timing of the experimental results ........................................................4

Table 7.4. Baseline engine calibration of 1300rpm, 3.3bar IMEPnet, and 1750rpm, 10,3bar

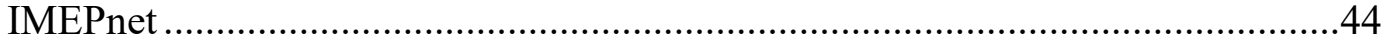

Table 7.5. Geometric specifications of Atkinson cycle mechanism with CR9.2, OER1.5,

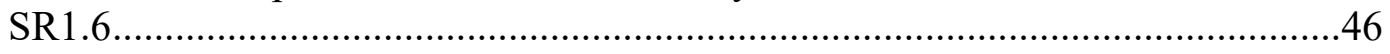

Table 7.6. Summary of baseline engine optimized cases ..............................................52

Table 7.7. Summary of optimized case of baseline and Atkinson Engine at 1300rpm, 3.3

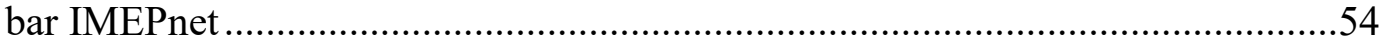

Table 7.8. Summary of optimized case of baseline and Atkinson Engine at 1750rpm, 10.3 bar IMEPnet 
Table 7.9 Geometry summary of baseline and Atkinson engine .61

Table 7.10 Mean piston speed baseline and Atkinson engine ......................................62

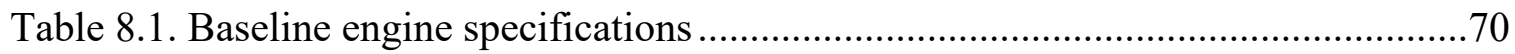

Table 8.2. Baseline engine calibration of 1500rpm, 14bar IMEPnet, (experimental data: the cycle of $95^{\text {th }}$ percentile of knock peak-peak) ............................................... 70

Table 8.3. Experimental results of valve timing @ $0.2 \mathrm{~mm}$ valve lift............................71

Table 8.4. Model constraints of knock, turbine-inlet temperature, and trapping ratio ......72

Table 8.5. Geometric specifications of Atkinson cycle over-expanded mechanism with

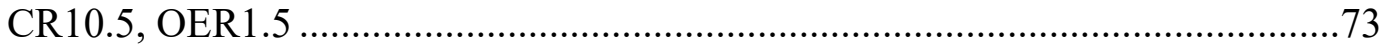

Table 8.6. Geometry characteristics of baseline and Atkinson engine ........................... 75

Table 8.7. Valve timing and cam profile adjustment of Atkinson cycle engine................76

Table 8.8. Optimized cam timing for baseline engine and Atkinson cycle engine at selected

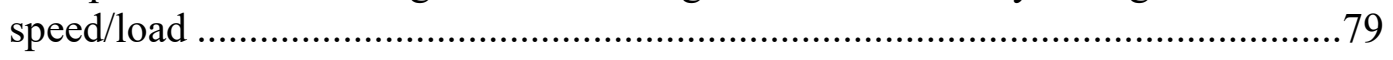

Table 8.9. Results of baseline and Atkinson cycle engine for knock propensity investigation at 1500rpm 13bar IMEPnet, CA50 = $14.8^{\circ}$ aTDC ….......................................8

Table 8.10. Normalized volume, crank angle-based location and timing ratio of $\tau A$ to $\tau B$ between baseline engine and Atkinson cycle engine.

Table 8.11. Results of baseline and Atkinson cycle engine at optimized cam timing, 1500rpm, 13 bar IMEPnet, .83

Table 8.12. Indicated efficiency improvement of Atkinson cycle engine at 1500rpm, 13bar IMEPnet, optimized cam timing.... . .86

Table 8.13. Results of baseline and Atkinson cycle engine at optimized cam timing, 3500rpm, 20 bar IMEPnet,..... .87

Table 8.14. Results of baseline and Atkinson cycle engine for exhaust temperature investigation at 3500rpm 20bar IMEPnet, Lambda $=1.0$.

Table 8.15. Indicated efficiency improvement of Atkinson cycle engine at 3500rpm, 20bar IMEPnet, optimized cam timing

Table 8.16. OE indicated efficiency, late blowdown loss and OE pumping of Atkinson cycle engine normalized by fuel energy at 1500rpm 13bar IMEPnet and 3500rpm 20bar IMEPnet 
Table 9.1. Geometric specifications of Atkinson cycle mechanism with CR10.5 and OER1.5

Table 9.2 Geometry Summary of Baseline Engine, HC engine, and Atkinson Engine ..115

Table 9.3. Valve timing and cam profile adjustment 116

Table 9.4. Baseline engine calibration of 1300rpm, 3.3bar IMEPnet and 1500rpm 14bar IMEPnet, (experimental data: the cycle of 95th percentile of knock peak-peak) 118

Table 9.5. Valve timing of the experimental results 118

Table 9.6. Model constraints of baseline engine, $\mathrm{HC}$ engine, and Atkinson cycle engine .120

Table 9.7. The operating condition of simulation 122

Table 9.8. Results of baseline engine, $\mathrm{HC}$ engine, and Atkinson cycle engine of optimized cam timing, at 1300rpm, 3.3 bar IMEPnet,

Table 9.9. Results of baseline engine, $\mathrm{HC}$ engine, and Atkinson cycle engine of optimized cam timing, at 1500rpm, 13 bar IMEPnet 130

Table 9.10. Results of baseline and Atkinson cycle engine of optimized cam timing, at 2500rpm, 10 bar IMEPnet

Table 9.11. Net indicate efficiency change between baseline engine, high compression engine, and Atkinson cycle engine

Table 10.1. Net indicate efficiency change between baseline engine, high compression engine, and Atkinson cycle engine 146 


\section{Preface}

This dissertation contains the manuscript which was published and submitted to scientific journals as a result of collaborate work. Full citation details for these publications are listed as follows:

Chapter 7 was originally published as a journal article titled "Investigation and Optimization of Cam Actuation of an Over-Expanded Atkinson Cycle Spark-Ignited Engine" in SAE International Journal of Advances and Current Practices in Mobility in 2019.

Chapter 8 is a paper titled "Investigation of High Load Operation of Spark-Ignited OverExpanded Atkinson Cycle Engine."

Chapter 9 is a paper titled "Comparing Methods for Improving Efficiency for Spark-Ignited Engines - Multi-link Mechanical Over-Expansion to High Compression Ratio with LIVC."

Chapter 7 is re-published in this dissertation to its entirety content-wise. However, the format has been modified to fit the overall format of this dissertation, and the cited resources are extracted from each paper and all cited references are listed in the reference section in Chapter 11. The papers listed in Chapter 8 and Chapter 9 were submitted to a peer-reviewed academic journal and under reviewing.

I am the first author of all publications mentioned above, and I am also the main person who has conducted the experiment, simulation, and processed the data. All the work including this dissertation is done under the guidance and supervision of Dr. Jeffrey Naber. 


\section{Acknowledgments}

I feel very fortunate that I had the chance to work with many great and wise people during my graduate study. Their guidance and support are invaluable to my life.

I would like to express my sincere gratitude to my research advisor, Dr. Jeffrey D. Naber. I would like to acknowledge his support throughout my Ph.D. degree while providing me the flexibility and responsibility. I also give my sincerely thanks to my committee members, Dr. Scott Miers, Dr. Jeremy Worm, and Dr. Kuilin Zhang for their guidance, careful review, and support on my research.

I would like to acknowledge the financial support by Michigan Tech Light-Duty Consortium, Department of Mechanical Engineering-Engineering Mechanics of Michigan Technological University, and Graduate School of Michigan Technological University.

I would like to sincerely thank the technical input from David Roth, Eric Blash, Tom Leone, Rick Davis, Jim Walker, Philipp Seyfried and all members of Michigan Tech LightDuty Consortium.

I would like to express my sincere gratitude to William Atkinson, Paul Dice, Joel Duncan, Christopher Morgan, Alex Normand, Tina Sarazin, Henry Schmidt, Julie Hendrickson, Tucker Alsup, and all APS Labs crew who gave me a lot of help to my research and daily life.

I would like to thank Dr. Stanislaw Szwaja, Dr. Lukasz Jan Kapusta, and Rafal Jan Rogoz who give me a lot of support in the dual fuel research.

I appreciate Wei Luo and Lei Feng who generously provide me the accommodation during my co-op. I also would like to thank Dr. Li Jiang, Dr. Shyam Jade, Mr. Jason Schwanke, and Mr. Kivanc Temel, and other colleagues who helped me have an unforgettable experience working on powertrain systems during my graduate co-op.

To my friends, Niranjan, Tyler, Nicolas, Yanyu, Sandesh, Ehsan, Vinicius, Zhihao, Chong, Jiajun, Jianyang, Jiongxun, Meng, Mingyang, Xuebin, Xin, Zhouquan, Zhuo, Amir, Basha, Behrouz, Behdad, Conor, Magdalena, Stas, Sid, Luo, Lei, Bin, Da, Guangcheng, Ke, Kenan, Ming, Yachan, Yunfeng, Jiaqi, Shengchao, Tianjun, Xiaodi, Zhuojun, Chengchun, Jingwen, Kelin, Xiaochi, Yurun, Yunjia, and many others, it is very delight for those accompany during the graduate study. They provided me so much support and encouragement to face all challenges.

Last but not least, I would like to acknowledge my family, Zhongling, Hong, Zhuli, and Luting for their continuous support and love. 


\section{List of abbreviations}

\begin{tabular}{|c|c|}
\hline aBDC & After bottom dead center \\
\hline ACAP & $\begin{array}{l}\text { Advanced combustion } \\
\text { analysis program }\end{array}$ \\
\hline AFR & Air to fuel ratio \\
\hline aTDC & After top dead center \\
\hline bBDC & Before bottom dead center \\
\hline BD1090 & $\begin{array}{l}10 \%-90 \% \text { mass fraction } \\
\text { burned duration }\end{array}$ \\
\hline BDC & Bottom dead center \\
\hline ВМЕР & $\begin{array}{l}\text { Brake mean effective } \\
\text { pressure }\end{array}$ \\
\hline BSFC & $\begin{array}{l}\text { Brake specific fuel } \\
\text { consumption }\end{array}$ \\
\hline bTDC & Before top dead center \\
\hline $\mathbf{C A}$ & Crank angle \\
\hline CA50 & $\begin{array}{l}\text { Crank angle of } 50 \% \text { mass } \\
\text { fuel burned }\end{array}$ \\
\hline CARB & $\begin{array}{l}\text { California Air Resources } \\
\text { Board }\end{array}$ \\
\hline $\mathbf{C R}$ & Compression ratio \\
\hline DI & Direct injection \\
\hline EGR & Exhaust gas recirculation \\
\hline
\end{tabular}

\begin{tabular}{|c|c|}
\hline EMOP & $\begin{array}{l}\text { Exhaust valve most } \\
\text { opening position }\end{array}$ \\
\hline ER & Expansion ratio \\
\hline GDI & Gasoline direct injection \\
\hline GE & Gas exchange \\
\hline IMEPnet & $\begin{array}{l}\text { Net indicated mean } \\
\text { effective pressure }\end{array}$ \\
\hline IMOP & $\begin{array}{l}\text { Intake valve most opening } \\
\text { position }\end{array}$ \\
\hline ISFC & $\begin{array}{l}\text { Net indicated specific fuel } \\
\text { consumption }\end{array}$ \\
\hline KLSA & $\begin{array}{l}\text { Knock-limited spark } \\
\text { advance }\end{array}$ \\
\hline LIVC & Late intake valve closing \\
\hline MAP & $\begin{array}{l}\text { Manifold } \\
\text { pressure }\end{array}$ \\
\hline MBT & Maximum brake torque \\
\hline MBT & Maximum brake torque \\
\hline MON & Motor octane number \\
\hline MPG & Mile per gallon \\
\hline NOMG & Nonmethane organic gas \\
\hline Non-OE & Non-over-expansion \\
\hline
\end{tabular}




\begin{tabular}{|l|l|}
\hline OE & Over expansion \\
\hline OER & Over expansion ratio \\
\hline RGF & Residual gas fraction \\
\hline RON & Research octane number \\
\hline RPM & Revolution per minute \\
\hline SI & Spark Ignited \\
\hline SR & $\begin{array}{l}\text { Expansion to compression } \\
\text { stroke ratio }\end{array}$ \\
\hline
\end{tabular}

\begin{tabular}{|l|l|}
\hline TDC & Top dead center \\
\hline $\mathbf{V}_{\text {max }}$ & $\begin{array}{l}\text { Maximum in-cylinder } \\
\text { volume during intake } \\
\text { stroke }\end{array}$ \\
\hline VVT & Variable valve timing \\
\hline $\boldsymbol{\eta}_{\text {net indicated }}$ & Net indicated efficiency \\
\hline $\boldsymbol{\eta}_{\text {net indicated, non-OE }}$ & $\begin{array}{l}\text { Non-over } \\
\text { indicated efficiency }\end{array}$ \\
\hline & $\begin{array}{l}\text { Over expanded indicated } \\
\text { efficiency }\end{array}$ \\
\hline $\boldsymbol{\eta}_{\text {indicated,oE }}$ & \\
\hline
\end{tabular}




\section{Abstract}

Recent fuel economy and emission regulations are the major concern of the research and development of modern internal combustion engine. Such technologies include variable valve timing (VVT), direct injection (DI), turbocharging, downsizing, and over-expanded cycle are used by many manufacturers to improve engine fuel economy or increase power density.

Current Atkinson cycle technology in the production engine is mainly realized by an advanced valvetrain system to reduce the effective compression ratio while maintaining the same expansion ratio. Another approach to realize over-expanded cycle engine is to utilize a multi-link cranktrain mechanism. Although the Atkinson cycle was originally patented in the $1880 \mathrm{~s}$, the research of the over-expanded cycle engine realized by a multilink cranktrain design is incomplete. This study focuses on the investigation of overexpanded engine realized by a cranktrain with a multi-link mechanism. The multi-link mechanism of cranktrain was developed and simulated with the constraints of packaging and match the same specification as the baseline engine including compression ratio, bore, and intake/compression stroke. This study also discusses adapting the cam profiles, cam phasing, and spark timing to compensate for the geometric characteristics difference between an Atkinson cycle engine and a conventional engine.

The 1-D engine model was developed and calibrated in the commercial engine program, GT-Suite/GT-Power, based on the experimental results from a production four-cylinder spark-ignited engine (not over-expanded). The simulations of multi-link over-expanded engine and high compression engine were realized by substituting the new cranktrain for the baseline cranktrain

In this study, the investigation of the multi-link over-expanded engine included a series of operating conditions from light load to high load. The results were compared at the optimized condition between the baseline engine, multi-link over-expand engine, and high compression engine. At the light load condition, it was observed that the net indicated efficiency of the over-expanded engine was slightly improved based on the adjustment method.

This study also investigated the operating condition of the baseline engine with knock constrained and exhaust temperature constrained conditions at medium to high load. With the optimization, the over-expanded cycle engine is less constrained than the baseline engine due to the reduced knock propensity and exhaust gas temperature resulting in the further improvement of net indicated efficiency.

The study of the multi-link over-expanded cycle engine includes the comparison with the latest production high compression ratio engine, representing state-of-the-art high efficiency engine technologies. The net indicated efficiency of multi-link over-expanded engine is even better than the peak efficiency point of the high compression engine. 


\section{Introduction}

\subsection{Background}

\subsubsection{U.S. Energy Trend in the Transportation Sector}

The annual energy outlook of 2018 released by the Department of Energy (DOE) shows that motor gasoline consumed 16.7 quadrillions British thermal unit (BTU) [1], which is $60 \%$ of the total transportation energy consumption in the United States. The energy used by Light-Duty Vehicles (LDV) was 15 quadrillion BTU, which accounts for more than $55 \%$ of the total energy consumed among different types of vehicles in the transportation sector. DOE has projected that LDV energy consumption will reduce to 11 quadrillion BTU in 2050 due to more stringent corporate average fuel economy (CAFE) standards.

The Automotive Trends Report released by Environmental Protection Agency (EPA) [2] showed that for the model year 2017 vehicles, $96 \%$ were powered solely by gasoline engines while less than $1.4 \%$ were pure electric. The DOE report Annual Energy Outlook 2019 with projections to 2050 released in 2019 [1] projected the sales volume of conventional gasoline LDV will still be more than $70 \%$ of total sales in 2050 . Although new LDVs of alternative powertrains will increase to more than $23 \%$, the projected proportion of LDV with internal combustion, gasoline engines is far from negligible.

Based on the reports made by DOE [1] and EPA [2], it can be concluded that the LDVs powered by conventional gasoline will still dominate the market for several decades in the United States. Therefore, research and development towards improving the efficiency of spark-ignited (SI) engines while reducing criteria emissions is still critical and the very near term needs tightening criteria emissions and fuel economy regulations. In order to meet this, advanced high efficiency internal combustion engines (ICE) are needed. Although other combustion systems including many low temperature combustion (LTC) engines have been in development over the last two decades [3, 4], nearly all LDV gasoline engines remain stoichiometric, spark-ignition because of cost, robustness, ability to meet extremely low oxides of nitrogen and unburnt hydrocarbon emissions.

\subsubsection{Emissions and Fuel Economy Regulations of Light-Duty Vehicle in the US}

In the effort to reduce emissions from vehicles, California Air Resources Board (CARB) and EPA both adopted the regulation vehicle criteria emissions [5]. In 2010, California's LEV II standards required the annual fleet average nonmethane organic gas (NOMG) no more than $35 \mathrm{mg} / \mathrm{mile}$ for passenger cars and $43 \mathrm{mg} / \mathrm{mile}$ for heavy-duty or light-duty trucks. 
Similarly, the EPA Tier 2 standard required the automotive manufactures to set the fleet average NOx limit of $0.07 \mathrm{~g} /$ mile [5]. The phased-in of these two standards have been completed.

In 2017, EPA and CARB set the EPA Tier 3 and California LEV III, respectively, as the light-duty vehicle emission standard. Both standards required fleet average NOMG and NOx emissions (combined) no more than 30mg/mile in 2025[5]. The PM standards of EPA Tier 3 and LEV III were set at $30 \mathrm{mg} / \mathrm{mile}$ and $1 \mathrm{mg} / \mathrm{mile}$ for each vehicle, respectively[5, 6]. Both standards are fully phased-in by 2025 .

Fuel economy standards have been proved to be one of the best approaches to controlling greenhouse emission [7]. National Highway Traffic Safety Administration (NHTSA) included two phases of light-duty corporate average fuel economy (CAFE) standards. The first phase (the model year 2017-2021) set the average fleet fuel economy at $40.3-41.0$ mile per gallon (mpg). The second phase (the model year 2022 - 2025) set the average fleet fuel economy at 48.7-49.7 mpg [8]. EPA has harmonized Green House Gas (GHG) standards with the NHTSA fuel economy standards. For the model year 2025 light-duty vehicle, the $\mathrm{CO} 2$ emission of EPA is $163 \mathrm{CO}_{2} \mathrm{~g} / \mathrm{mile}$, which is equivalent to $54.5 \mathrm{mpg}$ [9]. It should be noted that there is an ongoing review of these standards with a proposed hold on the 2022-2025 standards in the current administration [10]

It can be summarized that emissions and fuel economy regulations and standards will continue to become more stringent over the next decades even with a current hold placed on the CAFE standards. The regulations and standards have significantly improved local air-quality and reduced energy consumption; however, continue reductions are a challenge for the automobile industry as many of the known advancements have already been integrated (e.g., valve actuation, down-sizing and boosting). This dissertation examines one possible technology that has the potential to significantly improve the fuel conversion efficiency of spark-ignited, down-size, turbocharged, stoichiometric engines while maintaining all the advantages including the very high emissions reduction of the threeway-catalyst aftertreatment systems in terms of robustness and cost. The engine cycle and system examined is that of a multi-link, high degree of freedom crank-mechanism which provides for in-cylinder over-expansion among other benefits.

\subsubsection{Summary of High Efficiency Engine Technologies}

\subsubsection{Gasoline Direct Injection}

Gasoline direct injection (GDI) has been widely applied in the production SI engines at an increasing rate over the last two decades [11-15]. Unlike intake-manifold injection, GDI directly injects fuel into the air via an injector in the cylinder head. The injection pressure is varied from $4 \mathrm{MPa}$ to $35 \mathrm{MPa}$ depending on the speed and load conditions [16-18]. The high pressure of GDI systems enables atomization, mixing and vaporization of the fuel in 
the cylinder with the resulting benefit of charge cooling [19]. The latent heat of vaporization reduces the charge temperature and realizes a lower knock propensity. The compression ratio of a GDI SI engine can then be increased due to the charge cooling effect resulting in a lower knock propensity [20]. The GDI and charge cooling is also an enabling technology for turbocharging, boosting and downsizing.

The downside of the GDI fuel systems is more difficult to achieve the homogeneous mixing compared to port fuel injection due to the less time available for the mixing [20]. A common approach of GDI is to increase fuel injection pressure to overcome the mixing issue, but there are still issues with increase particulate matter emissions because of incomplete mixing and vaporization.

\subsubsection{Water Injection}

Water injection can be applied in the intake manifold or directly in-cylinder [21]. One of the major effects of water injection for spark-ignition engines is to mitigate knock. Similar to GDI, water injection utilizes the latent heat of vaporization to realize the charge cooling but in the case of water injection it provides an independent control parameter and has a $2 \mathrm{MJ} / \mathrm{kg}$ higher latent heat of vaporization (approximately at $30^{\circ} \mathrm{C}$ ) in comparison to gasoline $[22,23]$. With the large latent heat of vaporization, Hoppe et al. [24] indicated that water injection is able to decrease the intake charge gas temperature by $34^{\circ} \mathrm{C}$. The experimental results show that the indicated efficiency is approximately increased by $3.5 \%$ (relative) with the concept of direct-injected water injection.

\subsubsection{Variable Valve Timing and Variable Valve Actuation}

Variable valve timing (VVT) adjusts the phasing of intake camshaft or both intake and exhaust camshaft as a function of engine speed and load. The optimization of valve timing is able to reduce the pumping loss, adjust the internal residual, scavenging effect, reduce the effective displacement and compression ratio, and accelerate the light off the three-way catalyst [25-29]. Variable valve actuation (VVA) is a further advancement in the valvetrain system to adjust the cam duration(s). The strategy of late-intake-valve closing (LIVC) is usually realized by the VVA system to achieve a longer intake valve duration. A conventional engine is able to realize an over-expanded cycle by utilizing LIVC [30, 31$]$.

\subsubsection{Cooled Exhaust Gas Recirculation}

Cooled exhaust gas recirculation (cEGR) is a common approach to dilute the intake charge and displace air in the intake to reduce the need for throttling $[32,33]$. With the cEGR, the heat capacity of the charge gas is increased, resulting in the reduction of the combustion temperature and exhaust gas exhaust temperature. One of the other major benefits is to reduce the knock tendency with cEGR [34]. 


\subsubsection{Over-Expanded Engine}

The over-expanded cycle has been widely discussed in the automotive industry and already applied to production engines [35-37]. The typical way to realize an over-expanded cycle is to utilize an advanced valvetrain with the capability of variable valve timing and valve duration to achieve a strategy of early intake valve closing (EIVC) or late intake valve closing (LIVC). With the EIVC or LIVC, the effective intake or compression displacement is reduced while the expansion displacement remains the same. The different displacement volume between the compression stroke and expansion stroke realizes an over-expanded cycle. With the EIVC/LIVC, the engine indicated efficiency is improved especially at light to medium load conditions; however, a downside of this approach is the effective displacement of the engine. As a result, the load capability of the engine is limited by using EIVC/LIVC. Further, it is beneficial to have higher over expansion with an increasing load which is counter to the need to reduce the effective compression displacement. Another approach to achieve an over-expanded cycle is to modify the cranktrain with a multi-link or other type mechanism $[38,39]$. The multi-link mechanism can be designed as the same compression stroke as the baseline engine, while the expansion stroke is extended to realize the over-expanded cycle.

The previous study depicted a huge potential of the multi-link over-expanded engine at medium to high load conditions. The net indicated efficiency multi-link over-expanded engine can be increased by more than $10 \%$ with the stroke ratio of 1.5 at $2000 \mathrm{rpm} 16 \mathrm{bar}$ IMEPnet [40]. Brendel [41] stated that the optimized multi-link mechanism can reduce engine friction by $7 \%$. A lower knock propensity of the multi-link over-expanded engine was also observed, compared to the baseline engine [40].

\subsection{Research Motivation}

The analysis and optimization study of the multi-link over-expanded engine is incomplete at this stage. To further understand the characteristics of multi-link over-expanded engine, it is crucial that the indicated efficiency and performance between an over-expanded engine and state-of-the-art conventional engines is quantified. It is also important to quantify the indicated efficiency of over-expanded engine realized by the methods between EIVC/LIVC and multi-link mechanism.

Developing a 1D engine model is a promising approach to investigate the multi-link overexpanded engine. The simulation results quantify the relevant differences of the multi-link over-expanded engine and other high efficiency engines. It also provides the designing reference of the prototype engine with multi-link over-expanded mechanism. To fully utilize the advantages of the $1 \mathrm{D}$ engine model, the investigation of multi-link overexpanded engine includes the optimization of cranktrain, valvetrain, and comparison to 
other high efficiency engines based on the same constraints of exhaust gas temperature, knock intensity, residual gas fraction, and scavenging effects.

\subsection{Goals and Objectives}

This research is aimed to further the understanding of the potential indicated efficiency improvement of multi-link over-expanded direct-injected spark-ignited boosted engine, by developing, modeling, and optimizing the over-expanded cycle engine in 1D simulation. The characteristic differences of the multi-link over-expanded engine and other high efficiency engines were quantified. The following objectives were set to reach this goal.

\subsubsection{Mechanism Development Objectives}

- Investigate the kinematics of the multi-link over-expanded engine cranktrain and develop MATLAB code to describe the piston movement based on the mechanism geometric specification

- Select the constraints and optimize the multi-link over-expanded cranktrain to meet the demand for compression ratio, expansion ratio, and the stroke length of over-expansion engine specification.

\subsubsection{Engine Model Development Objectives}

- Instrument the baseline engine test platform and perform experimental studies for model calibration

- Calibrate baseline 1D engine model based on the baseline engine experimental results

- Develop a customized cranktrain in the 1D engine simulation tool based on the characteristics of over-expanded cycle mechanism.

- Optimized the engine through full-featured valvetrain with variable valve duration and variable valve timing.

- Optimized the engine with the constraints of knock, temperature, load, and combustion phasing via closed-loop controllers and utilize the design of experiments to perform simulation

\subsubsection{Simulation Objectives}

- Optimize the performance of multi-link over-expanded engine at light to medium load conditions without knock constraint.

- Optimize the performance of multi-link over-expanded engine at medium to high load conditions including knock and exhaust temperature constraints. 
- Quantify the optimized performance between a multi-link over-expanded engine and a high compression engine with constraints.

\subsection{Introduction to over-expanded cycle and over-expanded cycle engine}

\subsubsection{Over-expanded cycle}

An over-expanded cycle typically has a longer expansion stroke than a compression stroke. Figure 1.1 is the pressure-volume diagram for three ideal cycles. Otto-cycle follows the pressure trace of a-b-c-d-a. With the additional expansion, the over-expanded cycle follows the pressure trace of a-b-c-d-e-e'-a. James Atkinson originally patented the engine with the over-expanded cycle mechanism in 1887 [42]. The ideal condition of the over-expanded cycle is the engine fully expanded when the pressure at the end of power stroke equals to ambient condition (a-b-c-d-e-f-a).

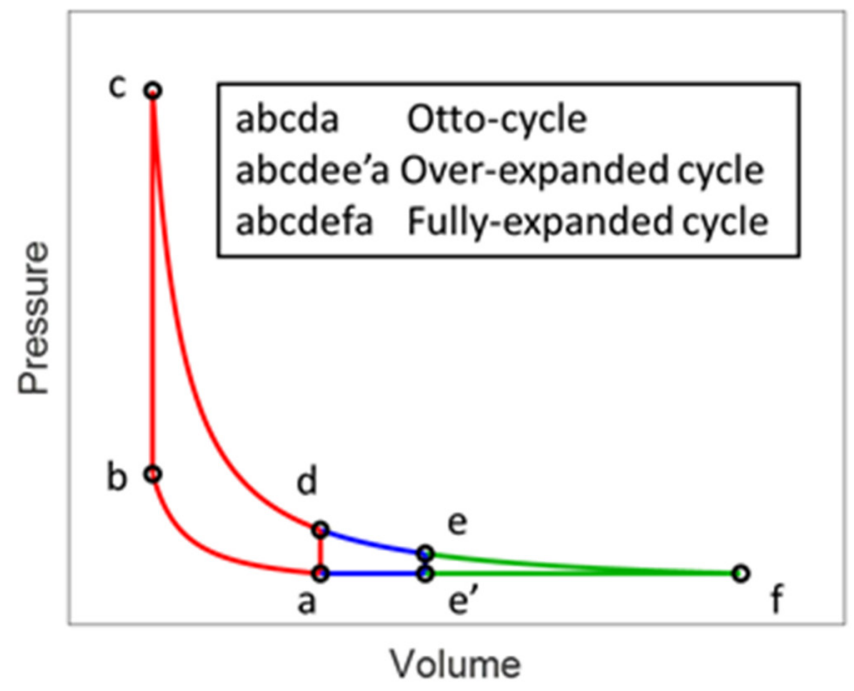

Figure 1.1 Pressure-volume diagram for the ideal cycle of (1) Otto-cycle, (2) Overexpanded cycle, and (3) Atkinson cycle

The indicated efficiency of Otto-cycle and the over-expanded cycle can be expressed as,

$$
\eta_{\text {otto-cycle }}=1-\frac{1}{C R^{\gamma-1}}
$$




$$
\eta_{O E \text { cycle }}=1-\frac{1}{E R^{\gamma-1}}\left(1+\frac{c_{v} T_{a}}{Q^{*}} C R^{\gamma-1}\left(1-\gamma\left(\frac{E R}{C R}\right)^{\gamma-1}+(\gamma-1)\left(\frac{E R}{C R}\right)^{\gamma}\right)\right)
$$

where,

CR - compression ratio

ER - the expansion ratio

$\gamma \quad-\quad$ specific heat ratio

$Q^{*} \quad-\quad$ specific internal energy

$T_{a} \quad-\quad$ temperature at location "a"

Table 1.1 Ideal cycle efficiency (constant volume combustion) at different CR and ER

\begin{tabular}{cccc}
\hline \hline CR & ER & ER/CR (OER) & $\boldsymbol{\eta}_{\boldsymbol{c} v}[\%]$ \\
\hline 9.2 & 9.2 & 1.0 & 48.6 \\
\hline 9.2 & 12.0 & 1.3 & 52.4 \\
\hline 9.2 & 13.8 & 1.5 & 54.1 \\
\hline 10.5 & 10.5 & 1.0 & 50.6 \\
\hline 10.5 & 13.4 & 1.3 & 54.2 \\
\hline 10.5 & 15.8 & 1.5 & 55.9 \\
\hline \hline
\end{tabular}

where,

$\gamma=1.3$

$Q^{*}=\frac{L H V}{1+A F R}=\frac{44000 \mathrm{~kJ} / \mathrm{kg}}{1+14.6}=2821 \mathrm{~kJ} / \mathrm{kg}$

$T_{a}=300 K$

\subsubsection{Over-expanded cycle engine}

Heywood has defined the fully-expanded cycle as the "Atkinson cycle" [22], however, the Patent by Atkinson did not mention the engine is necessary to be fully over-expanded [42]. It is common that modern engine technology calls an engine with over-expanded cycle as "Atkinson cycle engine". Ford motor company classified Atkinson cycle as one of the characterizations of powertrain technology in the study of vehicle fuel consumption [36]. 
Toyota named the Toyota A25A0FKS engine as Atkinson cycle engine due to the engine equipped with the advance valvetrain to realize LIVC [35]. EPA also states Mazda's 2014 SkyActiv 2.0 liter compression ratio (CR) 13:1 engine as the Atkinson cycle engine [37].

In summary, automotive industries reach an agreement to use the "Atkinson cycle engine" as the alternative of over-expanded engine. Although the original approach of Atkinson cycle engine is realized by a special design mechanism patent by Atkinson [42], the common approach of Atkinson cycle engine in most production engines today is realized by the strategy of late intake valve closing based on a high compression ratio engine.

In this dissertation, over-expanded cycle refers to an engine cycle operating with a high effective expansion ratio than compression ratio which is obtained by LIVC or other mechanisms (e.g. multi-link cranktrain).

Atkinson cycle uses the same definition as over-expanded cycle. An Atkinson cycle can be realized by LIVC or multi-link mechanism. The "Atkinson cycle engine" will be only utilized to define the over-expanded cycle engine realized by a multi-link mechanism. The displacement volume of the Atkinson cycle engine is based on the intake displacement volume. Furthermore, an analysis of energy losses is defined (in section 4.5) and performed in this dissertation to quantify the characteristics difference between the multi-link overexpanded engine and other high efficiency engines. 


\section{Literature Review}

The over-expanded engine has been under research by academia and the automotive industry for a long time. An in-depth review of the studies regarding over-expanded engine will be summarized and reviewed in this section.

Improving the conversion efficiency and reducing the emission is the major concern of modern spark-ignited engine design [40, 43]. Automotive industries use different approaches to achieve a higher fuel conversion efficiency, higher load capability and lower $\mathrm{CO}_{2}$ [44, 45]. However, the current technology of SI engine is still below the thermodynamic efficiency limit by a large margin [46].

Utilizing an over-expanded cycle or "Atkinson cycle" is a promising approach to improve the indicated efficiency. An Atkinson cycle engine is to realize longer expansion stroke than compression stroke resulting in an additional expansion and increase the indicated work per cycle [22]. The Atkinson cycle engine was patented by James Atkinson as an SI engine in 1887 [47]. The original patent of the Atkinson cycle engine has a multi-link mechanism to realize an alternate stroke, expansion stroke longer than compression stroke, in an engine cycle.

The concept of the engine design was also found in a Diesel engine. In the 1990s, Kentfield conducted both simulation study and experimental study on a Diesel-Atkinson cycle engine. The mechanism design of the engine had an over-expansion ratio of 1.4. The experimental results depicted that the brake specific fuel consumption (BSFC) was reduced by approximately $8 \%$ at 4.8 bar brake mean effective pressure (BMEP) [48, 49]. The study by Kentfield initially proved the concept of the Atkinson cycle is compatible with both sparkignited and compression-ignited engines, but the research of the compression-ignited engine using over-expanded cycle is limited. Most of the study regarding the overexpanded cycle is focus on the spark-ignited engines.

Different from the original Atkinson cycle engine design, an alternative approach to realize an Atkinson cycle in spark-ignited engines is to adapt the LIVC strategy based on a high compression engine. The LIVC strategy can reduce the effective compression ratio while maintaining the same geometric expansion ratio, resulting in an over-expanded cycle. Anderson et al. [50] observed that the over-expanded cycle realized by LIVC increase the net indicated efficiency at light load due to a lower pumping loss. Feng et al. [51] conducted a simulation research of over-expanded engine realized by LIVC. The simulation results showed the optimized BSFC was reduced by $6 \%$ compared to the baseline engine. Sakata et al. [52] conducted an experimental study of over-expanded engine based on the LIVC strategy. The specification of the over-expanded engine had an effective CR of 8.5 and an over-expansion ratio (OER) of 2.4. The BSFC of the over-expanded cycle engine was reduced by $18 \%$ compared to the baseline engine at the operation condition of $2500 \mathrm{rpm}$ 7 bar BMEP. In the automotive industries, the Atkinson cycle is typically realized by 
coupling the strategy of LIVC with a high compression engine, e.g., Toyota, Ford, Mazda, and GM [32, 37, 53, 54].

The downside of realizing Atkinson cycle via LIVC is that the effective displacement is lower due to the reduction of effective intake displacement. The lower effective displacement results in a limited load capability [22]. An experimental study by Gonca et al. [55] showed that the peak torque of an over-expanded engine with LIVC was reduced, especially at low load with LIVC. At 1500rpm, the peak torque was reduced by approximately $8 \%$ with $15^{\circ} \mathrm{CA}$ retarded LIVC.

The over-expanded cycle realized by a multi-link mechanism can be designed with the specification of the same intake and compression stroke as a baseline engine and a longer expansion stroke than compression stroke, which realizes the feature of over-expansion and maintains the same power density as the baseline engine. Austin [56] patented an overexpanded mechanism by utilizing the design of planetary gear in 1916. The over-expanded mechanism can reach an aggressive OER of 2.0. Pertl et al. [39] revisited the mechanism and conduct a simulation study based on the mechanism with a CR of 12.5 and OER of 2.0. The simulation results depicted that the indicated efficiency was increased by $14 \%$ at 6000rpm and full load condition. Another simulation study by Wang et al. [57] was based on the mechanism of the OER from 1.15 to 1.35 . The net indicated efficiency was increased by $1.3 \%$ and $5.7 \%$ at 3.5 bar and 8.5 bar IMEPnet, respectively compared to the baseline engine, at $1500 \mathrm{rpm}$. Fundamental guidance for designing a multi-link over-expanded engine was provided by Zhao et al. [58-60]. The study combined the concept of overexpanded cycle with cylinder deactivation and modifying the valvetrain system. The optimized BSFC was reduced by $10.5 \%$ at operating condition of 2000rpm, 2.1bar BMEP.

Honda developed a multi-link over-expanded mechanism, named as EX-Link, to realize an over-expanded cycle. An experimental study by Watanabe et al. [38] showed that the EXLink increased the net indicated efficiency by 5\% with the OER of 1.5 . An experimental study by Koga et al. [61] showed that the net indicated efficiency of EX-Link was improved by $12 \%$ at $3060 \mathrm{rpm}$, full load condition. The EX-Link was used in a combined heat and power generation unit. The resulted showed the power generation efficiency was improved by $3.8 \%$ compared to the baseline [62].

Brendel also investigated a similar mechanism as EX-Link with an optimized crankshaft design. Their experimental results by Brendel [41] indicated the engine friction was decreased by $7 \%$ compared to the baselin engine at 5000rpm with the optimized shaft. The study by Brendel stated the multi-link over-expanded engine is potentially to have a better NVH than a conventional engine. Later, Anandhan [63] continued the study of overexpanded engine based on the mechanism designed by Brendel. Anandhan's research focused on the thermodynamic aspect of the over-expanded engine. A serious of overexpanded mechanism was designed with the expansion to compression stroke ratio (SR) swept from 1.0 to 1.5 . The over-expanded engine was calibrated based on the experimental 
results from a conventional 2.0-liter boosted engine. It was observed that the indicated specific fuel consumption (ISFC) of the over-expanded engine was improved by more than $10 \%$ compared to the baseline engine. The results also depicted that the over-expanded engine has lower knock propensity at higher load compared to the baseline engine. Boretti. et al. [64] conducted an experimental study based on an over-expansion mechanism. The studied engine coupled with the effect of an over-expanded cycle and variable compression ratio. The brake fuel conversion efficiency of the studied engine was improved by approximately $30 \%$ compared to a baseline engine at 7.5 bar BMEP. However, the mechanism had a conservative OER of 1.1. The results by Boretti. et al. did not quantify the net indicated efficiency improvement based on the same compression ratio. The study of the over-expanded cycle engine at medium to high load condition was still incomplete, especially at exhaust gas temperature limit. A summary of the literature review of overexpanded engine study is listed in Table 2.1 .

It can be summarized that the compression ratio of over-expanded engine ranged from 8.4 to 15.5. The over-expanded cycle realized by LIVC was conducted with the OER up to 2.4. The OER multi-link over-expanded engine varied from 1.1 to 2.0. According to this literature review, the research of the over-expanded engine, especially the study of multilink over-expanded engine, is incomplete. The study of the over-expanded engine at light load is only based on the LIVC. The study of the over-expanded engine at high load was up to 16 bar IMEPnet, but the high load conditions with limited exhaust temperature were not investigated. The performance difference between the over-expanded engine realized by high compression with LIVC and multi-link over-expanded engine was also not quantified.

Table 2.1 Literature Review of over-expanded engine study

\begin{tabular}{|l|l|l|l|l|l|l|l|}
\hline Literature & Exp/Sim & $\begin{array}{l}\text { Type of OE } \\
\text { Engine }\end{array}$ & CR & OER & Speed/Load & $\begin{array}{l}\text { Results } \\
\text { (relative to } \\
\text { Baseline) }\end{array}$ & Main Output \\
\hline $\begin{array}{l}\text { Atkinson } \\
{[42]}\end{array}$ & $\begin{array}{l}\text { Patent an } \\
\text { over- } \\
\text { expanded } \\
\text { cycle engine }\end{array}$ & $\begin{array}{l}\text { Multi-link } \\
\text { over- } \\
\text { expanded } \\
\text { (OE) }\end{array}$ & - & - & - & - & $\begin{array}{l}\text { Original Patent } \\
\text { of Atkinson } \\
\text { cycle engine }\end{array}$ \\
\hline
\end{tabular}




\begin{tabular}{|c|c|c|c|c|c|c|c|}
\hline $\begin{array}{l}\text { Kentfield, } \\
1989,1992 \\
{[48,49]}\end{array}$ & 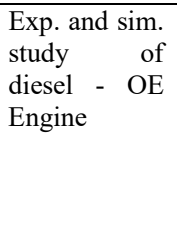 & $\begin{array}{l}\text { Multi-link } \\
\text { OE }\end{array}$ & $14: 1$ & $1.4: 1$ & 4.8bar BMEP & BSFC 8\% & $\begin{array}{l}\text { Developed } \\
\text { different OE } \\
\text { mechanism } \\
\text { based on the } \\
\text { original } \\
\text { Atkinson } \\
\text { mechanism }\end{array}$ \\
\hline $\begin{array}{l}\text { Feng, et al. } \\
2016 \\
{[51]}\end{array}$ & $\begin{array}{l}\text { Sim. study, } \\
\text { gasoline } \mathrm{OE} \\
\text { engine }\end{array}$ & $\begin{array}{l}\text { Conventional } \\
\text { four-stroke + } \\
\text { LIVC }\end{array}$ & $13: 1$ & - & $\begin{array}{l}\text { 2400rpm / } \\
\text { 8.5bar BMEP }\end{array}$ & BSFC 6\% & $\begin{array}{l}\text { Optimized } \\
\text { spark advance } \\
\text { and valve } \\
\text { timing }\end{array}$ \\
\hline $\begin{array}{l}\text { Sakata et al. } \\
2007 \\
{[52]}\end{array}$ & $\begin{array}{l}\text { Exp. study, } \\
\text { gasoline } \mathrm{OE} \\
\text { engine }\end{array}$ & $\begin{array}{l}\text { Conventional } \\
\text { four-stroke }+ \\
\text { LIVC }\end{array}$ & $\begin{array}{l}20: 1 \\
\text { (geo.) } \\
8.5: 1 \\
\text { (eff.) }\end{array}$ & $2.4: 1$ & $\begin{array}{l}\text { 2500rpm } \\
\text { 7bar BMEP }\end{array}$ & BSFC 18\% & $\begin{array}{l}\text { BSFC } \text { reduced } \\
\text { by } \\
\text { (relative) with } \\
\text { LIVC retarded } \\
60^{\circ}\end{array}$ \\
\hline $\begin{array}{l}\text { Pertl et al. } \\
2012,2015 \\
{[39,65]}\end{array}$ & $\begin{array}{l}\text { Sim. and exp. } \\
\text { study, } \\
\text { gasoline OE } \\
\text { engine }\end{array}$ & $\begin{array}{l}\text { OE } \\
\text { cranktrain } \\
\text { realized by a } \\
\text { planetary } \\
\text { gear }\end{array}$ & $12.5: 1$ & $2.0: 1$ & $\begin{array}{l}\text { 6000rpm } \\
\text { Full Load } \\
\text { (Atkinson } \\
\text { 7.9bar, } \\
\text { baseline } \\
\text { 6.7bar) } \\
\end{array}$ & $\begin{array}{l}\eta_{\text {net,indicated }} \\
14 \% \uparrow \\
\text { (simulation) }\end{array}$ & $\begin{array}{l}\text { Observed high } \\
\text { friction at high } \\
\text { speed in the } \\
\text { exp. study. }\end{array}$ \\
\hline $\begin{array}{l}\text { Wang et al. } \\
2012 \\
{[57]}\end{array}$ & $\begin{array}{l}\text { Simulation } \\
\text { study, } \\
\text { gasoline OE } \\
\text { engine }\end{array}$ & $\begin{array}{l}\text { OE cycle by } \\
\text { artificial } \\
\text { piston } \\
\text { movement }\end{array}$ & $10.4: 1$ & $1.3: 1$ & $\begin{array}{l}\text { 1500rpm } \\
\text { 3.5bar and } \\
\text { 8.5bar BMEP }\end{array}$ & $\begin{array}{l}\eta_{\text {net, indicated }} \\
1.3 \% \uparrow \quad \text { at } \\
3.5 \mathrm{bar} \\
\eta_{\text {net, indicated }} \\
5.7 \% \uparrow \quad \text { at } \\
8.5 \mathrm{bar}\end{array}$ & $\begin{array}{l}\text { Atkinson cycle } \\
\text { generates } \\
\text { lower } \mathrm{NO}_{\mathrm{x}} \\
\text { emission } \\
\text { attributed by } \\
\text { lower in- } \\
\text { cylinder } \\
\text { temperature } \\
\text { and increased } \\
\text { internal EGR }\end{array}$ \\
\hline $\begin{array}{l}\text { Zhao et al. } \\
2013,2018 \\
{[59,60]}\end{array}$ & $\begin{array}{l}\text { Simulation } \\
\text { study, } \\
\text { gasoline } \\
\text { engine }\end{array}$ & $\begin{array}{l}\text { Conventional } \\
\text { four stroke } \\
\text { engine } \quad+ \\
\text { LIVC }\end{array}$ & $12.5: 1$ & - & $\begin{array}{l}\text { 2000rpm / } \\
\text { 2.1bar BMEP }\end{array}$ & $\begin{array}{l}\text { BSFC } \\
10.5 \% \downarrow\end{array}$ & $\begin{array}{l}\text { Coupling the } \\
\text { effect of OE, } \\
\text { optimized } \\
\text { valve train, } \\
\text { and cylinder } \\
\text { deactivation. }\end{array}$ \\
\hline $\begin{array}{l}\text { Watanabe et } \\
\text { al. } 2006 \\
{[38]}\end{array}$ & $\begin{array}{l}\text { Simulation } \\
\text { and } \\
\text { experimental } \\
\text { study, } \\
\text { gasoline OE } \\
\text { engine } \\
\end{array}$ & $\begin{array}{l}\text { Gasoline OE } \\
\text { engine (EX- } \\
\text { Link system) }\end{array}$ & $8.5: 1$ & $1.4: 1$ & - & $\begin{array}{l}\eta_{\text {net,indicated }} \\
5 \% \uparrow\end{array}$ & - \\
\hline $\begin{array}{l}\text { Koga et al. } \\
2007 \\
{[61]}\end{array}$ & $\begin{array}{l}\text { Experimental } \\
\text { study, } \\
\text { gasoline OE } \\
\text { engine }\end{array}$ & $\begin{array}{l}\text { Gasoline OE } \\
\text { engine (EX- } \\
\text { Link system) }\end{array}$ & $8.5: 1$ & $1.4: 1$ & $\begin{array}{l}3060 \mathrm{rpm} / \\
\text { Full Load } \\
8.7 \text { bar BMEP } \\
\text { (Base) } \\
\text { 10.8bar } \\
\text { BMEP } \\
\text { (Atkinson) }\end{array}$ & $\begin{array}{l}\eta_{\text {net,indicated }} \\
12.2 \% \uparrow\end{array}$ & $\begin{array}{l}\text { Indicated } \\
\text { efficiency } \\
\text { was not } \\
\text { compared at } \\
\text { the same load. }\end{array}$ \\
\hline $\begin{array}{l}\text { Takita et al. } \\
2011 \text { [62] }\end{array}$ & $\begin{array}{l}\text { Experimental } \\
\text { study, } \\
\text { gasoline OE } \\
\text { engine }\end{array}$ & $\begin{array}{l}\text { Gasoline OE } \\
\text { engine (EX- } \\
\text { Link system) }\end{array}$ & $12.2: 1$ & $1.4: 1$ & 1950rpm & $\begin{array}{l}\eta_{\text {power generatio }} \\
3.8 \% \uparrow\end{array}$ & $\begin{array}{l}\text { Efficiency } \\
\text { based on a } \\
\text { power } \\
\text { generation } \\
\text { system }\end{array}$ \\
\hline $\begin{array}{l}\text { Brendel. } \\
2013[41]\end{array}$ & $\begin{array}{l}\text { Experimental } \\
\text { study, } \\
\text { gasoline OE } \\
\text { engine }\end{array}$ & $\begin{array}{l}\text { Multi-link } \\
\text { OE }\end{array}$ & - & - & 5000rpm & - & $\begin{array}{l}\text { Reduced } \\
\text { friction by } 7 \% \\
\text { at } 5000 \mathrm{rpm}\end{array}$ \\
\hline
\end{tabular}




\begin{tabular}{|l|l|l|l|l|l|l|l|}
\hline $\begin{array}{l}\text { Anadhan et } \\
\text { al. 2018 } \\
\text { [63] }\end{array}$ & $\begin{array}{l}\text { Simulation } \\
\text { study, } \\
\text { gasoline OE } \\
\text { engine }\end{array}$ & $\begin{array}{l}\text { Multi-link } \\
\text { OE }\end{array}$ & $10.0: 1$ & $\begin{array}{l}1.0: 1 \text { to } \\
1.5 \quad: 1 \\
(\mathrm{SR})\end{array}$ & $\begin{array}{l}2000 \mathrm{rpm} \\
16 \mathrm{bar} \\
\text { IMEPnet }\end{array}$ & $\begin{array}{l}\eta_{\text {net,indicated }} \\
10 \% \uparrow \quad \text { at } \\
\text { SR1.5 }\end{array}$ & $\begin{array}{l}\text { Lower knock } \\
\text { propensity of } \\
\text { OE engine. } \\
\text { Load decrease } \\
\text { at light load } \\
\text { to too } \\
\text { tue } \\
\text { much } \\
\text { ovpansion. }\end{array}$ \\
\hline $\begin{array}{l}\text { Boretti. et } \\
\text { al. [57] }\end{array}$ & $\begin{array}{l}\text { Experimental } \\
\text { study, } \\
\text { gasoline OE } \\
\text { engine }\end{array}$ & VCR & $\begin{array}{l}9.5: 1 \text { to } \\
15.5: 1\end{array}$ & $1.1: 1$ & 7.5 bar BMEP & $\eta_{\text {brake } 30 \% \uparrow} \begin{array}{l}\text { Coupling the } \\
\text { technology of } \\
\text { VCR and over- } \\
\text { expanded } \\
\text { cycle. }\end{array}$ \\
\hline
\end{tabular}




\section{Experimental Setup}

\subsection{Tested Engine Specification}

In this research, the test engine is a GM Ecotec LNF with 2.0 liter. It is an inline four-stroke spark-ignited boosted engine with variable valve timing. The engine geometric specification is listed in Table 3.1. The tested engine (Figure 3.1) was built in the Advanced Power System Labs (APS Labs) at Michigan Technological University. In Figure 3.1, the LNF engine was mounted on a cart, attached with an interface panel for the actuators and sensors to be attached.

Table 3.1 Geometric Specification of GM LNF Engine

\begin{tabular}{ll}
\hline \hline & GM LNF \\
\hline Bore (mm) & 86 \\
\hline Stroke (mm) & 86 \\
\hline Connecting Rod Length (mm) & 145.5 \\
\hline Wrist Pin Offset (mm) & 0.8 \\
\hline Compression Ratio (-) & 9.2 \\
\hline Total Displacement Volume (lit) & 0.4996 \\
\hline Cylinder Clearance Volume (lit) & 0.0609 \\
\hline Firing Order & $1-3-4-2$ \\
\hline Valve train specification & DOHC \\
\hline Camshaft Phasing Ranges & $25^{\circ}$ Intake $/ 25^{\circ}$ Exhaust Cam Angle \\
\hline Fuel Detail & $87 \mathrm{AKI}$, Gasoline \\
\hline \hline
\end{tabular}

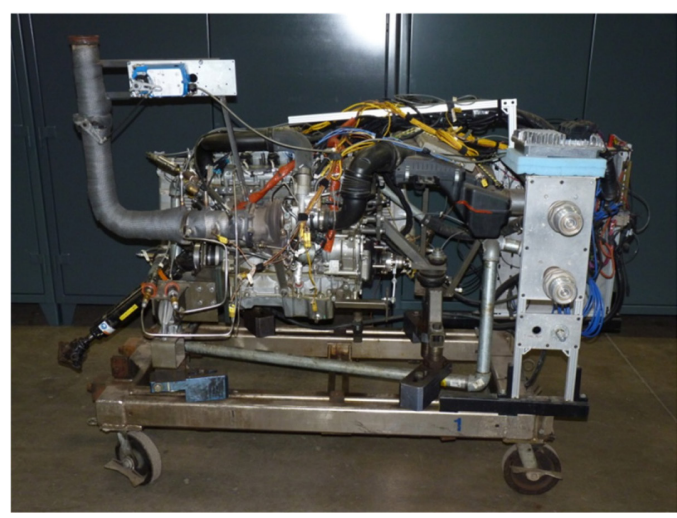

Figure 3.1 GM LNF engine on quick disconnect engine cart 


\subsubsection{Valvetrain of Tested Engine}

Cam timing of the tested engine using the production camshaft for both intake and exhaust sides. The cam profile is listed in Table 3.2.

Table 3.2 GM LNF baseline camshaft specification at the parked position

\begin{tabular}{lc}
\hline \hline \multicolumn{1}{c}{ GM I4 LNF Baseline Intake / Exhaust Camshaft Profile } \\
Intake Maximum Opening Position $\left({ }^{\circ}\right.$ aTDC) & 115 \\
Intake Peak Valve Lift (mm) & 10.3 \\
Intake Valve Lift Duration $\left({ }^{\circ} \mathrm{CA}\right)$ & 230 \\
Intake Valve Lash (mm) & 0.04 \\
Exhaust Maximum Opening Position ( ${ }^{\circ}$ aTDC) & -120 \\
Exhaust Peak Valve Lift (mm) & 10.3 \\
Exhaust Valve Lift Duration $\left({ }^{\circ} \mathrm{CA}\right)$ & 220 \\
Exhaust Valve Lash (mm) & 0.06 \\
Intake Maximum Opening Position $\left({ }^{\circ}\right.$ aTDC) & 115 \\
Intake Peak Valve Lift $(\mathrm{mm})$ & 10.3 \\
Intake Valve Lift Duration $\left({ }^{\circ} \mathrm{CA}\right)$ & 230 \\
\hline \hline
\end{tabular}

The baseline cam profiles are listed in Figure 3.2. The red curve represents the exhaust cam with $0.06 \mathrm{~mm}$ lash; the blue curve represents the intake cam with $0.04 \mathrm{~mm}$ last. The overlap of the valves is $40^{\circ} \mathrm{CA}$ at the parked position.

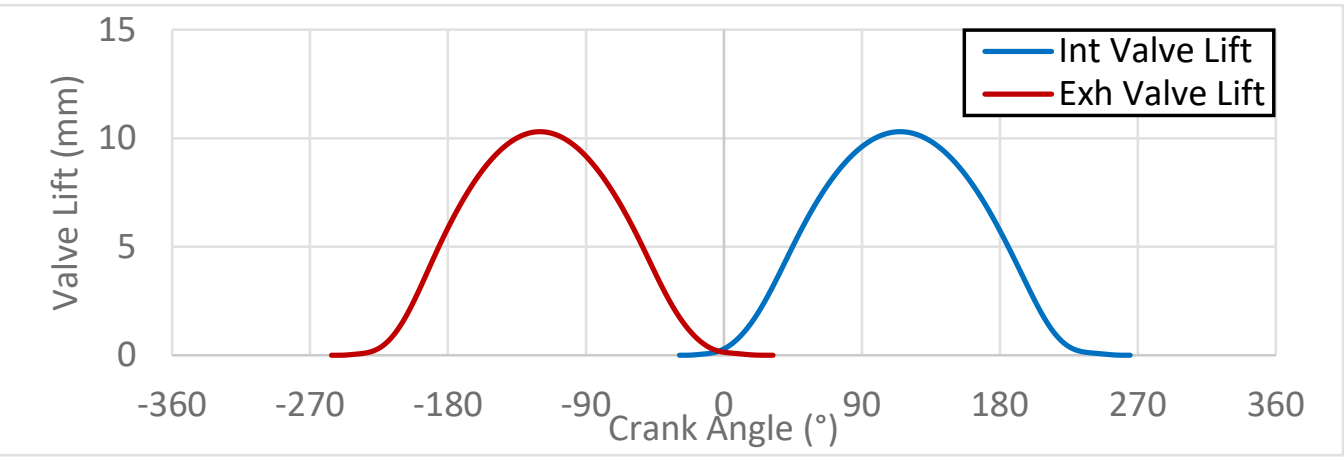

Figure 3.2 LNF baseline valve lift as a function of crank angle location

\subsection{Engine Control}

\subsubsection{Engine Calibration Tool}

The engine controller of this study utilized a production Bosch ECU with an ETAS engine calibration tool, as shown in Figure 3.3. ETAS was used to real-time indicated ECU signals or overwrite the default ECU calibration. 


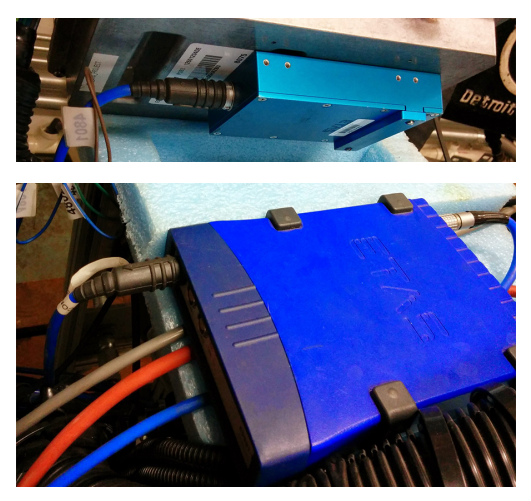

Figure 3.3 ETAS - engine calibration tool box

\subsection{Engine Test Cell Setup}

\subsubsection{Dynamometer Test Cell}

This dynamometer used in this study is a GE $350 \mathrm{~kW}$ (465 hp) motoring AC dynamometer. In the test cell, engines need to be mounted on the cart which allows the engine to be swapped between different projects efficiently. The data acquisition (DAQ) system in the test cell can be saved more than 200 channel test data in one test. The high-speed DAQ can log the real-time experimental results including combustion, engine torque, and air, fuel flow.

\subsubsection{Dynamometer System}

The dynamometer in the APS Labs test cell is manufactured by GE Motors (Model \# 5TKF445DC03A004) as shown in Figure 3.4. The absorbing power of the dynamometer is $460 \mathrm{hp}$ at $4000 / 8000 \mathrm{rpm}$. The motoring power of the dynamometer is $400 \mathrm{hp}$ @ $4000 / 8000 \mathrm{rpm}$. This engine can be attached to both sides of the dynamometer. In Figure 3.4 , the tested engine was mounted on one side of the dynamometer while the other side was not occupied. The dynamometer is able to be operated at either speed or load control mode. Torque measurement is based on a calibrated load cell sensor. 


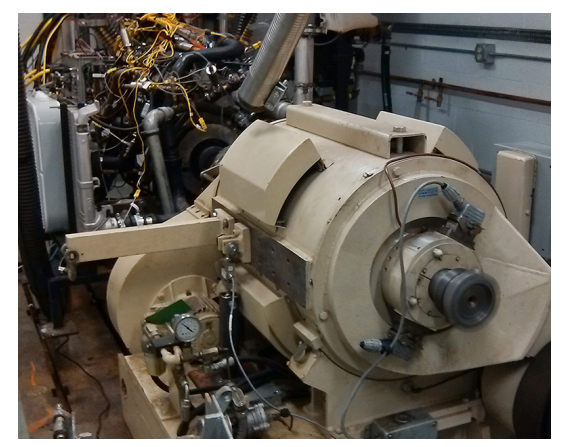

Figure 3.4 Dynamometer in APS Labs test cell \#2

\subsubsection{Real-Time Data Acquisition}

The real-time data acquisition used in this study is the Advanced Combustion Analysis Program (ACAP) DAQ chassis provided by DSP Technology Inc. The experimental results were saved with crank angle domain. The sampling rate is 1 data point per crank angle. The encoder used in this study is EPC 260, as shown in Figure 3.5. The tolerance of the encoder coaxiality was controlled within $\pm 0.05 \mathrm{~mm}$. In the ACAP, the logged changed included in-cylinder pressure, manifold absolute pressure (MAP), fuel flow, air/fuel flow ratio, spark advance, and dynamometer torque.

The results of in-cylinder pressure were measured by four piezo-electric pressure transducers (AVL GH12D). Those four transducers are installed through the holes near the spark plug, as Figure 3.6 shows. A charger amplifier is required to convert the coulomb signal to a voltage signal. The raw data of the in-cylinder pressure need to be pegged with the manifold pressure and converted as the absolute pressure. The manifold absolute pressure (MAP) sensor is logged as the same sample rate as the in-cylinder pressure transducers. The in-cylinder pressure was pegged at the bottom dead center before compression.

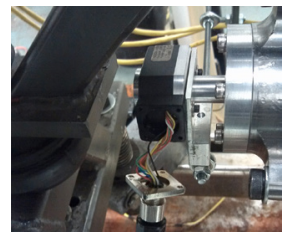

Figure 3.5. EPC Encoder Model 260

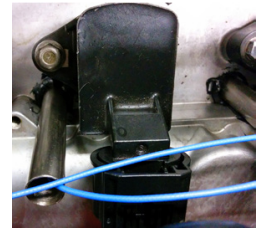

Figure 3.6. Pressure transducer installation 


\subsubsection{Low Speed Data Acquisition}

A National Instrument PXI chassis is utilized for logging time-average results as shown in Figure 3.7. Logged channels included pressure and temperature measurement with a $10 \mathrm{~Hz}$ sampling rate. The signal is transmitted via the integrated cable with one side linked to the PXI card and the other side linked to the engine cart interface. An uninterrupted power supply (UPS) was used for providing backup power to save data if the electricity supply is shut down (Figure 3.7).

\subsubsection{APS Labs Airflow Measurement}

The airflow rate is measured by the laminar flow elements (LFE) sensor, as shown in Figure 3.8. Volumetric velocity, ambient condition including temperature, pressure, humidity was also measured by LFE.

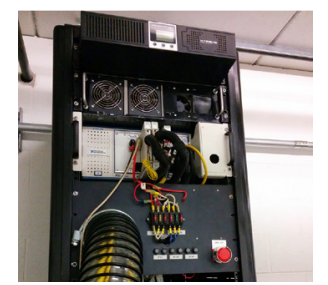

Figure 3.7. National Instruments PXI chassis

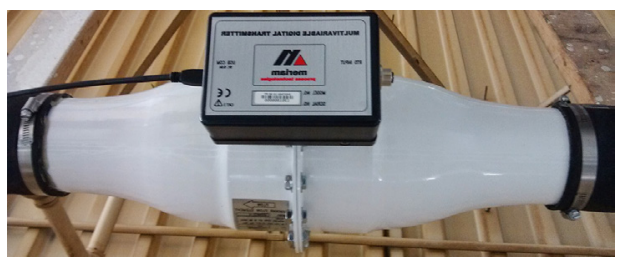

Figure 3.8. Meriam laminar flow elements

\subsubsection{Fuel Flow Measurement}

The fuel flow was measured by the Coriolis meter. The model number of the Coriolis meter is Micro Motion 1700, as shown in Figure 3.9. The current signal was converted to a voltage signal by adding the resistor on the output terminal of the Coriolis meter, as shown in Figure 3.10.

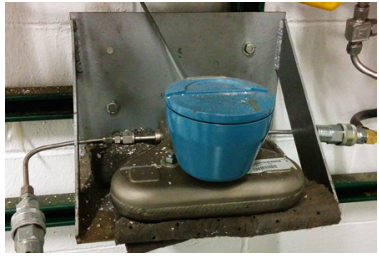

Figure 3.9. Micro Motion 1700

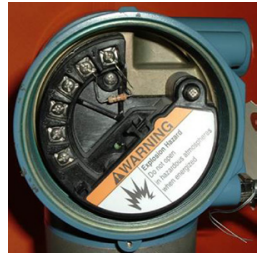

Figure 3.10. Wiring of Micro Motion 1700 


\subsection{Definition of Experiments}

The experimental study was based on the production GM LNF engine with default calibration. Four operating points were included in this study as shown in Table 3.3. The selected speed/load conditions represent the high fuel consumption point in US06 and FTP75.

The test procedure in the test cell includes the pre-check, engine warm-up, engine test, cooldown, and post-check.

In the pre-check, the engine cart was tightened on the testbed and connected with the engine dynamometer. All signal input/output wires were connected to the high-speed and lowspeed DAQ. The power relay was controlled via the NI interface. All signal channels needed to be checked before the engine spinning.

Engine warming up is to ensure the repeatability of the experimental results with the same engine coolant temperature and oil pressure. The warming up period took approximately 10 to 15 minutes, depending on the ambient condition.

The control points were conducted in the beginning and at the end of testing to track the repeatability of the experimental results. The control point is at 1300RPM 330kPa IMEPnet for firing condition and $1300 \mathrm{RPM} 95 \mathrm{kPa}$ MAP for motoring condition.

The cooldown step was to motor the engine after all firing tests finalized. An instant engine shutdown may damage the engine. The tested engine was kept motoring at least 5 minutes.

Table 3.3 Test matrix of experimental study

\begin{tabular}{ccccc}
\hline \hline Speed [rpm] & 1300 & 1250 & 1750 & 1500 \\
\hline BMEP [bar] & 330 & 600 & 950 & 1500 \\
\hline IMOP [ ${ }^{\circ}$ aTDC GE] & 91 & 91 & 91 & 91 \\
\hline EMOP [ ${ }^{\circ}$ aTDC GE] & -96 & -96 & -96 & -96 \\
\hline \hline
\end{tabular}

The post-check includes the check of software and hardware instrumentation. Zero offsets were logged after the engine stopped spinning.

Test fuel was $10 \%$ ethanol-blended gasoline (E10) with an anti-knock index of 87.0. The fuel report is included in Appendix 12A. The combustion phasing was controlled by either most brake torque (MBT) spark advance or knock limited spark advance (KLSA). In the light and medium load, 50\% fuel mass burned fraction (CA50) was controlled at $8^{\circ}$ aTDC. In knock-limited condition, KLSA was defined as knock peak-peak at $200 \mathrm{kPa}$. With the closed-loop lambda control, all experimental study was controlled at the stoichiometric condition. 


\section{Methodology}

\subsection{Baseline Model Development}

The baseline engine model was developed based on the GM Ecotec LNF 2.0-liter engine, which is the same engine as the experimental study. The original model was built based on the default calibration. The development of the baseline model includes combustion model calibration and close-loop controller development.

\subsubsection{Combustion Model}

The original combustion model use in the baseline engine is SI Wiebe function which is to describe a fixed heat release profile. In this study, the combustion model used the SI turbulence model to extend the predictability.

The SI turbulence model is used to predict the in-cylinder burn rate and knocking occurrence for spark-ignited engines. The model requires a detailed combustion chamber geometry. The combustion chamber was extracted from the computer-aided design (CAD) model as shown in Figure 4.1. The generated mesh of the combustion chamber in GT-Suite (Figure 4.2) is for the calculation of the SI-turbulence model. It can be used to validate the geometric relation between the cylinder head and piston.

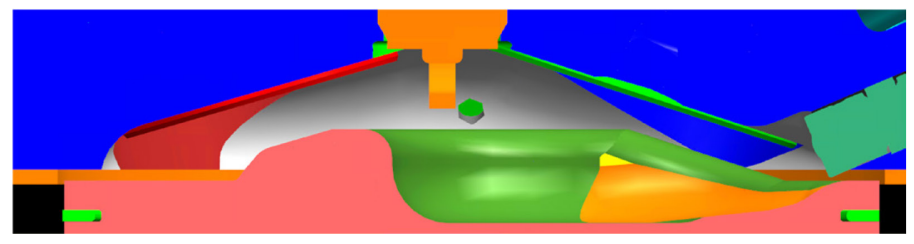

Figure 4.1 Combustion chamber in CAD model
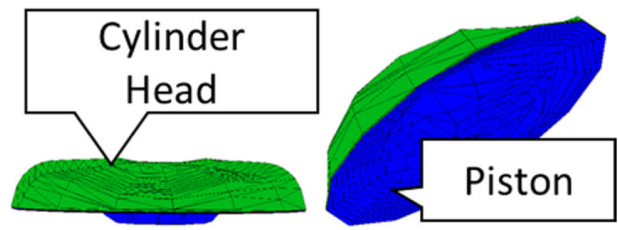

Figure 4.2 GT-Suite generated mesh of combustion chamber

\subsubsection{Knock Onset Prediction Model}

Knock onset prediction used in this dissertation is based on the empirical induction-time correlation [22]. The empirical relation for induction times is based on the kinetic 
mechanism given by Ra. et al. [66]. Three induction times were calculated to represent the low, intermediate, and high temperature regions, respectively as Equation 4-2 shows. The calculation of induction time $\tau$ is shown in Equation 4-3. The kinetics-fit model considers the effect of octane number, fuel concentration, oxygen concentration, dilution, and unburned zone temperature. Figure 4.3 is the induction time $\tau$ (black dashed line) as a function of unburned zone temperature. In the knock onset prediction model, knock occurred at the crank angle at which the induction time integral attained a value of 1.0 (Equation 4-1). The knock onset prediction model was calibrated to match the knock onset from the experimental results.

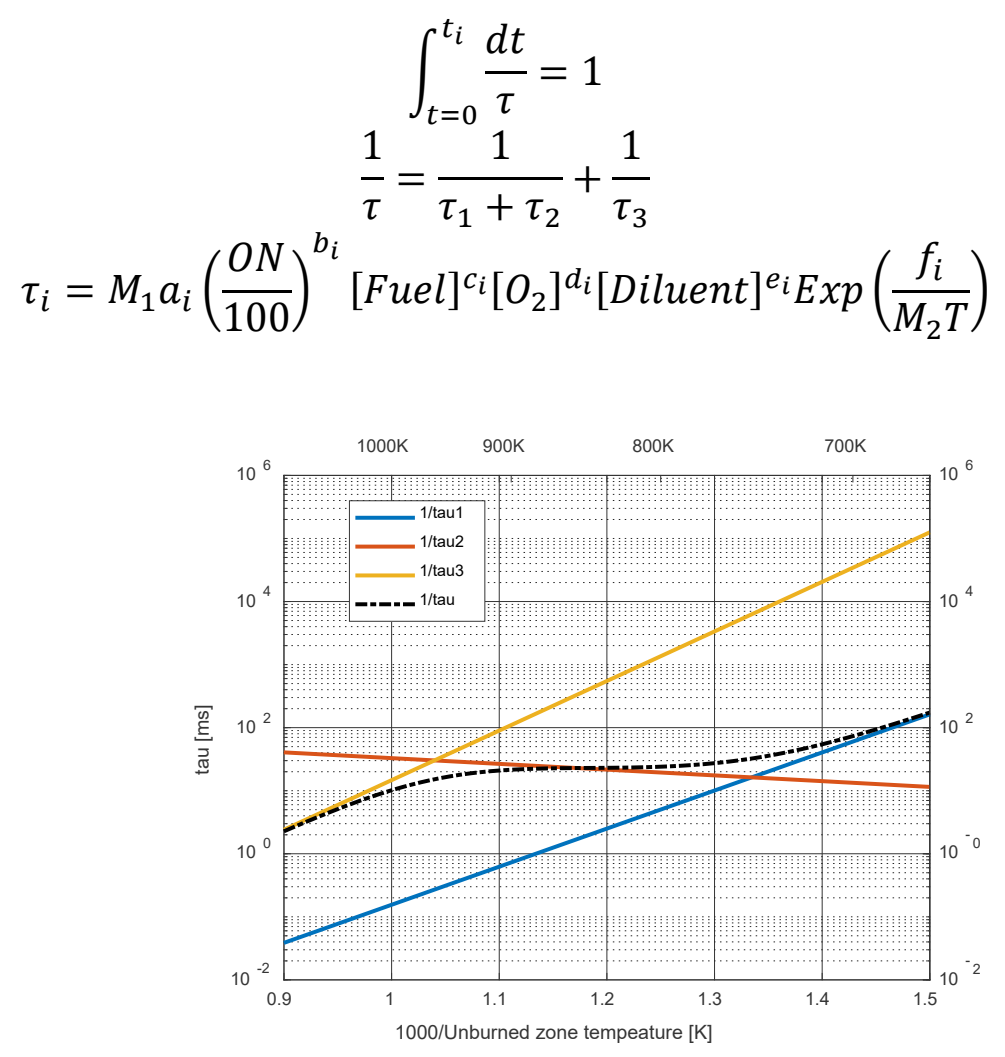

Figure 4.3 Induction times as a function of unburned zone temperature

\subsubsection{Model Controllers}

Model controllers were developed based on the PI controller for the constrained parameters including, combustion phasing, knock intensity, exhaust gas temperature, and engine load. The controllers used in the model are listed in Table 4.1. Only the load controller was used from the GT-Suite library. The other controllers were customized and calibrated based on the control input/output. The controller connection in the model is shown in Figure 4.4. 
Table 4.1 Controller Summary

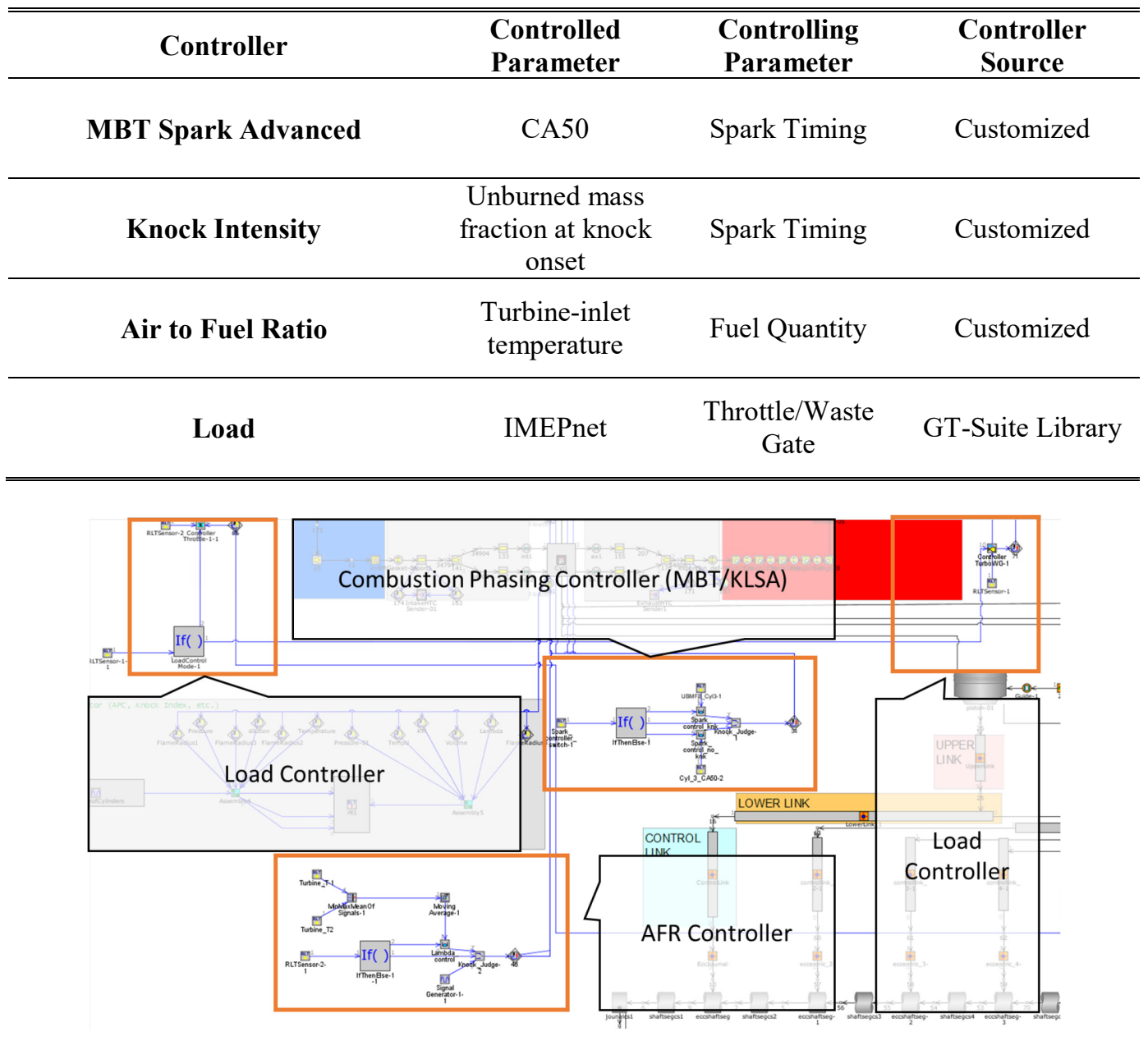

Figure 4.4 Engine controllers in the 1D model

\subsubsection{Model Constraints}

In this study, the model constraints include knock intensity, turbine-inlet temperature, residual gas fraction, and trapping ratio, summarized in Table 4.2.

Table 4.2 Model Constraints

\begin{tabular}{cc}
\hline \hline Model Constrains & Controlling Parameter \\
Unburn mass fraction at knock onset $\leq 10 \%$ & Spark Timing of SI Turbulence Model \\
Turbine-inlet Temperature $\leq 950^{\circ} \mathrm{C}$ & AFR \\
Trapping Ratio $\geq 99 \%$ & Cam Timing \\
Residual Gas Fraction $\leq 30 \%$ & Cam Timing \\
\hline \hline
\end{tabular}


The knock constraint was controlled by adjusting the spark timing in the SI turbulence model. Research by Chun et al. [67] shows a good correlation between mean knock intensity and unburned mass fraction at knock onset. In this dissertation, the KLSA is defined as the spark advance where the knock onset is at a $10 \%$ unburned mass fraction. The post-knock feature was turned on. If knock occurred in the simulation, the remaining unburned fuel was forced to be burned in the next time step of knock onset.

The turbine-inlet temperature limited is set at $950^{\circ} \mathrm{C}$ (time-average value) to represent the limitation of the boosting system. At high load conditions, the controllers will be automatically enriched fuel to reduce the exhaust temperature and the turbine-inlet temperature.

Residual gas fraction (RGF) and trapping ratio (TR) was adjusted by cam timing. The constraints of RGF and TR are at $30 \%$ and $99 \%$, respectively. RGF was used to constrain the internal dilution level at light load conditions. TR was used to constrain the scavenging effect at high load conditions.

$$
\begin{aligned}
& R G F=\frac{\text { mass }_{\text {trapped burned gas }}}{\text { mass }_{\text {trapped gas total }}} \\
& \text { trapping ratio }=\frac{\text { mass }_{\text {trapped }}}{\text { mass }_{\text {total through intake valve into cylinder }}}
\end{aligned}
$$

\subsubsection{Model Calibration}

The 1D engine model was calibrated through three pressure analysis (TPA) and fine-tuned for each speed/load condition. The calibration results are summarized in Table 4.3.

Table 4.3 Baseline engine calibration at selected operating conditions

\begin{tabular}{ccccccc}
\hline \hline & Experiment & Simulation & Experiment & Simulation & Experiment & Simulation \\
\hline Speed (rpm) & 1300 & 1300 & 1750 & 1750 & 1500 & 1500 \\
\hline IMEPnet (bar) & 3.3 & 3.3 & 10.3 & 10.3 & 14.4 & 14.4 \\
\hline MAP (kPa) & 47.5 & 47.5 & 96.9 & 96.8 & 129.6 & 129.5 \\
\hline $\begin{array}{c}\text { Net indicated } \\
\text { efficiency (\%) }\end{array}$ & 33.2 & 33.6 & 37.8 & 38.2 & 37.8 & 37.7 \\
\hline $\begin{array}{c}\text { Total Fuel flow } \\
(\mathrm{g} / \mathrm{s})\end{array}$ & 0.51 & 0.51 & 1.89 & 1.88 & 2.3 & 2.3 \\
\hline $\begin{array}{c}\text { Location of peak } \\
\text { pressure ( }{ }^{\circ} \text { aTDC) }\end{array}$ & 11.8 & 12.4 & 15.4 & 15.9 & 21.1 & 21.0 \\
\hline \begin{tabular}{c} 
Peak pressure (bar) \\
\hline Knock Onset \\
$\left({ }^{\circ}\right.$ aTDC)
\end{tabular} & 21.6 & 21.6 & 52.6 & 51.1 & 65.2 & 67.3 \\
\hline \hline
\end{tabular}




\subsection{Over-Expanded Engine Development}

\subsubsection{Development of multi-link over-expanded mechanism}

The design of the multi-link mechanism refers to the study by Watanabe et al. [38] and Brendel [41]. The schematic of the over-expanded mechanism is shown in Figure 4.5. The variables used in the mechanism design are summarized in Table 4.4.

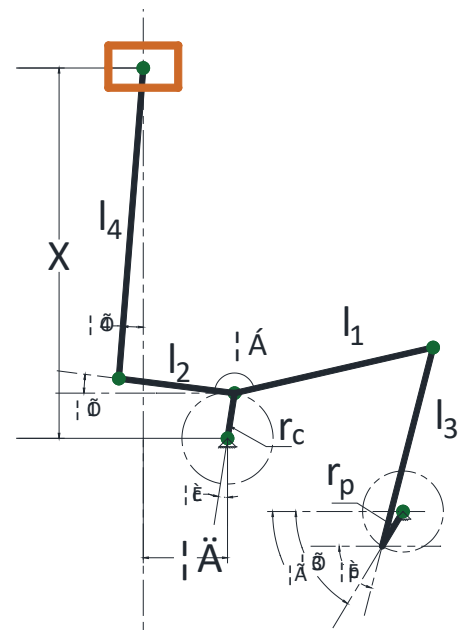

Figure 4.5 Schematic of multi-link over-expanded mechanism

Table 4.4 Design variable of over-expanded mechanism

\begin{tabular}{|c|c|c|}
\hline $\begin{array}{l}\text { Mechanism Driven } \\
\text { Parameter }\end{array}$ & $\theta \mathrm{c}$ & crank angle \\
\hline \multirow{2}{*}{$\begin{array}{l}\text { Independent Geometry } \\
\text { Design Parameters }\end{array}$} & $\mathrm{rp}$ & radius of control shaft \\
\hline & $\gamma$ & initial phasing of control shaft \\
\hline \multirow{9}{*}{$\begin{array}{l}\text { APA } 18 \text { geometry in } \\
\text { Brendel [41] }\end{array}$} & $\mathrm{rc}$ & radius of crank shaft \\
\hline & $\mathrm{k}$ & $\begin{array}{l}\text { scaling factor based upon the APA } 18 \text { geometry in } \\
\text { Brendel [1] }\end{array}$ \\
\hline & 11 & rod length between trigonal pin 1 and pin 3 \\
\hline & 12 & rod length between trigonal pin 2 and pin 3 \\
\hline & 13 & rod length between trigonal link and control shaft \\
\hline & 14 & connection rod length \\
\hline & 15 & $\begin{array}{l}\text { offset of crank shaft and control shaft in } \mathrm{x} \text {-axis } \\
\text { direction }\end{array}$ \\
\hline & 16 & $\begin{array}{l}\text { offset of crank shaft and control shaft in y-axis } \\
\text { direction }\end{array}$ \\
\hline & $\alpha$ & trigonal link angle \\
\hline
\end{tabular}




\begin{tabular}{|c|c|c|}
\hline & $\delta$ & crank-piston pin offset \\
\hline & $\eta$ & gear ratio of crank shaft and control shaft \\
\hline & $\mathrm{x}$ & $\begin{array}{l}\text { distance of crank pin and piston pin in y-axis } \\
\text { direction }\end{array}$ \\
\hline & $\theta \mathrm{p}$ & control shaft angle \\
\hline & $\phi 1$ & angular position of trigonal pin2-3 \\
\hline Dependent & $\phi 3$ & angular position of trigonal link and control shaft \\
\hline geometry & $\phi 4$ & angular position of connection rod \\
\hline & $\mathrm{V}_{\text {displacement }}$ & displacement volume \\
\hline & $\mathrm{V}_{\text {clearance }}$ & clearance volume \\
\hline & $\mathrm{CR}$ & compression ratio \\
\hline & ER & expansion ratio \\
\hline
\end{tabular}

The kinematics of the over-expanded mechanism is summarized as below,

$$
\begin{gathered}
x=k \cdot l_{4} \cdot \cos \left(\phi_{4}\right)+k \cdot l_{2} \cdot \sin \left(\phi_{1}+\alpha\right)+r_{c} \cdot \cos \left(\theta_{c}\right) \\
\delta=k \cdot l_{4} \cdot \sin \left(\phi_{4}\right)-k \cdot l_{2} \cdot \cos \left(\phi_{1}+\alpha\right)-r_{c} \cdot \sin \left(\theta_{c}\right) \\
k \cdot l_{5}=r_{c} \cdot \sin \left(\theta_{c}\right)+k \cdot l_{1} \cdot \cos \left(\phi_{1}\right)+k \cdot l_{3} \cdot \cos \left(\phi_{3}\right)-r_{p} \cdot \sin \left(\theta_{p}\right) \\
k \cdot l_{6}=\mathrm{r}_{\mathrm{p}} \cdot \cos \left(\theta_{p}\right)+k \cdot \mathrm{l}_{3} \cdot \sin \left(\phi_{3}\right)-k \cdot \sin \left(\phi_{1}\right)-\mathrm{r}_{\mathrm{c}} \cdot \cos \left(\theta_{c}\right) \\
\theta_{p}=\eta \cdot \theta_{c}+\gamma
\end{gathered}
$$

The constraints of the mechanism are summarized below,

$$
\begin{gathered}
C R_{O E}=C R_{\text {base }} \\
\mathrm{ER}=1.3,1.5
\end{gathered}
$$




$$
\begin{gathered}
V_{O E, \text { compression }}=V_{\text {Base, compression }} \\
\mathrm{X}_{\mathrm{TDC}, \text { firing }}-\mathrm{X}_{\mathrm{TDC}, \mathrm{GE}}<0.5 \mathrm{~mm}
\end{gathered}
$$

In the mechanism design, the total geometric variable is 23 . The number of geometric equations, design constraints, constant variables based on Brendel's design [41], are 5, 4, and 11 , respectively. Therefore, the design of freedom is 3 (23-5-4-11). It should be noted that $\theta \mathrm{c}$ is the driven variable of the mechanism. The design of the mechanism is to determine the combination of the initial phasing of the control shaft (rp) and radius of the control shaft $(\gamma)$.

Based on the kinematics equation, the piston location and in-cylinder volume as a function of the crank angle can be calculated, as shown in Figure 4.6 and Figure 4.7. In this study, four mechanisms were designed with CR of 9.2:1 and 10.5:1, OER of 1.3 and 1.5. The detail of the geometric specifications of the conventional engines and designed overexpansion engines are list in Table 4.5.

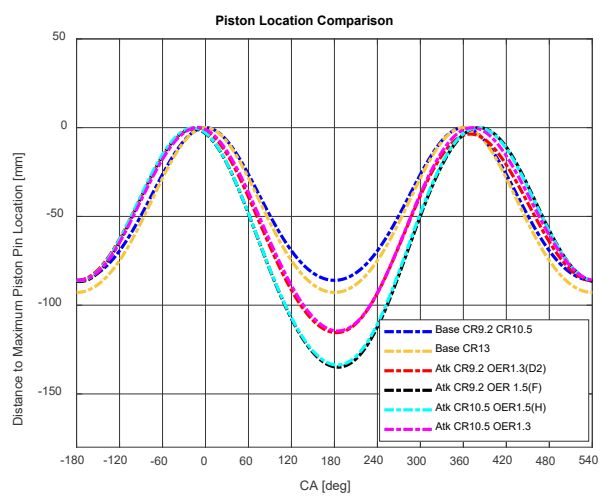

Figure 4.6 Piston location as a function of crank angle, baseline engine, and overexpanded mechanism. (" 0 " is at the TDC Firing)

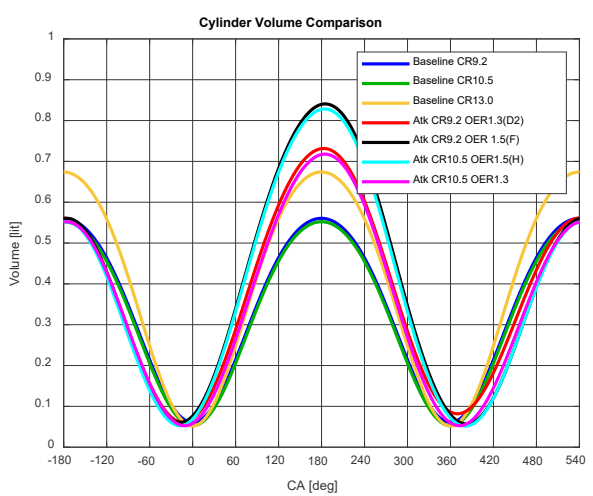

Figure 4.7 In-cylinder volume as a function of crank angle, baseline, and over-expanded cycle mechanism. ("0" is at the TDC Firing) 
Table 4.5 Geometric specifications of designed mechanisms

\begin{tabular}{|c|c|c|c|c|c|c|c|c|c|c|c|c|}
\hline \multicolumn{3}{|c|}{ Mechanism Parameters } & \multicolumn{3}{c|}{ Stroke Length [mm] } & \multicolumn{3}{c|}{ Volume [cc] } \\
\hline $\begin{array}{c}\text { Mechanism } \\
\text { Type }\end{array}$ & CR & ER & OER & $\begin{array}{c}\text { Bore } \\
\text { [mm] }\end{array}$ & $\begin{array}{c}\text { Comp } \\
\text { re. }\end{array}$ & Expan. & Exhaust & Intake & $\begin{array}{c}\text { BDC } \\
\text { before } \\
\text { Comp. }\end{array}$ & $\begin{array}{c}\text { TDC } \\
\text { Firing }\end{array}$ & $\begin{array}{c}\text { BDC } \\
\text { after } \\
\text { Expan. }\end{array}$ & $\begin{array}{c}\text { TDC } \\
\text { GE }\end{array}$ \\
\hline $\begin{array}{c}\text { Baseline } \\
9.2\end{array}$ & 9.2 & 9.2 & 1.0 & 86.0 & 86.0 & 86.0 & 86.0 & 86.0 & 560.5 & 60.9 & 560.5 & 60.9 \\
\hline $\begin{array}{c}\text { Baseline } \\
10.5\end{array}$ & 10.5 & 10.5 & 1.0 & 86.0 & 86.0 & 86.0 & 86.0 & 86.0 & 552.1 & 52.6 & 552.1 & 52.6 \\
\hline $\begin{array}{c}\text { Baseline } \\
13.0\end{array}$ & 13.0 & 13.0 & 1.0 & 89.0 & 100.0 & 100.0 & 100.0 & 100.0 & 674.0 & 51.8 & 674.0 & 51.8 \\
\hline $\begin{array}{c}\text { Atk CR9.2 } \\
\text { SR 1.4 } \\
\text { OER1.3 }\end{array}$ & 9.2 & 12.0 & 1.3 & 86.0 & 86.0 & 119.4 & 111.8 & 82.5 & 561.0 & 61.0 & 731.5 & 81.9 \\
\hline $\begin{array}{c}\text { Atk CR9.2 } \\
\text { SR1.6 } \\
\text { OER1.5 }\end{array}$ & 9.2 & 13.8 & 1.5 & 86.0 & 86.0 & 135.2 & 134.9 & 86.6 & 560.3 & 60.9 & 840.6 & 57.0 \\
\hline $\begin{array}{c}\text { Atk CR10.5 } \\
\text { SR 1.3 } \\
\text { OER1.3 }\end{array}$ & 10.5 & 13.7 & 1.3 & 86.0 & 86.0 & 114.5 & 114.5 & 86.0 & 552.0 & 52.6 & 717.7 & 52.8 \\
\hline $\begin{array}{c}\text { Atk CR10.5 } \\
\text { SR 1.6 } \\
\text { OER1.5 }\end{array}$ & 10.5 & 15.8 & 1.5 & 86.0 & 86.0 & 133.5 & 133.7 & 86.2 & 552.1 & 52.6 & 828.1 & 51.6 \\
\hline
\end{tabular}

\subsubsection{Adjustment of the multi-link over-expanded mechanism}

In Figure 4.7, it can be observed that the top dead center (TDC) and bottom dead center (BDC) of piston and crank are not at the same location. The BDC and TDC offsets of overexpanded mechanisms is listed in Table 4.6.

Those offsets result in the different stroke durations between the over-expanded engine and the baseline engine, e.g., intake stroke and compression stroke of the baseline engine being $17^{\circ}$ and $21^{\circ}$ more than the over-expanded engine, respectively.

The cam phasing, valve lift, and spark timing used in the baseline engine need to be adjusted before being applied to the over-expanded engine. The adjustment was to match the piston location by compensating the crank angle location. In this study, the spark timing and the valve timing of the over-expanded engine used the same piston location as the baseline; however, the crank angle location of the over-expanded cycle engine was adjusted corresponding to the method provided by Yang et al. [68]. The adjustment includes the cam timing, the profile of the valve lift, and spark timing. 
Table 4.6 Crank angle offset and stroke duration of designed over-expanded mechanisms

\begin{tabular}{|c|c|c|c|c|c|c|c|c|c|c|c|c|}
\hline \multicolumn{5}{|c|}{ Mechanism Parameters } & \multicolumn{4}{|c|}{ Offset to Crank DC [deg] } & \multicolumn{4}{|c|}{ Stroke Duration [deg] } \\
\hline $\begin{array}{l}\text { Mechanism } \\
\text { Type }\end{array}$ & $\mathrm{CR}$ & ER & OER & $\begin{array}{l}\text { Bore } \\
{[\mathrm{mm}]}\end{array}$ & $\begin{array}{c}\text { TDC } \\
\text { Firing }\end{array}$ & $\begin{array}{c}\text { BDC } \\
\text { after } \\
\text { Expan. }\end{array}$ & $\begin{array}{c}\text { TDC } \\
\text { GE }\end{array}$ & $\begin{array}{l}\text { BDC } \\
\text { after } \\
\text { Intake }\end{array}$ & Comp. & Exp. & Exh. & Int. \\
\hline $\begin{array}{c}\text { Atk CR9.2 } \\
\text { SR } 1.4 \\
\text { OER } 1.3\end{array}$ & 9.2 & 12.0 & 1.3 & 86.0 & -13.8 & 2.8 & -10.5 & -2.8 & 196.6 & 166.7 & 187.7 & 169 \\
\hline $\begin{array}{c}\text { Atk CR9.2 } \\
\text { SR1.6 } \\
\text { OER } 1.5\end{array}$ & 9.2 & 13.8 & 1.5 & 86.0 & -17.5 & 4.5 & 21.8 & 4.3 & 202.0 & 197.3 & 162.5 & 158.2 \\
\hline $\begin{array}{c}\text { Atk } \\
\text { CR10.5 SR } \\
1.3 \\
\text { OER1.3 }\end{array}$ & 10.5 & 13.7 & 1.3 & 86.0 & -11.3 & 4.3 & 12.3 & 3.8 & 195.6 & 188 & 171.5 & 1649 \\
\hline $\begin{array}{c}\text { Atk } \\
\text { CR10.5 SR } \\
1.6 \\
\text { OER1.5 }\end{array}$ & 10.5 & 15.8 & 1.5 & 86.0 & -18.0 & 4.0 & 20.3 & 3.3 & 202 & 1963. & 163 & 158.7 \\
\hline
\end{tabular}

The spark timing of the over-expanded engine was adjusted referred to the offset of TDC firing. Cam timing adjustment of the over-expanded engine was based on the crank location where the piston was at TDC/BDC. Equation 4-15 calculates the offset of the intake cam phasing, which refers to the TDC gas exchange (GE) and BDC after intake stroke. Equation 4-16 is the offset of the exhaust cam phase, which refers to the BDC after the expansion stroke and TDC GE. The valve opening duration was scaled based on the ratio of stroke length between the two engines, as shown in Equation 4-17 and Equation 4-18.

$$
\begin{gathered}
\text { Off set }_{\text {Intkake Cam }}=\frac{\left(T D C_{G E}+B D C_{\text {Intake }}\right)}{2} \\
\text { Offset } \text { Exhaust Cam }=\frac{\left(T D C_{G E}+B D C_{\text {Exhaust }}\right)}{2} \\
\text { Scale }_{\text {Intake valve duration / lift }}=\frac{\text { Stroke }_{\text {Atk, Intake }}\left({ }^{\circ} \mathrm{CA}\right)}{180} \\
\text { Scale }_{\text {Exhaust valve duration } / \text { lift }}=\frac{\text { Stroke }_{\text {Atk,Exhaust }}\left({ }^{\circ} \mathrm{CA}\right)}{180}
\end{gathered}
$$

The valve lift comparison between pre-adjustment and post-adjustment of the overexpanded engine (CR10.5 OER 1.5) as a function of the crank angle is shown in Figure 4.8. It can be observed the mechanism has a longer exhaust valve duration and short intake valve duration. 


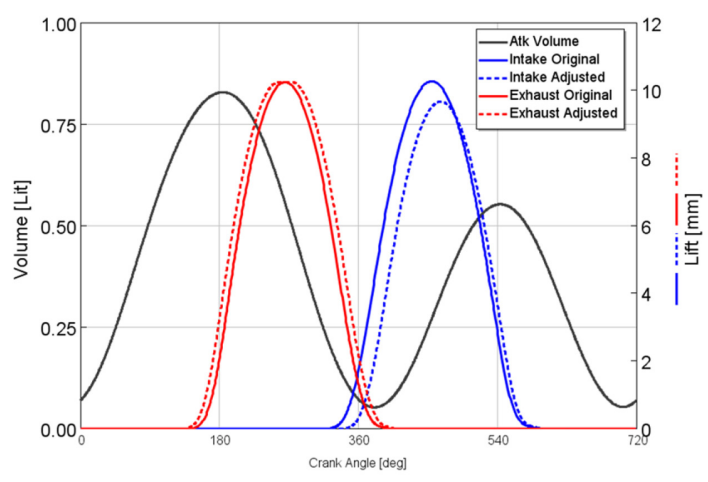

Figure 4.8 Volume and valve list as a function of crank angle of over-expanded engine

\subsubsection{Indicated work definition of over-expanded cycle}

The main characteristics of the multi-link over-expanded engine are the over-expansion during the power stroke. The definition of the indicated work and pumping work need to be modified according to the mechanism characteristics. Figure 4.9 is a log pressure vs. log normalized volume diagram of an over-expanded engine. The gross indicated work of an over-expanded engine is generated in the period $a \rightarrow b \rightarrow c$. The gross indicated work can be further separated as the component of non-over-expansion $(a \rightarrow b)$ and over-expansion $(b \rightarrow c)$. Pumping work is generated in a period of $c \rightarrow a$. The indicated work breakdown of the over-expanded engine in the whole cycle can be summarized as Figure 4.10 shows.

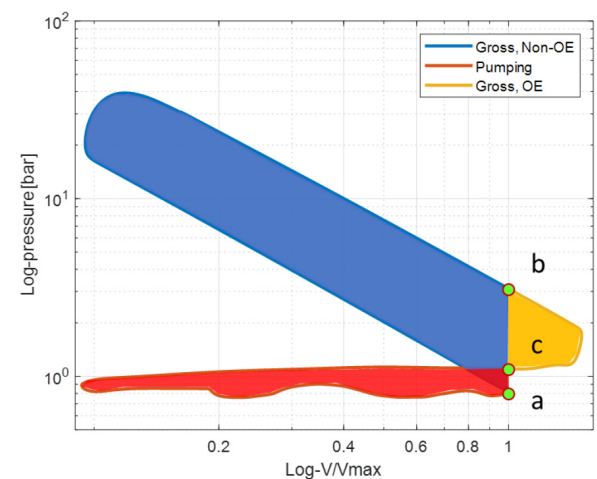

Figure 4.9 Gross work and pumping work of over-expanded engine in a $\log \mathrm{P}-\log \mathrm{V} / \mathrm{V}_{\max }$ diagram $\left(\mathrm{V}_{\max }\right.$ is the maximum in-cylinder volume at the end of intake stroke)

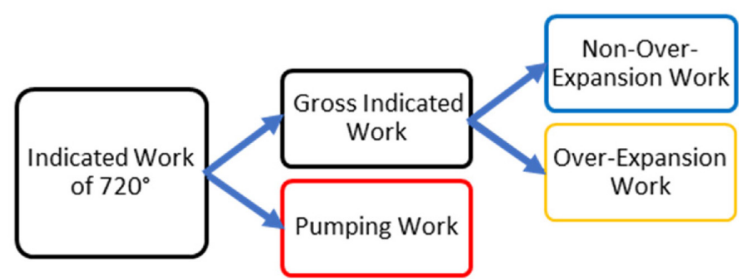

Figure 4.10 Indicated work breakdown of over-expanded engine

In the over-expanded cycle, over-expansion (OE) indicated efficiency is determined by the indicated work during over expansion normalized by the fuel energy $\left(\eta_{\text {indicated,OE }}\right.$, Equation 4-16). The non-over-expansion (non-OE) indicated efficiency is determined by 
the indicated work of non-OE indicated work normalized by the fuel energy ( $\eta_{\text {indicated, non-OE,net }}$, Equation 4-17). As the over-expansion is excluded from the calculation of $\eta_{\text {indicated,non-OE,net }}, \eta_{\text {indicated,non-OE,net }}$ is comparable to the net indicated work of a baseline engine. Equation 4-18 is the normalized pumping work.

$$
\begin{gathered}
\eta_{\text {net indicated }}=\frac{\text { Work }_{G_{-} \text {Non_oE }}+\text { Work }_{G_{-} O E}+\text { Work }_{\text {Pumping }}}{\text { Fuel Energy }} \\
\eta_{\text {indicated,OE }}=\frac{\text { Work }_{G_{\_} O E}}{\text { Fuel Energy }} \\
\eta_{\text {net indicated, non-OE }}=\frac{\text { Work }_{G_{-} \text {Non_oE }}+\text { Work } k_{\text {Pumping }}}{\text { Fuel Energy }} \\
\eta_{\text {pumping loss }}=\frac{\text { Work }_{\text {Pumping }}}{\text { Fuel Energy }}
\end{gathered}
$$

\subsubsection{Development of the multi-link mechanism in GT-Suite}

The model design of the over-expanded mechanism follows the flowchart (Figure 4.11). A mechanism design was initially based on the MATLAB code. Then the designed specification from the MATLAB code was implemented into the GT-Suite. An overexpanded mechanism needs to be customized in GT-Suite and replace the baseline cranktrain to realize the over-expanded cycle. After the development of the single-cylinder version mechanism is finalized, the mechanism is converted into the four-cylinder version. The last step is the validate the mechanism by cross-checking the piston location between the original MATLAB code and GT-Suite output.

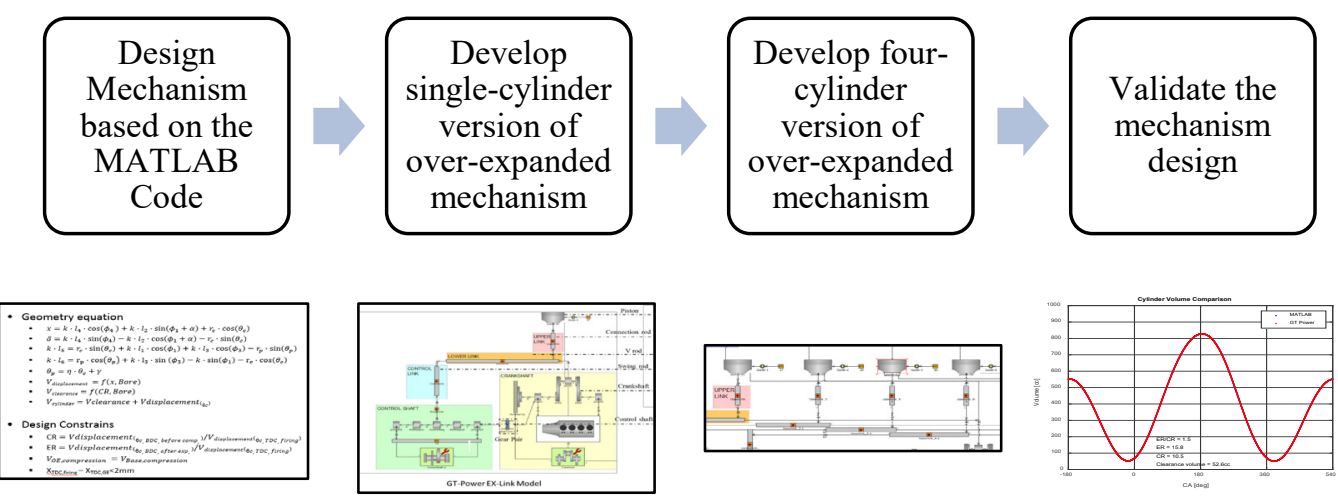

Figure 4.11. Development of the multi-link mechanism and implementation in GT-Suite 


\subsection{High Compression Engine Development}

In this study, the high compression engine refers to the specification of Toyota's M20AFXS 2.0-liter engine [33]. The specification of the high compression engine is listed in Table 4.7. In the simulation, the cranktrain was based on the LNF and modified with the specification of the high compression engine.

Table 4.7 Geometric specification of baseline engine and high compression engine

\begin{tabular}{ccc}
\hline \hline Mechanism Type & Baseline & HC [33] \\
CR & 9.2 & 13.0 \\
Bore [mm] & 86.0 & 80.5 \\
Stroke [mm] & 86.0 & 97.6 \\
\hline \hline
\end{tabular}

\subsubsection{LIVC Strategy}

In this study, the high compression engine used LIVC to realize an over-expanded cycle. The multi-link over-expanded engine also used the LIVC strategy to optimize the intake cam timing and duration at the light load condition. The valve lift as a function of the crank angle is shown in Figure 4.12. It can be observed the LIVC is realized by holding the IVO as same as the baseline and extending the valve duration by adding the dwell at maximum valve lift.

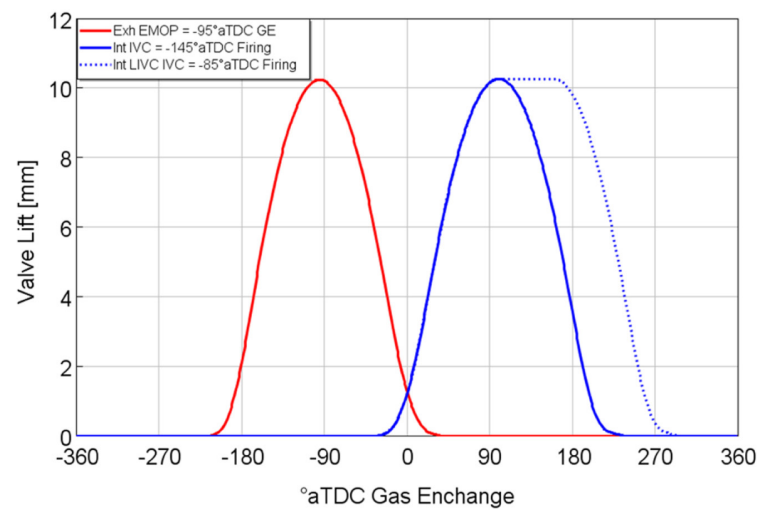

Figure 4.12. Valve lift of LIVC and non-LIVC of high compression engine

\subsection{Optimization of Simulation Results}

A cam timing sweep for both intake and exhaust camshaft was conducted to optimize the studied engines. The optimized condition is the cam timing with the highest net indicated efficiency with constraints (see constraints in Table 4.2). 
The cam timing sweep for the light load study was by sweeping intake valve most opening position (IMOP) from $95^{\circ}$ to $140^{\circ} \mathrm{aTDC}$ gas exchange (GE) and exhaust valve most opening position (EMOP) from $-140^{\circ}$ to $-95^{\circ} \mathrm{aTDC} \mathrm{GE}$ with $5^{\circ} \mathrm{CA}$ interval.

The cam timing for the high load study is swept IMOP from $95^{\circ}$ to $110^{\circ}$ aTDC gas exchange (GE) and swept EMOP from $-140^{\circ}$ to $-95^{\circ} \mathrm{aTDC}$ GE with $5^{\circ} \mathrm{CA}$ interval. The intake cam timing sweep range was reduced due to the limited load capability at retarded intake valve timing.

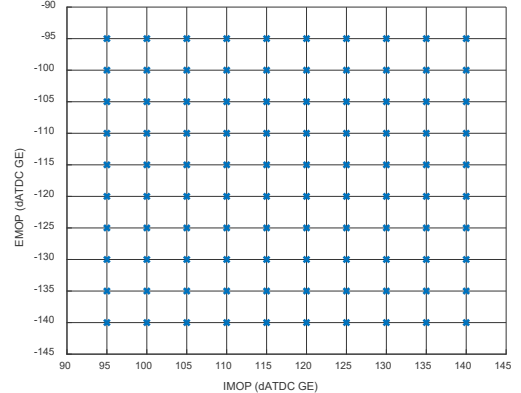

Figure 4.13 Cam timing sweep of IMOP and EMOP for over-expanded engine, light load study

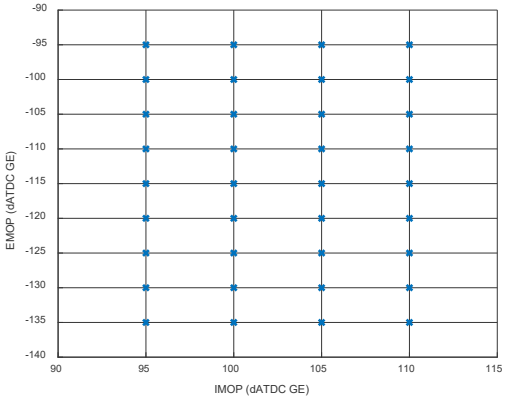

Figure 4.14 Cam timing sweep of IMOP and EMOP for over-expanded engine, high load study

The cam timing sweep for the comparison study between high compression engine and multi-link over-expanded mechanism was by sweeping intake valve closing (IVC) from $150^{\circ}$ to $-110^{\circ}$ aTDC firing and sweeping EMOP from $-135^{\circ}$ to $-95^{\circ}$ aTDC GE with $5^{\circ} \mathrm{CA}$ interval. For the LIVC condition, IVC was swept from $-105^{\circ}$ to $-85^{\circ}$ aTDC firing.

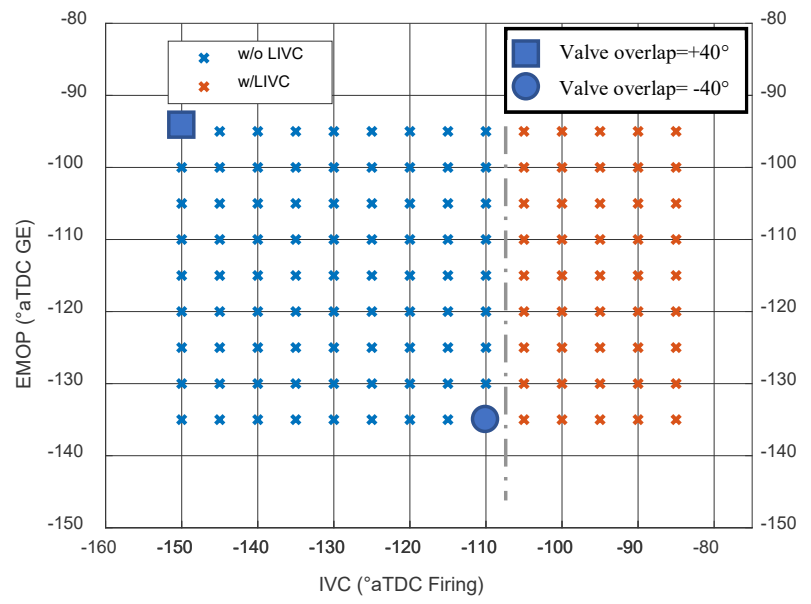

Figure 4.15 Cam timing sweep of IMOP and EMOP, the comparison study between high compression engine and multi-link over-expanded engine. 


\subsection{Analysis of Energy Loss}

The analysis of the energy losses was performed based on the additional simulation to quantify the characteristics difference between the studied engines. Figure 4.16 is the flow chart of the energy loss calculation. The calculations of each factor refer to Equation 4-23 to Equation 4-27. Pumping loss (Factor 1) was calculated by the pumping work normalized by the fuel energy as Equation 4-23 shows. Other energy losses from Factor 2 to Factor 4 are listed from Equation 4-24 to Equation 4-27, respectively. For example, the combustion phasing loss calculation (Factor 2) was determined by the indicated efficiency difference between the original case and the optimized combustion phasing condition.

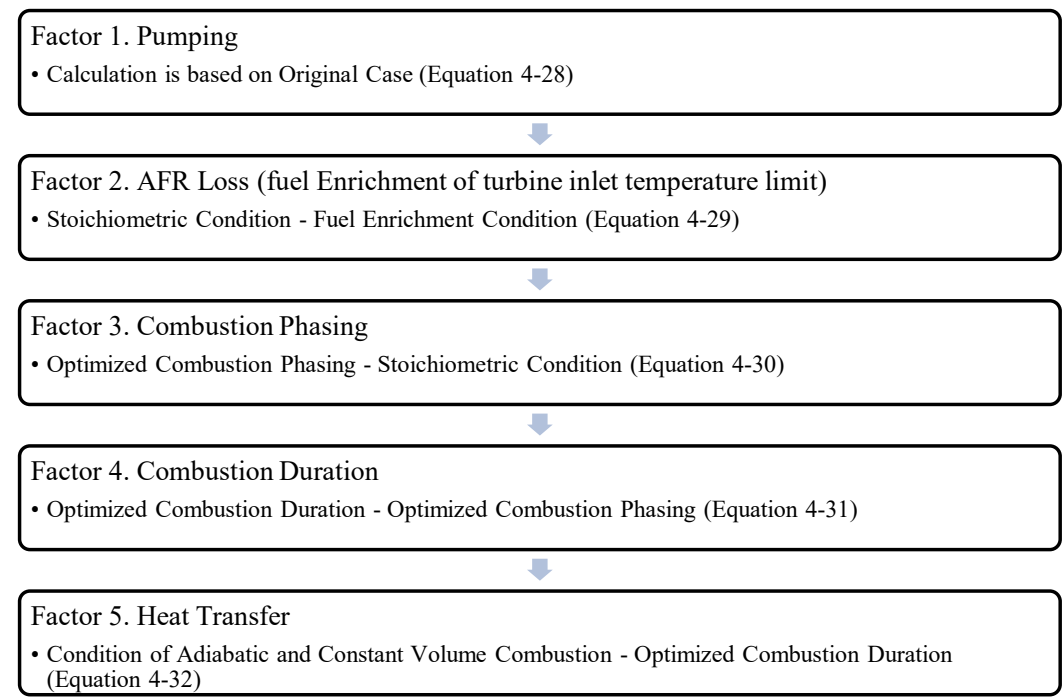

Figure 4.16 Energy loss calculation flow chart

$$
\begin{gathered}
\text { Loss }_{\text {pumping }}=\text { Work }_{\text {Pumping }} / \text { Fuel Energy } \\
\text { Loss }_{A F R}=\eta_{\text {stoichiometric }}-\eta_{\text {fuel enriched original case }} \\
\text { Loss }_{\text {comb.phasing }}=\eta_{\text {opt.comb.phasing }}-\eta_{\text {stoichiometric }} \\
\text { Loss }_{\text {comb.duration }}=\eta_{\text {opt.comb duration }}-\eta_{\text {opt.comb.phasing }} \\
\text { Loss }_{H T}=\eta_{H T \text { off }}-\eta_{\text {opt.comb duration }}
\end{gathered}
$$




\section{Main Research Contributions}

The current understanding of an over-expanded engine via a multi-link crank mechanism is limited compared to other high-efficiency engines, including over-expanded engines realized by LIVC. There is still much to be understood with respect to constrained design and optimization of the crank mechanism, especially considering the application to a boosted, downsized, GDI SI engine. The study by Anandhan et al. [40] stated that the indicated efficiency penalty at light load conditions due to lower in-cylinder pressure at the engine of the expansion, resulting in negative pumping during the period of overexpanding.

There are a number of new production naturally aspirated (BMEP $<13$ bar) high compression ratio VVT/VVA engines [33, 37] with brake efficiencies approximately at $38 \%$ which is worth to be compared with the multi-link over-expanded engine. Further, the characteristics and benefits of a multi-link over-expanded engine at high load conditions (e.g. >13 bar BMEP), especially when the baseline engine is limited by knock and exhaust temperature, are not fully understood.

In this work, the study of the multi-link over-expanded engine was based on the development of mechanism design with multiple degrees of freedom through the use of 1D engine simulation. The investigation used a conventional boosted GDI engine as a baseline and compared it with the over-expanded engine realized by multi-link mechanism. The multi-link over-expanded engine and the baseline engine were compared at the optimized condition. A primary finding is the improvement in net indicated efficiency over the baseline condition is higher as the load increase, which is due to increased indicated work during the over expansion. With the optimization and adjustment of the spark timing and valvetrain, the multi-link over-expanded is able to avoid the indicated efficiency penalty and provide a 5.9\% improvement (relative) compared to the baseline engine [68]. It is also observed that the pumping loss and OE indicated efficiency is the main factor to affect the net indicated efficiency of multi-link over-expanded engine. At 1300rpm 3.3bar IMEPnet, 1750rpm 10.3 bar IMEPnet, the net indicated efficiencies of multi-link over-expanded engine were increased by $5.9 \%$ and $11.5 \%$ (relative) compared to the baseline engines, respectively.

Next, the multi-link over-expanded engine was investigated at 1500rpm 13bar IMEPnet and 3500rpm 20bar IMEPnet. The selected operating conditions were at the knock-limited and exhaust gas temperature-limited conditions. It is observed that the piston speed is the main factor to reduce the knock propensity of multi-link over-expanded engine. Further, at turbine-inlet temperature-limited condition, the over-expanded engine required less fuel enrichment compared to the baseline engine. As the air-to-fuel ratio of over-expanded engine was approximately at stoichiometric condition, the efficiency loss due to the fuel enrichment of multi-link over-expanded engine was $4.4 \%$ lower (absolute) than the baseline engine. The multi-link over-expanded engine had a higher heat transfer loss 
compared to the baseline engine due to the longer stroke duration and higher cylinder surface area of the expansion stroke. At 1500rpm 13bar IMEPnet and 3500rpm 20bar IMEPnet, the net indicated efficiencies of multi-link over-expanded engine were increased by $15.7 \%$ and $27.3 \%$ (relative) compared to the baseline engines, respectively.

Furthermore, this work has compared the characteristics and performances between a multi-link over-expanded engine and a state-of-the-art high compression engine. It is observed that the net indicated efficiency of multi-link over-expanded engine with LIVC was very close to the high compression engine with LIVC. Once the load increase from 3.3bar IMEPnet to 13bar IMEPnet, LIVC strategy was not able to be realized on the high compression engine due to limited load capability. At 1500rpm 13bar IMEPnet, the multilink over-expanded engine the high compression engines were compared at non-LIVC conditions. The net indicated efficiency of multi-link over-expanded engine was $13.7 \%$ (relative) higher than the high compression engine due to the lower knock propensity of the multi-link over-expanded engine. The operating condition at the peak brake efficiency point of the high compression engine (2500rpm 10bar IMEPnet) was also compared. The multi-link over-expanded engine can still increase the net indicated efficiency by $8.6 \%$ (relative) compared to the high compression engine.

The research, as conducted in this thesis, shows the significant potential of the multi-link over-expanded engine to improve fuel conversion efficiency significantly above the current state-of-the-art. The improvement of net indicated efficiency increases with engine load providing further benefit to the downsized and boosted engine for further fuel economy improvements. 


\section{Dissertation Structure}

The main content of this dissertation consists of three papers. The first published paper has the publisher's permission. The other two papers have been submitted to a journal article and are currently under review. Each paper describes in detail the studies introduced in the chapter of the main research contributions. The format of the original published papers has been modified to comply with the format of this dissertation. The referenced resources in the original papers have been extracted and combined with the resources cited in other sections of this dissertation to form a complete list of resources provided in the chapter of the reference list.

Publications included in this dissertation are as follows:

Chapter 7

Yang, Z., Miganakallu Narasimhamurthy, N., Miller, T. and Naber, J., "Investigation and Optimization of Cam Actuation of an Over-Expanded Atkinson Cycle Spark-Ignited Engine". SAE International Journal of Advances and Current Practices in Mobility, 2019. 2(1): p. 639-653, DOI: 10.4271/2019-01-0250.

\section{Chapter 8}

Yang, Z., Miganakallu Narasimhamurthy, N., Miller, T., Vinhase. V., Naber, J., and Roth, D., "Investigation of High Load Operation of Spark-Ignited Over-Expanded Atkinson Cycle Engine." Submitted to a peer-reviewed academic journal

\section{Chapter 9}

Yang, Z., Miganakallu Narasimhamurthy, N., Miller, T., Naber, J., and Roth, "Comparing Methods for Improving Efficiency for Spark-Ignited Engines - Multi-link Mechanical Over-Expansion to High Compression Ratio with LIVC." Submitted to a peer-reviewed academic journal 


\section{Investigation and Optimization of Multi-Link Over- Expanded Engine at Light Load Conditions}

This paper was originally published in the 2019 SAE world congress and reprinted in the SAE Journal of Advances and Current Practices in Mobility in 2019. It corresponds to the first stage of the research described in the main research contributions chapter.

In this study, a multi-link over-expanded engine model was developed based on the experimental results of a baseline engine. An adjustment method regarding the overexpanded mechanism characteristics was proposed. The previous study stated the net indicated efficiency of a multi-link over-expanded engine was penalized at light load conditions. In this study, the multi-link over-expanded engine is able to avoid the efficiency penalty and even improve the efficiency at light load conditions with the adjustment method. A sensitivity analysis of the combustion phasing and load was conducted in the simulation study. The multi-link over-expanded engine and the baseline engine were also optimized and compared based on the cam phasing sweep with the constraints at one light load condition and one medium load condition. 


\title{
Investigation and Optimization of Cam Actuation of an Over-Expanded Atkinson Cycle Spark-Ignited Engine
}

\author{
Yang, Z., Narasimhamurthy, N. M., Miller, T., and Naber, J. \\ Michigan Technological University \\ Michigan Technological University \\ Department of Mechanical Engineering - Engineering Mechanics \\ 1400 Townsend Drive, Houghton, Michigan, USA 49931 \\ Email: zhuyongy@mtu.edu, jnaber@mtu.edu
} Reprinted with permission Copyright (C) 2019 SAE International. Further distribution of this
material is not permitted without prior permission from SAE. 


\subsection{Abstract}

An over-expanded spark ignited engine was investigated in this work via engine simulation with a design constrained, mechanically actuated Atkinson cycle mechanism. A conventional 4-stroke spark-ignited turbo-charged engine with a compression ratio of 9.2 and peak brake mean effective pressure of 22 bar was selected for the baseline engine. With geometry and design constraints including bore, stroke, compression ratio, clearance volume at top dead center (TDC) firing, and packaging, one over-expanded engine mechanism with over expansion ratio (OER) of 1.5 was designed. Starting with a validated 1D engine simulation model which included calibration of the in-cylinder heat transfer model and SI turbulent combustion model, investigations of the Atkinson engine including cam optimization was studied. The engine simulation study included the effects of offset of piston TDC locations as well as different durations of the 4-strokes due to the mechanism design. Incremental effects of adjusted combustion phasing and scaled valve durations to a fully optimized cam duration and phasing are determined, and the impacts of each discussed. A constant speed load sweep was conducted to compare the net indicated fuel conversion efficiency difference between baseline and Atkinson cycle engine. Besides, two speed load conditions (1300rpm, 3.3bar IMEPnet and 1750rpm and 10.3bar IMEPnet) with valve timing optimization were also investigated.

Results from the study indicate that with an increase in the load from 4bar to $12 \mathrm{bar}$ IMEPnet at 2500rpm, over expansion contributed to an increase of $2.3 \%$ in net indicated efficiency. Furthermore, with valve optimization, negative work was avoided in the Atkinson cycle engine at 3.3bar IMEPnet, 1300rpm with an increase of $2 \%$ in the net indicated fuel conversion efficiency. At 10.3bar IMEPnet and 1750rpm, net indicated fuel conversion efficiency increased by $4.6 \%$.

\subsection{Introduction}

Improving the fuel conversion efficiency of internal combustion engines is one of the major concerns of engine design [40]. Utilizing an "Atkinson cycle" or over-expanded cycle is an option to improve the indicated fuel conversion efficiency by making the compression stroke and expansion stroke different and increasing resulting expansion work [22]. The Atkinson cycle engine was originally invented by James Atkinson and patented in 1887 [47]. It has a multi-link mechanism to produce a true engine cycle of longer expansion stroke than compression stroke.

In the 1990s, investigation of Diesel-Atkinson engine was performed by Kentfield. The results indicated that the brake specific fuel consumption (BSFC) with an OER of 1.4 at 4.8bar BMEP was reduced by approximately $8 \%$ compared to the baseline engine $[48,49]$. In comparison to the mechanical mechanism, an alternative common approach to obtain Atkinson cycle in spark-ignition engines is to utilize a high geometric compression ratio 
and reduce the effective compression ratio by late intake valve closing (LIVC). One investigation of realizing an Atkinson cycle with LIVC was conducted by Sakata et al. [52] where the effective compression ratio was 8.5 with LIVC, and OER was 2.4 . The brake specific fuel consumption (BSFC) of this configuration was reduced by $18 \%$ compared to baseline at 2500rpm 7bar BMEP. Similar research by Feng et al. [51] showed that the minimum BSFC was reduced by $6 \%$ compared to the baseline engine with optimized airto-fuel ratio, valve timing, and spark timing. Anderson et al. [50] showed the overexpansion cycle realized by LIVC. It was observed that net indicated efficiency was improved from light load with lower pumping losses as the effective displacement of the engine was reduced. Automotive manufacturers have utilized LIVC to realize an Atkinson cycle in production gasoline SI engines with advanced variable valve train (VVT), e.g., Ford, GM, Mazda and Toyota [32, 37, 53, 54].

One major disadvantage of realizing Atkinson cycle by LIVC is that the IMEP and power density decrease significantly because the total displacement is not used during intake [22]. An engine operated with a true Atkinson cycle can maintain the power density by maintaining intake and compression stroke the same and realizing a longer expansion stroke than compression stroke mechanically.

Although the first Atkinson cycle engine was proposed in 1880s, the research and development of a true Atkinson cycle engine compared to the conventional engine is still in a very early stage. It is worthwhile to explore the engine efficiency improvement potential by using 1-D simulation tool. Pertl et al. [39] developed a mechanism based on the patent by Austin [56] where a very aggressive configuration of Atkinson engine was utilized with a CR of 12.5 and OER of 2.0. From their 1D simulation results, the indicated efficiency was increased by $14 \%$ at $6000 \mathrm{rpm}$ full load condition. Wang et al. [57] also conducted the simulation of an engine with a true Atkinson cycle with an OER from 1.15 to 1.35 . At $1500 \mathrm{rpm}$, net indicated efficiency was improved by $1.3 \%$ and $5.7 \%$ at $3.5 \mathrm{bar}$ and 8.5bar IMEPnet respectively compared to the baseline engine. The research by Zhao et al. [58-60] provided a fundamental guidance for designing a true Atkinson cycle engine and optimization method. By utilizing the cylinder deactivation and modifying the valvetrain system, BSFC was reduced by $10.5 \%$ at 2000rpm, 2.1 bar BMEP.

Recently, Honda developed the EX-Link mechanism to realize an Atkinson cycle. The EXLink product by Honda is used in a micro-combined heat and power generation unit. The experimental results showed that the relative net indicated efficiency was improved by $5 \%$ with OER of 1.5 [38]. Later, the EX-Link was examined at 3060rpm, full load condition, and it was found that the relatively net indicated efficiency of Atkinson engine was improved by $12 \%$ [61]. This resulted in a $3.8 \%$ improvement of the power generation efficiency, compared to the baseline [62]. A similar mechanism with better shaft balance was also analyzed by Brendel. Their experimental results showed that engine friction was reduced by $7 \%$ at $5000 \mathrm{rpm}$ with shaft balancing [41]. Following this, research by Anandhan [63] was conducted based on the mechanism designed by Brendel. In this work, 
sets of true Atkinson mechanisms were designed and the expansion to compression stroke ratio (SR) was swept from 1.0 to 1.5 . The simulation results in this study were calibrated based on the experimental results from a $2 \mathrm{~L}$ turbocharged engine. The simulation results showed that the indicated specific fuel consumption (ISFC) was improved by more than $10 \%$ with a SR of 1.5. It was also observed that the Atkinson cycle engine has lower knock propensity at higher load compared to the baseline engine. A summary of the literature review of Atkinson engine study is in Table 7.1.

Table 7.1 Literature review summary of Atkinson cycle engine study

\begin{tabular}{|c|c|c|c|c|c|c|c|}
\hline Reference & $\begin{array}{l}\text { Type of } \\
\text { Study }\end{array}$ & $\begin{array}{l}\text { Type of } \\
\text { Atkinson } \\
\text { Engine }\end{array}$ & CR & OER & $\begin{array}{l}\text { Speed/ } \\
\text { Load }\end{array}$ & $\begin{array}{l}\text { Improvement } \\
\text { Compare to } \\
\text { Baseline } \\
\text { (Relative) }\end{array}$ & $\begin{array}{l}\text { Main Output and } \\
\text { Comments }\end{array}$ \\
\hline $\begin{array}{l}\text { Kentfield, } \\
1989,1992 \\
{[48,49]}\end{array}$ & $\begin{array}{l}\text { Experimental } \\
\text { and simulation } \\
\text { study, Diesel } \\
\text { Atkinson } \\
\text { Engine } \\
\end{array}$ & $\begin{array}{l}\text { Four stroke } \\
\text { extended } \\
\text { expansion }\end{array}$ & 14 & 1.4 & $\begin{array}{l}\text { 4.8bar } \\
\text { BMEP }\end{array}$ & BSFC $8 \% \downarrow$ & $\begin{array}{l}\text { Proposed several over- } \\
\text { expansion designs } \\
\text { based on the original } \\
\text { Atkinson's over-center } \\
\text { mechanism }\end{array}$ \\
\hline $\begin{array}{l}\text { Sakata et } \\
\text { al. } 2007 \\
{[52]}\end{array}$ & $\begin{array}{l}\text { Experimental } \\
\text { study, } \\
\text { gasoline } \\
\text { Atkinson } \\
\text { engine }\end{array}$ & $\begin{array}{l}\text { Conventional } \\
\text { four stroke } \\
\text { engine with } \\
\text { LIVC }\end{array}$ & $\begin{array}{l}20 \\
\text { (geom.) } \\
8.5 \\
\text { (effect.) }\end{array}$ & 2.4 & $\begin{array}{l}2500 \mathrm{rpm} / \\
7 \mathrm{bar} \\
\text { BMEP }\end{array}$ & BSFC $18 \% \downarrow$ & $\begin{array}{l}\text { BSFC (CR 10:1 IVC } \\
\text { retarded } 60^{\circ} \text { compared } \\
\text { to baseline) reduced } 9 \% \\
\text { compared to the } \\
\text { baseline (CR 10:1) }\end{array}$ \\
\hline $\begin{array}{l}\text { Feng, et al. } \\
2016 \\
{[51]}\end{array}$ & $\begin{array}{l}\text { Simulation } \\
\text { studies, } \\
\text { Atkinson } \\
\text { gasoline } \\
\text { engine }\end{array}$ & $\begin{array}{l}\text { Conventional } \\
\text { four stroke } \\
\text { engine with } \\
\text { LIVC }\end{array}$ & 13 & - & $\begin{array}{l}2400 \mathrm{rpm} / \\
8.5 \mathrm{bar} \\
\text { BMEP }\end{array}$ & BSFC $6 \% \downarrow$ & $\begin{array}{l}\text { Optimized AFR, valve } \\
\text { timing, and ignition } \\
\text { timing of Atkinson } \\
\text { cycle engine }\end{array}$ \\
\hline $\begin{array}{l}\text { Pertl et al. } \\
2012,2015 \\
{[39,65]}\end{array}$ & $\begin{array}{l}\text { Simulation } \\
\text { and } \\
\text { experimental } \\
\text { study, } \\
\text { gasoline } \\
\text { Atkinson } \\
\text { engine }\end{array}$ & $\begin{array}{l}\text { Atkinson } \\
\text { crank train } \\
\text { realized by } \\
\text { planetary } \\
\text { gear system }\end{array}$ & 12.5 & 2.0 & $\begin{array}{l}6000 \mathrm{rpm} / \\
\text { Full Load } \\
\text { (Atkinson } \\
7.9 \mathrm{bar}, \\
\text { baseline } \\
6.7 \text { bar) } \\
\end{array}$ & $\begin{array}{l}\eta_{\text {net,indicated }} \\
14 \% \uparrow \\
\text { (simulation) }\end{array}$ & $\begin{array}{l}\text { High friction was } \\
\text { observed at high engine } \\
\text { speed in the } \\
\text { experimental study. }\end{array}$ \\
\hline $\begin{array}{l}\text { Wang et al. } \\
2012 \\
{[57]}\end{array}$ & $\begin{array}{l}\text { Simulation } \\
\text { study, } \\
\text { gasoline } \\
\text { Atkinson } \\
\text { engine }\end{array}$ & $\begin{array}{l}\text { Atkinson } \\
\text { cycle by } \\
\text { modified } \\
\text { piston } \\
\text { movement in } \\
\text { simulation }\end{array}$ & 10.4 & 1.3 & $\begin{array}{l}1500 \mathrm{rpm} / \\
3.5 \mathrm{bar} \\
\text { and } \\
8.5 \mathrm{bar} \\
\text { BMEP }\end{array}$ & $\begin{array}{l}\eta_{\text {net,indicated }} \\
1.3 \% \uparrow(3.5 \text { bar }) \\
\\
\\
\eta_{\text {net, indicated }} \\
5.7 \% \uparrow(8.5 \text { bar })\end{array}$ & $\begin{array}{l}\text { Atkinson cycle } \\
\text { generates lower } \mathrm{NO}_{\mathrm{x}} \\
\text { emission attributed by } \\
\text { lower in-cylinder } \\
\text { temperature and } \\
\text { increased internal EGR }\end{array}$ \\
\hline $\begin{array}{l}\text { Zhao et al. } \\
2013,2018 \\
{[59,60]}\end{array}$ & $\begin{array}{l}\text { Simulation } \\
\text { study, } \\
\text { gasoline } \\
\text { engine }\end{array}$ & $\begin{array}{l}\text { Conventional } \\
\text { four stroke } \\
\text { engine with } \\
\text { LIVC }\end{array}$ & 12.5 & - & $\begin{array}{l}\text { 2000rpm/ } \\
2.1 \mathrm{bar} \\
\text { BMEP }\end{array}$ & BSFC $10.5 \% \downarrow$ & $\begin{array}{l}\text { BSFC reduced by } \\
10.5 \% \text { wit Atkinson, } \\
\text { cylinder deactivation } \\
\text { and optimized valve } \\
\text { train. Fuel economy }\end{array}$ \\
\hline
\end{tabular}




\begin{tabular}{|c|c|c|c|c|c|c|c|}
\hline & & & & & & & $\begin{array}{l}\text { improved up to } 7.7 \% \text { by } \\
\text { coupling genetic } \\
\text { algorithm and 1-D } \\
\text { simulation models }\end{array}$ \\
\hline $\begin{array}{l}\text { Watanabe } \\
\text { et al. } 2006 \\
\text { [38] }\end{array}$ & $\begin{array}{l}\text { Simulation } \\
\text { and } \\
\text { experimental } \\
\text { study, } \\
\text { gasoline } \\
\text { engine }\end{array}$ & $\begin{array}{l}\text { Gasoline } \\
\text { Atkinson } \\
\text { (EX-Link } \\
\text { system) }\end{array}$ & 8.5 & 1.4 & - & $\begin{array}{l}\eta_{\text {net,indicated }} \\
5 \% \uparrow\end{array}$ & - \\
\hline $\begin{array}{l}\text { Koga et al. } \\
2007 \\
{[61]}\end{array}$ & $\begin{array}{l}\text { Experimental } \\
\text { study, } \\
\text { gasoline } \\
\text { engine }\end{array}$ & $\begin{array}{l}\text { Gasoline } \\
\text { Atkinson } \\
\text { (EX-Link } \\
\text { system) }\end{array}$ & 8.5 & 1.4 & $\begin{array}{l}\text { 3060rpm/ } \\
\text { Full Load } \\
8.7 \mathrm{bar} \\
\text { BMEP } \\
\text { (Base) } \\
10.8 \mathrm{bar} \\
\text { BMEP } \\
\text { (Atkinson } \\
\text { ) }\end{array}$ & $\begin{array}{l}\eta_{\text {net, } \text {,indicated }} \\
12.2 \% \uparrow\end{array}$ & $\begin{array}{l}\text { The net indicated } \\
\text { efficiency is not } \\
\text { compared at same } \\
\text { load. }\end{array}$ \\
\hline $\begin{array}{l}\text { Takita et al. } \\
2011 \text { [62] }\end{array}$ & $\begin{array}{l}\text { Experimental } \\
\text { study, } \\
\text { gasoline } \\
\text { engine }\end{array}$ & $\begin{array}{l}\text { Gasoline } \\
\text { Atkinson } \\
\text { (EX-Link } \\
\text { system) }\end{array}$ & 12.2 & 1.4 & 1950rpm & $\begin{array}{l}\eta_{\text {power generation }} \\
3.8 \% \uparrow\end{array}$ & $\begin{array}{l}\text { EX-Link applied on } \\
\text { power generation } \\
\text { system Micro } \\
\text { Combined Heat and } \\
\text { Power Generation Unit }\end{array}$ \\
\hline $\begin{array}{l}\text { Brendel. } \\
2013 \text { [41] }\end{array}$ & $\begin{array}{l}\text { Experimental } \\
\text { study, } \\
\text { Atkinson } \\
\text { engine }\end{array}$ & $\begin{array}{l}\text { Four stroke } \\
\text { extended } \\
\text { expansion }\end{array}$ & - & - & 5000rpm & - & $\begin{array}{l}\text { The experimental } \\
\text { results show engine } \\
\text { friction was reduced by } \\
7 \% \text { at } 5000 \text { rpm with } \\
\text { balancing }\end{array}$ \\
\hline $\begin{array}{l}\text { Anadhan et } \\
\text { al. } 2018 \\
{[63]}\end{array}$ & $\begin{array}{l}\text { Simulation } \\
\text { study, } \\
\text { Atkinson } \\
\text { gasoline } \\
\text { engine }\end{array}$ & $\begin{array}{l}\text { Four stroke } \\
\text { extended } \\
\text { expansion }\end{array}$ & 10.0 & $\begin{array}{l}1.0 \text { to } \\
1.5 \\
\text { (SR) }\end{array}$ & $\begin{array}{l}\text { 2000rpm/ } \\
\text { 16bar } \\
\text { IMEPnet }\end{array}$ & $\begin{array}{l}\eta_{\text {net, indicated }} \\
10 \% \uparrow(\text { SR1.5) }\end{array}$ & $\begin{array}{l}\text { Tendency to knock of } \\
\text { Atkinson cycle engine } \\
\text { is reduced and increase } \\
\text { its indicated efficiency. } \\
\text { Load decrease } 6-10 \mathrm{kPa} \\
\text { at } 2 \text { bar IMEPnet due to } \\
\text { over-expansion loop. }\end{array}$ \\
\hline
\end{tabular}

Summarizing the findings in Table 7.1, the following are observed. The compression ratio of the engines studied ranges from 8.4 to 14.0. With the use of LIVC, Sakata increased the OER to 2.4. Using a multi-link Atkinson cycle mechanism, the studied OER varied from 1.1 to 2.0. Reviewing all papers, the highest load condition of the Atkinson engine was found to be 16bar IMEPnet. For those studies of OER high than 1.5, net indicated efficiency was improved over $12 \%$, but the engine performance at light load condition was not discussed. The extra indicated working losses due to over expansion at lower load needs to be considered. For an Atkinson engine with OER at 1.3 to 1.5, the relative efficiency improvement ranges from $8 \%$ to $10.5 \%$. A recent study by Anadhan et al. investigates the characteristics of the true Atkinson cycle engine including the peak load output with turbocharger limitations. 
This work will address the following topics with respect to characteristics and indicated efficiency of an over-expanded mechanically actuated Atkinson engine in comparison to a baseline engine:

1. Differences in piston movement and stroke durations between true Atkinson cycle engine and conventional engine.

2. Quantify the contribution of over expansion as a function of engine load.

3. Spark timing adjustment and cam timing optimization of both intake and exhaust valves

4. Contribution and trends of factors leading to improved net indicated efficiency as a function of cam phasing.

The objective of the current study was to develop and calibrate a 1-D engine model from the baseline engine data with load control and spark timing control (MBT spark timing). The engine model simulated the dynamics of the Atkinson mechanism including piston location as a function of crank angle. The Atkinson mechanism design was constrained by packaging, bore and stroke, and CR of the baseline engine. First, a load sweep at constant engine speed was examined and compared to the baseline engine. Then two speed-load conditions 1300rpm, 3.3bar IMEPnet, and 1750rpm, 10.3bar IMEPnet were selected for full optimization. At these conditions, the net indicated efficiency and evaluation of key contributors to the improvement are discussed and compared to the baseline with optimized cam phasing.

\subsection{Methodology}

\subsubsection{Experimental Results and Baseline Model}

The baseline engine of this study is a GM Ecotec direct-injection spark-ignited turbocharged inline 4-cylinder engine with a compression ratio (CR) of 9.2. Table 7.2 lists the specifications of the baseline engine.

Table 7.2. Baseline engine specifications

\begin{tabular}{ll}
\hline \hline Displaced volume & $1998 \mathrm{cc}$ \\
Stroke & $86 \mathrm{~mm}$ \\
Bore & $86 \mathrm{~mm}$ \\
Connecting Rod & $145.5 \mathrm{~mm}$ \\
Compression ratio & $9.2: 1$ \\
\hline
\end{tabular}


The speed/load conditions (1300rpm, 3.3bar IMEPnet, and 1750rpm, 10.3bar IMEPnet) representative of high fuel consumption conditions in US06 and FTP75 driving cycles are considered for this study at the stoichiometric condition. Tested fuel was $10 \%$ ethanol blended gasoline (E10) with an anti-knock index of 87.0.

The engine simulation study was performed with the commercial engine program (GTSuite / GT-Power). The baseline model was calibrated based on experimental results over a wide range of speed load conditions including the two shown in Table 7.3. Valve timing for the baseline experimental results are given in Table 7.3 (1300rpm, 3.3bar IMEPnet and 1750rpm, 10.3bar IMEPnet). A comparison of the experimental to modeling results after calibration of the SI turbulent combustion model is given in Table 7.4.

Table 7.3. Valve timing of the experimental results

\begin{tabular}{lll}
\hline \hline Speed/Load & $1300 \mathrm{rpm} / 3.3$ bar IMEPnet & 1750rpm/10.3bar IMEPnet \\
Exhaust Valve Open & $27^{\circ}$ BBDC @ 0.2 mm lift & $27^{\circ}$ BBDC @ $0.2 \mathrm{~mm} \mathrm{lift}$ \\
Exhaust Valve Close & $13^{\circ}$ ATDC @ 0.2 mm lift & $13^{\circ}$ ATDC @ $0.2 \mathrm{~mm} \mathrm{lift}$ \\
Inlet Valve Open & $15^{\circ}$ BTDC @ $0.2 \mathrm{~mm} \mathrm{lift}$ & $26^{\circ}$ BTDC @ $0.2 \mathrm{~mm} \mathrm{lift}$ \\
Inlet Valve Close & $36^{\circ}$ ABDC @ $0.2 \mathrm{~mm} \mathrm{lift}$ & $25^{\circ}$ ABDC @ $0.2 \mathrm{~mm} \mathrm{lift}$ \\
\hline \hline
\end{tabular}

Table 7.4. Baseline engine calibration of 1300 rpm, 3.3bar IMEPnet, and 1750rpm, $\underline{10,3 \text { bar IMEPnet }}$

\begin{tabular}{ccccc}
\hline \hline & Experiment & Simulation & Experiment & Simulation \\
Speed (rpm) & 1300 & 1300 & 1750 & 1750 \\
IMEPnet (bar) & 3.3 & 3.3 & 10.3 & 10.3 \\
MAP (kPa) & 47.5 & 47.5 & 96.9 & 96.8 \\
Net indicated efficiency (\%) & 33.2 & 33.6 & 37.8 & 38.2 \\
Total Fuel flow (g/s) & 0.51 & 0.51 & 1.89 & 1.88 \\
Location of peak pressure ( $\left.{ }^{\circ} \mathbf{a T D C}\right)$ & 11.8 & 12.4 & 15.4 & 15.9 \\
Peak pressure (bar) & 21.6 & 21.6 & 52.6 & 51.1 \\
\hline \hline
\end{tabular}

\subsubsection{Atkinson Cycle Mechanism}

The Atkinson cycle engine mechanism design is based on the study by Brendel [41]. The geometric specification within the Atkinson design was constrained to match the baseline engine bore, compression stroke, and compression ratio. A design with an over expansion ratio (OER) of 1.5 stroke ratio (SR) of 1.6 was developed, where the definition of SR and OER are given in Equation 7-1 and Equation 7-2. 


$$
\begin{gathered}
S R=\frac{\text { Expansion Stroke }}{\text { Compression Stroke }} \\
O E R=\frac{E R}{C R}=\frac{\text { Vol piston @BDC after expansion }}{\text { Vol }}
\end{gathered}
$$

One way to approach an Atkinson cycle mechanism in GT-Suite is to define a lookup table of piston location as a function of crank angle. The engine crank train mechanism model is not necessary for this scenario. An alternative to realize the Atkinson cycle in the simulation is to develop a model including the geometric specification of each linkage. The advantage of this approach is that the piston movement no longer depends on the lookup table and only depends on the defined linkage length and pin location. The current work follows this approach. Figure 7.1 shows the schematic of Atkinson cycle model with the detailed engine crank train. The Atkinson cycle engine crank train was physically simulated based on the defined geometric specifications given in Table 7.5.

A single-cylinder version of the Atkinson mechanism is shown in Figure 7.2 as output from GT-Suite. In Figure 7.2, the crankshaft is located at $0^{\circ} \mathrm{CA}$ TDC. However, the piston has already passed the location of TDC seen by the TDC firing offset between the crank and piston location (Figure 7.3). An offset also exists in the other TDC/BDC's, respectively. The difference between Atkinson and conventional engine mechanism also includes the stroke durations. In a conventional engine, the period of each stroke is $180^{\circ}$ starting from TDC firing. For the Atkinson mechanism in this study, intake and compression strokes were $163^{\circ} \mathrm{CA}$ and $158^{\circ} \mathrm{CA}$ respectively (less than $180^{\circ} \mathrm{CA}$ ); expansion and exhaust stroke were $202^{\circ} \mathrm{CA}$ and $197^{\circ} \mathrm{CA}$ respectively (longer than $180^{\circ} \mathrm{CA}$ ). A summary of the geometry comparison between baseline and Atkinson mechanism is listed in the appendix in Table 7.9. An adjustment of the spark timing, cam timing, and valve duration is required to compensate for the difference between baseline and Atkinson mechanism as a result of the different durations of the strokes. 


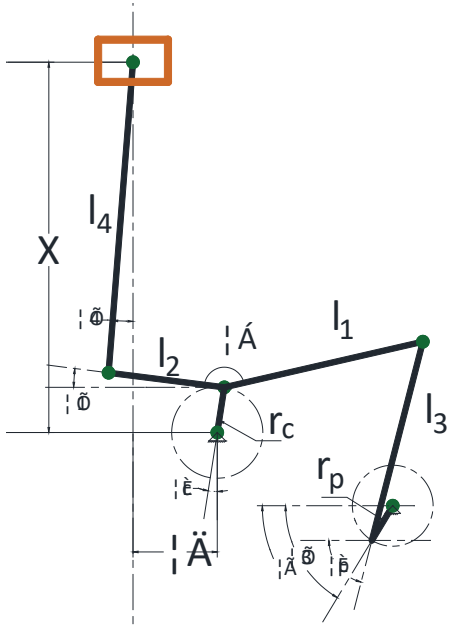

Figure 7.1. Schematic of the Atkinson mechanism

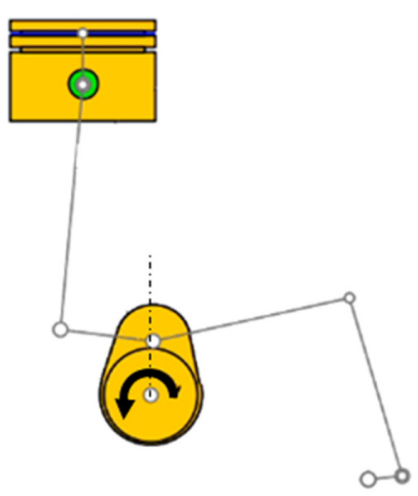

Figure 7.2. Single-Cylinder Version of Atkinson Mechanism at Crank TDC, Output from GT-Suite
Table 7.5. Geometric specifications of Atkinson cycle mechanism with CR9.2, OER1.5, SR1.6

\begin{tabular}{cc}
\hline \hline CR & 9.2 \\
ER & 13.8 \\
OER & 1.5 \\
SR & 1.6 \\
Bore & $86 \mathrm{~mm}$ \\
Compression & $86 \mathrm{~mm}$ \\
Intake Stroke & $86 \mathrm{~mm}$ \\
$\mathbf{l}_{\mathbf{4}}$ & $221.4 \mathrm{~mm}$ \\
$\mathbf{l}_{\mathbf{2}}$ & $83.1 \mathrm{~mm}$ \\
$\mathbf{l}_{\mathbf{1}}$ & $161.0 \mathrm{~mm}$ \\
$\mathbf{l}_{\mathbf{3}}$ & $165.0 \mathrm{~mm}$ \\
$\mathbf{r}_{\mathbf{c}}$ & $35.2 \mathrm{~mm}$ \\
$\mathbf{r}_{\mathbf{p}}$ & $5.1 \mathrm{~mm}$ \\
$\boldsymbol{\delta}$ & $60 \mathrm{~mm}$ \\
$\boldsymbol{\alpha}$ & $159.9^{\circ}$ \\
\hline
\end{tabular}

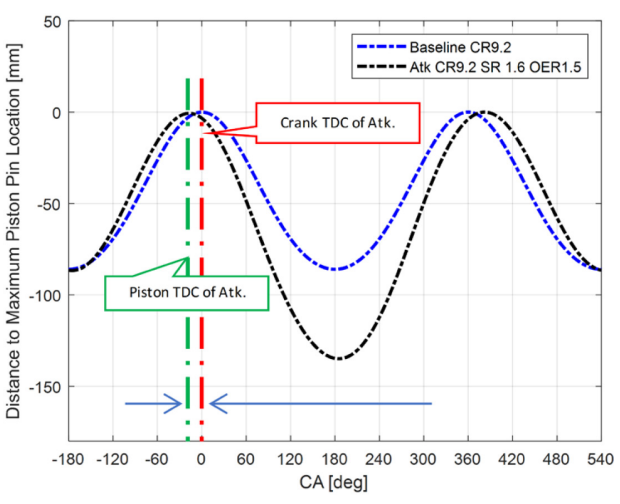

Figure 7.3 Piston location as a function of crank angle comparison between baseline and Atkinson mechanism. ("0" mean at TDC Firing) 


\subsubsection{Spark Timing Adjustment}

The spark timing was adjusted based on the difference between crank angle location at $0^{\circ} \mathrm{CA}$ TDC and piston location at $0^{\circ} \mathrm{CA}$ TDC firing. The piston TDC Firing of the Atkinson mechanism was $17.5^{\circ} \mathrm{CA}$ earlier than the crank angle located at $0^{\circ} \mathrm{CA}$ TDC. To maintain the combustion phasing consistency and be relative to the piston location, the spark timing of the Atkinson engine was advanced $17.5^{\circ} \mathrm{CA}$ than baseline.

A spark timing sweep at a constant speed and load was performed to evaluate the effect of combustion phasing of the Atkinson engine. As shown in Figure 7.4, crank angle of 50\% mass fuel burned (CA50) relative to piston TDC was swept between $5^{\circ}$ to $25^{\circ}$ ATDC for both the baseline and Atkinson engine at 1750rpm, 10.3bar IMEPnet. From this figure, it is observed that the trend of net indicated efficiency with combustion phasing of Atkinson engine followed the baseline engine results, both increased with advancing CA50 to $10^{\circ} \mathrm{ATDC}$. From 5 to $10^{\circ} \mathrm{ATDC}$, the curves remain quite flat and accounting for increased friction from increase peak-pressure with advancing CA50, a CA50 of $10^{\circ}$ ATDC was utilized as the minimum best spark timing (MBT) in the following analysis.

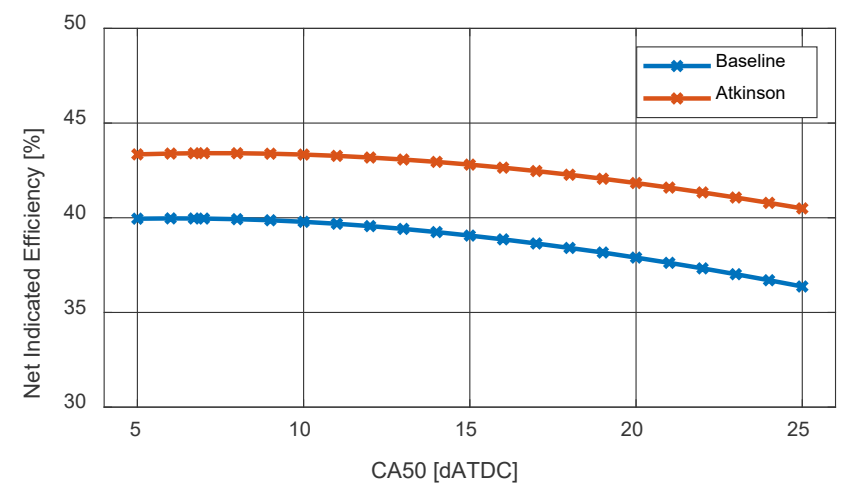

Figure 7.4. Spark timing sweep of baseline and Atkinson engine at 1750rpm, 10.3bar $\underline{\text { IMEPnet }}$

\subsubsection{Cam Timing and Valve Duration Adjustment}

The valvetrain adjustment for the Atkinson engine includes the adjustment of cam timing and valve duration. The offsets for the Atkinson engine piston location at TDC firing, BDC after expansion, TDC gas exchange (GE), and BDC after intake compared to the baseline engine are $-17.5^{\circ} \mathrm{CA}, 4.5^{\circ} \mathrm{CA}, 21.8^{\circ} \mathrm{CA}$, and $4.3^{\circ} \mathrm{CA}$ respectively (see detail in appendix, Table 7.9). The intake cam phasing adjustment was based on the average offset value of TDC GE and BDC after intake (Equation 7-3); the exhaust cam phase adjustment was 
based on the average offset value of BDC after expansion and TDC GE (Equation 7-4). The scaling of the valve duration was based on the stroke duration change in crank angle. (Equation 7-5 and Equation 7-6)

Adjusted valve lift as a function of crank angle is shown in Figure 7.5. The exhaust valve duration was extended to match the longer exhaust stroke in the Atkinson cycle engine by adding dwell in the maximum valve lift. Intake stroke duration of the Atkinson mechanism is $163^{\circ} \mathrm{CA}$. The intake stroke of Atkinson mechanism was applied in Equation 7-5 to determine the scaling factor of the intake valve duration and valve lift.

$$
\begin{aligned}
& \text { Offset }_{I M O P}=\frac{\left(T D C_{G E}+B D C_{\text {Intake }}\right)}{2} \\
& \text { Off }_{\text {set }} \text { EMOP }=\frac{\left(T D C_{G E}+B D C_{\text {Exhaust }}\right)}{2} \quad 7-4 \\
& \text { Scale }_{\text {Intake valve duration } / \text { lift }}=\frac{\text { Stroke }_{\text {Atk,Intake }}(\stackrel{\mathrm{o}}{)}}{180} \quad 7-5 \\
& \text { Scale }_{\text {Exhaust valve duration / lift }}=\frac{\text { Stroke }_{\text {Atk,Exhaust }}(\stackrel{\circ}{)}}{180} \quad 7-6
\end{aligned}
$$

A $\log$ PV diagram comparison between the baseline and adjusted Atkinson engine for 1750 rpm, IMEPnet of 10.3 bar is shown in Figure 7.6. In Figure 7.6, $\mathrm{x}$-axis is the in-cylinder volume normalized by the BDC volume at the start of compression stroke. With the adjustment of valve phasing, duration, and spark timing, the adjusted Atkinson case matched the baseline in the log PV diagram. In the Atkinson mechanism, the overexpansion period is when the normalized volume is greater than 1.0 during expansion stroke.

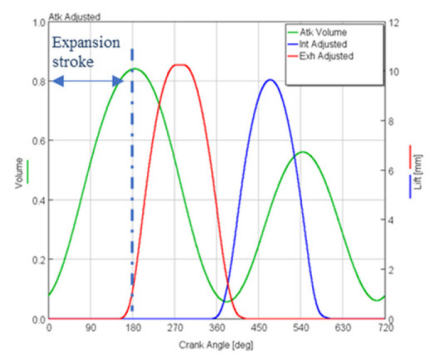

Figure 7.5. Volume, valve lift as a function of crank angle of Atkinson engine

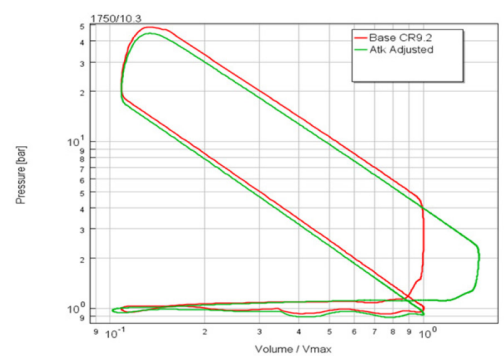

Figure 7.6. Log PV of baseline and adjusted Atkinson Engine at 1750rpm, 10.3bar IMEPnet 


\subsection{Results and Discussion}

\subsubsection{Definition of the Pumping Loop and Gross Loop of an Atkinson Cycle}

Based on the characteristics of Atkinson cycle mechanism, pumping loop and gross loop need to be redefined based on the piston location. The gross loop in the Atkinson cycle is the pressure trace highlighted with blue and amber combined in Figure 7.7. It starts from "a" before the start of the compression stroke and finishes when the piston is at "c" as shown in Figure 7.7. The rest of the cycle is the pumping loop (highlighted in red, $c \rightarrow a$ ). As Figure 7.7 shows, the gross loop can be further separated into two parts, which are nonover-expanded gross loop (blue curve), and over-expanded gross loop (amber curve).

The net indicated efficiency of Atkinson cycle is listed in Equation 7-7. Net indicated efficiency for non-OE period (non-OE indicated efficiency) is given in Equation 7-8. Indicated efficiency contributed by $\mathrm{OE}$ (OE indicated efficiency) is given in Equation 7-9.

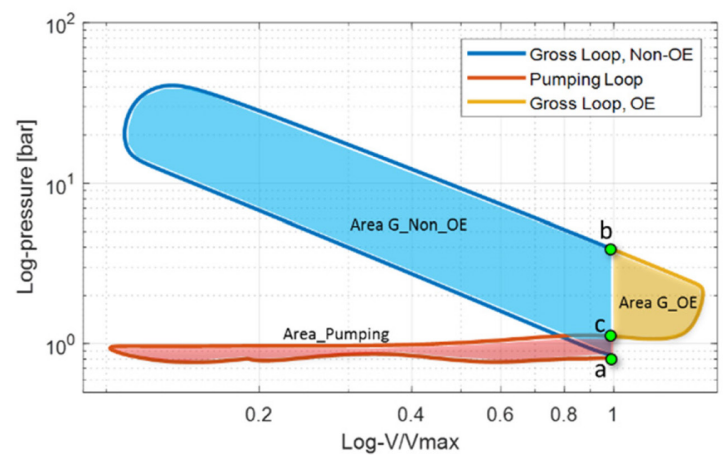

Figure 7.7. Definition of the gross loop and pumping loop in an Atkinson cycle

$$
\begin{aligned}
& \eta_{\text {net indicated }}=\frac{\text { Work }_{G_{\_} \text {Non_oE }}+\text { Work }_{G_{-} O E}+\text { Work }_{\text {Pumping }}}{\text { Fuel Energy }} \quad \text { 7-7 } \\
& \eta_{\text {net indicated, non-OE }}=\frac{\text { Work }_{\text {G_Non_oE }_{-}+\text {Work }_{\text {Pumping }}}}{\text { Fuel Energy }} \quad 7-8 \\
& \eta_{\text {indicated }, \text { OE }}=\frac{\text { Work }_{G_{\_} O E}}{\text { Fuel Energy }} \quad \text { 7-9 }
\end{aligned}
$$

\subsubsection{Atkinson Cycle Engine Load Sweep @ 2500rpm}

A load sweep from 4bar to $12 \mathrm{bar}$ IMEPnet or both baseline and Atkinson engine was conducted at 2500 rpm. Cam timing corresponding to 1300rpm, 3.3bar IMEPnet condition 
was used (Table 7.3). Spark timing was controlled to obtain a CA50 at $10^{\circ}$ ATDC at MBT condition.

The net indicated efficiency comparison between baseline and Atkinson engine is shown in Figure 7.8. The baseline net indicated efficiency increased from $35.2 \%$ to $40.0 \%$ with an increase in load. For the Atkinson engine, the net indicated efficiency increased from $37.5 \%$ to $45.3 \%$. The relative increase of the Atkinson cycle indicated efficiency was $6.5 \%$ at 4 bar and increased to $13.3 \%$ at 12 bar.

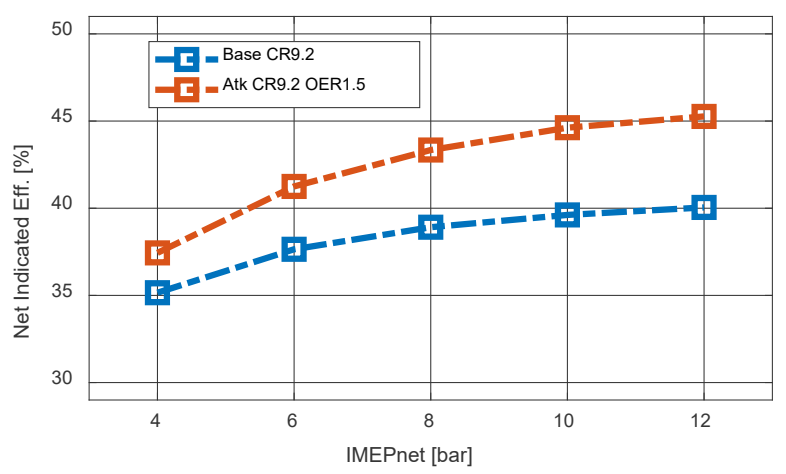

Figure 7.8. Net indicated efficiency of baseline and Atkinson engine at 2500rpm, 4 to $\underline{12 \text { bar IMEPnet }}$

Figure 7.9 shows the net indicated efficiencies for the baseline and Atkinson engines at five loads in a bar chart. In Figure 7.9, x-axis represents the speed and load conditions respectively whereas $y$-axis represents the net indicated efficiency. The baseline engine data is shown in blue bars. The Atkinson engine net indicated efficiencies are broken into two parts. They are the net indicated efficiencies of the non-over-expanded portion (in orange) and of the over-expanded portion (in amber). Refer to Equation 8 for non-OE indicated efficiency and Equation 9 for OE indicated efficiency portions. It can be observed that the net indicated efficiency of Atkinson cycle engine non-over-expanded portion is very close to the baseline engine with an observed difference within $0.3 \%$. Furthermore, the OE indicated efficiency (in amber) increases with load. At higher loads, the in-cylinder pressure was higher in the expansion stroke that leads to higher gross work in the over expanded portion resulting in higher net indicated efficiency. At all loads, there was not a significant variation between the efficiencies of the baseline and the Atkinson non-OE indicated efficiency indicating that the increase in the indicated efficiency of Atkinson cycle is primarily due to the increase in the efficiency of the over-expanded portion. 


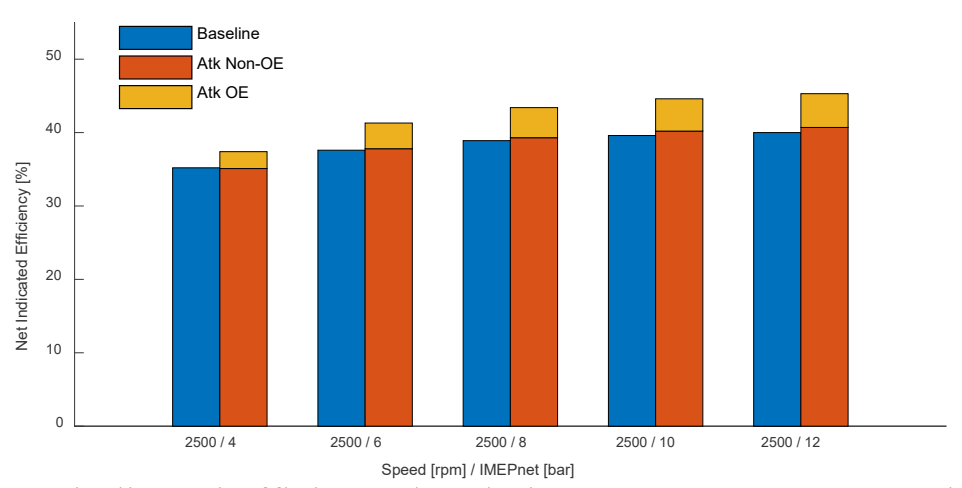

Figure 7.9. Net indicated efficiency break down at 2500rpm, 4 to $12 \mathrm{bar}$ IMEPnet

\subsubsection{Cam Timing Optimization}

A cam-timing sweep for both intake and exhaust valves was performed to determine the optimized cam timing at 1300rpm, 3.3bar IMEPnet and 1750rpm, 10.3bar IMEPnet. The cam timing sweep (100 simulation points in total) of the intake valve most opening position (IMOP) and exhaust valve most opening position (EMOP) is listed in Figure 7.10, while the cam duration is held as constant as the baseline valve duration scaled by 7-5 and 7-6. To make the comparison to baseline easier, reported IMOP and EMOP in Figure 7.10 are the cam timings before adjustment. IMOP was swept from 95 to $140^{\circ}$ ATDC gas exchange (GE) and EMOP from -140 to $-95^{\circ} \mathrm{ATDC}$ GE. The resolution for the sweeping was $5^{\circ} \mathrm{CA}$. In total, 100 cases were simulated for each speed load condition. The optimized case was defined as the cam timing where the net indicated efficiency was maximum. The simulation includes the impact of heat-transfer and combustion with the calibration remaining constant between the baseline and Atkinson engines. Residual gas fraction limit was set at $30 \%$ as a dilution limit which corresponds to a 10-90\% mass fraction burn duration (BD1090) of $26^{\circ} \mathrm{CA}$ at the lower load. Both speed load conditions were controlled at the stoichiometric condition. Combustion phasing was controlled at $10^{\circ}$ ATDC via adjustment of spark timing.

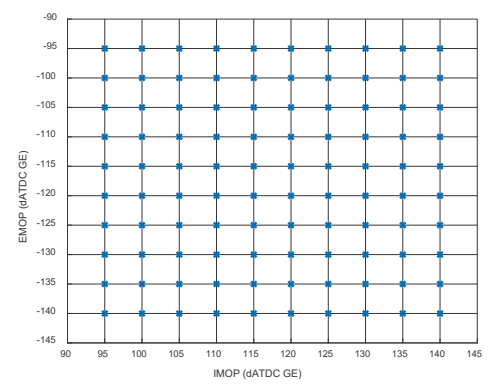

Figure 7.10. Cam timing sweep of IMOP and EMOP 
Cam timing was first optimized for baseline. Results of baseline with optimized cam timing are provided in Table 7.6. For the baseline condition, no knock was observed at 1300rpm, 3.3bar IMEPnet whereas light knock occurred at higher valve overlap cam timing at 1750rpm, 10.3bar IMEPnet (in appendix, Figure 7.24). As the unburned mass fraction of fuel at knock onset was very low $(<10 \%)$, combustion phasing was still maintained under the MBT spark timing. For the Atkinson cycle engine, no knock was observed at the two load conditions. Therefore, combustion phasing was controlled at MBT spark timing for all cases in this study.

Table 7.6. Summary of baseline engine optimized cases

\begin{tabular}{lll}
\hline \hline Speed/IMEPnet (rpm/bar) & $1300 / 3.3$ & $1750 / 10.3$ \\
Net Indicated Efficiency $(\%)$ & 34.1 & 40.0 \\
IMOP $\left({ }^{\circ}\right.$ ATDC GE) & 100 & 140 \\
EMOP $\left({ }^{\circ}\right.$ ATDC GE) & -95 & -95 \\
RGF $(\%)$ & 28.0 & 5.1 \\
BD1090 $\left({ }^{\circ}\right)$ & 25.5 & 15.9 \\
PMEP $(\mathrm{kPa})$ & 48 & 10 \\
\hline \hline
\end{tabular}

\subsubsection{Atkinson Cycle Engine @ 1300rpm 3.3bar IMEPnet}

Running the simulations for the 100-point cam phasing optimization as given above for the low load point with a fixed IMEPnet of 3.3 bar at 1300rpm, several factors of the cycle were extracted to determine the response of the parameters to the cam phasing. Figure 7.11Figure 7.15 are the contour maps for RGF, BD1090, PMEP, OE indicated efficiency and net indicated efficiency at $1300 \mathrm{rpm}$. These parameters are plotted in contour plots as a function of IMOP on the $\mathrm{x}$-axis and EMOP on the $\mathrm{y}$-axis with the optimized cam timing indicated by a cross (red). On the $\mathrm{x}$-axis, proceeding right indicates that the intake cam timing was retarded after TDC with respect to the gas exchange process. Similarly, on the $y$-axis, proceeding upwards indicates that the exhaust cam timing was retarded after TDC with respect to the gas exchange process. The point on the top left of the contour map indicates a retarded exhaust cam timing and advanced intake cam timing resulting in the highest valve overlap. Similarly, a point on the bottom right indicates an advanced exhaust cam timing with retarded intake cam timing corresponding to minimum valve overlap. Late intake valve timing occurs along the line of constant IMOP at $140^{\circ}$ aTDC GE. As valve overlap increases, increased amounts of exhaust gases were retained in the cylinder as shown in Figure 10 for RGF. The RGF threshold limit was set at 30\%, indicated by the dotted line shown in Figure 7.11-Figure 7.15.

In Figure 7.12, BD1090 followed the trend of RGF. As the RGF increased from 5-30\% (Figure 7.11), the turbulent flame speed reduced and the BD1090 increased by $10^{\circ} \mathrm{CA}$ from $15^{\circ}$ to $25^{\circ}$. 
Figure 7.13 shows the contour map for PMEP of the Atkinson cycle using the definition of pumping loop (Figure 7.7). It is observed that PMEP reduces with increased residuals and retarded intake timing. As the IMOP was retarded, PMEP decreased due to a reduction in the effective displacement volume. At the highest net indicated efficiency of $36 \%$ and at a constrained RGF of $30 \%$, PMEP is seen to be $46 \mathrm{kPa}$.

The contour map of OE indicated efficiency is shown in Figure 7.14. It was observed that the OE indicated efficiency follows the trend of valve overlap. At lower load, with retarded IVC, PMEP decreased, however, it also led to a reduction in the OE indicated efficiency because IVC retard was accompanied by a decrease in the effective displacement volume leading to a reduction in the peak pressure. Following this, in the expansion stroke, the pressure decreases to be lower than atmospheric pressure by the end of the stroke resulting in negative indicated work during over expansion.

Figure 7.15 shows the variation of net indicated efficiency of the entire cycle with intake and exhaust cam phasing. It was observed that net indicated efficiency had a similar trend as PMEP and OE indicated efficiency. A higher valve overlap resulted in a reduction in PMEP accompanied by an increase in the OE indicated efficiency. Therefore, at higher valve overlap, the net indicated efficiency of Atkinson cycle increased due to the combined effects of lower PMEP and higher OE indicated efficiency. By considering the RGF limit, the optimized cam timing at 1300rpm 3.3bar IMEPnet occurred at IMOP of $110^{\circ}$ ATDC GE, and EMOP of $-95^{\circ}$ ATDC GE. Net indicated efficiency at the optimized cam timing was higher by $2.0 \%$ compared to the baseline condition. Details of the comparison of the baseline optimized cam phasing and Atkinson over expansion optimized cam phasing are given in Table 7.7.

The log PV diagrams for the baseline condition and Atkinson engine at 1300rpm 3.3bar IMEPnet are shown in Figure 7.16. Optimized exhaust cam timing as shown in Table 5 are nearly the same for two engines. For the Atkinson cycle engine, the cylinder pressure at EVO was close to ambient pressure. With the valve optimization, there was only a very small portion of the over-expanded cycle where the pressure was lower than the ambient pressure as a result of the negative work generated at the end of the expansion stroke due to over-expansion at this speed load condition.

If the cam phasing were not optimized, the Atkinson engine may incur higher negative work as Anandhan et al. mentioned in [22] leading to a net indicated efficiency lower than the baseline condition. Lower loads would require additional optimization, longer intake valve durations and or higher dilution robustness to avoid over-expansion. 


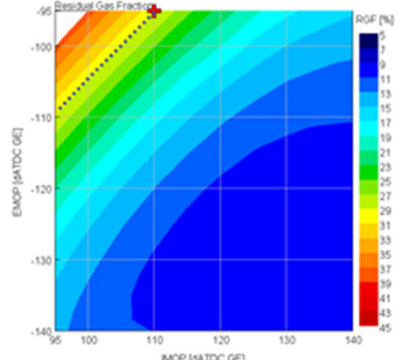

Figure 7.11. Residual gas fraction of intake and exhaust cam timing sweep at $1300 \mathrm{rpm}, 3.3 \mathrm{bar}$ IMEPnet

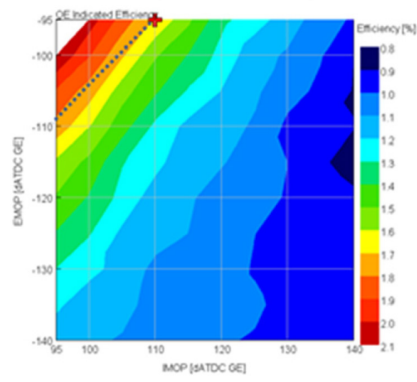

Figure 7.14. OE indicated Efficiency of intake and exhaust cam timing sweep at $1300 \mathrm{rpm}, 3.3 \mathrm{bar}$ IMEPnet

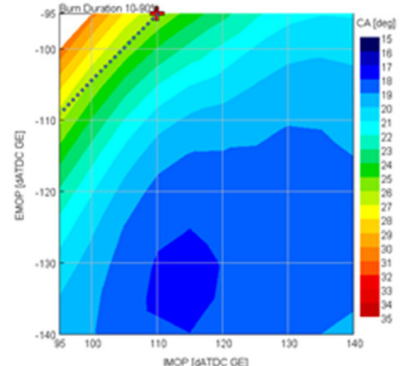

Figure 7.12. Burn duration $10 \%-90 \%$ of intake and exhaust cam timing sweep at 1300rpm, 3.3bar IMEPnet

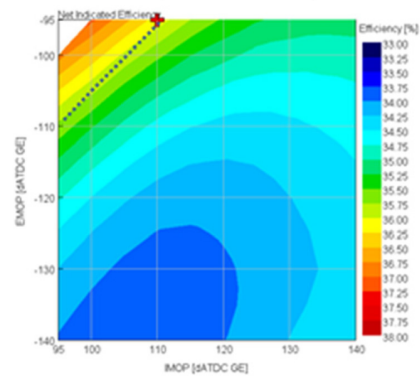

Figure 7.15. Net indicated Efficiency of intake and exhaust cam timing sweep at $1300 \mathrm{rpm}, 3.3 \mathrm{bar}$ IMEPnet

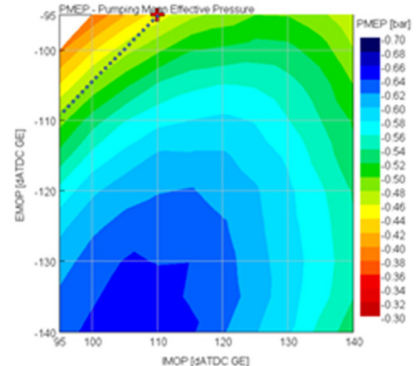

Figure 7.13. PMEP of intake and exhaust cam timing sweep at $1300 \mathrm{rpm}$, 3.3bar IMEPnet

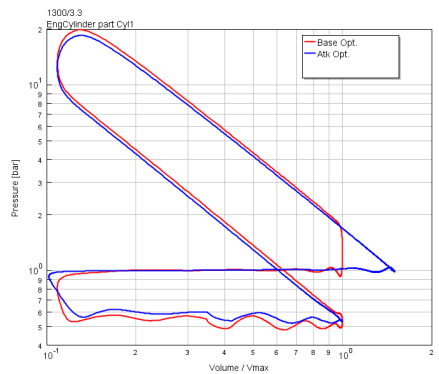

Figure 7.16. Log PV diagram of optimized baseline and Atkinson engine at $1300 \mathrm{rpm}, 3.3 \mathrm{bar}$ IMEPnet

Table 7.7. Summary of optimized case of baseline and Atkinson Engine at 1300rpm, 3.3 bar IMEPnet

\begin{tabular}{ccc}
\hline \hline & Baseline & Atkinson \\
Speed/IMEPnet (rpm/bar) & $1300 / 3.3$ & $1300 / 3.3$ \\
IMOP ( $\left(^{\circ}\right.$ ATDC GE) & 100 & 110 \\
EMOP ( ${ }^{\mathbf{O} A T D C ~ G E)}$ & -95 & -95 \\
RGF (\%) & 28.0 & 29.4 \\
BD1090 ( $)$ & 25.5 & 26.0 \\
PMEP (kPa) & 48 & 45 \\
Net Indicated efficiency (\%) & 34.1 & 36.1 \\
\hline \hline
\end{tabular}




\subsubsection{Atkinson Cycle Engine @ 1750rpm 10.3bar IMEPnet}

Again running the simulation for the 100 cam phasing points as outlined above, Figure 7.17Figure 7.20 are the contour maps for RGF, BD1090, PMEP, OE indicated efficiency, and net indicated efficiency at $1750 \mathrm{rpm}, 10.3 \mathrm{bar}$ IMEPnet. In the figures, the optimized cam timings with the maximum indicated efficiency are marked in red. In Figure 7.17, the RGF is seen to increase with increasing valve overlap, that is, retarding the exhaust and advancing the intake phasing. The maximum value of RGF at this load was $11 \%$, significantly less than the RGF limit of $30 \%$ at $1300 \mathrm{rpm}, 3.3 \mathrm{bar}$ IMEPnet.

Burn durations 10-90\% indicated as BD1090 are shown in Figure 7.18. The change in burn durations was not significantly affected by cam timing at higher loads with the variation observed to be less than $2^{\circ}$.

In Figure 7.19, the PMEP contour map is shown with the highest PMEP at (-)30kPa when both intake and exhaust valve timing were advanced (bottom left in Figure 7.19). Moving right along the diagonal, it was observed that a gradual decrease in PMEP occurs due to increased retard of the intake cam timing. At retarded intake cam timing, the effective displacement volume was reduced leading to lower pumping losses. Retarding the exhaust valve timing increases the RGF and reducing the pumping work.

With respect to the OE indicated efficiency as shown in Figure 7.20, early intake valve closing led to higher peak pressure, which increased the available energy for expansion. At slightly retarded exhaust valve timing, more indicated work was provided in the over expansion resulting in higher $\mathrm{OE}$ indicated efficiency. However, at the fully retarded exhaust cam timing, the exhaust valve opens late. This increases the work during the exhaust stroke before blowdown is complete leading to a reduction in $\mathrm{OE}$ indicated efficiency. Early exhaust valve opening led to the loss of work in the expansion resulting in lower OE indicated efficiency. An EMOP of $-125^{\circ}$ to $-105^{\circ}$ is a tradeoff between the losses due to early EVO and the recompression work during exhaust stroke due to retarded EVO.

Figure 7.21 shows the contour map of indicated net efficiency. It can be observed that the trend of net indicated efficiency follows PMEP trend at early exhaust cam timing. As the exhaust cam timing was retarded, net indicated efficiency was nearly constant as observed between EMOP -105 to $-95^{\circ}$ ATDC GE. In this figure, two islands of maximum indicated efficiency of $44.6 \%$ were observed at retarded EMOP timings at EMOP of $-105^{\circ}$ ATDC GE for a case with advanced IMOP at $95^{\circ} \mathrm{ATDC}$ GE and the second with a retarded IMOP of $135^{\circ}$ ATDC GE. A variation in the net indicated efficiency results from changes in (i) PMEP and (ii) additional work in the OE portion of the stroke. Earlier IVO resulted in higher overlap and increased trapped gases, higher compression pressures and higher peak pressures increasing OE work as shown in Figure 7.20. At retarded IMOP, the effect of reduced PMEP was predominant in the increase in net indicated efficiency (Figure 7.19). 
Figure 7.22 shows the log PV diagram of the optimized Atkinson cycle engine compared to baseline condition at maximum net indicated efficiency. For the Atkinson cycle engine, maximum net indicated efficiency was observed at two zones due to the variations in PMEP and additional work in over expanded portion. In Figure 7.22, legend "Base. Opt." refers to the optimized baseline engine condition, "Atk. Opt. Low PMEP" refers to the optimized Atkinson cycle due to lower pumping losses and "Atk. Opt. High OE Ind. Eff." refers to the optimized Atkinson cycle due to an increase in OE indicated efficiency. It was observed that the peak pressures of the Atkinson cycle at two optimized cases are lower than the baseline engine. The average MAP of the Atkinson cycle with low PMEP (blue) is higher, but the pressure at IVC is lower compared to the other optimized Atkinson cycle condition (green). In-cylinder pressure of the Atkinson cycle with high OE indicated efficiency at the beginning of the over expansion is higher resulting in higher OE indicated efficiency. However, the indicated work generated in the over-expanded portion is offset by the higher pumping losses resulting in the same net indicated efficiency for the two Atkinson cycle conditions.

Summary of the optimized baseline condition and Atkinson engine at 1750rpm, 10.3bar IMEP $_{\text {net }}$ is given in Table 7.8. Two optimized cam timings of the Atkinson cycle are included with one at the early IMOP with lower PMEP and the other at retarded IMOP with higher $\mathrm{OE}$ indicated efficiency. An improvement of $4.6 \%$ in the net indicated efficiency was observed in both cases compared to the baseline condition.

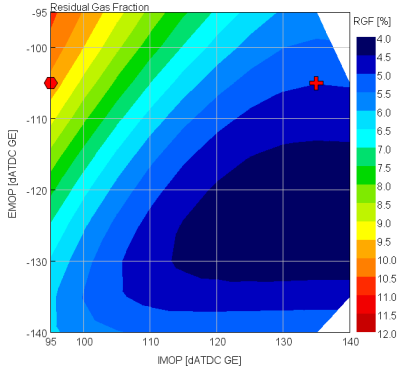

Figure 7.17. Residual gas fraction of intake and exhaust cam timing sweep at 1750rpm, $\underline{10.3 \mathrm{bar} \text { IMEPnet }}$

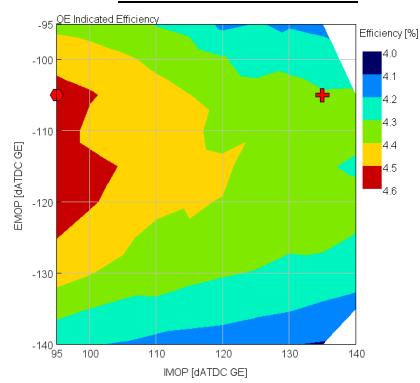

Figure 7.20. OE indicated efficiency of intake and exhaust cam timing sweep at 1750rpm, 10.3bar IMEPnet

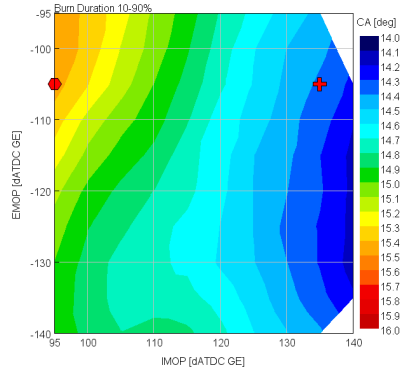

Figure 7.18. Burn duration 10\%$90 \%$ of intake and exhaust cam timing sweep at $1750 \mathrm{rpm}$, 10.3bar IMEPnet

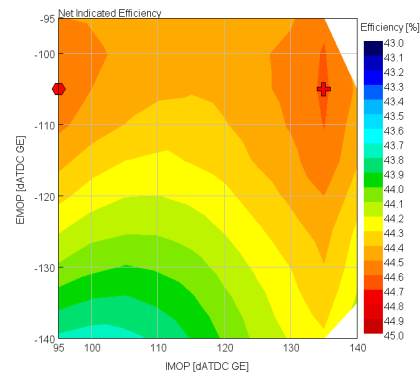

Figure 7.21. Net indicated efficiency of intake and exhaust cam timing sweep at $1750 \mathrm{rpm}$, 10.3bar IMEPnet

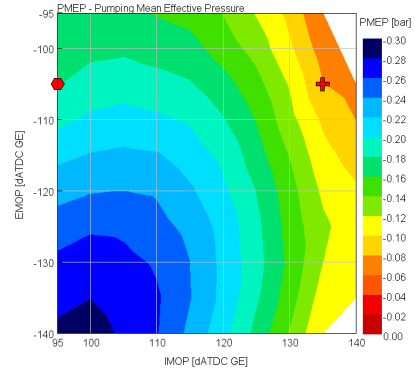

Figure 7.19. PMEP of intake and exhaust cam timing sweep at 1750rpm 10.3bar, IMEPnet

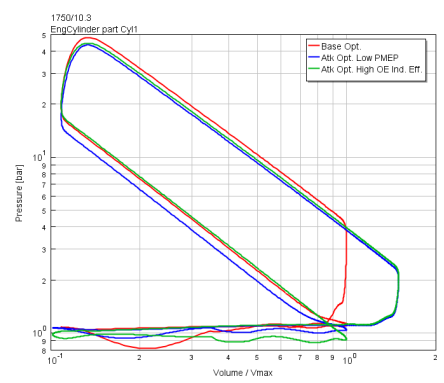

Figure 7.22. Log PV diagram of optimized baseline and Atkinson engine at 1750rpm, 10.3bar IMEPnet 
Table 7.8. Summary of optimized case of baseline and Atkinson Engine at 1750rpm, 10.3 $\underline{\text { bar IMEPnet }}$

\begin{tabular}{|c|c|c|c|}
\hline & Baseline & $\begin{array}{l}\text { Atkinson (Low } \\
\text { PMEP) }\end{array}$ & $\begin{array}{c}\text { Atkinson } \\
\text { (High OE } \\
\text { Indicated } \\
\text { Efficiency) }\end{array}$ \\
\hline $\begin{array}{l}\text { Speed/IMEPnet } \\
\text { (rpm/bar) }\end{array}$ & $1750 / 10.3$ & $1750 / 10.3$ & $1750 / 10.3$ \\
\hline IMOP ( ${ }^{\circ} \mathrm{ATDC}$ GE) & 140 & 135 & 95 \\
\hline EMOP ( ${ }^{\circ}$ ATDC GE) & -95 & -105 & -105 \\
\hline RGF (\%) & 5.1 & 5.4 & 10.3 \\
\hline $\mathrm{BD} 1090\left(^{\circ}\right)$ & 15.9 & 14.4 & 15.5 \\
\hline PMEP (kPa) & 10 & 7 & 17 \\
\hline $\begin{array}{l}\text { Net Indicated } \\
\text { efficiency (\%) }\end{array}$ & 40.0 & 44.6 & 44.6 \\
\hline
\end{tabular}

Figure 7.23 shows the bar chart of efficiencies at the low load and high load conditions for four configurations. Barcharts represent the net indicated efficiencies of the baseline engine from experimental results, optimized baseline from simulation, Atkinson cycle simulation with no adjustment, and optimized Atkinson cycle. At 1300rpm, 3.3bar IMEPnet, the net indicated efficiency of non-adjusted Atkinson cycle was $0.6 \%$ lower than the optimized baseline from simulation (blue). It can be concluded that the adjustment for spark timing, valve duration and valve timing is necessary to avoid over-expansion in the light load resulting in a negative impact from increased pumping. With the optimized cam timing for the baseline and Atkinson cycle engine, an absolute increase by $2.0 \%$ and relative increase by $5.9 \%$ was observed for the optimized Atkinson cycle compared to the baseline with the applied RGF limit.

At 1750rpm, 10.3bar IMEPnet, an increase by $4.6 \%$ (absolute) and an increase by $11.5 \%$ (relative) in the net indicated efficiency of the optimized Atkinson cycle engine was observed in comparison to the baseline-optimized engine. As seen in the load sweep (Figure 7.9), as the pressures increase at fixed exhaust valve opening times, more indicated work is generated during the period of over-expansion, which leads to a higher net indicated efficiency. 


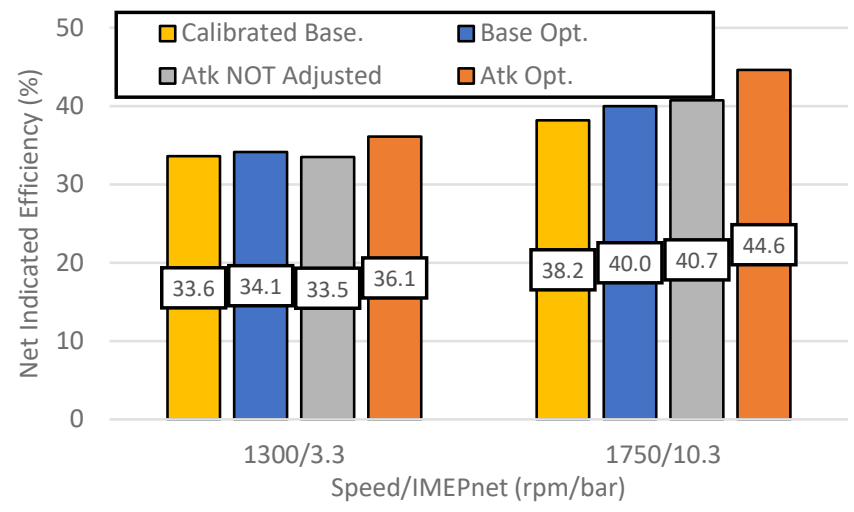

Figure 7.23. Net indicated efficiency of optimized baseline, non-adjusted Atkinson cycle, and optimized Atkinson cycle engine, at 1300rpm, 3.3bar IMEPnet and 1750rpm, 10.3bar IMEPnet

\subsection{Summary/Conclusions}

An engine simulation study with a true mechanically actuated Atkinson cycle has been studied. The model calibration was based on the experimental data from a spark-ignited 2L turbocharged engine, DI, variable cam timing engine with CR 9.2. The Atkinson engine was designed with the same compression ratio, bore, and compression stroke as baseline with an OER of 1.5.

In this study, the engine simulation model was calibrated based on the experimental results with load control, spark timing control (MBT spark timing).

The engine model also includes design constraints based upon packaging. The physical mechanism was simulated directly in the engine model, and it generates the dynamics of each component including the piston movement as a function of crank angle.

The adjustment of spark timing, valve duration, cam timing, and optimization of cam phasing were considered in this study based upon the mechanism differences and durations of the different strokes.

The pumping loop of an Atkinson engine was defined with respect to the piston location instead of using the BDC after expansion and BDC after intake of crank location as the start and end in a baseline engine. The addition of overexpansion work was broken out as the $\mathrm{OE}$ efficiency to understand how the overexpansion contributed to the increase in overall efficiency.

Based upon the simulation studies conducted, the following findings and observations are made: 
- With an increase in load, higher improvement in net indicated efficiency over the baseline condition due to increased indicated work during the over expansion.

- The effect of combustion phasing or CA50 on location of maximum efficiency at 1750rpm, 10.3bar IMEPnet was found to be at $8^{\circ}$ to $10^{\circ}$ ATDC.

- The maximum net indicated efficiency of $45 \%$ was observed at 12 bar IMEPnet. This represents a $13 \%$ relative increase in efficiency compared to the baseline.

- For an optimized Atkinson cycle engine, net indicated efficiency is dependent on OE indicated efficiency and pumping losses. At $1300 \mathrm{rpm}, 3.3 \mathrm{bar}$ IMEPnet, BD1090 followed the increasing trend of RGF which increased with valve overlap with a maximum RGF limit of 30\%. The net indicated efficiency followed the trend of PMEP. At higher valve overlap, net indicated efficiency increased due to the increase in $\mathrm{OE}$ indicated efficiency and the decrease in the pumping losses. However, the highest efficiency was constrained by the RGF limit for the lower load condition.

- At 1750rpm, 10.3 bar IMEPnet, Atkinson cycle engine had minor variation in burn duration due to reduced RGF (less than 12\%). PMEP at the maximum efficiency at optimized cam timing did not follow the RGF trend.

- The OE indicated efficiency of higher load was observed to be maximum at early intake cam timing and slightly retarded exhaust cam timing (EMOP $-125^{\circ}$ to $-105^{\circ}$ ATDC GE). Early intake valve opening led to higher peak pressure which increased the available energy of the combustion gases. At slightly retarded exhaust valve timing, more indicated work was provided in the over expansion resulting in higher $\mathrm{OE}$ indicated efficiency. An EMOP of $-125^{\circ}$ to $-105^{\circ}$ is a tradeoff between the blowdown losses due to early EVO and the recompression work during exhaust stroke due to retarded EVO.

- Optimized cam timing at 1750rpm, 10.3 bar IMEPnet were observed to be in the region of IMOP $95^{\circ}$ and $135^{\circ} \mathrm{ATDC}$ GE, and EMOP $-105^{\circ} \mathrm{ATDC}$ GE. Net indicated efficiency at 1750rpm, 10.3 bar IMEPnet followed PMEP trend at early exhaust cam timing. At EMOP $-105^{\circ}$ ATDC GE, net indicated efficiency was maximum at two zones caused by PMEP and OE indicated efficiency. At an early intake valve timing, the increase in net indicated efficiency was primarily due to an increase in the OE indicated efficiency. At a retarded intake valve timing, the effect of reduced PMEP was predominant in the increase in net indicated efficiency.

- The net indicated efficiency comparison between non-adjusted Atkinson and optimized Atkinson engine shows the adjustment for spark timing, valve duration and valve timing were necessary to avoid over-expansion at light load resulting in a negative impact from increased pumping. With the fully optimized cam timing, net indicated efficiency of Atkinson engine at 1300rpm, 3.3 bar IMEPnet and 1750rpm, 10.3bar IMEPnet were observed to have an absolute increase by $2.0 \%$ and $4.6 \%$ respectively, and a relative increase of $5.9 \%$ and $11.5 \%$ respectively, compared to the baseline condition. 
Further analysis of Atkinson engine under boosted conditions with limits of combustion knock and impact on turbo-charge performance should be examined. With increased expansion, residual gases will be cooler and lead to a lower charge temperatures resulting in lower combustion knock levels. However, with lower exhaust gas pressures with expansion, it is uncertain whether existing turbocharge and boost performance will be achieved with high OER's.

\subsection{Acknowledgments}

This work was supported by MTU Light Duty Consortium. The authors would like to thank David Roth for initiating and guiding this work.

\subsection{Definitions/Abbreviations}

$\begin{array}{ll}\text { BD1090 } & \begin{array}{l}10 \%-90 \% \text { mass fraction burned } \\ \text { duration }\end{array} \\ \text { BDC } & \text { Bottom dead center } \\ \text { BSFC } & \text { Brake specific fuel consumption } \\ \text { CA50 } & \begin{array}{l}\text { Crank angle of 50\% mass fuel } \\ \text { burned }\end{array} \\ \text { CR } & \text { Compression ratio } \\ \text { EMOP } & \text { Exhaust valve most opening } \\ \text { GE } & \text { position } \\ \text { IMEPnet } & \text { Gas exchange } \\ \text { IMOP } & \text { Net indicated mean effect pressure } \\ \text { ISFC } & \text { Intake valve most opening position } \\ \text { LIVC } & \text { Net indicated specific fuel consumption } \\ \text { MAP } & \text { Late intake valve closing } \\ \text { OER } & \text { Manifold absolute pressure } \\ \text { OE } & \text { Over expansion ratio } \\ \text { RGF } & \text { Over expansion } \\ \text { SR } & \text { Residual gas fraction } \\ \text { TDC } & \text { Expansion to compression stroke ratio } \\ \text { VVT } & \text { Top dead center } \\ \boldsymbol{\eta}_{\text {net indicated }} & \text { Variable valve timing } \\ \boldsymbol{\eta}_{\text {net indicated,non-oE }} & \text { Net indicated efficiency } \\ \boldsymbol{\eta}_{\text {indicated,oE }} & \text { Over expanded indicated efficiency } \\ & \end{array}$




\subsection{Appendix}

Table 7.9 Geometry summary of baseline and Atkinson engine

\begin{tabular}{|c|c|c|c|}
\hline & Mechanism Type & Baseline & Atkinson \\
\hline & $\mathrm{CR}$ & 9.2 & 9.2 \\
\hline & ER & 9.2 & 13.8 \\
\hline & OER & 1.0 & 1.5 \\
\hline & Bore $[\mathrm{mm}]$ & 86.0 & 86.0 \\
\hline \multirow{4}{*}{ Stroke [mm] } & Compression & 86.0 & 86.0 \\
\hline & Expansion & 86.0 & 135.2 \\
\hline & Exhaust & 86.0 & 134.9 \\
\hline & Intake & 86.0 & 86.6 \\
\hline \multirow{4}{*}{ Volume [cc] } & BDC before Comp. & 560.5 & 560.3 \\
\hline & TDC Firing & 60.9 & 60.9 \\
\hline & BDC after Expansion & 560.5 & 840.6 \\
\hline & TDC Gas GE & 60.9 & 57 \\
\hline \multirow{4}{*}{$\begin{array}{c}\text { Piton Location } \\
\text { Crank Angle [deg] }\end{array}$} & TDC Firing & 0 & -17.5 \\
\hline & BDC after Expansion & 180 & 184.5 \\
\hline & TDC GE & 360 & 381.8 \\
\hline & BDC after Intake & 540 & 544.3 \\
\hline \multirow{4}{*}{$\begin{array}{c}\text { Stroke Duration in } \\
\text { Crank Angle }\left({ }^{\circ}\right)\end{array}$} & Compression & 180 & 158 \\
\hline & Expansion & 180 & 202 \\
\hline & Exhaust & 180 & 197 \\
\hline & Intake & 180 & 163 \\
\hline
\end{tabular}


Table 7.10 Mean piston speed baseline and Atkinson engine

\begin{tabular}{|c|c|c|c|}
\hline & Mechanism Type & Baseline & Atkinson \\
\hline \multirow{4}{*}{$\begin{array}{c}\text { Mean Piston } \\
\text { Speed @ 1330rpm } \\
(\mathbf{m} / \mathbf{s e c})\end{array}$} & Compression & & 4.34 \\
\cline { 2 - 2 } & Expansion & \multirow{2}{*}{3.81} & 5.34 \\
\cline { 2 - 2 } & Exhaust & 5.46 \\
\hline \multirow{2}{*}{$\begin{array}{c}\text { Mean Piston } \\
\text { Speed @ 1750rpm } \\
(\mathbf{m} / \mathbf{s e c})\end{array}$} & Intake & & 4.25 \\
\cline { 2 - 2 } & Compression & & 5.71 \\
\cline { 2 - 2 } & Expansion & \multirow{2}{*}{5.02} & 7.03 \\
\hline
\end{tabular}

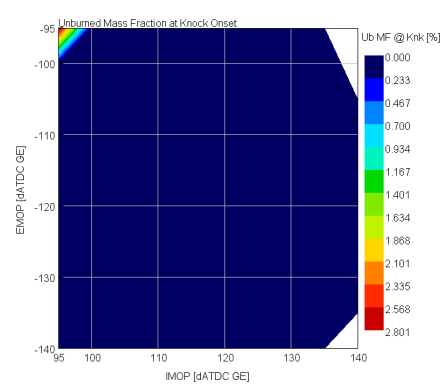

Figure 7.24. Unburned fuel mass fraction at knock onset of intake and exhaust cam timing sweep at $1750 \mathrm{rpm}$, 10.3bar IMEPnet,baseline

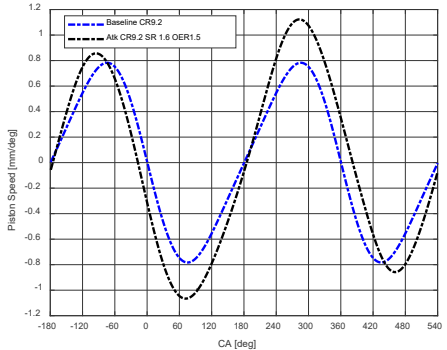

Figure 7.25. Piston speed as a function of crank angle comparison between baseline and Atkinson mechanism. ("0" mean at TDC Firing) 


\section{Investigation of High Load Operation of Spark-Ignited Over-Expanded Atkinson Cycle Engine}

This paper was submitted to a peer-reviewed academic journal and is currently under review. It corresponds to the second stage of the research described in the main research contributions chapter

In this study, a multi-link over-expanded engine model was developed based on the experimental results of a baseline engine. The multi-link over-expanded engine and the baseline engine were optimized and compared based on the cam phasing sweep with the constraints of knock and exhaust temperature at two high load conditions. An energy loss analysis, including combustion phasing and fuel enrichment, was conducted and compared between the baseline engine and the multi-link over-expanded engine. 


\section{Investigation of High Load Operation of Spark-Ignited Over-Expanded Atkinson Cycle Engine}

Yang, Z., Narasimhamurthy, M., Miller, T., Vinhaes, V., and Naber, J.

Michigan Technological University

David Roth

Roth Engine Science LLC

Michigan Technological University

Department of Mechanical Engineering - Engineering Mechanics

1400 Townsend Drive, Houghton, Michigan, USA 49931

Email: zhuyongy@mtu.edu,jnaber@mtu.edu 


\subsection{Keywords}

Internal combustion engine

Atkinson cycle

High efficiency

Combustion knock

\subsection{Highlights}

1-D simulation of over-expanded Atkinson cycle engine with a multi-link mechanism.

Atkinson cycle engine is shown to have lower knock propensity and is able to operate airfuel ratio close to stoichiometric condition at high load condition.

At high load, the energy losses including combustion phasing and fuel enrichment are compared between baseline engine and Atkinson cycle engine.

The net indicated efficiency for Atkinson cycle engine is $27 \%$ higher relative to the baseline engine.

\subsection{Abstract}

The Atkinson-cycle is a four-stroke cycle engine with an expansion stroke longer than compression stroke. An Atkinson cycle engine with the additional expansion (overexpansion) increases the total indicated work per cycle compared to an Otto-cycle engine. For a boosted spark-ignited engine, at high load, the fuel conversion efficiency is penalized due to the retarded spark timing to reduce the knock intensity and enriched fuel to reduce the exhaust gas temperature for component protection. An Atkinson over-expanded engine is shown to have lower knock propensity and lower exhaust temperatures at air-fuel ratios close to stoichiometric due to increased expansion, which is advantageous compared to a conventional engine.

A boosted spark-ignited over-expanded engine was investigated in this work through 1-D engine simulation. A conventional 4-stroke turbocharged spark-ignited engine with 10.5:1 compression ratio (CR) and 22 bar peak brake mean effective pressure (BMEP) was selected as the baseline engine. The Atkinson cycle engine model was developed and calibrated based on a multi-link Atkinson cycle mechanism with design constraints. The compression ratio (CR) and over expansion ratio (OER) of the Atkinson cycle engine are 10.5 and 1.5, respectively. The geometric specification of the over-expansion engine 
mechanism was based on the previous study with adjusted valve lift, combustion phasing, and optimized cam timing. A kinetic knock model was calibrated in baseline and Atkinson engine models based upon experimental data from the conventional engine. Two speed and load conditions of 1500rpm, 13 bar net indicated mean effective pressure (IMEPnet) and 3500rpm, 20 bar IMEPnet with valve timing optimization were investigated.

Previous studies found that the net indicated efficiency of Atkinson cycle engine realized by a multi-link mechanism was improved by $11.5 \%$ relatively compared to the conventional engine at light to medium load conditions. The improvement in efficiency was mainly realized by the indicated work generated from over-expansion. The component of the over-expansion in Atkinson cycle is the period during power stroke when piston passes beyond the maximum in-cylinder volume at intake stroke. In this study, the increase in indicated efficiency of Atkinson cycle engine was not only from the over-expansion but also from the non-over-expansion portion of the cycle. A breakdown of the energy losses was conducted to investigate the different characteristics between a conventional engine and an Atkinson cycle engine. The results indicated that Atkinson cycle engine benefits from lower knock propensity and lower exhaust temperature.

At 1500rpm, 13bar IMEPnet, the simulation results indicated that energy loss due to combustion phasing was $2.1 \%$ and $0.4 \%$ for baseline and Atkinson cycle engine. Net indicated efficiency of Atkinson cycle engine was increased by 16\%. At 3500rpm, 20bar IMEPnet, the baseline engine was operated at knock limited spark timing and fuel enrichment to reduce the turbine-inlet temperature. Net indicated efficiency of optimized Atkinson cycle engine at 3500rpm 20bar IMEPnet was higher by $27 \%$ in comparison to the optimized baseline engine. In comparison, Atkinson cycle engine was able to perform at lower fuel enrichment with maximum brake torque (MBT) spark timing. The energy loss due to fuel enrichment was $6.0 \%$ for baseline engine and $1.6 \%$ for Atkinson cycle indicating that the Atkinson cycle engine was beneficial to maximize its efficiency. Similarly, the energy loss due to combustion phasing was $1.2 \%$ and $0.6 \%$ for baseline and Atkinson cycle engine, respectively.

\subsection{Introduction}

Internal combustion engines must achieve higher fuel conversion efficiency and lower emission to meet legislation at stoichiometric condition[40, 43]. Engine downsizing with boosting is one major approach to enhance engine efficiency and torque capability, as well as $\mathrm{CO}_{2}$ reduction $[44,45]$. As the load increases, engines will have higher knock probability mainly depending on the temperature, pressure, and propagation of the flame front $[45,69$, 70]. Retarding spark timing is normally used as a method to reduce the knock occurrence because of the decrease in the end-gas temperature. However, such methods penalize engine efficiency due to lower pressure at expansion [70]. In addition, a turbocharged engine operated at retarded spark timing leads to higher exhaust gas temperatures and may 
reach the temperature limit of turbine or exhaust valve depending on the engine operating conditions [71]. Fuel enrichment is applied in direct injection (DI) engines to reduce exhaust gas temperature [72]. Consequently, such unburned fuel leads to a lower fuel conversion efficiency along with higher emissions[73].

To overcome the efficiency penalty at knock limited and turbine inlet temperature limited condition, several methods have been studied as listed below

- Cooled exhaust gas recirculation [34, 69, 71, 74-77]

- Water injection $[24,74,78,79]$

- Over-expanded Atkinson cycle [64]

Heat capacity of the charge gas is increased by adding cooled EGR, which reduces the charge temperature during compression and exhaust gas temperature. Kumano. and Yamaoka. et al. [34], illustrated a lower knock propensity and higher peak torque by adding cooled EGR. Combustion phasing advance effect is about $0.6^{\circ} \mathrm{CA}$ per $1 \%$ of EGR ratio. The maximum torque increased by $1.5 \%$ approximately per $1 \%$ of EGR ratio at $4000 \mathrm{rpm}$.

Water injection is another promising technique to mitigate knock. Hoppe et al. [24] indicated that the intake charge gas temperature is $34^{\circ} \mathrm{C}$ lower than no water-injected condition due to its large latent heat of vaporization. Experimental results show that the thermal efficiency is increased between $3.3 \%$ and $3.8 \%$ relatively with the water injection concept. At full load condition, water injection results in a decrease of exhaust temperature of approximately $100^{\circ} \mathrm{C}$ and an increase in net indicated efficiency up to $16 \%$ [24]. However, some critical issues of water injection need to be considered including the increase in burn durations, combustion instability [80], and extra cost of water storage system or onboard water recovery system [81].

Compared to cooled EGR and water injection, utilizing Atkinson cycle changes the actual volume trace of an engine. Previous research investigated the thermodynamic potential of Atkinson cycle engine [82], but the actual performance and characteristics of an Atkinson cycle engine are not fully understood yet, especially at high load conditions. The most relevant research was conducted by Boretti. et al. [64]. A mechanism with alternating stroke was developed and discussed. The mechanism has a conservative expansion to compression stroke ratio of 1.1. The brake fuel conversion efficiency of the engine was increased by approximately 30\% at 7.5bar BMEP with the coupled effect of variable compression and Atkinson cycle compared to a baseline engine. Although the indicated efficiency improvement is promising, the effect of the Atkinson cycle is not quantified due to the compression ratio difference not eliminated in this study. In addition, Atkinson cycle engine operating condition under turbine inlet temperature limit with fuel enrichment is not investigated.

According to Jing. et al.[82], Atkinson cycle engine can be realized by modifying the valvetrain or cranktrain. Modifying valvetrain is to reduce the effective compression stroke 
or displacement with the strategy of retarding intake valve closing (LIVC), which leads to a lower effective compression ratio compared to the expansion ratio. It also improves the fuel economy due to reduced pumping loss. The principle of reducing pumping loss with LIVC is by applying a larger throttle opening and higher intake manifold pressure to compensate the reduced effective displacement. According to studies of the Atkinson cycle engine at part load conditions, the fuel consumption was improved between $5.7 \%$ and $7.4 \%[83-85]$.

However, by adopting LIVC strategy, the reduced effective displacement also decreases the peak load output since the power density is lower with LIVC. In addition, according to Luisi et al. [86], the efficiency benefit of LIVC is difficult to be achieved at high engine speeds. Using a modified over-expansion cranktrain, it is possible to avoid the power density penalty by designing a mechanism with the same intake stroke and longer expansion stroke than a conventional engine to realize the over-expansion. The latest research of Atkinson cycle engine used a multi-link mechanism to realize an overexpansion cycle $[38,40,65,68,87]$. The mechanism was based on a variable compression ratio mechanism [88] and adding a gear pair between control shaft and crank shaft. A planetary gear system was also discussed to realize the Atkinson cycle [39]. Research by Yang et al. [68] investigated the benefit of Atkinson cycle engine with a multi-link mechanism under light-medium load conditions. A more detailed literature review regarding the fuel conversion efficiency benefit of Atkinson cycle engine study were completed by Zhao [82] and Yang et al. [68].

The study by and Yang et al. [68]. separated the gross work into the portions of non-overexpansion and over-expansion, as Figure 8.1 shows. This research indicated that the net indicated efficiency of the Atkinson cycle engine was much higher compared to the baseline engine, while the net indicated work by the portion of non-over-expansion was found close to the baseline engine at light to medium load condition. Hence net indicated efficiency improvement of Atkinson cycle engine is mainly contributed by the component of over-expansion. The net indicated efficiency of Atkinson cycle engine with compression ratio 9.2 and over-expansion ratio 1.5 was $11.5 \%$ (relatively) higher than the baseline with same compression ratio. 


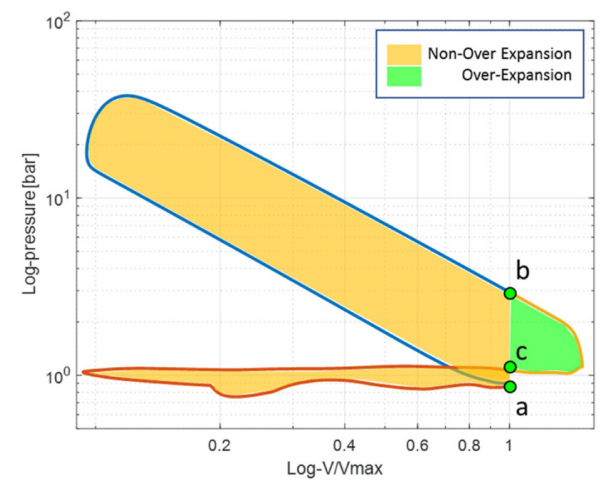

Figure 8.1. $\log \mathrm{P}-\log \mathrm{V} / \mathrm{V}_{\max }$ of Atkinson cycle split by non-over-expansion and overexpansion ( $\mathrm{V}_{\max }$ is the maximum in-cylinder volume during intake stroke)

This study follows previous study by Yang et al. [68] regarding the Atkinson cycle engine realized by a multi-link mechanism and addresses the following topics.

1) Quantify the knock propensity difference between the baseline engine and Atkinson engine at $1500 \mathrm{rpm}, 13 \mathrm{bar}$ IMEPnet.

2) Quantify the energy losses associated with combustion phasing and duration, air to fuel ratio (AFR), in-cylinder heat transfer, and pumping work.

3) Quantify Atkinson cycle engine net indicated efficiency improvement with respect to the portion of non-overexpansion and over-expansion at 1500rpm, 13bar IMEPnet and 3500rpm, 20bar IMEPnet.

This research developed and calibrated a 1-D model for the baseline and Atkinson cycle engine based on the experimental data and embedded with spark timing control (knock limited spark timing / MBT), load control, and AFR control. The design of Atkinson cycle engine mechanism was constrained by bore, stroke, baseline compression ratio, and packaging. The dynamics of the over-expansion mechanism was simulated including the piston movement of the whole engine cycle. The knock propensity of two engines was first investigated at the same speed and load condition with the same combustion phasing. Two engine operating conditions were simulated for full optimization, which were 1500rpm $13 \mathrm{bar}$ IMEPnet and 3500rpm 20bar IMEPnet. At the selected operating conditions, the net indicated efficiency and different types of losses were investigated between baseline and Atkinson cycle engine with optimized cam phasing. The major efficiency loss was the result of the combustion phasing and AFR caused by the knock propensity and turbineinlet temperature difference, respectively. The following content in this paper will use "Atkinson cycle engine" to represent an Atkinson cycle engine with multi-link mechanism. 


\subsection{Methodology}

\subsubsection{Experimental Results and Baseline Model}

The baseline engine of this study was modified based on a GM Ecotec turbocharged directinjected spark-ignited 4-cylinder engine. The compression ratio of the baseline engine model was modified from 9.2 to 10.5 to represent the state of the art of engine technology with respect to knock mitigation strategies (e.g. Mazda Skyactiv Engine with CR 10.5:1). Table 8.1 lists the specifications of the baseline engine.

Table 8.1. Baseline engine specifications

\begin{tabular}{ll}
\hline \hline Displaced volume & $1998 \mathrm{cc}$ \\
Stroke & $86 \mathrm{~mm}$ \\
Bore & $86 \mathrm{~mm}$ \\
Connecting Rod & $145.5 \mathrm{~mm}$ \\
Compression ratio & $10.5: 1$ \\
\hline
\end{tabular}

The operating conditions selected in this study are 1500rpm, 13bar IMEPnet, and 3500rpm, 20bar IMEPnet representing high load conditions with the constraints of knock and turbineinlet temperature. $10 \%$ ethanol blended gasoline (E10) was the fuel utilized in this study. The anti-knock index of the fuel was $87.0(\mathrm{RON}+\mathrm{MON} / 2)$.

A 1-D engine simulation study was conducted using the commercial engine software (GTSuite / GT-Power). The calibration of the baseline engine was based on a wide range of speed/load conditions including the operating condition as shown in Table 8.2. The valve timing of the selected baseline condition is provided in Table 8.3. The cycle of the $95^{\text {th }}$ percentile of knock peak-peak in the experiments was selected for knock model $[22,66]$ calibration. The comparison of the experimental data to the modeling results is shown in Table 8.2.

Table 8.2. Baseline engine calibration of 1500rpm, 14bar IMEPnet, (experimental data: the cycle of $95^{\text {th }}$ percentile of knock peak-peak)

\begin{tabular}{ccc}
\hline \hline & Experiment & Simulation \\
Speed (rpm) & 1500 & 1500 \\
IMEPnet (bar) & 14.4 & 14.4 \\
MAP (kPa) & 129.6 & 129.5 \\
Net indicated efficiency (\%) & 37.8 & 37.7 \\
Total Fuel flow (g/s) & 2.3 & 2.3 \\
Location of peak pressure $\left({ }^{\circ} \mathbf{a T D C}\right)$ & 21.1 & 21.0 \\
Peak pressure (bar) & 65.2 & 67.3 \\
Knock Onset $\left({ }^{\circ} \mathbf{a T D C}\right)$ & 21.1 & 21.0 \\
\hline \hline
\end{tabular}


Table 8.3. Experimental results of valve timing @ $0.2 \mathrm{~mm}$ valve lift

\begin{tabular}{lc}
\hline \hline Speed/Load & $1500 \mathrm{rpm} / 14 \mathrm{bar}$ IMEPnet \\
Intake Valve Opening & $15^{\circ} \mathrm{bTDC}$ \\
Intake Valve Closing & $37^{\circ} \mathrm{aBDC}$ \\
Exhaust Valve Opening & $27^{\circ} \mathrm{bBDC}$ \\
Exhaust Valve Closing & $14^{\circ} \mathrm{aTDC}$ \\
\hline
\end{tabular}

\subsubsection{Knock Onset Prediction}

Knock study in the cycle simulation program used empirical induction-time correlation [22]. The empirical relation for induction time is based on the kinetic mechanism given by Ra. et al. [66]. Three induction times were calculated for low, intermediate, and high temperature regions, respectively as 8-2 shows. The calculation of induction time $\tau$ is shown in 8-3. It can be observed that the kinetics-fit model considers the effect of octane number, fuel concentration, oxygen concentration, dilution, and unburned zone temperature. Figure 8.2 shows the induction time $\tau$ (black dashed line) as a function of unburned zone temperature. In the model, knock was predicted to occur at the crank angle at which the induction time integral attains a value of 1.0. The model was calibrated to match the knock onset with the experimental results as shown in Table 8.2.

$$
\begin{aligned}
& \int_{t=0}^{t_{i}} \frac{d t}{\tau}=1 \\
& \frac{1}{\tau}=\frac{1}{\tau_{1}+\tau_{2}}+\frac{1}{\tau_{3}} \\
& \tau_{i}=M_{1} a_{i}\left(\frac{O N}{100}\right)^{b_{i}}[\text { Fuel }]^{c_{i}}\left[O_{2}\right]^{d_{i}}[\text { Diluent }]^{e_{i}} \operatorname{Exp}\left(\frac{f_{i}}{M_{2} T}\right)
\end{aligned}
$$

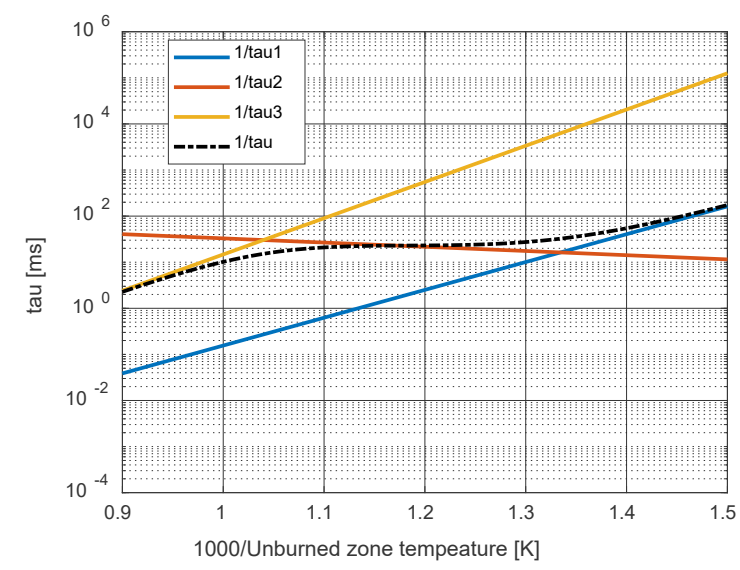

Figure 8.2 Induction time as a function of unburned zone temperature 


\subsubsection{Constraints of Knock, Turbine-Inlet Temperature and Scavenging Effect}

In this study, the model was simulated with the constraints of knock level, turbine-inlet temperature, and trapping ratio (Table 8.4). The knock constraint was realized by adjusting the spark timing within the SI turbulence combustion model. According to the research by Chun et al. [67], mean knock intensity can be correlated with unburned mass fraction at knock onset. In this study, the knock-limited spark advance (KLSA) was defined as the spark advance where the knock onset is at 10\% unburned mass fraction. If knock occurred in the simulation, remaining unburned fuel is forced to be burned in the next time step of knock onset. Turbine-inlet temperature was controlled to remain under $950^{\circ} \mathrm{C}$ (timeaverage value) by adjusting AFR. The scavenging effect was quantified by trapping ratio. The definition of trapping ratio is unburned non-fuel gas trapped in the cylinder normalized by the total mass of unburned non-fuel gas through intake valves into the cylinder, given in $8-4$. The lower limit of trapping ratio is $99 \%$.

Table 8.4. Model constraints of knock, turbine-inlet temperature, and trapping ratio

\begin{tabular}{ll}
\hline Model Constrains & Controlling Parameter \\
Unburn mass fraction at knock onset $\leq \mathbf{1 0 \%}$ & Spark Timing of SI Turbulence Model \\
Turbine-inlet Temperature $\leq \mathbf{9 5 0} \mathbf{C}^{\circ} \mathrm{C}$ & AFR \\
Trapping Ratio $\geq \mathbf{9 9 \%}$ & Cam Timing \\
\hline \hline
\end{tabular}

$$
\text { trapping ratio }=\frac{\text { mass }_{\text {trapped }}}{\text { mass }_{\text {total through intake valve into cylinder }}}
$$

\subsubsection{Atkinson Cycle Mechanism}

The mechanism design of Atkinson cycle engine is based on the research by Yang. et al.[68]. The geometric specification of the Atkinson cycle engine was constrained by matching the compression ratio, bore, and baseline engine. In this study, one Atkinson engine design with CR of 10.5 and OER of 1.5 was developed. The definition of OER is given in 8-5.

$$
O E R=\frac{E R}{C R}=\frac{V_{\text {ol }} \text { piston @ BDC after expansion }}{\text { Vol }_{\text {piston } @ B D C \text { after intake }}}
$$

One approach to simulate an Atkinson cycle in the 1-D environment is to create a look-up table of piston movement as a function of crank angle. This method ignores the characteristic of cranktrain kinetics. Another solution is to define the geometric specification of each component in the multi-link mechanism. The dynamics of the overexpanded mechanism can be better understood by developing a cranktrain model. This 
work utilized the second solution. Figure 8.3 is the cranktrain mechanism schematic of the Atkinson cycle model. The geometric specifications of the Atkinson cycle engine cranktrain are provided in Table 8.5.

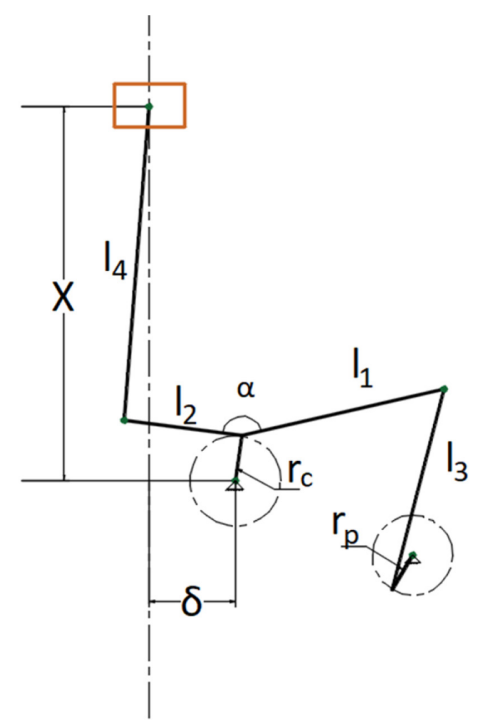

Figure 8.3. Schematic of the Atkinson cycle engine multi-link mechanism

Table 8.5. Geometric specifications of Atkinson cycle over-expanded mechanism with

\begin{tabular}{|c|c|}
\hline \multicolumn{2}{|c|}{ CR10.5, OER 1.5} \\
\hline CR & 10.5 \\
\hline ER & 15.8 \\
\hline OER & 1.50 \\
\hline Bore & $86 \mathrm{~mm}$ \\
\hline Compression & $86 \mathrm{~mm}$ \\
\hline Intake Stroke & $86 \mathrm{~mm}$ \\
\hline$l_{4}$ & $221.4 \mathrm{~mm}$ \\
\hline $\mathbf{l}_{2}$ & $83.1 \mathrm{~mm}$ \\
\hline$l_{1}$ & $164.6 \mathrm{~mm}$ \\
\hline $\mathbf{l}_{3}$ & $165.0 \mathrm{~mm}$ \\
\hline $\mathbf{r}_{\mathbf{c}}$ & $35.2 \mathrm{~mm}$ \\
\hline $\mathbf{r}_{\mathbf{p}}$ & $51.1 \mathrm{~mm}$ \\
\hline$\delta$ & $60 \mathrm{~mm}$ \\
\hline$\alpha$ & $159.9^{\circ}$ \\
\hline
\end{tabular}

With the provided mechanism specification, the piston location and in-cylinder volume as a function of crank angle is shown in Figure 8.4 and Figure 8.5. In Figure 8.4, an offset of $18^{\circ}$ can be seen between crank and piston location at top dead center firing. Offsets also exist in the other three top dead center (TDC) / bottom dead center's (BDC) position, respectively. Those differences result in the stroke durations, e.g., intake and compression 
strokes of the Atkinson cycle engine being $17^{\circ}$ and $21^{\circ}$ less than the baseline engine, respectively. Table 6 summarizes the geometric characteristics of two engines including the stroke length and volume/piston location at each $180^{\circ}$ from baseline TDC firing. As the geometric characteristics of the Atkinson cycle engine are different from the baseline engine, the cam phasing, valve lift, and spark timing utilized in the baseline engine should be adjusted before applied to the Atkinson cycle engine.

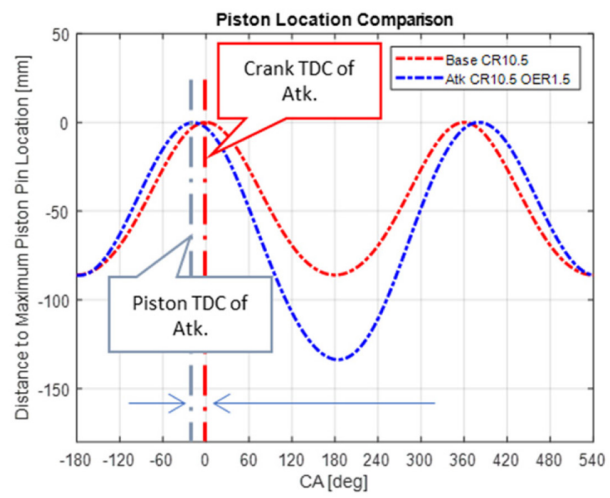

Figure 8.4. Piston movement as a function of crank angle of baseline and Atkinson cycle mechanism. (" 0 " of $\mathrm{x}$-axis is at crank angle of TDC Firing)

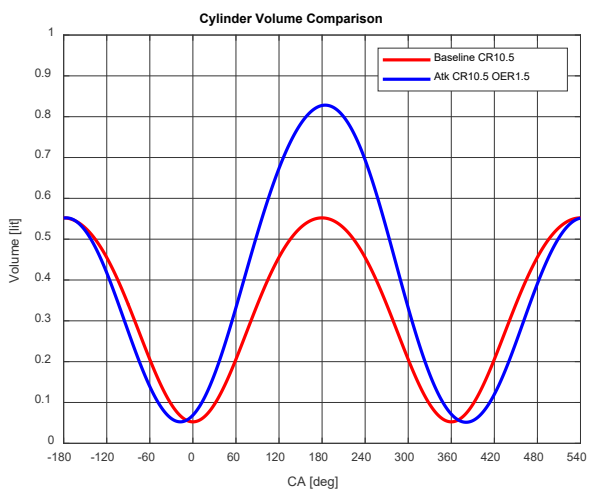

Figure 8.5. In-cylinder volume as a function of crank angle of baseline and Atkinson mechanism. (" 0 " of $\mathrm{x}$-axis is at crank angle of TDC Firing)

The objective of the adjustment is to compensate for the crank location difference at the same piston location due to the mechanism difference between two different engines. To maintain the consistency, spark timing and valve timing of the Atkinson cycle engine will use the same piston location as the baseline; however, the actual crank angle location of the Atkinson cycle engine is adjusted corresponding to the method mentioned in the following paragraph.

In this study, the adjustment refers to the method proposed by Yang et al. [68]. The spark timing of the Atkinson cycle engine was advanced by $18^{\circ} \mathrm{CA}$ than baseline based on the shift of TDC firing location. Cam timing adjustment depends on the crank angle of TDC/BDC. The shift of intake cam timing referred to the offset of TDC at gas exchange (GE) and BDC before compression (8-6); the shift of exhaust cam timing referred to the offset of BDC before exhaust stroke and TDC at GE (8-7). The duration of valve opening was scaled based on the actual stroke length of Atkinson cycle engine (8-8 and 8-9). 
Table 8.6. Geometry characteristics of baseline and Atkinson engine

\begin{tabular}{|c|c|c|c|}
\hline & Mechanism Type & Baseline & Atkinson \\
\hline & CR & 10.5 & 10.5 \\
\hline & ER & 10.5 & 15.8 \\
\hline & OER & 1.0 & 1.5 \\
\hline & Bore $[\mathrm{mm}]$ & 86.0 & 86.0 \\
\hline \multirow{4}{*}{ Stroke [mm] } & Compression & 86.0 & 86.0 \\
\hline & Expansion & 86.0 & 133.5 \\
\hline & Exhaust & 86.0 & 133.7 \\
\hline & Intake & 86.0 & 86.2 \\
\hline \multirow{4}{*}{ Volume [cc] } & BDC before Comp. & 552.1 & 552.1 \\
\hline & TDC Firing & 52.6 & 52.6 \\
\hline & BDC after Expansion & 552.1 & 828.1 \\
\hline & TDC Gas GE & 52.6 & 51.6 \\
\hline \multirow{4}{*}{$\begin{array}{c}\text { Piton Location } \\
\text { Crank Angle } \\
{\left[^{\circ}\right]}\end{array}$} & TDC Firing & 0 & -18.0 \\
\hline & BDC after Expansion & 180 & 184.0 \\
\hline & TDC GE & 360 & 380.3 \\
\hline & BDC after Intake & 540 & 544.3 \\
\hline \multirow{4}{*}{$\begin{array}{c}\text { Stroke } \\
\text { Duration in } \\
\text { Crank Angle } \\
{\left[^{\circ}\right]}\end{array}$} & Compression & 180 & 159 \\
\hline & Expansion & 180 & 202 \\
\hline & Exhaust & 180 & 196 \\
\hline & Intake & 180 & 163 \\
\hline \multicolumn{3}{|c|}{ Offset ${ }_{I M O P}=\frac{\left(T D C_{G E}+B D C_{\text {Intake }}\right)}{2}$} & $8-6$ \\
\hline \multicolumn{3}{|c|}{ Off set $_{E M O P}=\frac{\left(T D C_{G E}+B D C_{E x h a u s t}\right)}{2}$} & $8-7$ \\
\hline \multicolumn{3}{|c|}{ Scale $_{\text {Intake valve duration } / \text { lift }}=\frac{\text { Stroke }_{\text {Atk,Intake }}\left({ }^{\circ}\right)}{180}$} & $8-8$ \\
\hline \multicolumn{3}{|c|}{ Scale $_{\text {Exhaust valve duration / lift }}=\frac{\text { Stroke }_{\text {Atk, Exhaust }}\left({ }^{\circ}\right)}{180}$} & $8-9$ \\
\hline
\end{tabular}

The valve lift adjustment of exhaust and intake valve lift is shown in Figure 8.6. The valve opening duration of exhaust was modified by adding dwell at the maximum valve lift with $16^{\circ} \mathrm{CA}$ to match the exhaust stroke of the Atkinson cycle engine. The intake valve lift of the Atkinson cycle engine was scaled by 0.91 . Equation $8-8$ was used to scale the intake valve opening duration and intake valve lift. The results of valve timing and cam profile adjustment are listed in Table 8.7. 


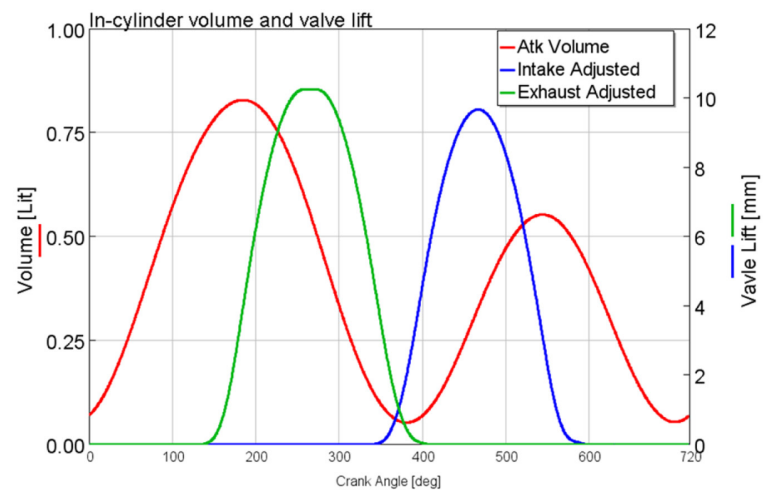

Figure 8.6. In-cylinder volume and valve lift of exhaust and intake cam as a function of crank angle of Atkinson cycle engine

Table 8.7. Valve timing and cam profile adjustment of Atkinson cycle engine

\begin{tabular}{lcc}
\hline \hline & Intake & Exhaust \\
Cam Timing Off set $\left[{ }^{\circ} \mathbf{C A}\right]$ & 5.9 & 6.1 \\
Scale $_{\text {valve duration } / \text { lift }[-]}$ & 0.91 & - \\
Cam Profile Dwell at max. valve lift $\left[{ }^{\circ} \mathbf{C A}\right]$ & - & 16 \\
\hline \hline
\end{tabular}

\subsection{Results and Discussion}

The major characteristic of an Atkinson cycle engine is the over-expansion in the power stroke. In Figure 8.7, the calculation of gross indicated work starts from point "a" which represents the beginning of compression stroke and terminates at "c". The gross indicated work is broken down into the portion of non-over-expansion (blue, $a \rightarrow b$ ) and overexpansion (yellow, $b \rightarrow c$ ). The remaining cycle $(\mathrm{red}, \mathrm{c} \rightarrow \mathrm{a}$ ) is the portion of pumping work. With the definition of over-expansion indicated work of the Atkinson cycle engine, indicated efficiency contributed by the over-expansion can be calculated separately from the total net indicated efficiency. 


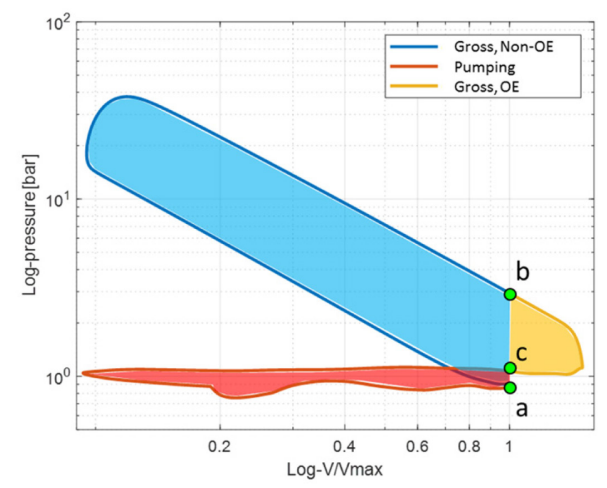

Figure 8.7. Gross loop and pumping loop in an Atkinson cycle $\log \mathrm{P}-\log \mathrm{V} / \mathrm{V}_{\max }\left(\mathrm{V}_{\max }\right.$ is the maximum in-cylinder volume during intake stroke)

Net indicated efficiency of the Atkinson cycle engine is given by Equation 8-10. The OE indicated efficiency $\left(\eta_{\text {indicated,OE }}\right.$, Equation 8-11) quantifies the indicated work during over expansion normalized by the fuel energy. The non-OE indicated efficiency ( $\eta_{\text {indicated, non-OE,net }}$ Equation 8-12, quantifies the indicated work of non-OE portion normalized by the fuel energy (non-OE indicated efficiency, $\eta_{\text {indicated, }}$ non-oE,net $)$. As the non-OE indicated efficiency excludes over-expansion, it is equivalent to the indicated efficiency of the baseline engine. The expression for normalized pumping work is listed in Equation 8-13.

$$
\begin{array}{lc}
\eta_{\text {net indicated }}=\frac{\text { Work }_{G_{\_} N o n_{-} O E}+\text { Work }_{G_{-} O E}+\text { Work }_{\text {Pumping }}}{\text { Fuel Energy }} & 8-10 \\
\eta_{\text {indicated,OE }=\frac{\text { Work }_{G_{-} O E}}{\text { Fuel Energy }}} & 8-11 \\
\eta_{\text {indicated,non-OE,net }}=\frac{\text { Work }_{G_{-} \text {Non_oE }}+\text { Wor } k_{\text {Pumping }}}{\text { Fuel Energy }} & 8-12 \\
\eta_{\text {pumping loss }}=\frac{\text { Work }_{\text {Pumping }}}{\text { Fuel Energy }} & 8-13
\end{array}
$$

In this study, intake and exhaust cam timing sweeps were conducted with 36 points as shown in Figure 8.8 at 1500rpm, 13bar IMEPnet and 3500rpm, 20bar IMEPnet. In the US06 and FTP75 driving cycle, the operating condition of 1500rpm 13bar IMEPnet is representative of a knock limited condition at high fuel consumption. The operating condition of 3500rpm 20bar IMEPnet is a high load condition with a constraint on exhaust temperature at the highest speed of the US06 driving cycle. In this study, cam timing is expressed by the intake cam maximum opening position (IMOP) and exhaust cam maximum opening position (EMOP). As mentioned earlier of the cam timing adjustment, 
the actual cam timing of the Atkinson cycle engine requires a conversion as listed in Table 8.7. The optimized cam timing was at the condition with the highest net indicated efficiency with constraints. In the developed model, the simulation includes predictive combustion, in-cylinder heat transfer, and knock integral models with the same calibration between the baseline and Atkinson cycle engines. Woschni's correlation [89] was used to compute engine in-cylinder heat-transfer. The combustion model used in this study is an SI turbulence model. Both speed load conditions were simulated with spark timing (knocklimited) controller with the knock model $[22,66,90]$ and AFR (turbine-inlet temperaturelimited) controller (Table 8.4).

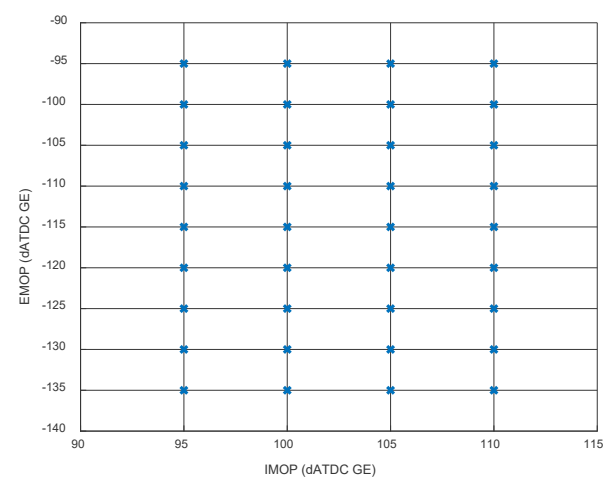

Figure 8.8. Intake and exhaust cam timing sweep for optimization

Figure 8.9 to Figure 8.12 show the net indicated efficiency contour maps for the two engines at 1500rpm 13bar IMEPnet and 3500rpm 20bar IMEPnet. The plus sign in each figure represents the highest net indicated efficiency with constraints. The net indicated efficiency of the Atkinson cycle engine was improved by more than 6\% (absolute value) compared to the baseline engine at both load conditions of 13bar and 20bar IMEPnet. It can be observed that the cam timing of peak net indicated efficiency were located at the highest valve overlap condition for baseline engine at both operating conditions. However, at high valve overlap, some unburned fuel can be delivered to exhaust and catalytic converter via the scavenging effect. In addition, at the same valve overlap the scavenging effect is not the same due to the different piston motion between two engines. Therefore, a trapping ratio of charge gas of $99 \%$ is set as the constraint to limit the scavenging effect for both engines at 1500 rpm 13bar IMEPnet and 3500rpm 20bar IMEPnet. The results of the trapping ratio of both engines are included in the appendix of Chapter 8.11. Optimized cam timing for baseline is summarized in Table 8.8.

For the Atkinson cycle engine, the optimized cam timing at 1500rpm 13bar IMEPnet was the same as the baseline engine. Optimized intake and exhaust cam timing at 3500rpm 20bar IMEPnet was $5^{\circ} \mathrm{CA}$ retarded and $5^{\circ} \mathrm{CA}$ advanced, respectively. It can be observed that the net indicated efficiency of the Atkinson cycle engine is less sensitive to the variation in cam phasing compared to the Atkinson cycle engine. The maximum to the 
minimum value of net indicated efficiency is $4 \%$ and $6 \%$ for the baseline engine at $13 \mathrm{bar}$ and 20bar, respectively. However, the maximum to the minimum value of the Atkinson cycle engine net indicated efficiency is $1 \%$ and $2 \%$ at $13 \mathrm{bar}$ and $20 \mathrm{bar}$, respectively. The following sections will discuss and compare the combustion performance and knock characteristics between two engines based on the results with cam optimized condition at 1500rpm 13bar IMEPnet and 3500rpm 20bar IMEPnet.

Table 8.8. Optimized cam timing for baseline engine and Atkinson cycle engine at selected speed/load

\begin{tabular}{|c|c|c|c|}
\hline & $\begin{array}{l}\text { Optimized Cam } \\
\text { Timing }\end{array}$ & Baseline & Atkinson \\
\hline \multirow{2}{*}{$\begin{array}{l}\text { 1500rpm 13bar } \\
\text { IMEPnet }\end{array}$} & IMOP $\left[{ }^{\circ} \mathbf{a T D C}\right.$ GE] & 105 & 105 \\
\hline & EMOP $\left[{ }^{\circ} \mathbf{a T D C}\right.$ GE] & -110 & -110 \\
\hline \multirow{2}{*}{$\begin{array}{l}\text { 3500rpm 20bar } \\
\text { IMEPnet }\end{array}$} & IMOP $\left[{ }^{\circ}\right.$ aTDC GE $]$ & 100 & 95 \\
\hline & EMOP $\left[{ }^{\circ} \mathbf{T T D C}\right.$ GE] & -110 & -115 \\
\hline
\end{tabular}

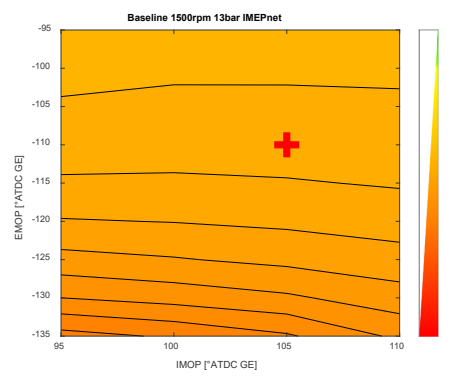

Figure 8.9. Baseline engine net indicated efficiency at 1500rpm 13bar IMEPnet

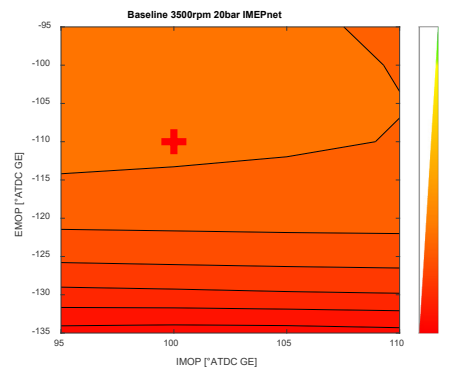

Figure 8.11. Baseline engine net indicated efficiency at 3500rpm 20bar IMEPnet

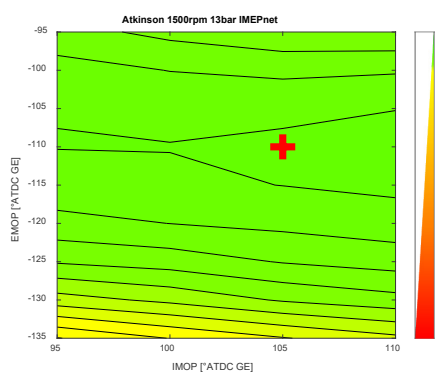

Figure 8.10. Atkinson cycle engine net indicated efficiency at $1500 \mathrm{rpm} \underline{13 \mathrm{bar}}$ IMEPnet

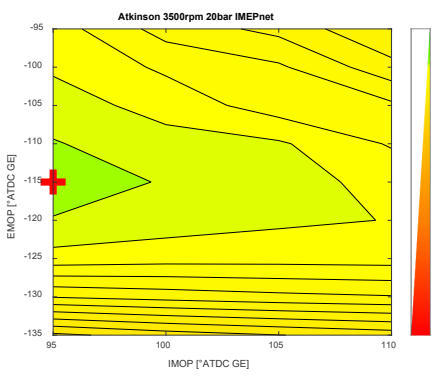

Figure 8.12. Atkinson cycle engine net indicated efficiency at $3500 \mathrm{rpm} 20 \mathrm{bar}$ IMEPnet 


\subsubsection{Baseline vs. Atkinson cycle engine @ 1500rpm 13bar IMEPnet}

The results of the baseline engine and Atkinson cycle engines include the knock propensity comparison and the investigation at the optimized condition. At the investigation of knock propensity, two engines were simulated at the same speed load, cam timing, and spark timing. At the investigation of optimized condition, two engines were both optimized with the same constraints.

\subsubsection{Knock Propensity @ 1500rpm 13bar IMEPnet}

In this study, the knock metric is the unburned fuel at knock onset. At the same combustion phasing, speed, and load condition, a higher value of unburned fuel at knock onset represents a higher knock propensity.

To investigate the knock propensity of baseline and Atkinson cycle engine, the operating condition of 1500rpm 13bar IMEPnet was selected with the same cam timing of IMOP $95^{\circ}$ aTDC GE and EMOP $-95^{\circ}$ aTDC GE. Combustion phasing of CA50 was controlled at $14.8^{\circ}$ aTDC when baseline engine knock onset occurred at $10 \%$ mass of unburned fuel. The selected cam timing and spark timing referred to the highest net indicated efficiency of baseline engine at 1500 rpm 13bar IMEPnet. As the turbine inlet temperature of both engines was lower than the threshold of $950^{\circ} \mathrm{C}$ at this operating condition, both engines were operated at the stoichiometric condition.

Table 8.9 lists the results of the baseline and Atkinson cycle engine at the same combustion phasing. It shows the unburn mass fraction of fuel at knock onset of the Atkinson is $8.1 \%$ lower than the baseline engine. Knock onset of the Atkinson occurs at $4.7^{\circ} \mathrm{CA}$ later than baseline. The knock onset difference can be also observed in Figure 8.13 by comparing the sudden pressure rise at the beginning of expansion stroke. The sudden pressure rise following the knock onset was due to the instant combustion of unburned fuel.

Table 8.9. Results of baseline and Atkinson cycle engine for knock propensity investigation at $\underline{1500 \mathrm{rpm}} \underline{13 \mathrm{bar}}$ IMEPnet, CA50 $=\underline{14.8^{\circ} \mathrm{aTDC}}$

\begin{tabular}{ccc}
\hline \hline & Baseline & Atkinson \\
Speed [rpm] / Load [IMEPnet] & \multicolumn{2}{c}{$1500 / 13$} \\
IMOP/EMOP [ ${ }^{\circ}$ aTDC GE] & \multicolumn{2}{c}{$95 /-95$} \\
CA50 [ ${ }^{\circ}$ aTDC] & 24.4 & 29.1 \\
Location of Knock Onset [ ${ }^{\circ}$ aTDC] & 10.0 & 1.9 \\
Unburned mass fraction of fuel @ knock onset [\%] & 40.7 & 45.7 \\
Total Net indicated efficiency [\%] & - & 4.9 \\
OE indicated efficiency [\%] & 18.1 & 16.8 \\
Burn Duration 10\%-90\% & & \\
\hline \hline
\end{tabular}




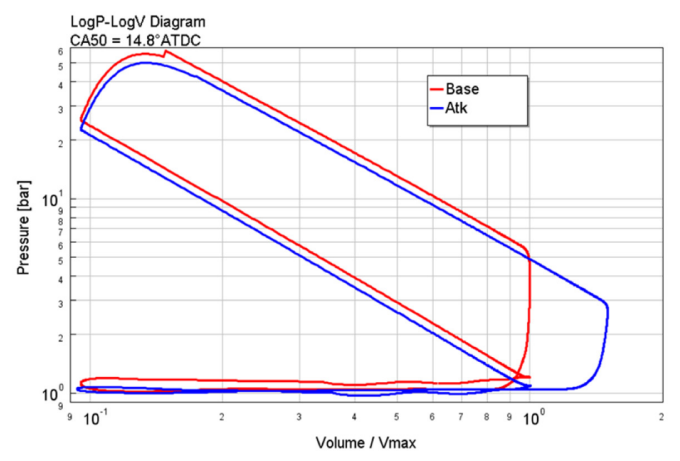

Figure 8.13. $\log \mathrm{P}-\log \mathrm{V} / \mathrm{V}_{\max }$ of baseline and Atkinson cycle engine for knock propensity investigation, at $\underline{1500 \mathrm{rpm}} \underline{13 \mathrm{bar}}$ IMEPnet, $\mathrm{CA} 50=\underline{14.8^{\circ} \mathrm{aTDC}}\left(\mathrm{V}_{\max }\right.$ is the maximum in-cylinder volume during intake stroke)

As the unburned zone temperature has the strongest dependency on the induction time (Equation 8-3), the engine with a lower unburned zone temperature will have a lower propensity to knock. In Figure 8.14, the unburned zone temperature between baseline and Atkinson cycle engine was similar from the compression stroke to knock onset resulting in similar induction time for both engines. Point " $A$ " and point "B" was selected based on the crank angle location of $-30^{\circ}$ aTDC to baseline knock onset $\left(24.4^{\circ}\right.$ aTDC) to represent the period of highly sensitive to the knock induction time integral. The relation of point " $\mathrm{A}$ " and point "B" at volume-based and crank angle-based location is listed in Table 8.10. In Figure 8.15, it can be observed that the absolute piston speed of the Atkinson cycle engine in the intake and compression stroke was higher than the baseline engine. The higher piston speed resulted in a $4 \%$ (relatively) longer duration from $\mathrm{A}$ to $\mathrm{B}$ of baseline than the Atkinson cycle engine. According to 8-1, the duration of induction time calculation is another factor in the knock induction time integral calculation. The higher piston speed reduces the residence time of unburned gas and resulted in a lower induction time integral and a lower knock level at knock onset.

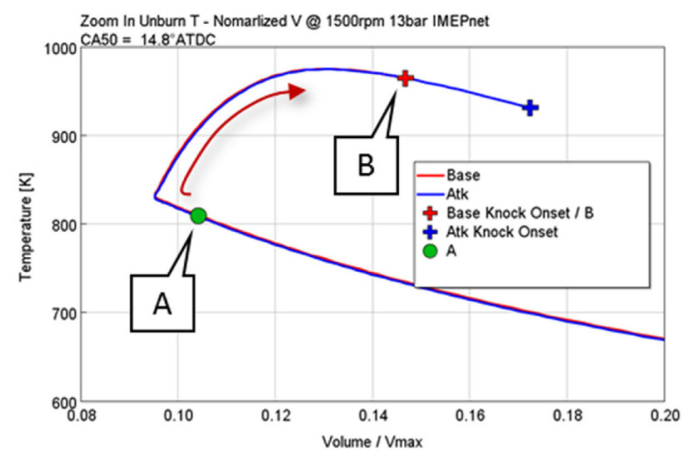

Figure 8.14. Unburned zone temperature of baseline and Atkinson cycle engine vs. normalized volume, at $\underline{1500 \mathrm{rpm}} \underline{13 \mathrm{bar}} \mathrm{IMEPnet}, \mathrm{CA} 50=\underline{14.8^{\circ} \mathrm{aTDC}}\left(\mathrm{V}_{\max }\right.$ is the maximum in-cylinder volume during intake stroke) 


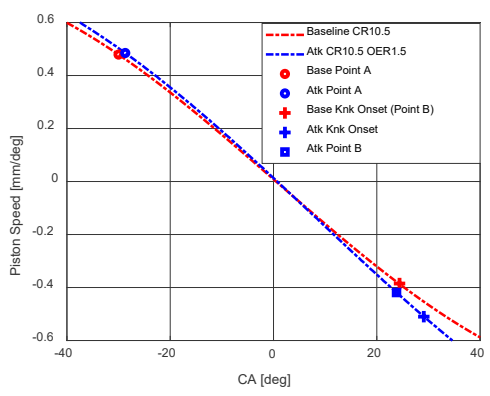

Figure 8.15. Piston speed as a function of crank angle of baseline and Atkinson cycle engine at $\underline{1500 \mathrm{rpm}} \underline{13 \mathrm{bar}}$ IMEPnet, CA50 $=\underline{14.8^{\circ} \mathrm{aTDC}}$

Table 8.10. Normalized volume, crank angle-based location and timing ratio of $\tau_{A}$ to $\tau_{B}$ between baseline engine and Atkinson cycle engine

\begin{tabular}{cccccc}
\hline \hline & $\begin{array}{c}\text { Normalized } \\
\text { Volume }\end{array}$ & $\begin{array}{c}\text { Base Crank } \\
\text { Angle [ }{ }^{\circ} \text { ATDC] }\end{array}$ & $\begin{array}{c}\text { Atk Crank } \\
\text { Angle [ }{ }^{\circ} \text { ATDC] }\end{array}$ & $\begin{array}{c}\text { Induction Time } \\
\text { Integral @ baseline } \\
\text { knock onset }\end{array}$ & $\frac{\boldsymbol{t}_{A-B, \text { base }}}{\boldsymbol{t}_{\boldsymbol{A}-\boldsymbol{B}, \text { atk }}}$ \\
A & 0.17 & -30.0 & -28.7 & 1.00 & 1.04 \\
B & 0.15 & 24.4 & 23.8 & 0.85 & \\
\hline \hline
\end{tabular}

A comparison of the induction time integrals is provided in Figure 8.16. The induction integral of the baseline engine is higher from $-30^{\circ} \mathrm{aTDC}$, and the integral calculation was terminated at knock onset. As a result of the faster piston speed of the Atkinson cycle engine, knock onset of the baseline engine occurs at $4.7^{\circ} \mathrm{CA}$ earlier than the Atkinson cycle engine. In Figure 8.16, it can be observed that the induction time integral of the Atkinson cycle engine at baseline knock onset was 0.85 . In addition, unburned fuel mass fraction at knock onset of the Atkinson cycle engine is $8.1 \%$ lower than the baseline engine, as shown in Table 8.9. Based upon the lower unburned fuel mass fraction at knock onset and retarded knock onset of Atkinson cycle engine, it can be concluded that the Atkinson cycle engine has a lower knock level than the baseline engine at 1500rpm 13bar IMEPnet with same cam timing, and CA50.

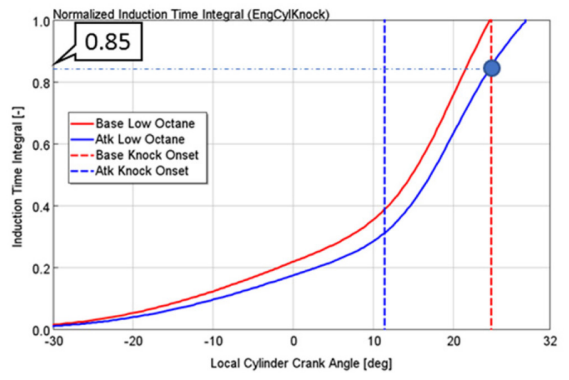

Figure 8.16. Overall $\tau$ ratio (baseline and Atkinson cycle engine) at $\underline{1500 \mathrm{rpm}}, \underline{13 \mathrm{bar}}$ IMEPnet, $\mathrm{CA} 50=\underline{14.8^{\circ} \mathrm{aTDC}}$ 


\subsubsection{Net Indicated Efficiency and Energy Loss Breakdown @ 1500rpm 13bar IMEPnet}

The simulation of the Atkinson cycle engine was performed with the 36-point cam phasing sweep at 1500rpm 13bar IMEPnet. The optimized case of the Atkinson cycle engine was compared with the baseline optimized condition at the same operating conditions as in Table 8.11. Figure 8.17 is the $\log \mathrm{PV}$ diagram comparing the baseline to the Atkinson cycle engine. As both engines were operated at KLSA, the engine with advanced combustion phasing (CA50) has a higher knock mitigating capability. As Table 8.11 shows, CA50 of the Atkinson cycle engine is $5.9^{\circ} \mathrm{CA}$ earlier than the baseline engine at KLSA. Figure 8.17 also indicated the knock onset where the sudden pressure rises in the expansion stroke. The " $\mathrm{V}_{\max }$ " used in Figure 8.5 represents the maximum in-cylinder volume during the intake stroke.

Table 8.11. Results of baseline and Atkinson cycle engine at optimized cam timing,

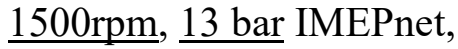

\begin{tabular}{ccc}
\hline \hline & Baseline & Atkinson \\
IMOP $\left[{ }^{\circ}\right.$ aTDC GE] & 105 & 105 \\
EMOP $\left[{ }^{\circ}\right.$ aTDC GE] & -110 & -110 \\
$\boldsymbol{\lambda}$ & 1.0 & 1.0 \\
Location of Knock Onset [ ${ }^{\circ}$ aTDC] & 28.0 & 21.1 \\
Combustion Phasing [ ${ }^{\circ}$ aTDC of CA50] & 18.2 & 12.3 \\
Unburned mass fraction of fuel @ knock onset & 10.0 & 10.0 \\
Total Net indicated efficiency [\%] & 40.2 & 46.5 \\
OE indicated efficiency [\%] & - & 4.9 \\
Trapping Ratio [\%] & $99.2 \%$ & $99.0 \%$ \\
\hline \hline
\end{tabular}

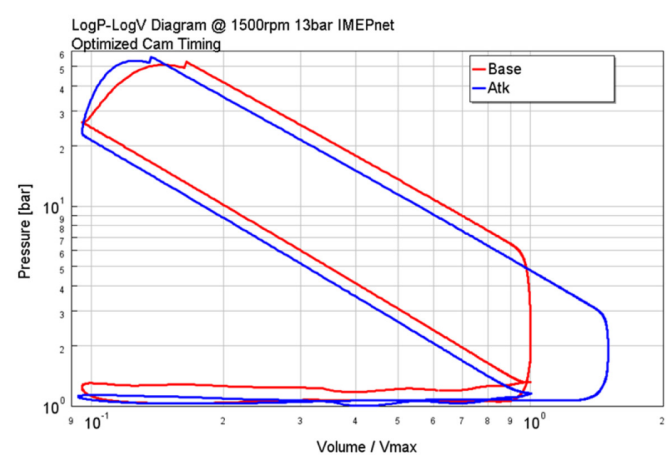

Figure 8.17. $\log \mathrm{P}-\log \mathrm{V} / \mathrm{V}_{\max }$ of baseline and Atkinson cycle engine at $1500 \mathrm{rpm}$ 13bar IMEPnet, knock limited spark timing, optimized cam timing $\left(\mathrm{V}_{\max }\right.$ is the maximum in-cylinder volume during intake stroke) 
Atkinson cycle engine gains the indicated efficiency benefit from the over-expansion initially. As load increases, over-expansion brings other benefits including the AFR closer to stoichiometric condition, combustion phasing close to MBT, as well as lower pumping loss.

Figure 8.18 shows the bar chart comparing the total net indicated efficiency of baseline and Atkinson cycle engine With the definition of over-expansion efficiency (OE-efficiency, 8-11), net indicated efficiency of Atkinson cycle engine is separated into portions of nonover-expansion (non-OE) and over-expansion (OE), which is $41.6 \%$ and $4.9 \%$, respectively. Figure 8.18 indicates that the Atkinson cycle engine does not only benefits from OE efficiency, but also has a $1.4 \%$ increase (absolute value) from the baseline nonOE indicated efficiency.

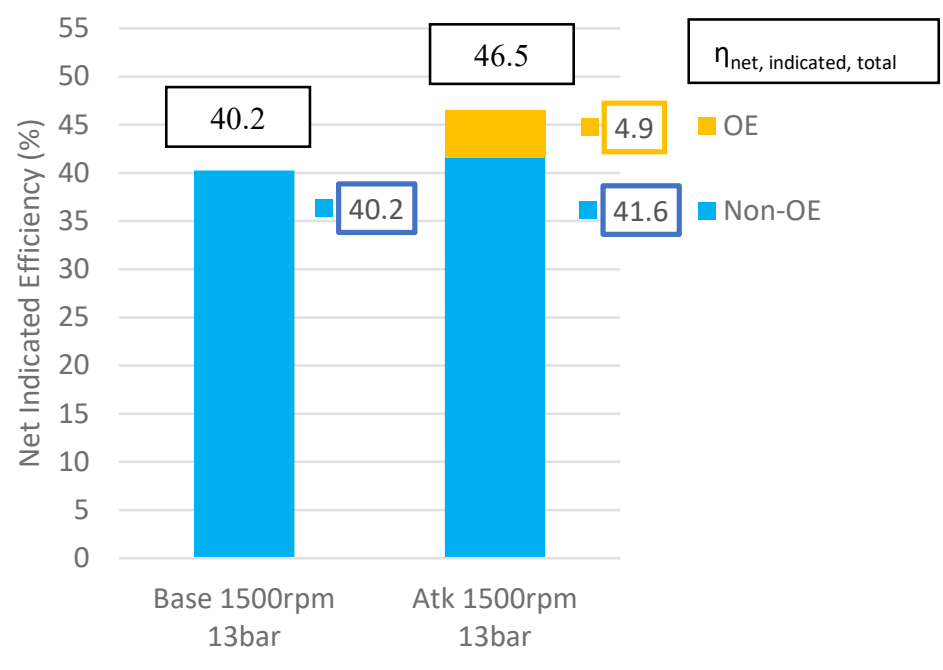

Figure 8.18. Net indicated efficiency of baseline and Atkinson cycle engine at $1500 \mathrm{rpm}$, 13bar IMEPnet, optimized cam timing

A breakdown of the energy losses was conducted to investigate the difference between $\mathrm{OE}$ indicated efficiency and non-OE indicated efficiency. The energy loss calculations follow the flow chart as given in Figure 8.19. The calculation of each factor is shown from 8-14 to 8-18. Pumping loss was determined by the pumping work normalized by the fuel energy (8-14). Calculation of other energy losses from factor 2 to factor 5 is shown between 8-15 and 8-18, respectively. For example, the calculation of AFR loss (8-15) compared the difference in net indicated efficiency between stoichiometric condition and fuel enrichment condition with turbine inlet temperature limit. 
Factor 1. Pumping
- Calculation is based on Original Case (Equation 13)

$\sqrt{2}$

Factor 2. AFR Loss (fuel Enrichment of turbine inlet temperature limit)

- Stoichiometric Condition - Fuel Enrichment Condition (Equation 14)

Factor 3. Combustion Phasing

- Optimized Combustion Phasing - Stoichiometric Condition (Equation 15)

Factor 4. Combustion Duration

- Optimized Combustion Duration - Optimized Combustion Phasing (Equation 16)

Factor 5. Heat Transfer

- Condition of Adiabatic and Constant Volume Combustion - Optimized Combustion Duration (Equation 17)

Figure 8.19. Flow chart of energy loss calculation

$$
\begin{aligned}
& \text { LosS }_{\text {pumping }}=\text { Work }_{\text {Pumping }} / \text { Fuel Energy } \\
& \text { LosS }_{A F R}=\eta_{\text {stoichiometric }}-\eta_{\text {fuel enriched original case }} \\
& \text { Loss }_{\text {comb.phasing }}=\eta_{\text {opt.comb.phasing }}-\eta_{\text {stoichiometric }} \\
& \text { LoSS }_{\text {comb.duration }}=\eta_{\text {opt.comb duration }}-\eta_{\text {opt.comb.phasing }} \\
& \text { LoSS }_{H T}=\eta_{H T \text { off }}-\eta_{\text {opt.comb duration }}
\end{aligned}
$$

At 1500rpm 13bar IMEPnet, the pumping loss and combustion duration loss for baseline engine and Atkinson cycle engine is less than $0.1 \%$. In addition, the turbine-inlet temperature is lower than the upper limit of $950^{\circ} \mathrm{C}$. Both engines were simulated under stoichiometric condition with no energy loss due to fuel enrichment $\left(\operatorname{Loss}_{A F R}=0\right)$.

Combustion phasing loss and heat transfer loss of both engines at 1500rpm 13bar IMEPnet are shown in Figure 8.20. As the CA50 of the Atkinson cycle engine is closer to MBT condition (see Table 8.11), the combustion phasing loss of the Atkinson cycle engine is 
1.7\% lower than the baseline engine. In Figure 8.20, heat transfer loss of the Atkinson cycle engine is $1.4 \%$ higher than the baseline engine. As the expansion stroke of the Atkinson cycle engine is much longer than the baseline, the Atkinson cycle engine has extra heat transfer losses during the period of over-expansion. As the extra heat transfer of the Atkinson cycle engine occurred at the over-expansion period, the HT loss does not affect non-OE indicated efficiency $\left(\eta_{\text {indicated, non-OE,net }}\right)$.

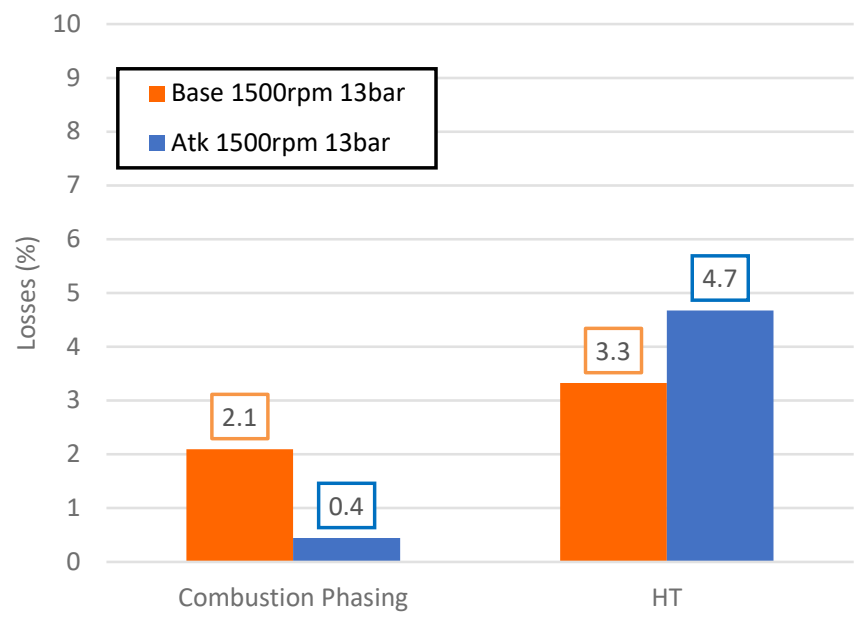

Figure 8.20. Energy loss of baseline and Atkinson cycle engine at $\underline{1500 \mathrm{rpm}}, \underline{13 \mathrm{bar}}$ IMEPnet,optimized cam timing

Therefore, at the operating condition of 1500rpm 13bar IMEPnet, the Atkinson cycle engine benefits from both $\mathrm{OE}$ portion and non-OE portion. The $\eta_{\text {indicated,OE }}$ and $\eta_{\text {indicated, non-OE,net }}$ of the Atkinson cycle engine was $4.9 \%$ and $1.4 \%$ higher compared to the baseline engine, respectively, as shown in Table 8.12. The non-OE indicated efficiency was mainly affected by the lower combustion phasing loss with the lower knock propensity. The total net indicated efficiency of the Atkinson cycle engine is $15.7 \%$ (relatively) higher than the baseline.

Table 8.12. Indicated efficiency improvement of Atkinson cycle engine at $\underline{1500 \mathrm{rpm}}$, 13bar IMEPnet, optimized cam timing

\begin{tabular}{cc}
\hline \hline Indicated Efficiency Improvement of Atkinson Cycle Engine \\
Over-expansion work (absolute increase) & $4.9 \%$ \\
Non-over-expansion work (absolute increase) & $1.4 \%$ \\
Total net indicated efficiency (relative increase) & $15.7 \%$ \\
\hline \hline
\end{tabular}




\subsubsection{Baseline vs. Atkinson cycle engine @ 3500rpm 20bar IMEPnet}

Another set of simulations were performed at 3500rpm 20bar IMEPnet with the 36-point cam phasing sweep. The model was constrained by $10 \%$ unburned fuel mass fraction at knock onset and $950^{\circ} \mathrm{C}$ of turbine-inlet temperature. An optimized case of the Atkinson cycle engine was selected to compare with the baseline optimized condition at the same speed and load condition as Table 8.13 shows. In Table 8.13, both engines were operated rich of stoichiometric mixture due to the constraint of turbine-inlet temperature $\left(950^{\circ} \mathrm{C}\right)$. The Atkinson cycle engine $(\lambda=0.96)$ operated closer to stoichiometric than the baseline engine $(\lambda=0.85)$, which means the Atkinson cycle engine was less constrained by the turbine-inlet temperature.

At 3500rpm 20bar IMEPnet, the CA50 of baseline and Atkinson cycle engines are $12^{\circ} \mathrm{aTDC}$ and $10^{\circ} \mathrm{aTDC}$, respectively. Since both engines were operated rich of stoichiometric due to the exhaust temperature constraint, an advanced combustion phasing was reached before knock onset, compared to the condition at 1500rpm 13bar IMEPnet (Table 8.11).

Table 8.13. Results of baseline and Atkinson cycle engine at optimized cam timing, 3500rpm, 20 bar IMEPnet,

\begin{tabular}{|c|c|c|}
\hline & Baseline & Atkinson \\
\hline IMOP $\left[{ }^{\circ} \mathbf{a T D C}\right.$ GE] & 100 & 95 \\
\hline EMOP $\left[{ }^{\circ} \mathbf{a T D C}\right.$ GE] & -110 & -115 \\
\hline$\lambda$ & 0.85 & 0.96 \\
\hline Temperature@ Turbine Inlet $\left[{ }^{\circ} \mathrm{C}\right]$ & 950 & 950 \\
\hline Location of Knock Onset $\left[{ }^{\circ}\right.$ aTDC] & 23.4 & 20.0 \\
\hline Combustion Phasing [ ${ }^{\circ} \mathrm{aTDC}$ of CA50] & 12.3 & 10.0 \\
\hline Unburned mass fraction of fuel @ knock onset & 10.0 & 10.0 \\
\hline Total Net indicated efficiency [\%] & 36.2 & 46.1 \\
\hline OE indicated efficiency [\%] & - & 4.4 \\
\hline Trapping ratio $[\%]$ & 99.5 & 99.2 \\
\hline
\end{tabular}

\subsubsection{Net Indicated Efficiency and Energy Loss Breakdown @ 3500rpm 20bar IMEPnet}

Figure 8.21 indicates non-OE and $\mathrm{OE}$ indicated efficiency of the Atkinson cycle engine is $41.7 \%$ and $4.4 \%$, respectively. Non-OE indicated efficiency of Atkinson cycle engine is $5.5 \%$ higher than baseline (absolute value). The efficiency difference of non-OE indicated efficiency is higher compared to the cases of 1500rpm 13bar IMEPnet. 


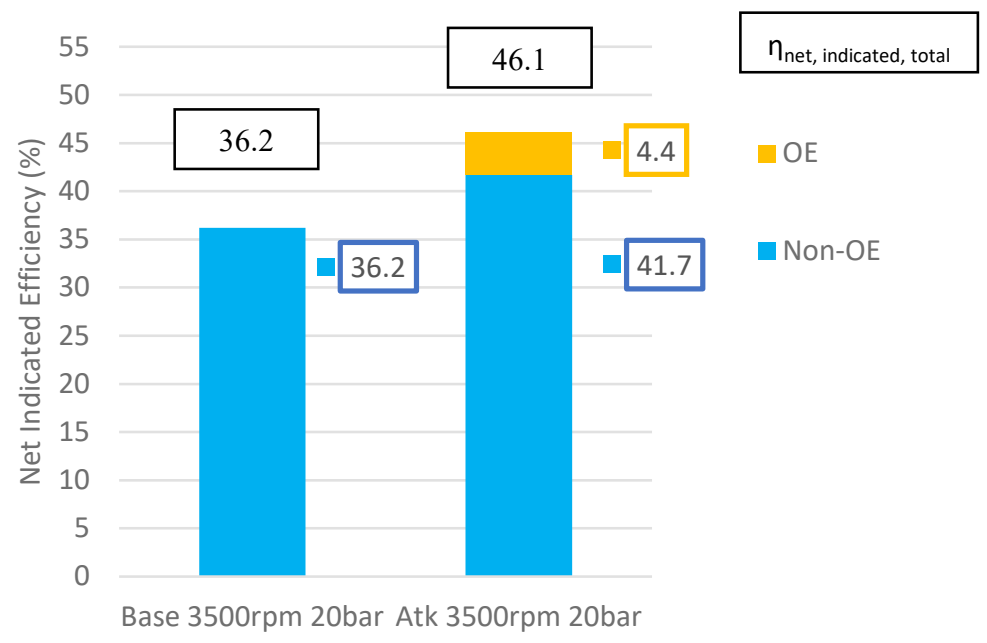

Figure 8.21. Net indicated efficiency of baseline and Atkinson cycle engine at 3500rpm, 20bar IMEPnet, optimized cam timing

In Figure 8.22, a breakdown chart is provided to quantify the energy losses including pumping work, AFR, combustion phasing, combustion duration, and heat transfer. At 3500rpm 20bar IMEPnet, the quantifying method of the energy loss breakdown follows the same flow chart (Figure 8.19) used in 1500rpm 13bar IMEPnet. Figure 8.22 indicates that the non-OE energy loss difference between two different engines are mainly from fuel enrichment $(\Delta=4.4 \%)$. It also includes lower combustion phasing and combustion duration which are $0.6 \%$, and $0.2 \%$, respectively.

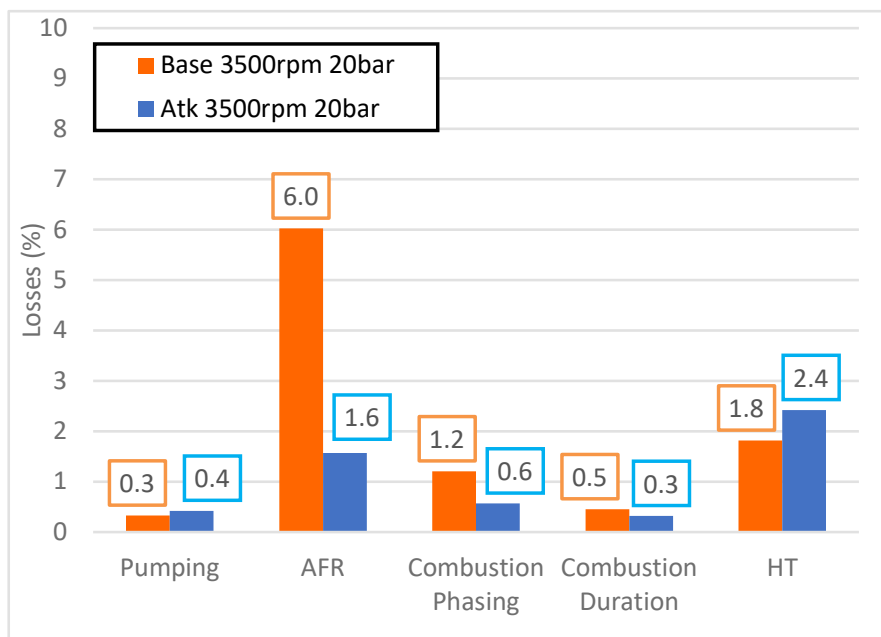

Figure 8.22. Efficiency loss of baseline and Atkinson cycle engine at $\underline{300 \mathrm{rpm}}, \underline{20 \mathrm{bar}}$ IMEPnet, optimized cam timing 
Atkinson cycle engine has lower fuel enrichment loss due to a decrease of in-cylinder temperature during the over-expansion period. In Figure 8.23, the in-cylinder temperature of both two engines was compared during the power stroke with the same speed load combustion phasing, cam timing and lambda as shown in Table 8.14. In Figure 8.23, the in-cylinder temperature is compared between two engines from the beginning of power stroke to EVO based on the operating condition of Table 8.14 listed. The in-cylinder temperature of the Atkinson cycle engine was further reduced during the over-expansion period. The in-cylinder temperature of the Atkinson cycle engine at BDC was decreased by $108 \mathrm{~K}$ compared to the temperature of the baseline engine at BDC.

With the effect of in-cylinder temperature decrease during over-expansion, the mixture of the Atkinson cycle engine was less fuel enriched $\left(\lambda_{A t k}=0.96\right)$ compared to the baseline engine $\left(\lambda_{\text {Base }}=0.85\right)$ at the same turbine inlet temperature constraint at $950^{\circ} \mathrm{C}$.

Table 8.14. Results of baseline and Atkinson cycle engine for exhaust temperature investigation at $\underline{3500 \mathrm{rpm}} \underline{20 \mathrm{bar}}$ IMEPnet, Lambda $=\underline{1.0}$

\begin{tabular}{ccc}
\hline \hline & Baseline & Atkinson \\
Speed [rpm] / Load [IMEPnet] & \multicolumn{2}{c}{$3500 / 20$} \\
IMOP/EMOP [ ${ }^{\circ}$ aTDC GE] & \multicolumn{2}{c}{$95 /-115$} \\
Lambda [-] & \multicolumn{2}{c}{1.0} \\
CA50 [ ${ }^{\circ}$ aTDC] & \multicolumn{2}{c}{12.0} \\
In-Cylinder Temperature @ EVO [K] & 1658 & 1550 \\
\hline \hline
\end{tabular}

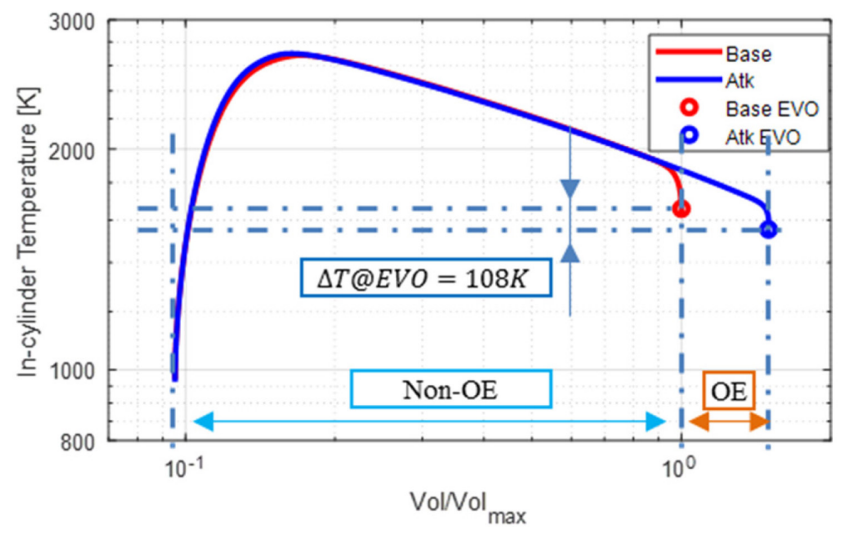

Figure 8.23. $\log \mathrm{T}-\mathrm{Log} \mathrm{V} / \mathrm{V}_{\max }$ of power stroke at $3500 \mathrm{rpm} 20 \mathrm{bar}$ IMEPnet, at same combustion phasing, cam timing, and Lambda $\left(\mathrm{V}_{\max }\right.$ is the maximum in-cylinder volume during intake stroke)

Figure 8.24 shows the optimized case log-PV diagram of baseline and Atkinson cycle engines at 3500rpm 20bar IMEPnet. From the definition of the Atkinson cycle engine pumping loop, the starting point of the pumping is at the location where $\mathrm{V} / \mathrm{V}_{\max }=1.0$. In 
Figure 8.24, it can be observed that the boost pressure of the Atkinson cycle engine is $20 \mathrm{kPa}$ lower than the baseline engine due to lower air consumption and less boost pressure requirement at the same load condition.

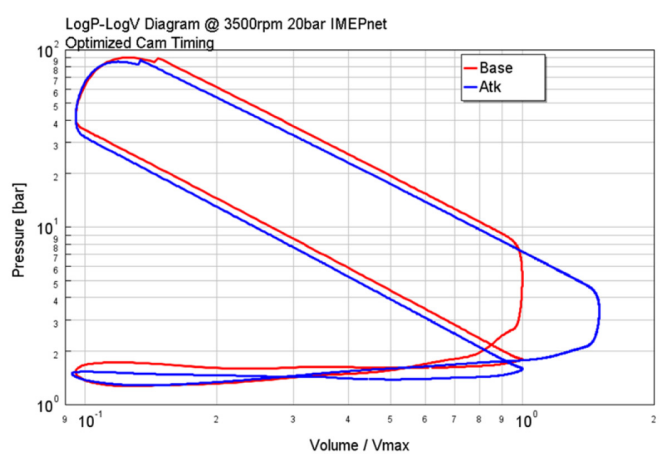

Figure 8.24. $\log \mathrm{P}-\log \mathrm{V} / \mathrm{V}_{\max }$ diagram of baseline and Atkinson cycle engine at $\underline{3500 \mathrm{rpm}} 20 \mathrm{bar}$ IMEPnet, knock limited spark timing, cam timing optimized ( $\mathrm{V}_{\max }$ is the maximum in-cylinder volume during intake stroke)

The Atkinson engine also has higher heat transfer during this operating condition due to longer duration and higher cylinder surface area of the expansion stroke. At 3500rpm 20bar IMEPnet, non-OE indicated efficiency of Atkinson cycle engine is primarily benefited from the stoichiometric AFR, as well as lower combustion phasing loss and pumping loss.

Figure 8.25 summarizes the normalized turbine energy (Energyturbine/Energy fuel) at 1500rpm, 13bar IMEPnet and 3500rpm, 20bar IMEPnet for both-engines. It can be found that the normalized turbine energy increases with load. As the in-cylinder pressure and temperature of the Atkinson cycle engine were decreased after over-expansion, the normalized turbine energy was $1.0 \%$ and $0.2 \%$ lower than the baseline engine at $1500 \mathrm{rpm}$ 13bar IMEPnet and 3500rpm 20bar IMEPnet, respectively. It can be observed that at $3500 \mathrm{rpm} 20 \mathrm{bar}$ IMEPnet, the $\Delta W_{\text {Turbine }}$ was $0.8 \%$ higher compared to the condition of $1500 \mathrm{rpm} 13 \mathrm{bar}$ IMEPnet ( $\Delta W_{\text {Turbine } @ 20 \mathrm{bar}}-\Delta W_{\text {Turbine } @ 13 b a r}=0.8 \%$ ). This observation needs to be further investigated by reviewing the relation between overexpansion and boost system. 


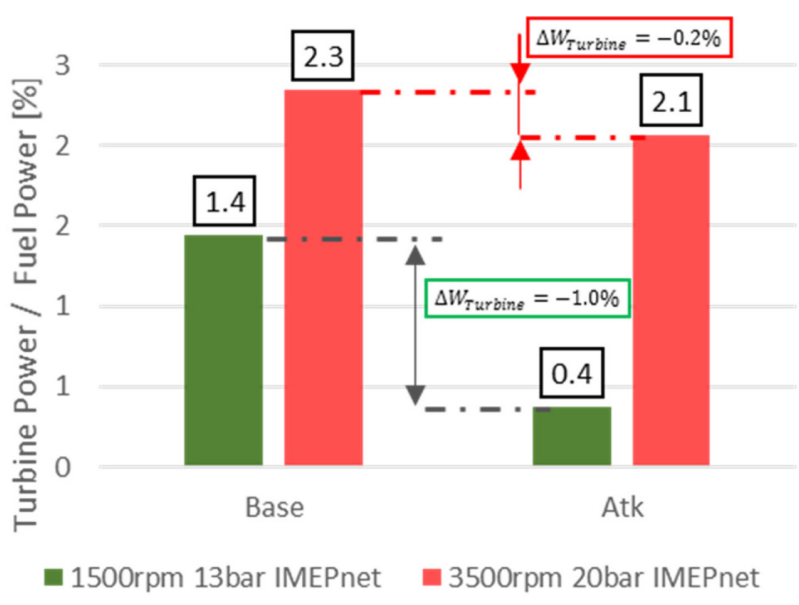

Figure 8.25. Turbine power normalized by fuel-in power of baseline and Atkinson cycle engine, at 1500rpm, 13bar IMEPnet and 3500rpm, 20bar IMEPnet

At the operating condition of 3500rpm 20bar IMEPnet, the efficiency of the Atkinson cycle engine benefits from both $\mathrm{OE}$ portion and non-OE portion with $4.4 \%$ and $5.5 \%$, respectively, as shown in Table 8.15 . The non-OE indicated efficiency difference was mainly affected by AFR loss between two engines. The total net indicated efficiency of the Atkinson cycle engine is $27.3 \%$ (relatively) higher than the baseline. The OE-indicated efficiency at $20 \mathrm{bar}$ is $0.5 \%$ lower (absolute value) than $13 \mathrm{bar}$. The investigation of the OEindicated efficiency difference will be included in the next section.

Table 8.15. Indicated efficiency improvement of Atkinson cycle engine at $3500 \mathrm{rpm}$, 20bar IMEPnet, optimized cam timing

\begin{tabular}{cc}
\hline \hline Indicated Efficiency Improvement of Atkinson Cycle Engine \\
Over-expansion work (absolute increase) & $4.4 \%$ \\
Non-over-expansion work (absolute increase) & $5.5 \%$ \\
Total net indicated efficiency (relative increase) & $27.3 \%$ \\
\hline \hline
\end{tabular}

\subsubsection{Investigation of over expansion difference at 1500rpm 13bar IMEPnet and 3500rpm 20bar IMEPnet}

In the boosted condition, The indicated efficiency component of the OE was decreased from $4.9 \%$ to $4.4 \%$ at $1500 \mathrm{rpm}$ 13bar IMEPnet and 3500rpm 20bar IMEPnet, respectively, as shown in Figure 8.18

Figure 8.21. This difference of OE indicated efficiency is mainly due to the impact of the exhaust valve timing and boost system. Figure 8.26 highlights the over-expansion gross 
work (OE gross work), late blowdown, and over-expansion pumping (OE pumping) in the Atkinson cycle engine log PV diagram.
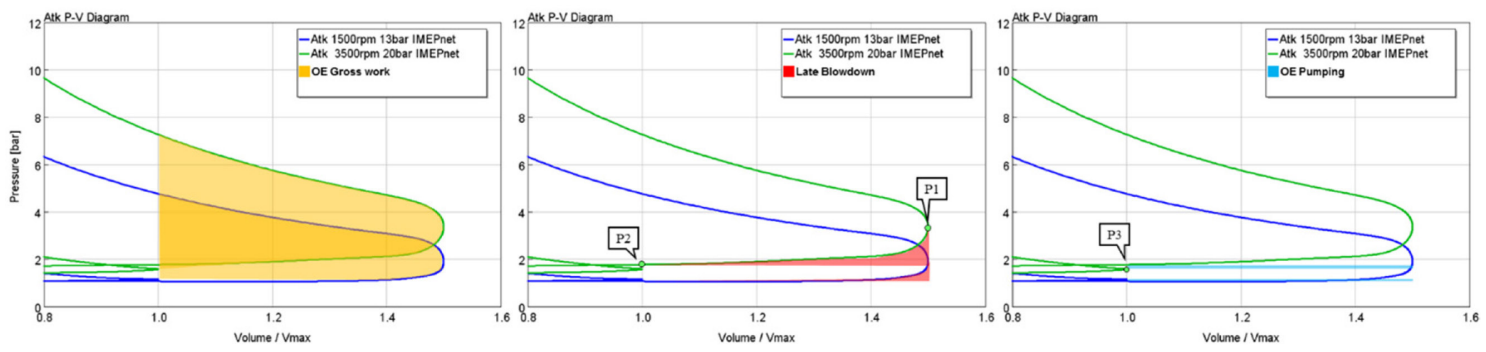

Figure 8.26. OE gross work, late blowdown, and OE pumping highlighted in Log $\mathrm{P}-\log$ $\mathrm{V} / \mathrm{V}_{\max }$ diagram of Atkinson cycle engine at 1500rpm 13bar IMEPnet and 3500 rpm 20bar IMEPnet with late expansion and OE pumping

In Figure 8.26, the indicated efficiency ( $\left.\eta_{\text {indicated,OE }}, 8-11\right)$ quantifies the indicated work (OE gross work) during over expansion normalized by the fuel energy. Late blowdown effect is defined in 8-19.

$$
\eta_{\text {Atk,late blowdown }}=\frac{\int_{\text {piston location @ P1 } 1}^{\text {piston location }\left(P-P_{2}\right) d V}}{\text { Fuel Energy }}
$$

In 8-19, pressure of $\mathrm{P}_{1}$ is at the (piston) location of bottom dead center after expansion stroke. Pressure of $\mathrm{P}_{2}$ is at the location of $\mathrm{V} / \mathrm{V}_{\max }=1.0$ during exhaust stroke. Pressure of $\mathrm{P}_{3}$ is at the location at the end of intake stroke, where $\mathrm{V} / \mathrm{V}_{\max }=1.0$

As Figure 8.26 shows, the late blowdown of the Atkinson cycle engine (highlighted in "red") starts at BDC (crank angle location of P1) and finishes at $\mathrm{V} / \mathrm{V}_{\max }=1.0$ (crank angle location of P2). Per definition in Figure 8.7, the crank angle location of P2 is also the starting point of the pumping loop. In the Atkinson cycle engine, the OE indicated efficiency is decreased when the efficiency loss of late blowdown is higher. The energy loss due to late blow down normalized by the fuel energy of the Atkinson cycle engine is $0.1 \%$ and $0.2 \%$ at $1500 \mathrm{rpm}, 13 \mathrm{bar}$ IMEPnet and 3500rpm, 20bar IMEPnet, respectively.

The over-expansion pumping (OE pumping, 8-20) is to quantify the pressure difference in exhaust and intake resulted in the efficiency loss/gain during the over-expansion period.

$$
\eta_{\text {Atk,OE pumping }}=\frac{\left(P_{3}-P_{2}\right) *\left(V_{@ P 2}-V_{@ P 3}\right)}{\text { Fuel Energy }}
$$

It can be observed that $\mathrm{P}_{2}$ was higher than $\mathrm{P}_{3}$ at 3500rpm 20bar IMEPnet, however, $\mathrm{P}_{2}$ was lower than $\mathrm{P}_{3}$ at $1500 \mathrm{rpm}$ 13bar IMEPnet. As 8-20 shows, the pressure difference resulted $\eta_{A t k, O E \text { pumping }}$ is negative at 3500rpm 20bar IMEPnet, while the OE pumping is positive at $1500 \mathrm{rpm} 13 \mathrm{bar}$ IMEPnet. The OE pumping is to quantify the efficiency loss/gain compared to the scenario when intake and exhaust pressure is same at $\mathrm{V} / \mathrm{V}_{\max }=1.0 \mathrm{~A}$ 
negative value of OE pumping has the same effect as late blown down, which resulted in the penalty of the OE indicated efficiency.

The results of OE indicated efficiency, efficiency losses of late blowdown and OE pumping are summarized in Table 8.16. $\Delta \eta$ in Table 8.16 is the efficiency difference of the Atkinson cycle engine between two speed load conditions.

Table 8.16. OE indicated efficiency, late blowdown loss and OE pumping of Atkinson cycle engine normalized by fuel energy at 1500rpm 13bar IMEPnet and 3500rpm 20bar

IMEPnet

\begin{tabular}{cccc}
\hline \hline & $\begin{array}{c}\text { 1500rpm 13bar } \\
\text { IMEPnet (1) }\end{array}$ & $\begin{array}{c}\text { 3500rpm 20bar } \\
\text { IMEPnet (2) }\end{array}$ & $\Delta \boldsymbol{\eta}$ (1)-(2) \\
$\boldsymbol{\eta}_{\text {indicated,oE }}$ & $4.9 \%$ & $4.4 \%$ & $0.5 \%$ \\
$\boldsymbol{\eta}_{\text {Atk, late blowdown }}$ & $-0.1 \%$ & $-0.2 \%$ & $0.1 \%$ \\
$\boldsymbol{\eta}_{\text {Atk, OE pumping }}$ & $0.2 \%$ & $-0.2 \%$ & $0.4 \%$ \\
\hline \hline
\end{tabular}

Figure 8.27 is the bar chart of efficiency difference, $\Delta \eta$, which includes the efficiency difference of late blowdown, OE pumping, and the OE indicated efficiency, as defined in Equation 8-21 to Equation 8-23. It can be observed that the total efficiency loss of late blowdown and OE pumping is close to the reduction of OE indicated efficiency. At boosted condition, the OE indicates loss of indicated efficiency was mainly due to late blowdown and OE pumping. An early blowdown will also penalize the OE indicated efficiency if the exhaust valve opening occurs earlier. In this study, an early blowdown loss was not observed (lower than $0.1 \%$ ).

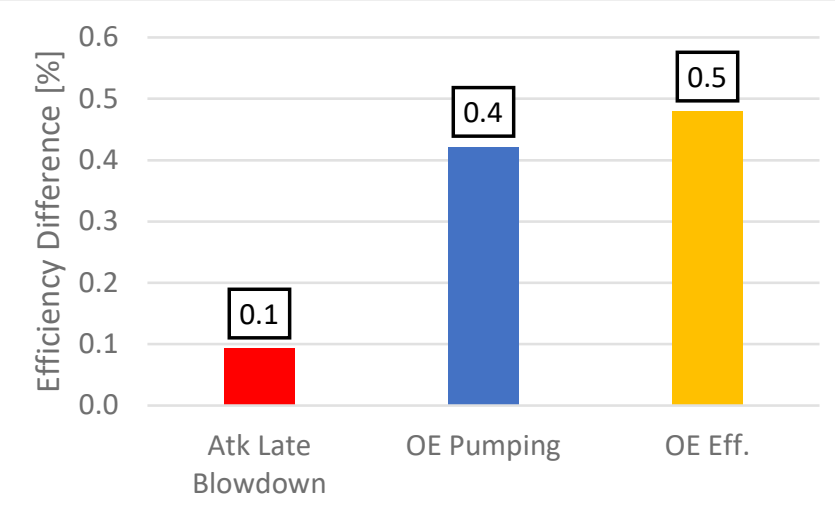

Figure 8.27. Normalized energy difference of Atkinson cycle engine late blowdown, pumping loss, and over-expansion indicated efficiency (3500rpm 20bar IMEPnet -

$\underline{1500 \mathrm{rpm}} \underline{13 \mathrm{bar}}$ IMEPnet)

$\Delta \eta_{\text {Atk late blow down }}=\eta_{\text {Atk late blow down @ 1500rpm 13bar }}-\eta_{\text {Atk late blow down @ 3500rpm 20bar }}$ 
Figure 8.28 shows the bar chart of net indicated efficiencies at the optimized case of the two operating conditions for baseline and Atkinson cycle engines. At 1500rpm, 13bar IMEPnet, the non-OE indicated efficiency of Atkinson cycle is $0.9 \%$ higher than baseline. Lower knock propensity reduces the combustion phasing loss of Atkinson cycle engine. $\mathrm{OE}$ at medium load contributes $4.9 \%$ increase in the net indicated efficiency. The total net indicated efficiency is increased by $14.3 \%$.

At 3500rpm 20bar IMEPnet, non-OE indicated efficiency of the Atkinson cycle is 5.5\% higher compared to baseline. At the high load condition, Atkinson engine requires less fuel enrichment than baseline as the in-cylinder temperature is lower due to combustion phasing difference and over-expansion. The total net indicated efficiency of the Atkinson cycle engine was increased by $27.3 \%$ compared to the baseline engine at 3500rpm 20bar IMEPnet. The OE indicated efficiency of the Atkinson cycle engine was reduced from $4.9 \%$ to $4.4 \%$ as the load increased from 13 bar to 20 bar IMEPnet. The reduction of the over-expansion efficiency was affected by late blowdown and OE pumping. Further optimization of exhaust valve duration and specification of the boost system is required to reduce the efficiency penalty of late blowdown and OE pumping during over-expansion.

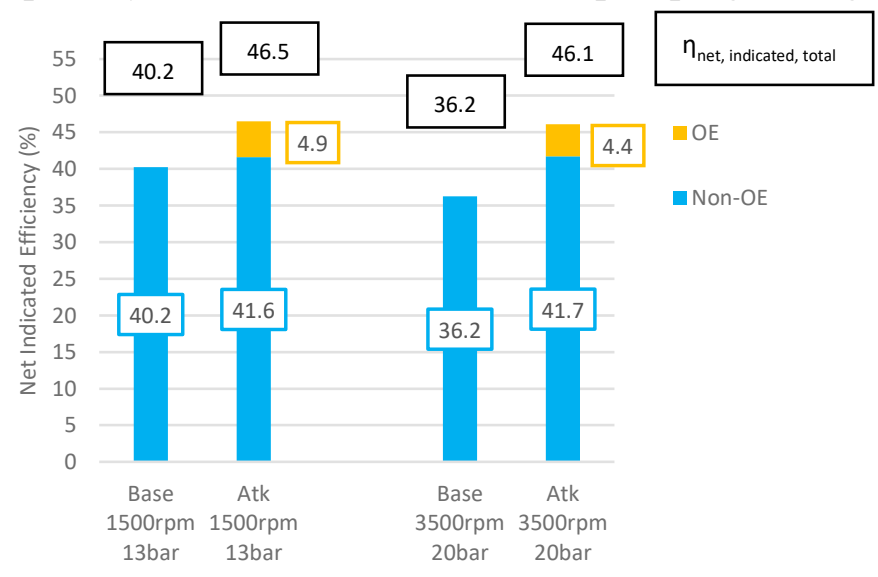

Figure 8.28. Summary of the optimized baseline and Atkinson cycle engine net indicated efficiency at optimized at 1500rpm, 13bar IMEPnet and 3500rpm, 20bar IMEPnet 


\subsection{Summary/Conclusions}

A 1-D engine simulation study with an Atkinson cycle multi-link mechanism was investigated. The engine models were developed and calibrated based on a CR of 9.2, direct-injected spark-ignited 2-liter 4-cylinder turbocharged engine with variable cam timing. The baseline engine with 22bar peak BMEP was modified to CR 10.5 in the simulation to represent the state of the art with respect to knock mitigation strategies. CA50 of $10^{\circ} \mathrm{ATDC}$ firing was used as MBT spark timing of Atkinson cycle engine. The Atkinson cycle engine was designed with $\mathrm{CR}$ of 10.5 and OER of 1.5. A detailed multi-link mechanism was developed to replace the baseline engine cranktrain in GT-Suite. It includes the kinetics of each linkage including the piston movement of the entire engine cycle. The geometric specification of the Atkinson cycle engine was constrained with the same bore, compression stroke, intake stroke, and compression ratio as the baseline.

As the mechanisms of baseline and Atkinson cycle engine are different, the piston movement and duration of strokes have different characteristics. Cam timing, valve lift profile, and spark timing of Atkinson cycle engine were adjusted based on the mechanism difference.

Experimental results were used to calibrate the baseline engine model. The controllers embedded in the model included the load control, spark timing control (knock limited spark timing / MBT spark timing), and AFR control (turbine-inlet temperature constraint). The Atkinson cycle engine also considered the design constraints based upon packaging.

In this study, the indicated work of the Atkinson cycle engine was divided into three parts, non-over-expansion, over-expansion, and pumping loop. The three portions were defined based upon the piston location instead of crank angle location. A non-OE indicated efficiency and $\mathrm{OE}$ indicated efficiency of the Atkinson cycle engine were defined in this study. Non-OE indicated efficiency is compared directly to the net indicated efficiency of baseline. The additional indicated work from over-expansion was defined as the $\mathrm{OE}$ efficiency to quantify the contribution of over-expansion to the overall thermal efficiency improvement as a result of Atkinson cycle.

Knock was studied by using empirical induction-time correlation with kinetics fit model. Three induction times were calculated for low, intermediate, and high temperature regions. The knock model was calibrated to match the knock onset based upon the experimental results of baseline engine.

Energy losses of both baseline and Atkinson cycle engines were quantified including loss of pumping work, fuel enrichment, combustion phasing, combustion duration, and heat transfer. The analysis of energy loss explains the advantage of Atkinson cycle engine at medium to high loads with the constraints of knock and turbine-inlet temperature. 
Based on the simulation, the following observations are made:

- The knock level of the baseline and the Atkinson cycle engine was compared at 1500rpm, 13bar IMEPnet. The simulation of baseline and Atkinson cycle engine were performed at the same valve timing and spark timing. The unburned temperature of Atkinson cycle engine was close to the baseline engine from spark advance to knock onset. At the same window, the piston speed of the Atkinson cycle engine was higher than the baseline engine, which resulted in a lower residence time of unburned gas mixture. As the overall induction time integral of the Atkinson cycle engine increased slower than the baseline engine, the knock onset of the Atkinson cycle engine was retarded by $4.7^{\circ} \mathrm{CA}$ in comparison to the baseline engine. The mass fraction of unburned fuel at knock onset for the Atkinson cycle engine was 8.1\% lower (absolute) than the baseline, which represents a lower knock level.

- At 1500rpm, 13bar IMEPnet, cam timing of the baseline and the Atkinson cycle engines were both optimized. Simulation of this operating condition was performed at KLSA. Combustion phasing loss of Atkinson cycle engine is $0.8 \%$ lower than baseline engine due to its lower knock propensity. CA50 of Atkinson cycle engine is at $12.3^{\circ} \mathrm{aTDC}$, which is $5.9^{\circ} \mathrm{CA}$ earlier than baseline under the same knock constraint.

- At 3500rpm, 20bar IMEPnet, baseline and Atkinson cycle engines were optimized and simulated with the constraints of knock intensity and turbine-inlet temperature. The losses of AFR, combustion phasing and combustion duration of the Atkinson cycle engine were $4.4 \%, 0.6 \%$, and $0.2 \%$ lower (absolute value) than baseline respectively.

- At 1500rpm, 13bar IMEPnet and 3500rpm, 20bar IMEPnet, heat transfer loss of Atkinson cycle engine was $0.6 \%$ higher than the baseline at those conditions, respectively. Higher heat transfer loss is caused by the increased duration of the power stroke $\left(22^{\circ}\right)$ and increased cylinder surface area (50\% relatively increase) during the power stroke in comparison to the baseline engine.

- The normalized turbine energy of the Atkinson cycle engine decreased by $1.4 \%$ and $0.6 \%$ compared to the baseline engine at 1500rpm, 13bar IMEPnet and 3500rpm, 20bar IMEPnet, respectively.

- In the Atkinson cycle engine, the starting point of late blowdown during overexpansion period occurs earlier than the pumping loop. At 1500rpm, 13bar IMEPnet and 3500rpm, 20bar IMEPnet, the late blowdown loss of Atkinson cycle engine was $0.1 \%$ and $0.2 \%$, respectively.

- OE pumping of the Atkinson cycle engine was $0.2 \%$ and $-0.2 \%$ at $1500 \mathrm{rpm}, 13 \mathrm{bar}$ IMEPnet and 3500rpm, 20bar IMEPnet, respectively. A negative OE pumping represents the $\mathrm{OE}$ indicated efficiency of Atkinson cycle engine was penalized by the exhaust pressure higher than the intake pressure. 
- At 3500rpm, 20bar IMEPnet, OE indicated efficiency was reduced by $0.5 \%$ compared to the $\mathrm{OE}$ indicated efficiency at $1500 \mathrm{rpm}, 13 \mathrm{bar}$ IMEPnet. The reduction in the $\mathrm{OE}$ indicated efficiency was equal to the total efficiency loss due to late blowdown and $\mathrm{OE}$ pumping between the two operating conditions.

- With the cam phasing fully optimized with the constraints of knock intensity and turbine-inlet temperature, the relative increase of the net indicated efficiencies of Atkinson cycle engine at 1500rpm, 13bar IMEPnet and 3500rpm, 20bar IMEPnet were $15.7 \%$ and $27.3 \%$ higher than baseline respectively.

Following these observations, the conclusions of the study are as given below:

- At the same speed, load, cam timing, and spark timing, the overall induction time integral of the Atkinson cycle engine was lower than the baseline engine due to the faster piston movement from spark advance to knock onset, resulting in a lower residence time of unburned gas mixture. The unburned mass fraction of fuel at knock onset was lower representing a lower knock level of the Atkinson cycle engine.

- At the high load condition, the indicated efficiency component of the non-OE of Atkinson cycle engine is higher than the net indicated efficiency of baseline engine at the same operating condition. The increase in the non-OE indicated efficiency of Atkinson cycle engine is due to lower combustion phasing and AFR losses. The lower combustion phasing loss is due to the lower knock propensity of Atkinson cycle engine compared to the baseline engine at KLSA. The lower AFR loss is due to the lower fuel enrichment requirement of the Atkinson cycle engine, as the in-cylinder temperature is lower due to the over-expansion and advanced combustion phasing of Atkinson cycle engine.

- Heat transfer loss of the Atkinson cycle engine is higher due to the longer duration and higher cylinder surface area of the expansion stroke.

- In the light load condition of Atkinson cycle engine, the load increase results in the increase of OE indicated efficiency. However, at the boosted condition of Atkinson cycle engine, the $\mathrm{OE}$ indicated efficiency decreased with an increase in the load. The reduction of $\mathrm{OE}$ indicated efficiency was affected by the negative effects of late blowdown and $\mathrm{OE}$ pumping.

- At light to medium load conditions, Atkinson cycle engine only benefits from the indicated work of over-expansion. At high load condition, with fully optimized cam timing and the constraints of knock and turbine inlet temperature, the net indicated efficiency of the Atkinson cycle engine combines the effect from the portion of nonover-expansion and over-expansion. The increase of the non-over-expansion is mainly due to the lower knock propensity and lower exhaust temperatures with air-fuel ratio closer to stoichiometric. 


\subsection{Future Work}

Further analysis to quantify the performance between Atkinson engine realized by overexpansion mechanism and high compression engine with LIVC should be examined. A high compression engine (e.g. CR 13:1) with LIVC can be realized as an Atkinson cycle without modifying the mechanism. LIVC strategy is already known for its benefit at light load conditions. However, at high load conditions, employing LIVC strategy will lead to lower full load capability due to a decrease in the effective displacement and compression ratio. The difference in combustion and knock characteristics at light load and high load conditions should be investigated between a cranktrain realized Atkinson cycle engine and a valvetrain realized Atkinson cycle engine (by LIVC) with high compression ratios.

In this study, the CR of both engines was the same, but an Atkinson cycle engine can be designed with a wide range of compression and expansion ratios. An Atkinson cycle engine with a lower CR can have the same ER as the studied engine if the OER is larger, and have significantly improved knock resistance, or alternatively the same OER and lower ER. This may further improve overall efficiency at high load. These variants may warrant further study. 


\subsection{Acknowledgments}

This work was supported by MTU Light Duty Consortium. The authors would like to thank the participating members of the MTU Light Duty Consortium and staff at MTU APS Labs for their support in the execution of this project.

\subsection{Definitions/Abbreviations}

\begin{tabular}{|c|c|}
\hline AFR & Air to fuel ratio \\
\hline aBDC & After bottom dead center \\
\hline aTDC & After top dead center \\
\hline bBDC & Before bottom dead center \\
\hline BDC & Bottom dead center \\
\hline bTDC & Before top dead center \\
\hline ВМЕР & Brake mean effective pressure \\
\hline BSFC & Brake specific fuel consumption \\
\hline $\mathbf{C A}$ & Crank angle \\
\hline CA50 & $\begin{array}{l}\text { Crank angle of } 50 \% \text { mass fuel } \\
\text { burned }\end{array}$ \\
\hline CR & Compression ratio \\
\hline DI & Direct injection \\
\hline EGR & Exhaust gas recirculation \\
\hline EMOP & $\begin{array}{l}\text { Exhaust valve most opening } \\
\text { position }\end{array}$ \\
\hline ER & Expansion ratio \\
\hline GE & Gas exchange \\
\hline IMEPnet & Net indicated mean effect pressure \\
\hline IMOP & Intake valve most opening position \\
\hline ISFC & Net indicated specific fuel consumption \\
\hline KLSA & Knock-limited spark advance \\
\hline LIVC & Late intake valve closing \\
\hline MAP & Manifold absolute pressure \\
\hline MBT & Maximum brake torque \\
\hline \multicolumn{2}{|l|}{ MON } \\
\hline Non-OE & Non-over-expansion \\
\hline $\mathbf{O E}$ & Over expansion \\
\hline OER & Over expansion ratio \\
\hline RGF & Residual gas fraction \\
\hline \multicolumn{2}{|l|}{ RON } \\
\hline RPM & Revolution per minute \\
\hline SI & Spark Ignited \\
\hline
\end{tabular}




$\begin{array}{ll}\text { SR } & \text { Expansion to compression stroke ratio } \\ \text { TDC } & \text { Top dead center } \\ \text { VVT } & \text { Variable valve timing } \\ \mathbf{V}_{\mathbf{m a x}} & \begin{array}{l}\text { Maximum in-cylinder volume during } \\ \text { intake stroke }\end{array} \\ \boldsymbol{\eta}_{\text {net indicated }} & \text { Net indicated efficiency } \\ \boldsymbol{\eta}_{\text {net indicated, } \text { non-oE }} & \text { Non-over expanded indicated efficiency } \\ \boldsymbol{\eta}_{\text {indicated,oE }} & \text { Over expanded indicated efficiency }\end{array}$

\subsection{Appendix}

\section{Knock Onset Prediction Model [66, 90]}

$\tau_{i}=M_{1} a_{i}\left(\frac{O N}{100}\right)^{b_{i}}[\text { Fuel }]^{c_{i}}\left[O_{2}\right]^{d_{i}}[\text { Diluent }]^{e_{i}} \operatorname{Exp}\left(\frac{f_{i}}{M_{2} T}\right)$

$M_{1} \quad$ - Knock Induction Time Multiplier

ON - Fuel Octane Number

$M_{2} \quad$-Activation Energy Multiplier

Fuel, $\mathrm{O}_{2}$, and Diluent

-concentrations expressed in $\mathrm{mol} / \mathrm{m} 3$

-diluent concentration is the sum of concentrations of $\mathrm{N}_{2}, \mathrm{CO}_{2}$, and $\mathrm{H}_{2} \mathrm{O}$.

$a_{i}$ through $f_{\mathrm{i}}$ are model constants shown in the table below [90].

\begin{tabular}{|c|c|c|c|c|c|c|}
\hline $\boldsymbol{i}$ & $\boldsymbol{a}$ & $\boldsymbol{b}$ & $\boldsymbol{c}$ & $\boldsymbol{d}$ & $\boldsymbol{e}$ & $\boldsymbol{f}$ \\
\hline $\mathbf{1}$ & $4.46 \mathrm{E}-07$ & 3.613 & -0.64 & -0.564 & 0.3978 & 12920 \\
\hline $\mathbf{2}$ & 11941.42 & 3.163 & -0.64 & -1.4596 & 0.4867 & -1957 \\
\hline $\mathbf{3}$ & $8.91 \mathrm{E}+07$ & 0 & -0.25 & -0.547 & 0 & 16856 \\
\hline
\end{tabular}




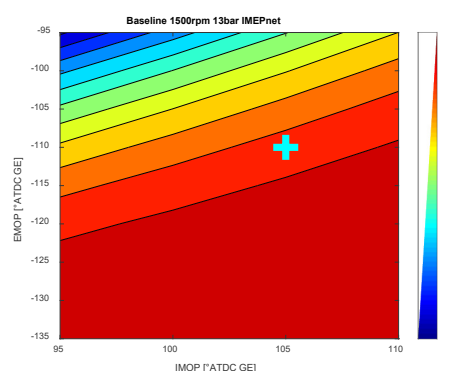

Figure 8.29. Baseline engine trapping ratio at $1500 \mathrm{rpm} 13 \mathrm{bar}$ IMEPnet

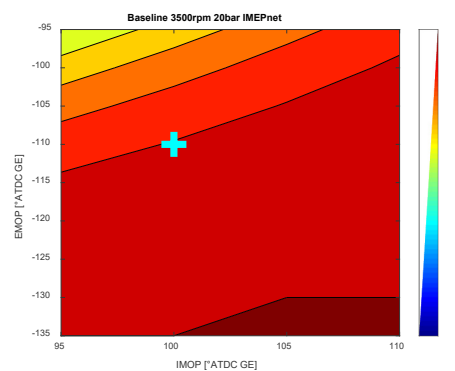

Figure 8.31. Baseline engine trapping ratio at $3500 \mathrm{rpm}$ 20bar IMEPnet

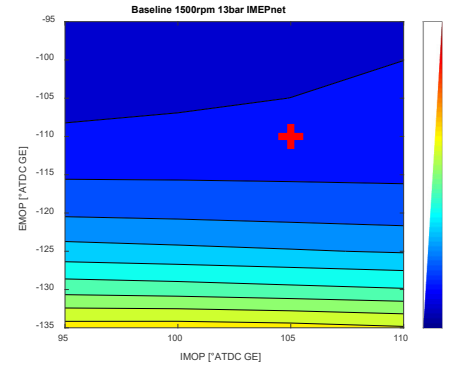

Figure 8.33. Baseline engine CA50 at 1500rpm 13bar IMEPnet

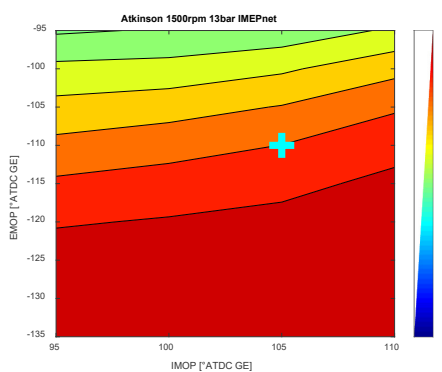

Figure 8.30. Atkinson cycle engine trapping ratio at $1500 \mathrm{rpm}$ 13bar IMEPnet

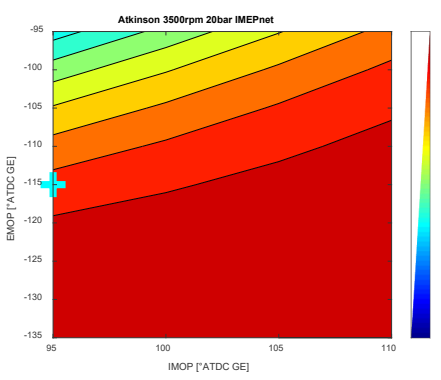

Figure 8.32. Atkinson cycle engine trapping ratio at 3500 rpm 20bar IMEPnet

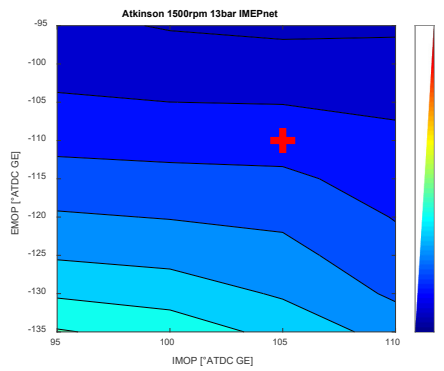

Figure 8.34. Atkinson cycle engine CA50 at $\underline{1500 \mathrm{rpm}} \underline{13 \mathrm{bar}}$ IMEPnet 


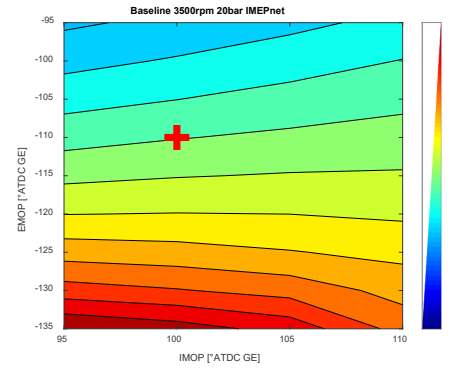

Figure 8.35. Baseline engine CA50 at 3500rpm 20bar IMEPnet

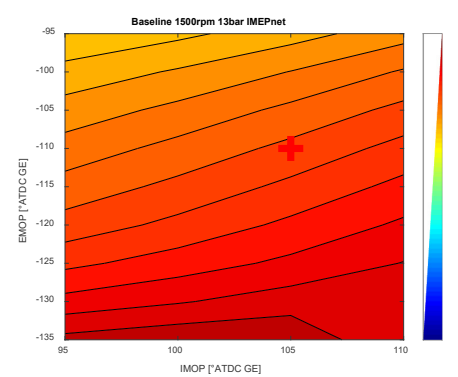

Figure 8.37. Baseline engine PMEP at 1500rpm 13bar IMEPnet (Positive value represents boost condition)

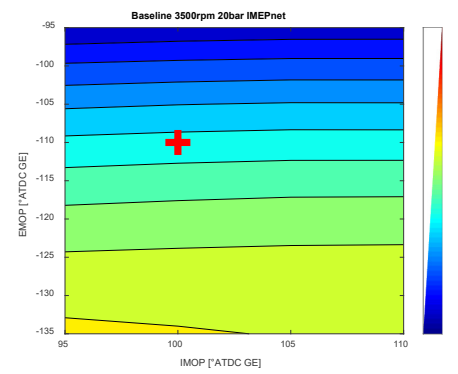

Figure 8.39. Baseline engine PMEP at 3500rpm 20bar IMEPnet

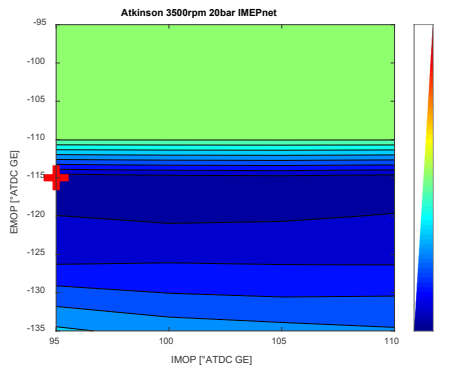

Figure 8.36. Atkinson cycle engine CA50 at 3500 rpm 20bar IMEPnet

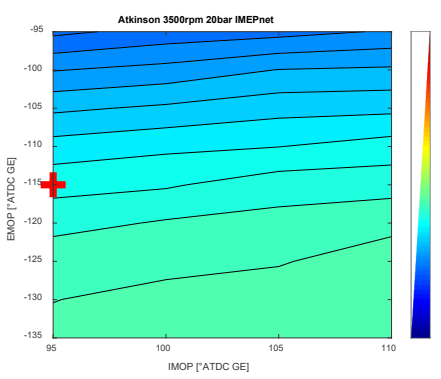

Figure 8.38. Atkinson cycle engine PMEP at 3500rpm 20bar IMEPnet

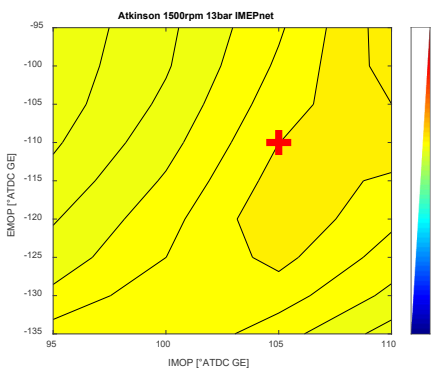

Figure 8.40. Atkinson cycle engine PMEP at 1500 rpm 13bar IMEPnet 


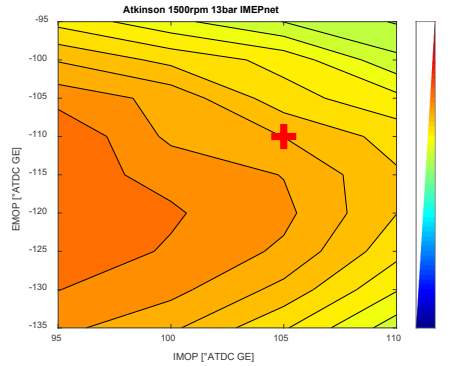

Figure 8.41. Baseline engine OE indicated efficiency at 3500 rpm 20bar IMEPnet

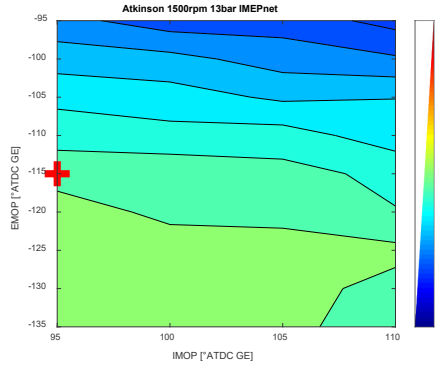

Figure 8.42. Atkinson cycle engine OE indicated efficiency at 3500rpm 20bar IMEPnet 


\section{Comparing Methods for Improving Efficiency for Spark-Ignited Engines - Multi-link Mechanical Over- Expansion to High Compression Ratio with LIVC}

This paper was submitted to a peer-reviewed academic journal and is currently under review. It corresponds to the third stage of the research described in the main research contributions chapter.

In this study, a multi-link over-expanded engine model was developed based on the experimental results of a baseline engine. Three engines were studied, a baseline engine with CR 10.5:1, a high compression engine with CR 13:1, and a multi-link over-expanded engine with CR 10.5:1 and OER 1.5. The multi-link over-expanded engine, high compression engine, and the baseline engine were optimized and compared based on a cam phasing sweep with constraints at three operating conditions. The high compression engine and multi-link over-expanded engine used LIVC strategy at the light load condition. The high load condition is a knock-limited operating condition. The medium load condition is the peak brake efficiency point of the high compression engine. An energy loss analysis was conducted and compared between the three engines. 


\section{Comparing Methods for Improving Efficiency for Spark- Ignited Engines - Multi-link Mechanical Over-Expansion to High Compression Ratio with LIVC}

Yang, Z., Narasimhamurthy, M., Miller, T., and Naber, J.

Michigan Technological University

David Roth

Roth Engine Science LLC

Michigan Technological University

Department of Mechanical Engineering - Engineering Mechanics

1400 Townsend Drive, Houghton, Michigan, USA 49931

Email:zhuyongy@mtu.edu,jnaber@mtu.edu 


\subsection{Keywords}

Internal combustion engine

Over expanded cycle

High compression ratio

High efficiency

Combustion knock

\subsection{Highlights}

Over-expanded and high compression engine are investigated based on 1D simulation.

Effect of LIVC is investigated on studied engines at light load conditions.

Multi-link engine benefits from its lower knock propensity and over-expansion.

Efficiency of multi-link engine is $13.7 \%$ higher than high compression engine.

\subsection{Abstract}

A common approach of high efficiency engines is to utilize high compression with late intake valve closing (LIVC) to realize an over-expanded cycle. A multi-link cranktrain can also realize an over-expanded cycle with the same geometric intake displacement as a baseline engine while extending the expansion stroke. These two types of over-expanded cycle engines and a baseline engine are investigated and compared in this simulation study. The baseline engine model is calibrated based on the experimental results from a fourcylinder, boosted, spark-ignited engine with compression ratio (CR) of 10.5:1. The CR of high compression ratio engine and multi-link over-expanded engine is 13.0:1 and 10.5:1, respectively. The over-expansion ratio of multi-link engine is 1.5 . These three engines were optimized and investigated at three conditions: $1300 \mathrm{rpm} 330 \mathrm{kPa}$ net IMEPnet, 1500rpm $1300 \mathrm{kPa}$ IMEPnet, and 2500rpm 1000kPa IMEPnet. At 1300rpm 330kPa IMEPnet, multilink over-expanded engine and high compression engine both used LIVC. With LIVC, the net indicated efficiency of the high compression engine and multi-link engine were improved by $5.2 \%$ and $2.4 \%$ (relative), respectively, compared to the same engine without LIVC. Multi-link over-expanded engine benefited from its lower knock propensity and over-expansion at medium to high load conditions. At 1500rpm 1300kPa IMEPnet, the net indicated efficiency of the multi-link engine was $13.7 \%$ and $14.2 \%$ (relative) higher than the high compression engine and baseline engine, respectively. At the peak brake 
efficiency condition of the high compression engine, the net indicated efficiency of multilink engine was $8.6 \%$ (relative) higher than the high compression engine.

\subsection{Nomenclature}

\section{Definitions/Abbreviations}

\begin{tabular}{|c|c|c|c|}
\hline \multirow[b]{3}{*}{ AFR } & \multirow[b]{3}{*}{ Air to fuel ratio } & \multirow{2}{*}{$\begin{array}{l}\text { LIVC } \\
\text { MAP }\end{array}$} & \multirow{2}{*}{$\begin{array}{l}\text { Late intake valve closing } \\
\text { Manifold absolute pressure }\end{array}$} \\
\hline & & & \\
\hline & & MBT & Maximum brake torque \\
\hline BDC & Bottom dead center & Non-OE & Non-over-expansion \\
\hline BSFC & $\begin{array}{l}\text { Brake specific fuel } \\
\text { consumption }\end{array}$ & OE & Over expansion \\
\hline $\mathbf{C A}$ & Crank angle & OER & Over expansion ratio \\
\hline $\mathrm{CA50}$ & Crank angle of $50 \%$ & RGF & Residual gas fraction \\
\hline CADO & mass fuel burned & SI & Spark Ignited \\
\hline $\mathbf{C R}$ & Compression ratio & SR & Expansion to compression \\
\hline DI & Direct injection & DN & stroke ratio \\
\hline FGR & Exhaust & TDC & Top dead center \\
\hline Luin & recirculation & VVT & Variable valve timing \\
\hline EMOP & $\begin{array}{l}\text { Exhaust valve most } \\
\text { opening position }\end{array}$ & $\eta_{\text {net indic }}$ & \\
\hline ER & Expansion ratio & Net indic & efficiency \\
\hline GE & Gas exchange & $\eta_{\text {net indic }}$ & non-OE \\
\hline IMEPnet & $\begin{array}{l}\text { Net indicated mean effect } \\
\text { pressure }\end{array}$ & Non-ove & anded indicated efficiency \\
\hline IMOP & $\begin{array}{l}\text { Intake valve most opening } \\
\text { position }\end{array}$ & $\begin{array}{l}\text { Iindicate } \\
\text { Over exp }\end{array}$ & indicated efficiency \\
\hline ISFC & $\begin{array}{l}\text { Net indicated specific fuel } \\
\text { consumption }\end{array}$ & & \\
\hline
\end{tabular}

\subsection{Introduction}

The annual energy outlook of 2018 released by the United States Department of Energy (DOE) shows that $60 \%$ of the total transportation energy consumption is motor gasoline in the United States [1]. The energy used by Light-Duty Vehicles (LDV) was 16 quadrillion kilojoules, which accounts for more than $55 \%$ of the total energy consumed in the transportation sector. DOE has projected that LDV energy consumption will reduce to 12 quadrillion kilojoules in 2050 due to more stringent corporate average fuel economy (CAFE) standards. The Automotive Trends Report released by the United States Environmental Protection Agency (EPA) [2] showed that for the model year 2017 vehicles, $96 \%$ were powered by gasoline engines while less than $1.4 \%$ were pure electric. Although new LDVs of alternative powertrains will increase to more than $23 \%$ in 2050 based on the projection by DOE [1], the projected proportion of LDV with internal combustion, gasoline engines is far from negligible. 
Based on the reports made by DOE [1] and EPA [2], the LDVs powered by conventional gasoline will still dominate the market for several decades. Therefore, research and development towards improving the efficiency of spark-ignited (SI) engines while reducing criteria emissions is still critical and the very near term needs tightening criteria emissions and fuel economy regulations. In order to meet this, different approaches such as engine downsizing with boost systems can be applied to improve the engine thermal conversion efficiency, load capability, and reduction of $\mathrm{CO}_{2}$ [45]. However, current SI engine technology is still below the thermodynamic efficiency ceiling by a large margin [46].

At light load conditions, spark-ignited engines are usually throttled for load control at stoichiometric condition [91]. The throttled condition of an SI engine results in a pumping loss. In addition, heat transfer (HT) is also one of the major efficiency losses due to the lower temperature of the cylinder head and cylinder wall [92].

At high load conditions, the SI engine has high knock propensity depending on the temperature and the propagation of the flame front $[45,69,70]$. To reduce the knock probability, retarding spark timing is one of the common calibration methods. However, it would result in an engine efficiency penalty due to the lower in-cylinder pressure during expansion [70].

To overcome the efficiency penalty, a method called the Atkinson cycle, or an overexpanded cycle can be utilized by making the expansion stroke longer than the compression stroke and therefore increasing the expansion work. The fuel conversion efficiency of the over-expanded engine with constant volume combustion can be expressed as,

$$
\eta_{O E \text { cycle }}=1-\frac{1}{E R^{\gamma-1}}\left(1+\frac{c_{v} T_{a}}{Q^{*}} C R^{\gamma-1}\left(1-\gamma\left(\frac{E R}{C R}\right)^{\gamma-1}+(\gamma-1)\left(\frac{E R}{C R}\right)^{\gamma}\right)\right)
$$

where,
CR - compression ratio
ER - the expansion ratio
$\gamma \quad-\quad$ specific heat ratio
Q* $\quad$ - $\quad$ specific internal energy
T_a - temperature at the start of compression 
The Atkinson cycle engine was originally patented by James Atkinson in 1887 [47]. The engine was designed with a multi-link mechanism to realize an engine cycle with a longer expansion stroke than compression stroke. An alternative approach to realize an Atkinson cycle is using a high geometric compression ratio engine and late intake valve closing (LIVC). This method realizes the Atkinson cycle by reducing the effective compression ratio while maintaining the same expansion ratio. Sakata et al. [52] investigated an Atkinson cycle study with LIVC where the effective and geometric compression ratios were 8.5 and 20, respectively. The brake specific fuel consumption (BSFC) of this study was reduced by $18 \%$ relative to the baseline engine at $2500 \mathrm{rpm}, 700 \mathrm{kPa}$ BMEP. Many automotive manufacturers also utilize LIVC to realize an Atkinson cycle in production SI engines with advanced valvetrains, e.g., Mazda, Ford, GM, and Toyota [32, 37, 53, 54].

One of the disadvantages of utilizing an Atkinson cycle by high compression and LIVC is higher knock probability and decreased peak load output due to the reduced displacement volume. Costa et al. [93] conducted a comparison study of full load engine performance at different engine compression ratios. Two fuels with different ethanol blend ratios were compared. When using the lower ethanol ratio fuel, the thermal efficiency of the high compression ratio engine was penalized and lower than the baseline engine due to the higher knock probability, resulting in a more retarded combustion phasing. The indicated mean effective pressure (IMEP) and power density of the engine with LIVC were lower due to reduced effective intake displacement resulting in a lower load capability[85].

Although the Atkinson cycle engine was initially invented in the 1880 s, compared to the conventional engine, the research of the Atkinson cycle engine with a multi-link mechanism is still in a very early stage. The most recent study of the Atkinson cycle engine with a multi-link mechanism is by Anandhan and Yang et al.[63, 68]. In Anandhan's simulation [63], the results showed the indicated specific fuel consumption (ISFC) was decreased by more than $10 \%$ with an expansion to compression ratio of 1.5 . Research by Yang et al. [68] investigated the benefit of Atkinson cycle engine with the multi-link mechanism at partial load conditions. The Atkinson cycle engine was developed with CR 9.2 and OER 1.5. The net indicated efficiency of the Atkinson cycle engine was increased by $11.5 \%$ compared to the baseline engine with the same CR. The gross indicated work of the Atkinson cycle engine was broken down into the portions of non-over-expansion and over-expansion, as shown in Figure 9.1. The results indicated that, at light to medium load conditions, the total net indicated efficiency improvement of the Atkinson cycle engine was mainly attribute to the indicated work of over-expansion. The indicated efficiency contributed by non-over-expansion was the same in comparison to the baseline net indicated efficiency. 


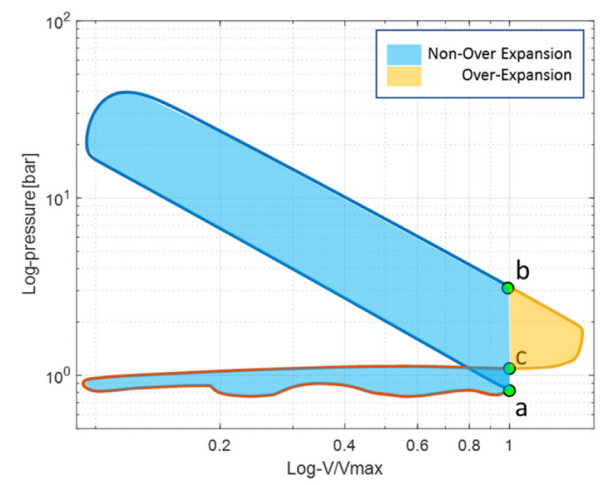

Figure 9.1. Log V/Vmax diagram of Atkinson cycle highlighted with the portion of nonover-expansion and over-expansion (Vmax is the maximum in-cylinder volume at the end of the intake stroke)

A literature review summary of over-expanded engine study is listed in Table 9.1.

Table 9.1. Summary of over-expansion engine study with method of over-expansion, engine specification, operation condition, and the improvement compare to baseline

\begin{tabular}{|c|c|c|c|c|c|c|}
\hline Reference & Study Type & $\begin{array}{l}\text { Method of } \\
\text { Over- } \\
\text { Expansion }\end{array}$ & CR & OER & $\begin{array}{l}\text { Speed/ } \\
\text { Load }\end{array}$ & $\begin{array}{l}\text { Improvement } \\
\text { Compare to } \\
\text { Baseline } \\
\text { (Relative) }\end{array}$ \\
\hline $\begin{array}{l}\text { Sakata et al. } \\
2007 \\
{[52]}\end{array}$ & $\begin{array}{l}\text { Experiment } \\
\text { al study }\end{array}$ & $\mathrm{HC}+\mathrm{LIVC}$ & $\begin{array}{l}20 \text { (geo.) } \\
8.5 \\
\text { (effect.) }\end{array}$ & 2.4 & $\begin{array}{l}\text { 2500rpm/ } \\
700 \mathrm{kPa} \text { BMEP }\end{array}$ & $\begin{array}{l}\text { Improved BSFC } \\
\text { by } 18 \%\end{array}$ \\
\hline $\begin{array}{l}\text { Feng, et al. } 2016 \\
\text { [51] }\end{array}$ & $\begin{array}{l}\text { Simulation } \\
\text { studies }\end{array}$ & $\mathrm{HC}+\mathrm{LIVC}$ & 13 & - & $\begin{array}{l}\text { 2400rpm/ } \\
\text { 850kPa BMEP }\end{array}$ & $\begin{array}{l}\text { Improved BSFC } \\
\text { by } 6 \%\end{array}$ \\
\hline $\begin{array}{l}\text { Pertl et al. 2012, } \\
2015 \\
{[39,65]}\end{array}$ & $\begin{array}{l}\text { Simulation } \\
\text { and } \\
\text { experimenta } \\
1 \text { study }\end{array}$ & $\begin{array}{l}\text { Planetary } \\
\text { gear } \\
\text { cranktrain }\end{array}$ & 12.5 & 2.0 & $\begin{array}{l}\text { 6000rpm/ } \\
\text { 800kPa IMEPnet }\end{array}$ & $\begin{array}{l}\text { Improved } \\
\eta_{\text {net, } \text {,indicated }} \text { by } \\
14 \%\end{array}$ \\
\hline $\begin{array}{l}\text { Zhao et al. 2013, } \\
2018[59,60]\end{array}$ & $\begin{array}{l}\text { Simulation } \\
\text { study }\end{array}$ & $\mathrm{HC}+\mathrm{LIVC}$ & 12.5 & - & $\begin{array}{l}2000 \mathrm{rpm} / \\
210 \mathrm{kPa} \text { BMEP }\end{array}$ & $\begin{array}{l}\text { Improved BSFC } \\
\text { by } 10.5 \%\end{array}$ \\
\hline Ellies et al. & $\begin{array}{l}\text { Production } \\
\text { Engine } \\
\text { Benchmark }\end{array}$ & $\mathrm{HC}+\mathrm{LIVC}$ & $\begin{array}{l}13 \text { (geo.) } \\
5 \\
\text { (effect.) }\end{array}$ & 2.6 & $\begin{array}{l}\text { Combined Driving } \\
\text { Cycle }\end{array}$ & $\begin{array}{l}\text { Improved FE by } \\
3.4 \%\end{array}$ \\
\hline
\end{tabular}




\begin{tabular}{|c|c|c|c|c|c|c|}
\hline Hakariya et al. & $\begin{array}{l}\text { Production } \\
\text { Engine } \\
\text { Benchmark }\end{array}$ & $\mathrm{HC}+\mathrm{LIVC}$ & 13 & 13 & $\begin{array}{l}\text { 2400rpm/ 850kPa } \\
\text { BMEP }\end{array}$ & $\begin{array}{l}\text { Improved Peak } \\
\text { Efficiency by } \\
14 \%\end{array}$ \\
\hline $\begin{array}{l}\text { Wang et al. } \\
2012 \\
{[57]}\end{array}$ & $\begin{array}{l}\text { Simulation } \\
\text { study }\end{array}$ & $\begin{array}{l}\text { Mandatory } \\
\text { piston } \\
\text { movement } \\
\text { in } \\
\text { simulation }\end{array}$ & 10.4 & 1.3 & $\begin{array}{l}1500 \mathrm{rpm} / \\
350 \mathrm{kPa} \text { and } 850 \mathrm{kPa} \\
\text { BMEP }\end{array}$ & $\begin{array}{l}\text { Improved } \\
\eta_{\text {net, indicated by }} \text { by } \\
5.7 \% @ 850 \mathrm{kPa}\end{array}$ \\
\hline $\begin{array}{l}\text { Watanabe et al. } \\
2006 \\
{[38]}\end{array}$ & $\begin{array}{l}\text { Simulation } \\
\text { and } \\
\text { experimenta } \\
1 \text { study }\end{array}$ & $\begin{array}{l}\text { Multi-link } \\
\text { Cranktrain }\end{array}$ & 8.5 & 1.4 & - & $\begin{array}{l}\text { Improved } \\
\eta_{\text {net,indicated }} \text { by } \\
5 \%\end{array}$ \\
\hline $\begin{array}{l}\text { Koga et al. } \\
2007 \\
{[61]}\end{array}$ & $\begin{array}{l}\text { Experiment } \\
\text { al study }\end{array}$ & $\begin{array}{l}\text { Multi-link } \\
\text { Cranktrain }\end{array}$ & 8.5 & 1.4 & $\begin{array}{l}\text { 3060rpm } \\
\text { 1080kPa BMEP }\end{array}$ & $\begin{array}{l}\text { Improved } \\
\eta_{\text {net,indicated }} \text { by } \\
12.2 \%\end{array}$ \\
\hline $\begin{array}{l}\text { Takita et al. } \\
2011[62]\end{array}$ & $\begin{array}{l}\text { Experiment } \\
\text { al study }\end{array}$ & $\begin{array}{l}\text { Multi-link } \\
\text { Cranktrain }\end{array}$ & 12.2 & 1.4 & 1950rpm & $\begin{array}{l}\text { Improved } \\
\eta_{\text {power generation }} \mathrm{b} \\
\text { y } 3.8 \%\end{array}$ \\
\hline $\begin{array}{l}\text { Brendel. } 2013 \\
\text { [41] }\end{array}$ & $\begin{array}{l}\text { Experiment } \\
\text { al study }\end{array}$ & $\begin{array}{l}\text { Multi-link } \\
\text { Cranktrain }\end{array}$ & - & - & $5000 \mathrm{rpm}$ & $\begin{array}{l}\text { Reduced friction } \\
\text { with optimized } \\
\text { cranktrain }\end{array}$ \\
\hline $\begin{array}{l}\text { Anadhan et al. } \\
2018 \text { [63] }\end{array}$ & $\begin{array}{l}\text { Simulation } \\
\text { study }\end{array}$ & $\begin{array}{l}\text { Multi-link } \\
\text { Cranktrain }\end{array}$ & 10.0 & $\begin{array}{l}1.0 \\
\text { to } \\
1.5 \\
(\mathrm{SR}) \\
\end{array}$ & $\begin{array}{l}\text { 2000rpm } \\
1600 \mathrm{kPa} \text { IMEPnet }\end{array}$ & $\begin{array}{l}\text { Improved } \\
\eta_{\text {net,indicated }} \text { by } \\
10 \%\end{array}$ \\
\hline $\begin{array}{l}\text { Yang et al. } 2019 \\
{[68]}\end{array}$ & $\begin{array}{l}\text { Simulation } \\
\text { study }\end{array}$ & $\begin{array}{l}\text { Multi-link } \\
\text { Cranktrain }\end{array}$ & 9.2 & 1.5 & $\begin{array}{l}\text { 1300rpm/ 330kPa } \\
\text { IMEPnet, 1750rpm } \\
\text { 1030kPa IMEPnet }\end{array}$ & \begin{tabular}{|l} 
Improved \\
$\eta_{\text {net,indicated }}$ by \\
$12 \%$
\end{tabular} \\
\hline
\end{tabular}

Summarizing the literature in Table 9.1, it can be observed the over-expanded engine based on the high compression engine with LIVC has been widely studied and applied in the production vehicle. It should be note that the downside of LIVC is the decreased intake displacement, which results in a lower load capability. The strategy of LIVC can only be applied in the light to medium load conditions. Using a multi-link over-expanded engine can realize the same geometric intake placement as a baseline engine while extending the expansion stroke. Both two methods are very promising to realize an over-expanded cycle. However, the performance and efficiency differences between high compression engine with LIVC and multi-link over-expanded engine is not fully understood yet. It is worth to explore these two methods of improving spark-ignited engine at operating conditions. 
This study follows previous research by Yang et al. [68] and discusses the characteristics of a high compression engine with LIVC and an over-expanded, mechanically actuated Atkinson cycle engine. The results of the two engines were also compared to a baseline engine. This study aims to address the new topics listed below,

- Quantify the net indicated efficiency difference between a high compression engine and a multi-link over-expanded engine with LIVC at light load conditions, knock limited high load conditions, and operating conditions at peak brake efficiency of the high compression engine.

- Compare and examine the energy loss of the high compression engine and multilink over-expanded engine with respect to combustion phasing, combustion duration, in-cylinder heat transfer, and pumping work.

Based on these two new topics, the advantage of the multi-link over-expanded engine is quantified in comparison to the high compression engine and the baseline engine. The comparison study also includes the limitation of the over-expansion realized by high compression with LIVC. To further explore the potential of the efficiency improvement, the studied engines were compared at the peak efficiency point of the high compression engine. Most of the research regarding the over-expanded engine only investigated a single type engine. The analysis of the multi-link over-expanded with comparison to other high efficiency engine is not conducted yet but will be included in this study. These observations provide an insight of the future research and development of over-expanded engine which is able to further improve the efficiency of spark-ignited engine.

This study quantifies the characteristic differences of a high compression ratio engine and a multi-link over-expanded engine at different load conditions using 1-D simulation. The high compression ratio engine and multi-link over-expanded engine use the same calibration as the baseline engine. The baseline engine model was developed and calibrated based on the experimental results with the load control and spark timing control (maximum brake torque / knock limited). A kinetics-fit knock model was calibrated to predict the knock onset for three engines. The LIVC strategy of the high compression engine is realized by retarding the intake cam timing based on a conventional variable valve timing (VVT) system with the same intake cam profile. The multi-link over-expanded engine model simulated the dynamics of a multi-link mechanism. The mechanism design was constrained by CR, stroke, bore of the baseline engine, as well as the packaging. Three speed-load conditions of $1300 \mathrm{rpm} 330 \mathrm{kPa}$ IMEPnet, 1500rpm 1300kPa IMEPnet, and 2500rpm 1000kPa IMEPnet were selected with full optimization. At the selected operating conditions, the net indicated efficiency and energy loss were investigated among the three different types of engines. In this paper, "HC" denotes a high compression engine. The over-expanded cycle of the $\mathrm{HC}$ engine is realized by LIVC with extended intake valve duration at light load conditions. "Atkinson cycle engine" or "Atk" denotes the type of engine with a multi-link mechanism to realize the over-expanded cycle. Atkinson cycle 
engine also utilized LIVC strategy to optimize the intake cam timing and valve profile at light load condition.

\subsection{Methodology}

\subsubsection{Atkinson Cycle Mechanism}

The mechanism of the Atkinson cycle engine in this study is based on the research by Yang. et al.[68]. The geometric specification design of the Atkinson cycle engine was constrained to match the baseline engine geometric specifications, including bore, compression stroke, and intake stroke. In this study, the OER of the Atkinson engine was developed to be 1.5. The definition of OER is given in Equation 9-2

$$
O E R=\frac{E R}{C R}=\frac{V o l_{\text {piston } @ B D C \text { after expansion }}}{\text { Vol }_{\text {piston } @ B D C \text { after intake }}}
$$

To provide details on the characteristics of the cranktrain kinetics for the Atkinson cycle engine, a multi-link mechanism was modeled as shown in Figure 9.2. The geometric specification of each linkage and component is provided in Table 9.2.

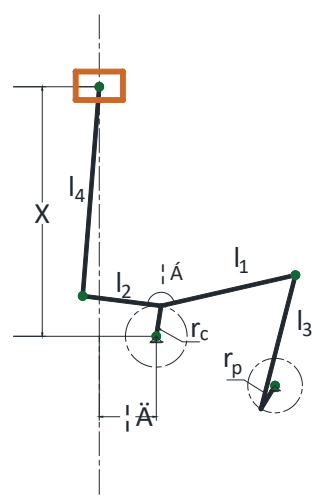

Table 9.2. Geometric specifications of Atkinson cycle mechanism with CR10.5

Figure 9.2. Schematic of the Atkinson mechanism

\begin{tabular}{cc}
\multicolumn{2}{c}{ and OER1.5 } \\
\hline \hline CR & 10.5 \\
ER & 15.8 \\
OER & 1.50 \\
Bore & $86 \mathrm{~mm}$ \\
Compression Stroke & $86 \mathrm{~mm}$ \\
Intake Stroke & $86 \mathrm{~mm}$ \\
$\mathbf{I}_{\mathbf{4}}$ & $221.4 \mathrm{~mm}$ \\
$\mathbf{I}_{\mathbf{2}}$ & $83.1 \mathrm{~mm}$ \\
$\mathbf{l}_{\mathbf{1}}$ & $164.6 \mathrm{~mm}$ \\
$\mathbf{l}_{\mathbf{3}}$ & $165.0 \mathrm{~mm}$ \\
$\mathbf{r}_{\mathbf{c}}$ & $35.2 \mathrm{~mm}$ \\
$\mathbf{r}_{\mathbf{p}}$ & $51.1 \mathrm{~mm}$ \\
$\boldsymbol{\delta}$ & $60 \mathrm{~mm}$ \\
$\boldsymbol{\alpha}$ & $159.9^{\circ}$ \\
\hline \hline
\end{tabular}

With the provided cranktrain mechanism model, the piston location and in-cylinder volume of the baseline and Atkinson cycle engine as a function of CA are shown in Figure 9.3 and Figure 9.4. In Figure 9.3, $18^{\circ}$ was set as the offset to compensate for the difference between 
crank and piston location at top dead center firing. The offsets of crank location and piston location also exist in the other three top dead center (TDC) / bottom dead centers (BDC).

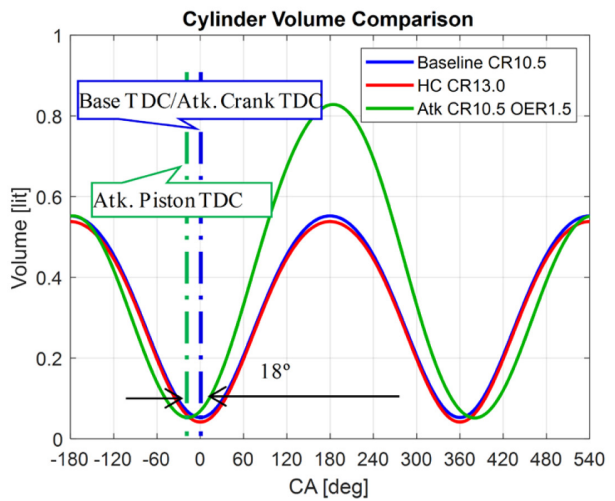

Figure 9.3. Piston location as a function of crank angle, baseline, and Atkinson mechanism. ("0" is at the TDC Firing)

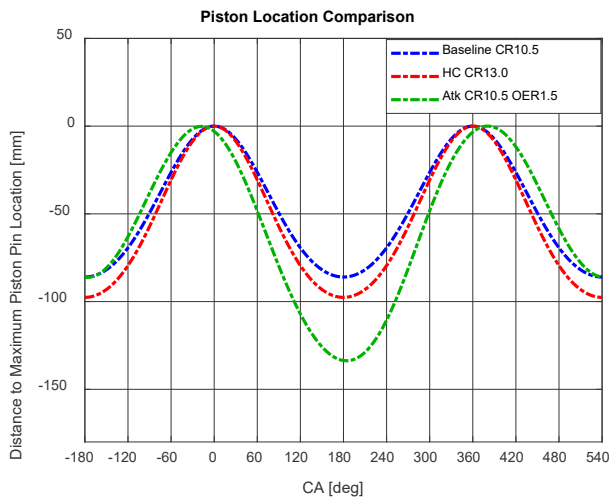

Figure 9.4. In-cylinder volume as a function of crank angle, baseline, and Atkinson mechanism. ("O" is at the TDC Firing)

Those offsets result in the different stroke durations between the baseline and the Atkinson cycle engine, e.g, intake and compression strokes of the baseline engine being $17^{\circ}$ and $21^{\circ}$ more than the Atkinson cycle engine, respectively. The characteristics of the geometric specification were summarized and listed in Table 9.3 for the baseline engine, high compression engine, and Atkinson cycle engine, including the stroke length and piston/incylinder volume location at each $180^{\circ}$ from baseline TDC firing.

As Table 9.3 shows, the geometric characteristics of the three engines are different. The spark timing, cam phasing, and valve lift used in the baseline engine should be adjusted before being applied to the Atkinson cycle engine. This was done by matching the piston location of different mechanisms by compensating the crank angle location. To maintain consistency, the valve timing and the spark timing of the Atkinson cycle engine use the same piston location as the baseline; however, the actual crank angle location of the Atkinson cycle engine was adjusted corresponding to the method provided by Yang et al. [68]. The adjustment of the Atkinson cycle engine includes the spark timing, cam timing, and the profile of the valve lift. 
Table 9.3 Geometry Summary of Baseline Engine, HC engine, and Atkinson Engine

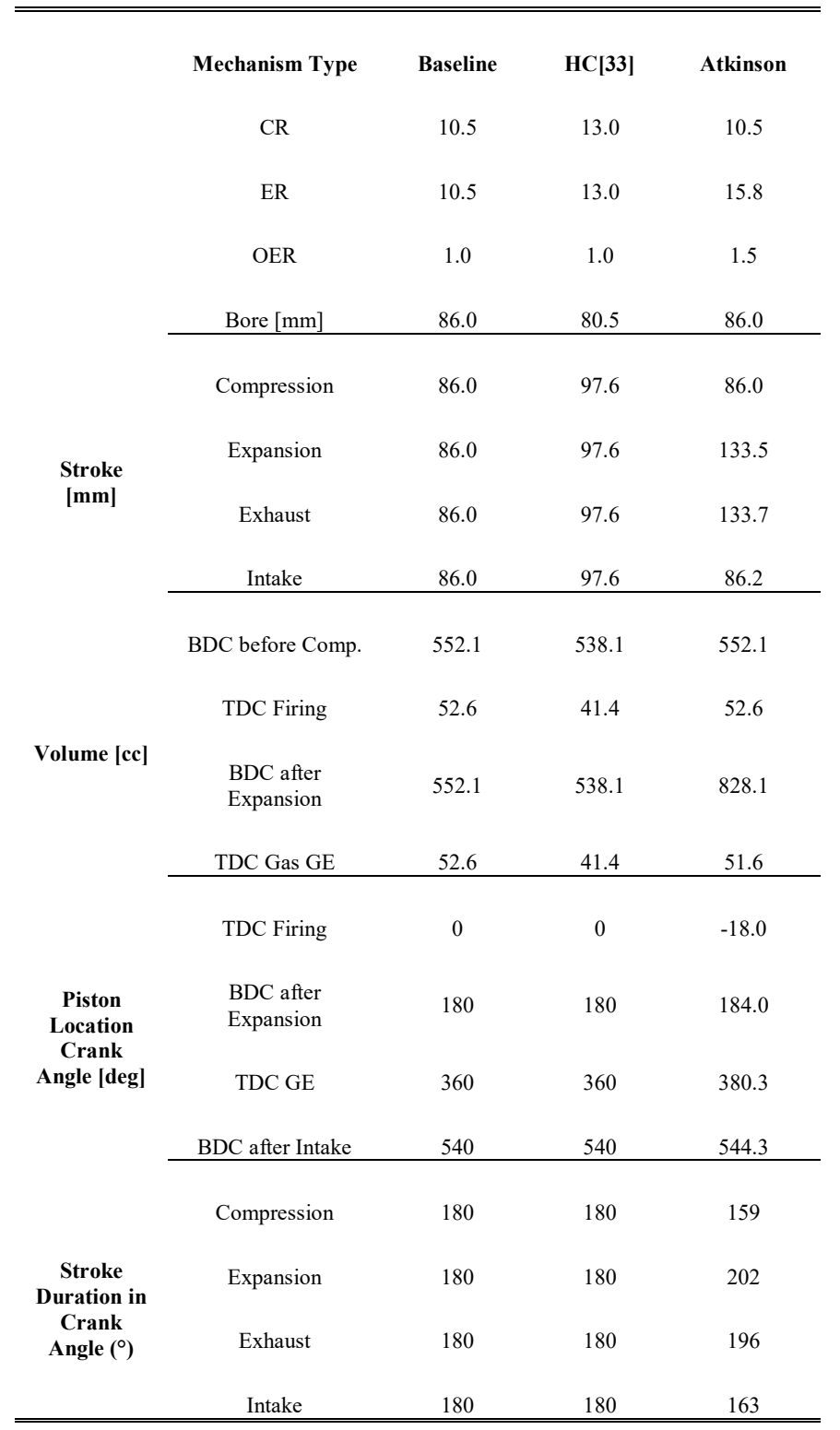

In the studied Atkinson cycle engine mechanism, the spark timing of the Atkinson cycle engine was advanced $18^{\circ} \mathrm{CA}$ compared to baseline based upon the TDC firing shift. Cam timing adjustment of the Atkinson cycle engine was dependent on the crank location where the piston was at TDC/BDC. The shift of intake cam phasing refers to the TDC gas exchange (GE) and BDC after intake stroke (Equation 9-3); the shift of exhaust cam phase refers to the BDC after the expansion stroke and TDC GE (Equation 9-4). The valve opening duration was scaled based on the ratio of stroke length between the two engines, as shown in Equation 9-5 and Equation 9-6 


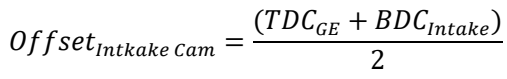

$$
\begin{aligned}
& \text { Offset }_{\text {Exhaust Cam }}=\frac{\left(T D C_{G E}+B D C_{\text {Exhaust }}\right)}{2} \quad 9-4 \\
& \text { Scale }_{\text {Intake valve duration / lift }}=\frac{\text { Stroke }_{\text {Atk, Intake }}\left({ }^{\circ}\right)}{180} \quad 9-5 \\
& \text { Scale }_{\text {Exhaust valve duration } / \text { lift }}=\frac{\text { Stroke }_{\text {Atk Exhaust }}\left({ }^{\circ}\right)}{180} \quad 9-6
\end{aligned}
$$

The valve lift adjustment of the intake and exhaust valve is shown in Figure 9.5. The exhaust valve opening duration was modified by adding dwell at the maximum valve lift with $16^{\circ} \mathrm{CA}$ to match the exhaust stroke of the Atkinson cycle engine. The intake valve lift of the Atkinson cycle engine was scaled by 0.91 using Equation 9-6. The adjustment of valve timing and cam profile are summarized in Table 9.4.

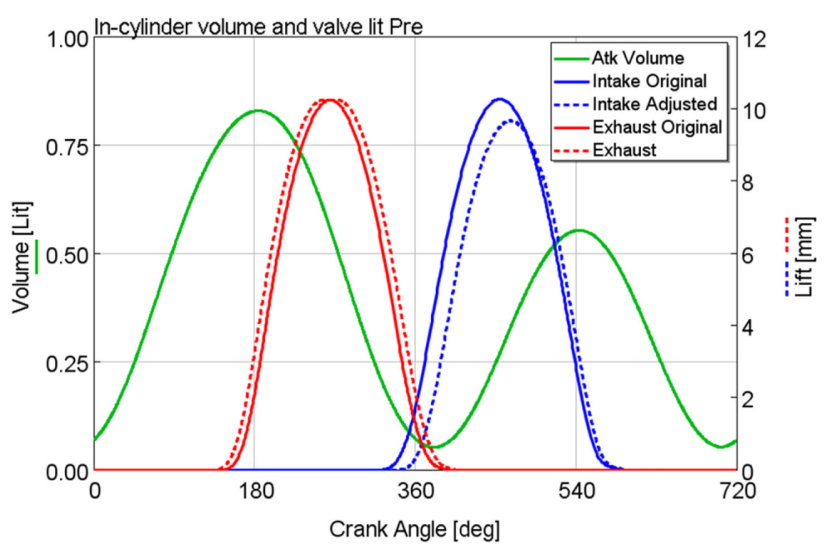

Figure 9.5. Volume, valve lift as a function of crank angle of Atkinson cycle engine Table 9.4. Valve timing and cam profile adjustment

\begin{tabular}{lcc}
\hline \hline & Intake & Exhaust \\
\hline Cam Timing Offset $\left[{ }^{\circ} \mathbf{C A}\right]$ & 5.9 & 6.1 \\
Scale $_{\text {valve duration } / \text { lift }[-]}$ & 0.91 & - \\
Cam Profile Dwell at max. valve lift $\left[{ }^{\circ} \mathbf{C A}\right]$ & - & 16 \\
\hline \hline
\end{tabular}




\subsubsection{Experimental Results and Model Setup}

The baseline engine was modified based on a GM, Ecotec, boosted, direct-injected, sparkignited, inline 4-cylinder engine with $\mathrm{CR}$ of 9.2:1. In the simulation, compression ratio was modified from 9.2 to 10.5 to represent state-of-the-art of engine technology with respect to current knock mitigation strategies (e.g. Volvo T6 $\mathrm{CR}=10.3: 1$, BMEP $=2500 \mathrm{kPa}$ [94], Toyota A25A-FKS 2.5L CR=10.4:1, BMEP $=1300 \mathrm{kPa}$ [53], and Ford Duratec $\mathrm{CR}=10.5$, $\mathrm{BMEP}=1300 \mathrm{kPa}[95])$. The specification of the $\mathrm{HC}$ engine was referenced from the design of Toyota M20A-FKS 2.0L CR 13:1 [33].

The engine simulation was performed with the commercial engine program (GT-Suite / GT-Power). The combustion model used in this study was an SI turbulence model. Engine in-cylinder heat-transfer used Woschni's correlation [89]. A spark timing controller was added to control the spark advance at maximum brake torque (MBT) or knock limited condition. According to the Atkinson cycle engine study by Yang et al. [68], combustion phasing of $50 \%$ mass fraction burn of fuel (CA50) of $10^{\circ}$ aTDC is defined as MBT spark advance for the study of the Atkinson cycle engine. Detail of the knock model used in this study will be provided in the following section.

In this study, the tested fuel was $10 \%$ ethanol-blended gasoline (E10). The anti-knock index of the fuel used in the simulation was (RON+MON/2) of 91.0.

The major sensors used in the experimental study are listed in Table.9.5. Advanced Combustion Analyzer Program (ACAP) is the data acquisition system (DAQ) used for realtime monitoring combustion metrics and recording experimental data. The baseline model was developed and calibrated based on the experimental data over a wide range of speed and load conditions including the two conditions as Table 9.6 shows. Valve timing of two baseline operating conditions is given in Table 9.7. In the experimental study at $1500 \mathrm{rpm}$ $1440 \mathrm{kPa}$ IMEPnet, the knock limited spark timing was used to maintain the average knock

peak-peak at $200 \mathrm{kPa}$. The experimental results of the cycle with the 95th percentile of knock peak-peak were selected for the model $[22,66]$ calibration. The definition of knock onset in the experiment refers to the method used by Vikram et al.[96], when knock peakto-peak pressure oscillations exceed $200 \mathrm{kPa}$. In the simulation, knock onset is predicted by the calibrated kinetics-fit model [22,66], which will be discussed in the following section. The comparison of the experimental data to simulation results is given in Table 9.6. 
Table.9.5. In-cylinder pressure transducer, manifold pressure, encoder, and fuel flow meter of Experimental Study

\begin{tabular}{cc}
\hline & Model. \\
\hline In-cylinder Pressure Transducer & AVL GH12D \\
\hline Manifold Pressure & PX310-030 G5V \\
\hline Encoder & EPC 260 \\
\hline Fuel Mass Flow Coriolis Meter & Micro Motion 1700 \\
\hline
\end{tabular}

Table 9.6. Baseline engine calibration of 1300rpm, 330kPa IMEPnet and 1500 rpm $1400 \mathrm{kPa}$ IMEPnet, (experimental data: the cycle of 95th percentile of knock peak-peak)

\begin{tabular}{ccccc}
\hline & Exp. & Sim. & Exp. & Sim. \\
\hline Speed (rpm) & 1300 & 1300 & 1500 & 1500 \\
\hline IMEPnet (kPa) & 330 & 330 & 1440 & 1440 \\
\hline MAP (kPa) & 47.5 & 47.3 & 129.6 & 129.5 \\
\hline Net indicated efficiency (\%) & 33.2 & 33.1 & 37.8 & 37.7 \\
\hline Total Fuel flow (g/s) & 0.51 & 0.52 & 2.3 & 2.3 \\
\hline $\begin{array}{c}\text { Location of peak pressure } \\
\left({ }^{\circ} \mathbf{A T D C}\right)\end{array}$ & 11.8 & 11.8 & 21.1 & 21.0 \\
\hline Peak pressure (kPa) & 2160 & 2170 & 6520 & 6730 \\
\hline Knock Onset $\left({ }^{\circ} \mathbf{A T D C}\right)$ & - & - & 21.1 & 21.0 \\
\hline \hline
\end{tabular}

Table 9.7. Valve timing of the experimental results

\begin{tabular}{ll}
\hline \hline Exhaust Valve Open & $27^{\circ}$ BBDC @ $0.2 \mathrm{~mm} \mathrm{lift}$ \\
Exhaust Valve Close & $14^{\circ}$ ATDC @ $0.2 \mathrm{~mm} \mathrm{lift}$ \\
Inlet Valve Open & $15^{\circ}$ BTDC @ $0.2 \mathrm{~mm} \mathrm{lift}$ \\
Inlet Valve Close & $37^{\circ}$ ABDC @ $0.2 \mathrm{~mm}$ lift \\
\hline \hline
\end{tabular}

\subsubsection{Knock Onset Prediction and Model Constrains}

Knock investigation in this study was based on the empirical induction-time correlation [22]. The induction time of the empirical relation utilized the kinetic mechanism given by 
Ra. et al. [66]. Three induction times, $\tau_{1}, \tau_{2}$, and $\tau_{3}$ were utilized to represent the low, intermediate, and high temperature regions, respectively, as shown in Equation 9-7. The calculation of the overall induction time $\tau$ is shown in Equation 9-8, which considers the effect of octane number, fuel concentration, oxygen concentration, dilution, and unburnt zone temperature. The overall induction time as a function of unburnt zone temperature based on the simulation results at $1500 \mathrm{rpm} 1300 \mathrm{kPa}$ IMEPnet are shown in Figure 9.6. As Equation 9-9 shows, knock was predicted to occur when the induction time integral reaches 1.0 in the simulation. The model was calibrated based on the knock onset from the experimental data, as shown in Table 9.6.

$$
\begin{aligned}
& \frac{1}{\tau}=\frac{1}{\tau_{1}+\tau_{2}}+\frac{1}{\tau_{3}} \\
& \tau_{i}=M_{1} a_{i}\left(\frac{\text { ON }}{100}\right)^{b_{i}}[\text { Fuel }]^{c_{i}}\left[O_{2}\right]^{d_{i}}[\text { Diluent }]^{e_{i}} \operatorname{Exp}\left(\frac{f_{i}}{M_{2} T}\right) \\
& \int_{t=0}^{t_{i}} \frac{d t}{\tau}=1
\end{aligned}
$$

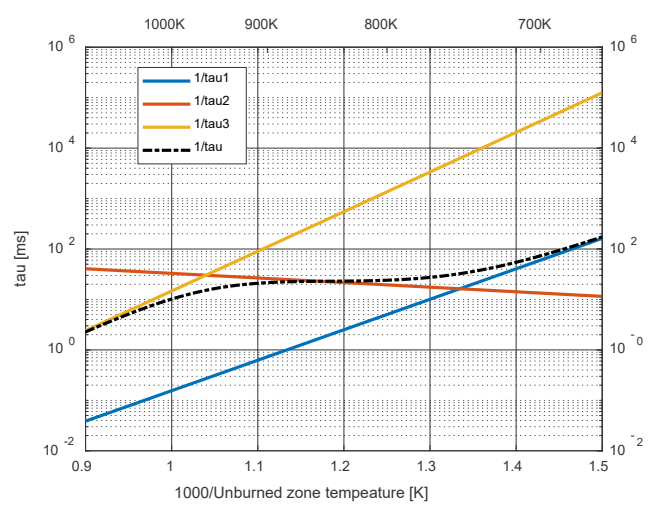

Figure 9.6. Induction time $\left(\tau_{1}, \tau_{2}, \tau_{3}\right.$, and $\left.\tau\right)$ as a function of unburned zone temperature at $1500 \mathrm{rpm} 1300 \mathrm{kPa}$ IMEPnet, optimized condition

\subsubsection{Model Constraints}

In this study, the model constraints include knock level, residual gas fraction, and trapping ratio, as shown in Table 9.8. 
Table 9.8. Model constraints of baseline engine, $\mathrm{HC}$ engine, and Atkinson cycle engine

\begin{tabular}{cccc}
\hline \hline $\begin{array}{c}\text { Model } \\
\text { Constrains }\end{array}$ & $\begin{array}{c}\text { Unburn mass } \\
\text { fraction at knock } \\
\text { onset } \leq 10 \%\end{array}$ & $\begin{array}{c}\text { Residual Gas } \\
\text { Fraction } \leq \\
30 \%\end{array}$ & $\begin{array}{c}\text { Trapping } \\
\text { Ratio } \geq 99 \%\end{array}$ \\
\hline $\begin{array}{c}\text { Controlling } \\
\text { Parameter }\end{array}$ & $\begin{array}{c}\text { Spark Timing of } \\
\text { SI Turbulence } \\
\text { Model }\end{array}$ & $\begin{array}{c}\text { CAM } \\
\text { Timing }\end{array}$ & $\begin{array}{c}\text { CAM } \\
\text { Timing }\end{array}$ \\
\hline \hline
\end{tabular}

The knock constraint was controlled by the spark timing within the SI turbulence combustion model. Research by Chun et al. shows a good correlation between mean knock intensity and unburned mass fraction at knock onset [67]. In this study, the knock-limited spark advance (KLSA) was defined as the spark advance where the knock onset is at $10 \%$ unburned mass fraction. If knock occurred in the simulation, remaining unburned fuel is forced to be burned in the next time step of knock onset.

Residual gas fraction (RGF) and trapping ratio were controlled by adjusting cam timing. The constraints of RGF and trapping ratio are no more than $30 \%$ and no less than $99 \%$, respectively. RGF is defined as the ratio of total trapped mass of burned gas over total mass trapped in the cylinder, as shown in Equation 9-10. Trapping ratio is utilized to quantify the scavenging effect. The definition of trapping ratio is unburned non-fuel gas trapped in the cylinder divided by the total mass of unburned non-fuel gas through the intake valve into the cylinder, as shown in Equation 9-11.

$$
\begin{gathered}
R G F=\frac{\text { mass }_{\text {trapped burned gas }}}{\text { mass }_{\text {trapped gas total }}} \\
\text { trapping ratio }=\frac{\text { mass }_{\text {trapped }}}{\text { mass }_{\text {total through intake valve into cylinder }}}
\end{gathered}
$$

\subsection{Results and Discussion}

One of the characteristics of an Atkinson cycle engine is the over-expansion in the power stroke. As the piston movement is different between baseline and Atkinson cycle engine, the definition of the indicated work and pumping work should also be modified according to the mechanism difference. As Figure 9.7 shows, the whole engine cycle of an Atkinson cycle engine at part load conditions can be broken down into the portion of gross indicated work (blue and yellow, a $\rightarrow$ c, Figure 9.8) and the pumping work (red, $c \rightarrow$ a, Figure 9.8). For an Atkinson cycle engine, the gross indicated work can be further separated as the portion of non-over-expansion (blue, $\mathrm{a} \rightarrow \mathrm{b}$ ) and over-expansion (yellow, $\mathrm{b} \rightarrow \mathrm{c}$ ).

In the Atkinson cycle, OE indicated efficiency ( $\eta_{\text {indicated,oE }}$, Equation 9-13) quantifies the indicated work during over expansion normalized by the fuel energy. The non-OE indicated efficiency ( $\eta_{\text {indicated, non-OE,net }}$, Equation 9-14), quantifies the indicated work 
of non-OE portion normalized by the fuel energy (non-OE indicated efficiency, $\left.\eta_{\text {indicated,non-OE,net }}\right)$. As the non-OE indicated efficiency excludes over-expansion, $\eta_{\text {net indicated,non-OE }}$ is comparable to the net indicated work of a baseline engine. The calculation of the normalized pumping work is listed in Equation 9-15.

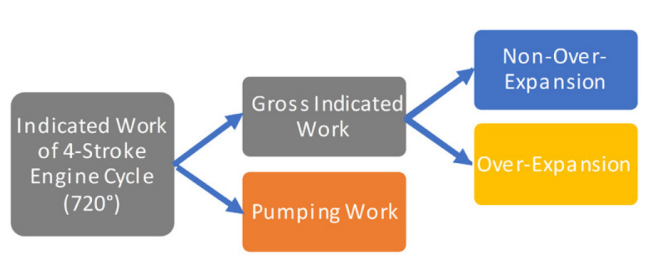

Figure 9.7. Indicated work of Atkinson cycle breakdown

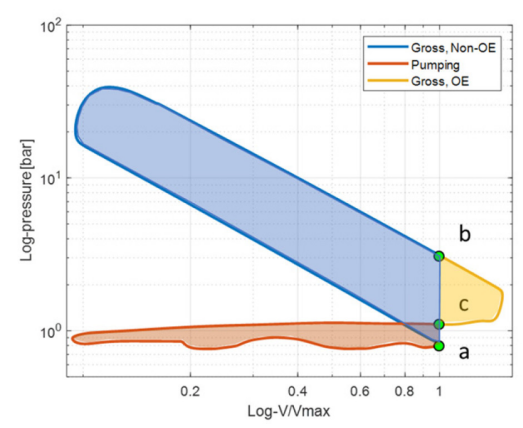

Figure 9.8. Gross loop and pumping loop in an Atkinson cycle $\log \mathrm{P}-\log$ $\mathrm{V} / \mathrm{Vmax}$ diagram (Vmax is the maximum in-cylinder volume at the end of intake stroke)

$$
\begin{aligned}
& \eta_{\text {net indicated }}=\frac{\text { Work }_{G_{-} \text {Non_oE }}+\text { Work }_{G_{\text {GOE }}}+\text { Work }_{\text {Pumping }}}{\text { Fuel Energy }} \\
& \eta_{\text {indicated,oE }}=\frac{\text { Work }_{\text {G_oE }}}{\text { Fuel Energy }} \\
& \eta_{\text {net indicated,non-OE }}=\frac{\text { Work }_{G_{-} \text {Non_oE }}+\text { Work }_{\text {Pumping }}}{\text { Fuel Energy }} \\
& \eta_{\text {pumping loss }}=\frac{\text { Work }_{\text {Pumping }}}{\text { Fuel Energy }}
\end{aligned}
$$

Three operating conditions were investigated in this study as shown in Table 9.9. In FTP75 and US06 driving cycles, the operating conditions of 1300rpm, 330kPa IMEPnet representative of high probability and fuel consumption conditions were selected in this study. The operating condition of $1500 \mathrm{rpm} 1300 \mathrm{kPa}$ IMEPnet is representative of a knock limited condition. The operation condition of $2500 \mathrm{rpm} 1000 \mathrm{kPa}$ IMEPnet represents the peak brake efficiency point of the $\mathrm{HC}$ engine [33]. 
Table 9.9. The operating condition of simulation

\begin{tabular}{cc}
\hline \hline Speed [rpm] & IMEPnet [kPa] \\
\hline $\mathbf{1 3 0 0}$ & 330 \\
$\mathbf{1 5 0 0}$ & 1300 \\
$\mathbf{2 5 0 0}$ & 1000 \\
\hline \hline
\end{tabular}

A cam timing sweep for the intake and exhaust camshaft was conducted for the optimization at the three operating conditions. The optimized cam timing was at the condition of the highest net indicated efficiency with constraints. In Figure 9.9, cam timing is expressed by the exhaust cam maximum opening position (EMOP) and intake valve closing (IVC). Blue and red points represent the conditions of non-LIVC and LIVC, respectively. At the non-LIVC conditions, IVC was swept from $-150^{\circ}$ to $-110^{\circ}$ aTDC firing $\left(\mathrm{IMOP}=95^{\circ}\right.$ to $\left.135^{\circ} \mathrm{aTDC}\right)$. EMOP was swept from $-135^{\circ}$ to $-95^{\circ}$ aTDC GE. In the nonLIVC cam timing, valve overlap was $-40^{\circ} \mathrm{CA}$ and $+40^{\circ} \mathrm{CA}$, respectively, at IVC $=-$ $150^{\circ}$ aTDC firing, $\mathrm{EMOP}=-95^{\circ} \mathrm{aTDC} \mathrm{GE}$ (rectangle mark), and $\mathrm{IVC}=-110^{\circ} \mathrm{aTDC}$ firing, $\mathrm{EMOP}=-135^{\circ} \mathrm{aTDC}$ GE (circle mark) shown in Figure 9.9.

The LIVC condition was simulated with an extra 45 points as shown in Figure 9.9. At these LIVC conditions, IVC was swept from $-105^{\circ}$ to $-85^{\circ}$ aTDC firing. EMOP of LIVC condition was swept at the same range as non-LIVC condition with expanded intake valve duration. Figure 9.10 depicts the valve lift of the high compression engine at non-LIVC and LIVC conditions. The IVO at LIVC condition was held as same as the non-LIVC condition of IVC at $-145^{\circ}$ aTDC firing. The LIVC used an extended intake valve duration, reducing the effective intake displacement resulting in decreased load capability. As such, LIVC with extended intake valve duration was applied on the high compression engine and Atkinson cycle engine at 1300rpm 330kPa IMEPnet in this study. In practical application, LIVC without a performance penalty can be realized with a Cam Lobe Switch System, e.g. Honda VTEC [97].

It is important to note that the actual cam timing of the Atkinson cycle engine was adjusted based on the cam timing sweep used in Figure 9.9. The adjustment method refers to the results mentioned earlier in Table 9.4.
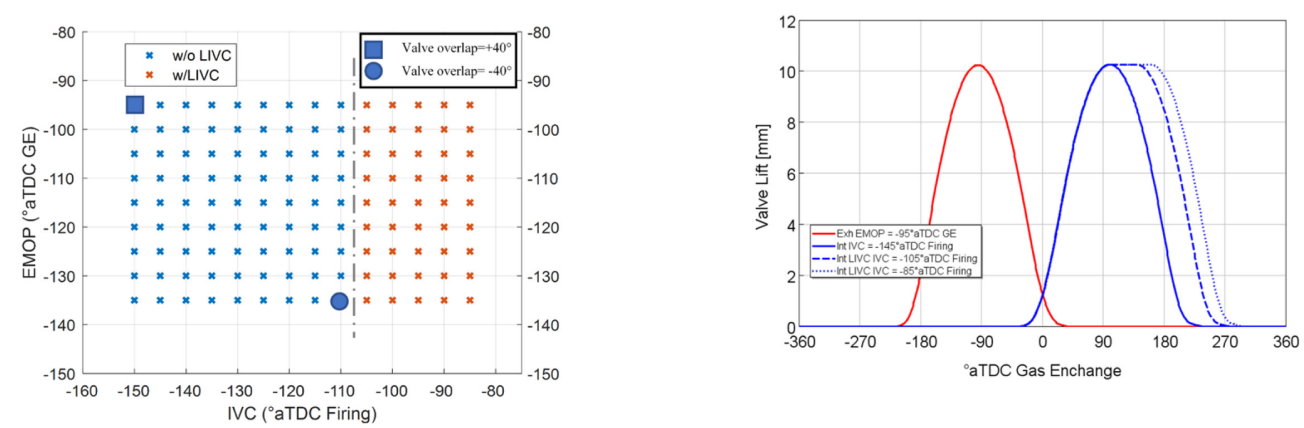
Figure 9.9. Intake and Exhaust Cam

Timing Sweep for Optimization
Figure 9.10. Valve lift of Non-LIVC and LIVC condition of $\mathrm{HC}$ engine at $1300 \mathrm{rpm}$ $\underline{330 \mathrm{kPa} \text { IMEPnet }}$

\subsubsection{Atkinson cycle engine at 1300rpm 330kPa IMEPnet}

The simulations of the baseline engine, high compression engine, and Atkinson cycle engine were performed with an 81-point cam phasing sweep at 1300rpm 330kPa IMEPnet as shown in Figure 9.9. The high compression engine and Atkinson cycle engine was performed with an additional 45-points with LIVC by extending the intake valve duration. The net indicated efficiencies as a function of intake and exhaust cams are shown in Figure 9.11. The optimized cam timing for each engine is also highlighted in Figure 9.11. Figure 9.12, shows the RGF at different cam timing. With the constraint of RGF, the optimized intake cam timings were retarded by $10^{\circ} \mathrm{CA}$ on average compared to the cam timing at the highest net indicated efficiency. The two figures on the right side in Figure 9.11 represent the high compression engine with LIVC and Atkinson cycle engine with LIVC, respectively. The $\mathrm{x}$-axis in the figure of the LIVC conditions was swept from $-105^{\circ}$ to $85^{\circ}$ aTDC firing. The optimized cam timing of high compression with LIVC was located at most retarded EMOP and IVC. The optimized cam timing of the Atkinson cycle engine with LIVC was at IVC $-95^{\circ}$ aTDC firing, EMOP $-100^{\circ}$ aTDC GE and constrained by RGF. 

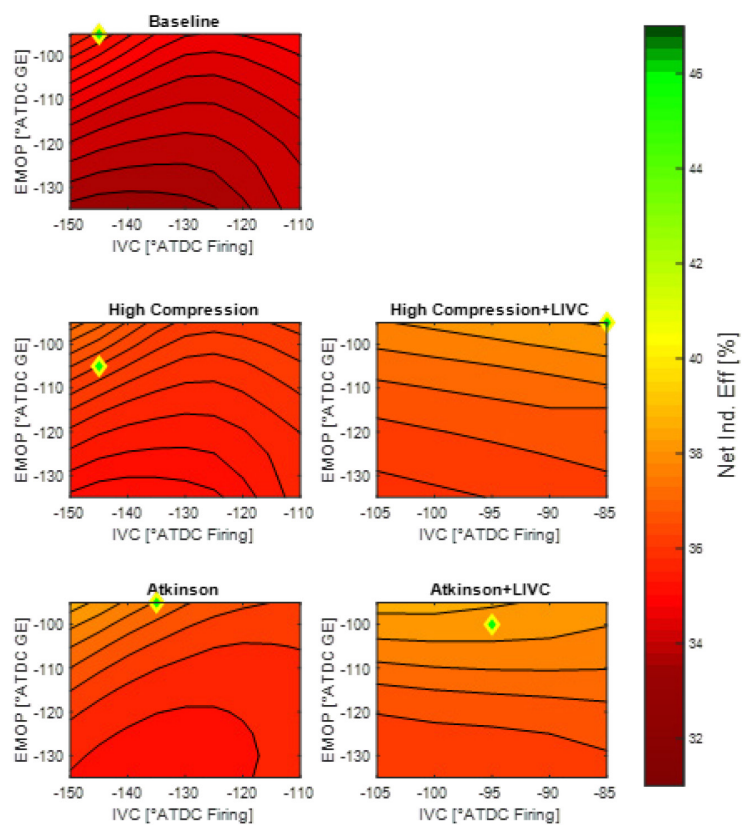

Figure 9.11. Net indicated efficiency as a function of IVC and EMOP, baseline engine, $\mathrm{HC}$ engine, and Atkinson cycle engine at 1300rpm 330kPa IMEPnet
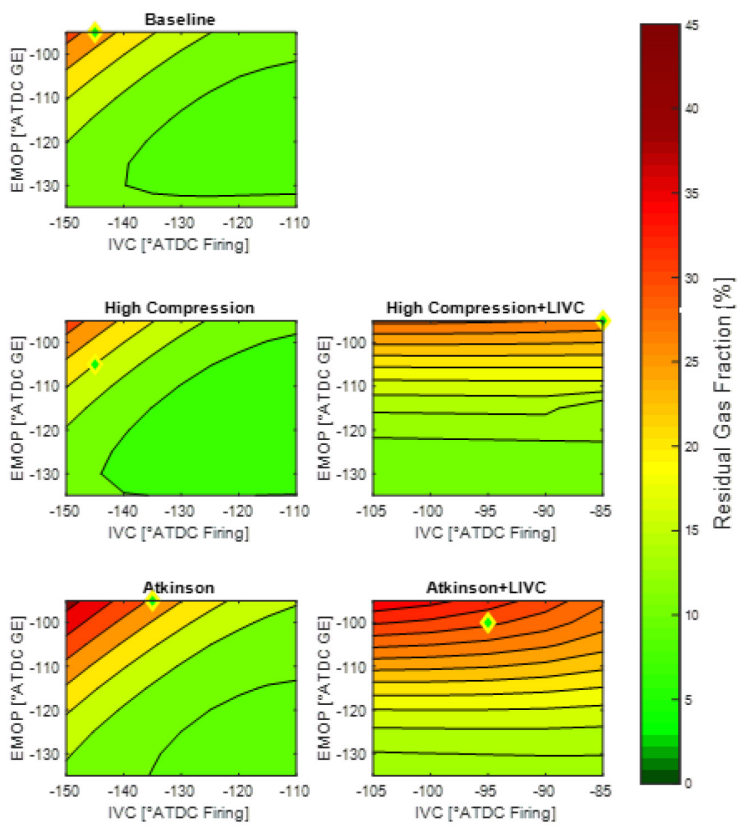

Figure 9.12. RGF as a function of IVC and EMOP, baseline engine, HC engine, and Atkinson cycle engine at 1300rpm 330kPa IMEPnet 
The optimized cases of three engines are compared as shown in Table 9.10. "Atkinson" represents the multi-link over-expanded engine. "HC+LIVC" and "Atk+LIVC" represent the high compression engine and Atkinson cycle engine using an extended intake valve duration to realize LIVC. As Table 9.10 shows, CA50 and the RGF of three engines were controlled at $10^{\circ}$ aTDC and below the constraint of $30 \%$, respectively. The manifold absolute pressure (MAP) of the baseline engine, HC engine with LIVC, and Atkinson cycle engine with LIVC were $52 \mathrm{kPa}, 72 \mathrm{kPa}$, and $80 \mathrm{kPa}$, respectively. The strategy of LIVC reduced the pumping mean effective pressure (PMEP) for high compression engine and Atkinson cycle engine by $21 \mathrm{kPa}$ and $24 \mathrm{kPa}$, respectively, compared to the same engine without LIVC.

Table 9.10. Results of baseline engine, HC engine, and Atkinson cycle engine of optimized cam timing, at 1300rpm, 330kPa IMEPnet,

\begin{tabular}{cccccc}
\hline \hline & Baseline & HC & HC+LIVC & Atkinson & Atk+LIVC \\
\hline IVO [ ${ }^{\circ}$ ATDC GE] & -44 & -39 & -39 & -44 & -39 \\
\hline IVC [ ${ }^{\circ}$ ATDC Firing] & -145 & -145 & -90 & -135 & -95 \\
\hline EMOP [ ${ }^{\circ}$ ATDC GE] & -95 & -95 & -95 & -95 & -95 \\
\hline $\boldsymbol{\lambda}$ & 1.00 & 1.00 & 1.00 & 1.00 & 1.00 \\
\hline $\begin{array}{c}\text { Combustion Phasing } \\
{\left[{ }^{\text {ATDC of CA50] }}\right.}\end{array}$ & 10 & 10 & 10 & 10 & 10 \\
\hline $\begin{array}{c}\text { Total Net indicated } \\
\text { efficiency [\%] }\end{array}$ & 35.5 & 37.1 & 38.6 & 37.4 & 38.3 \\
\hline $\begin{array}{c}\text { OE indicated } \\
\text { efficiency [\%] }\end{array}$ & - & - & - & 1.5 & 1.0 \\
\hline $\begin{array}{c}\text { Residual Gas Fraction } \\
{[\%]}\end{array}$ & 28 & 28 & 28 & 29 & 30 \\
\hline PMEP [kPa] & 48 & 50 & 29 & 45 & 21 \\
\hline MAP [kPa] & 52 & 51 & 72 & 55 & 80 \\
\hline \hline
\end{tabular}

Figure 9.13 is the log PV diagram at the optimized condition of three engines. The red, blue and, green curves represent the baseline engine, high compression engine, and Atkinson cycle engine, respectively. Blue and dash lines represent non-LIVC and LIVC conditions, respectively. With LIVC, the starting of the compression was around 0.7 of $\mathrm{V} / \mathrm{Vmax}$. Vmax is the maximum in-cylinder volume at the end of the intake stroke. The effect of de-throttling was obvious with LIVC. The manifold absolute pressure (MAP) difference between non-LIVC and LIVC for high compression engine and Atkinson cycle engine was $21 \mathrm{kPa}$ and $25 \mathrm{kPA}$, respectively.

Figure 9.14 is the bar chart comparing the net indicated efficiency of the baseline engine, HC, HC+LIVC, Atkinson, and Atkinson+LIVC, which were 35.5\%, 36.7\%, 38.6\%, 37.4\%, and $38.3 \%$, respectively. The high compression engine with LIVC increased the net indicated efficiency by $8.7 \%$ (relative) compared to the baseline. At the non-LIVC condition, the net indicated efficiency of the Atkinson cycle engine is separated into portions of $36.0 \%$ non-over-expansion (non-OE) and $1.5 \%$ over-expansion (OE), 
respectively. With the LIVC strategy, the OE efficiency of the Atkinson cycle engine was lower due to the lower in-cylinder pressure at expansion.

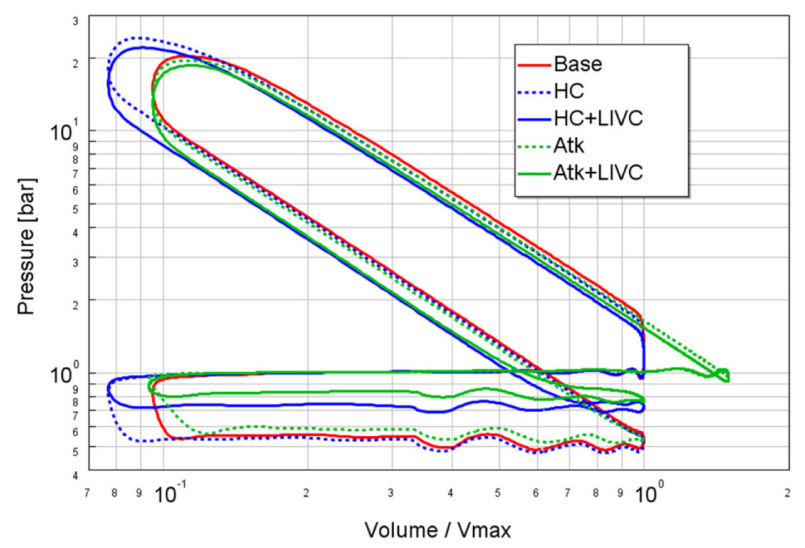

Figure 9.13. Log PV diagram of baseline engine, $\mathrm{HC}$ engine, and Atkinson cycle engine at $1300 \mathrm{rpm} 330 \mathrm{kPa}$ IMEPnet, knock limited spark timing, cam timing optimized (Vmax is the maximum in-cylinder volume at the end of intake stroke)

Figure 9.14. Net indicated efficiency of baseline engine, $\mathrm{HC}$ engine, and Atkinson cycle engine at $\underline{1300 \mathrm{rpm}, 330 \mathrm{kPa} \text { IMEPnet }}$

A breakdown of the energy losses was conducted to quantify the energy loss difference between the three engines. Figure 9.15 is the flow chart of the energy loss calculation. The calculation of each factor is shown from Equation 9-16 to Equation 9-19. Pumping loss was determined by the pumping work normalized by the fuel energy from Equation 9-16. Calculations of other energy losses from factor 2 to factor 4 are given from Equation 9-17 to Equation 9-19, respectively. For example, the combustion phasing loss calculation (Factor 2) was the efficiency difference between the optimized combustion phasing condition and the original case. 


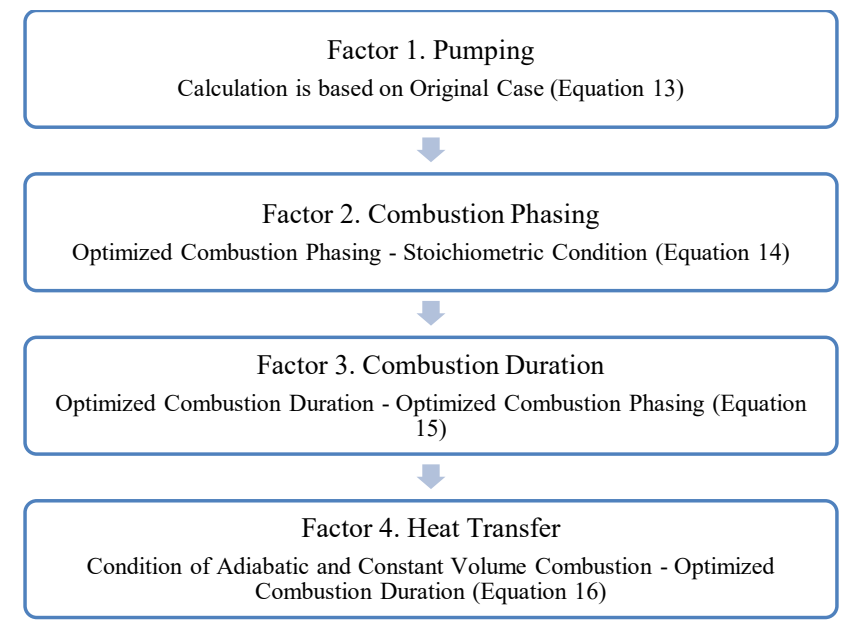

Figure 9.15. Flow chart of energy loss calculation

$$
\begin{array}{ll}
\text { LosS }_{\text {pumping }}=\text { Work }_{\text {Pumping }} / \text { Fuel Energy } & 9-16 \\
\text { Loss }_{\text {comb.phasing }}=\eta_{\text {original }}-\eta_{\text {opt.comb.phasing }} & 9-17 \\
\text { Loss }_{\text {comb.duration }}=\eta_{\text {opt.comb.phasing }}-\eta_{\text {opt.comb duration }} & 9-18 \\
\text { LosS }_{H T}=\eta_{\text {opt.comb duration }}-\eta_{H T \text { off }} &
\end{array}
$$

Figure 9.16, compares the energy loss of the three engines at the optimized condition. Pumping loss of the baseline engine was at 5.2\%. With the LIVC, the pumping loss of a high compression engine was $1.9 \%$ lower (absolute) than the baseline engine. The pumping loss of the Atkinson cycle engine is the lowest at $2.4 \%$ due to the combining effect of overexpansion realized by LIVC and multi-link mechanism. No combustion phasing loss was observed at 1300rpm 330kPa IMEPnet due to the spark timing being controlled at MBT condition. The combustion duration losses were close among all three engines

In Figure 9.16, the heat transfer of the baseline engine, high compression engine, and Atkinson cycle engine were $5.5 \%, 6.6 \%$, and $6.0 \%$, respectively. With the higher 
compression ratio of the high compression engine, the peak in-cylinder pressure of the high compression engine was higher than the other two engines. The in-cylinder temperature follows the trend of pressure resulting in higher heat transfer loss in the high compression engine. The heat transfer of the Atkinson was $0.5 \%$ higher than the baseline mainly due to the longer duration $\left(22^{\circ} \mathrm{CA}\right)$ and larger cylinder surface area $(50 \%$ higher, relative $)$ of the expansion stroke. Heat transfer of the high compression engine was $0.6 \%$ higher (absolute) than for the Atkinson cycle engine. A heat transfer breakdown chart of the Atkinson cycle engine is shown in Figure 9.17. The non-OE portion heat transfer of the Atkinson cycle engine is $0.3 \%$ lower (absolute) than the baseline engine mainly due to the faster piston movement speed and lower peak pressure. The OE portion heat transfer of the Atkinson cycle engine is $0.8 \%$.

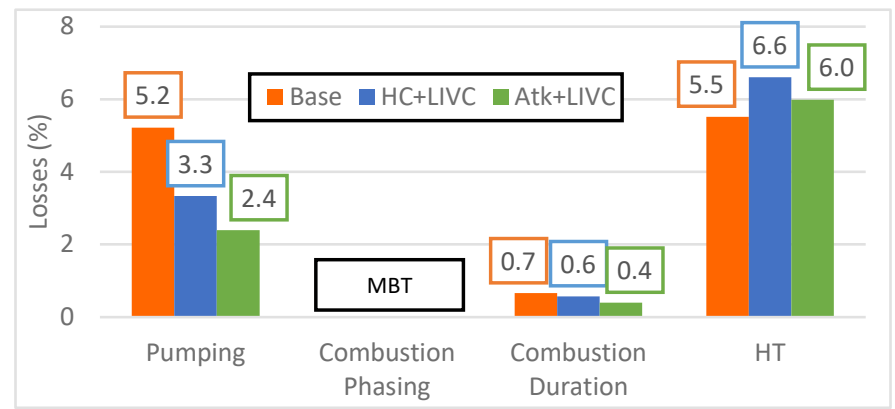

Figure 9.16. Efficiency losses of baseline engine, $\mathrm{HC}$ engine, and Atkinson cycle engine at $1300 \mathrm{rpm}, 330 \mathrm{kPa}$ IMEPnet

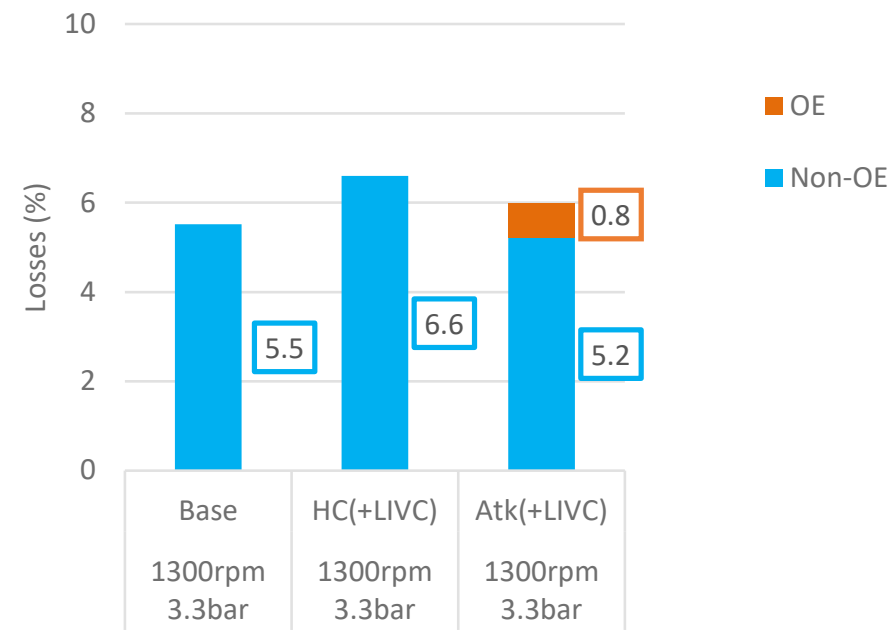

Figure 9.17 Heat transfer loss of baseline engine, $\mathrm{HC}$ engine, and Atkinson cycle engine at $1300 \mathrm{rpm}, 330 \mathrm{kPa}$ IMEPnet 


\subsubsection{Atkinson cycle engine at 1500rpm $1300 \mathrm{kPa}$ IMEPnet}

The second set of simulations was performed at 1500rpm 1300kPa IMEPnet with an 81point cam phasing sweep. The net indicated efficiency as a function of intake and exhaust cam is shown in Figure 9.18. The results at 1500rpm 1300kPa IMEPnet were not fully displayed due to the lower engine load capability at retarded intake valve timing. At $1500 \mathrm{rpm} 1300 \mathrm{kPa}$ IMEPnet, the optimized cam timing was constrained by the trapping ratio ( $\geq 99 \%)$ as shown in Figure 9.19 .
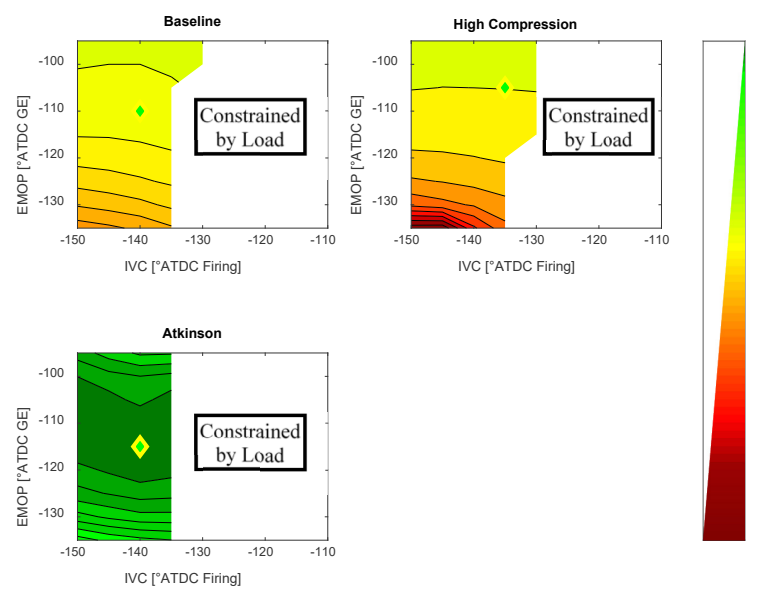

Figure 9.18. Net indicated efficiency as a function of IVC and EMOP, baseline engine, $\mathrm{HC}$ engine, and Atkinson cycle engine at 1500rpm 1300kPa IMEPnet
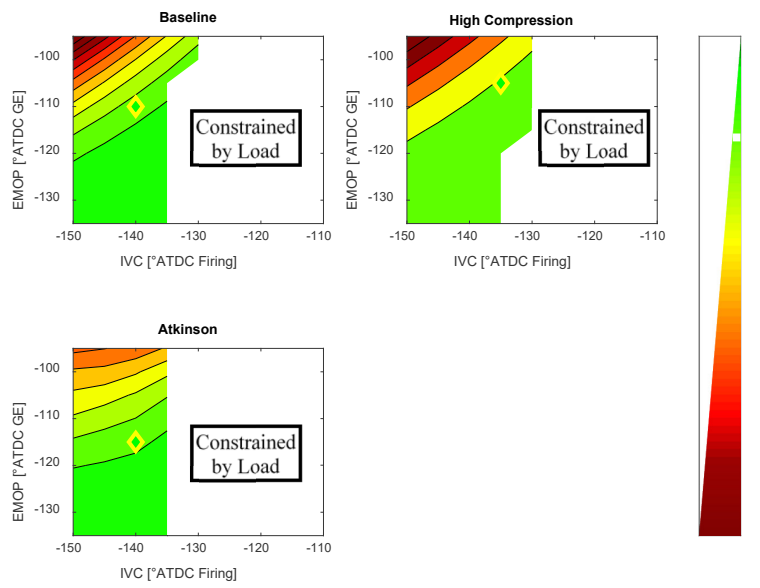

Figure 9.19. Residual gas fraction as a function of IVC and EMOP, baseline engine, HC engine, and Atkinson cycle engine at 1500rpm 1300kPa IMEPnet 
The optimized cases of baseline engine, high compression engine and Atkinson cycle engine at 1500rpm 1300kPa IMEPnet were compared in Table 9.11. At 1500rpm 1300kPa IMEPnet, all three engines were simulated at KLSA. CA50 of the high compression engine is $11.4^{\circ} \mathrm{CA}$ retarded compared to $\mathrm{MBT}$ condition due to the higher compression ratio resulting in the higher knock propensity. Conversely, CA50 of the Atkinson cycle engine was only $0.1^{\circ} \mathrm{CA}$ retarded compared to the MBT. MAP also indicates that all three engines were at boosted conditions.

Table 9.11. Results of baseline engine, $\mathrm{HC}$ engine, and Atkinson cycle engine of optimized cam timing, at $1500 \mathrm{rpm}, 1300 \mathrm{kPa}$ IMEPnet

\begin{tabular}{|c|c|c|c|}
\hline & Baseline & $\mathrm{HC}$ & Atkinson \\
\hline IVC [ $^{\circ}$ ATDC Firing] & -140 & -135 & -140 \\
\hline IVO [ ${ }^{\circ} \mathrm{ATDC}$ GE] & -39 & -34 & -39 \\
\hline EMOP $\left[{ }^{\circ} \mathbf{A T D C}\right.$ GE] & -110 & -105 & -115 \\
\hline$\lambda$ & 1.0 & 1.0 & 1.0 \\
\hline Combustion Phasing [ [ATDC of CA50] & 15.7 & 21.4 & 10.1 \\
\hline Location of Knock Onset [ $\left.{ }^{\circ} \mathrm{ATDC}\right]$ & 26.2 & 32.6 & 21.3 \\
\hline Unburned mass fraction of fuel @ knock onset [\%] & 10.0 & 10.0 & 10.0 \\
\hline Total Net indicated efficiency [\%] & 40.8 & 41.0 & 46.6 \\
\hline OE indicated efficiency [\%] & - & - & 4.9 \\
\hline MAP [kPa] & 125 & 127 & 111 \\
\hline
\end{tabular}

Figure 9.20 is the log-PV diagram for the three engines at the optimized conditions. It is observed that the combustion phasing of the high compression engine is more retarded than the other two engines. In the log-PV diagram, the pressure rises in the power stroke represent the knock onset for each engine. With the efficiency increase from the overexpansion, the Atkinson cycle engine requires less air and fuel than the other two engines, resulting in a lower intake pressure.

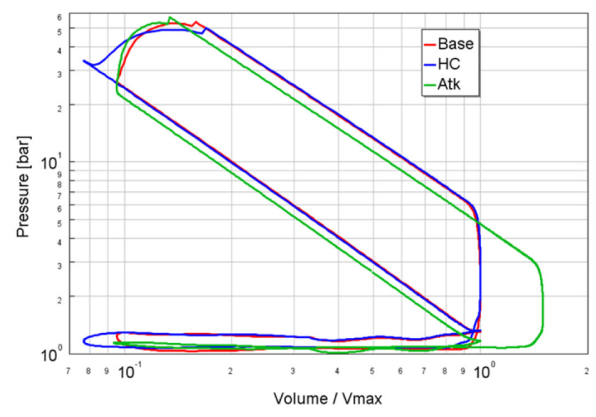

Figure 9.20. Log PV diagram of baseline engine, $\mathrm{HC}$ engine, and Atkinson cycle engine at $1500 \mathrm{rpm} 1300 \mathrm{kPa}$ IMEPnet, knock limited spark timing, cam timing optimized (Vmax is the maximum in-cylinder volume at the end of intake stroke) 
Figure 9.21 shows the net indicated efficiency of the baseline engine, high compression engine, and Atkinson cycle engine at $1500 \mathrm{rpm} 1300 \mathrm{kPa}$ IMEPnet. The net indicated efficiency of the Atkinson cycle engine was separated by non-OE and $\mathrm{OE}$ indicated efficiency. Net indicated efficiency of the high compression engine and Atkinson cycle engine was $0.5 \%$ and $14.2 \%$ (relative) higher than the baseline engine. In the $14.2 \%$ relative increase of net indicated efficiency, the non-OE and $\mathrm{OE}$ indicated efficiency of Atkinson cycle engine contributed $2.2 \%$ and $12.0 \%$, respectively. The net indicated efficiency of the Atkinson cycle engine was $13.7 \%$ higher (relative) than the high compression engine.

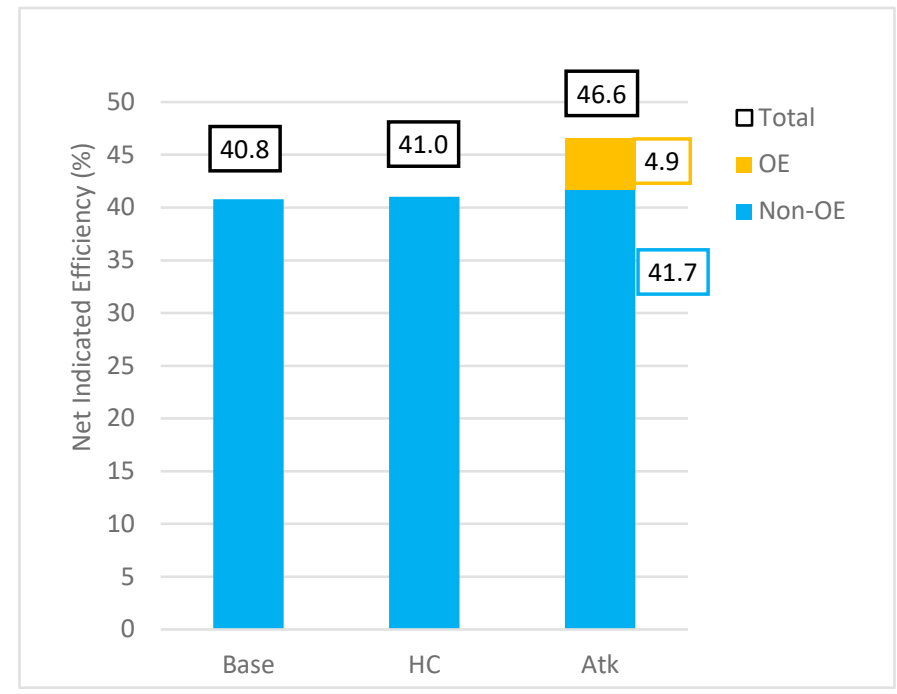

Figure 9.21. Net indicated efficiency of baseline engine, HC engine, and Atkinson cycle engine at $\underline{1500 \mathrm{rpm}, 1300 \mathrm{kPa} \text { IMEPnet }}$

In Figure 9.22, a breakdown of energy losses is shown including combustion phasing loss, combustion duration loss, and heat transfer loss. As the engine was simulated under a boosted condition, pumping loss was zero. At 1500rpm 1300kPa IMEPnet, combustion phasing loss of the baseline engine, high compression engine, and Atkinson cycle engine was $1.5 \%, 2,7 \%$, and $0.4 \%$, respectively. Combustion phasing loss of the high compression engine was $1.2 \%$ higher (absolute) than the baseline engine. Conversely, the combustion phasing of the Atkinson cycle engine is $1.1 \%$ lower (absolute) compared to the baseline engine. At KLSA, the CA50 of baseline engine, high compression engine, and Atkinson cycle engine was $15.7^{\circ}, 21.4^{\circ}$, and $10.1^{\circ}$ aTDC. The CA50 of the Atkinson cycle engine was $11.3^{\circ}$ aTDC advanced compared to the high compression engine. In addition, the KLSA of the Atkinson cycle engine was close to MBT, resulting in a combustion phasing loss for the Atkinson cycle engine 2.3\% (absolute) lower than the high compression engine. The trend of higher heat transfer loss of the high compression and Atkinson cycle engine was similar as observed in the $1300 \mathrm{rpm} 330 \mathrm{kPa}$ IMEPnet condition. A heat transfer breakdown chart of Atkinson cycle engine is shown in Figure 9.23. The non-OE portion heat transfer of the Atkinson cycle engine is the same as the baseline. The heat transfer 
(OE portion) of Atkinson cycle engine is $0.6 \%$. It can be observed that the high heat transfer of the Atkinson cycle engine was mainly contributed by the OE portion.

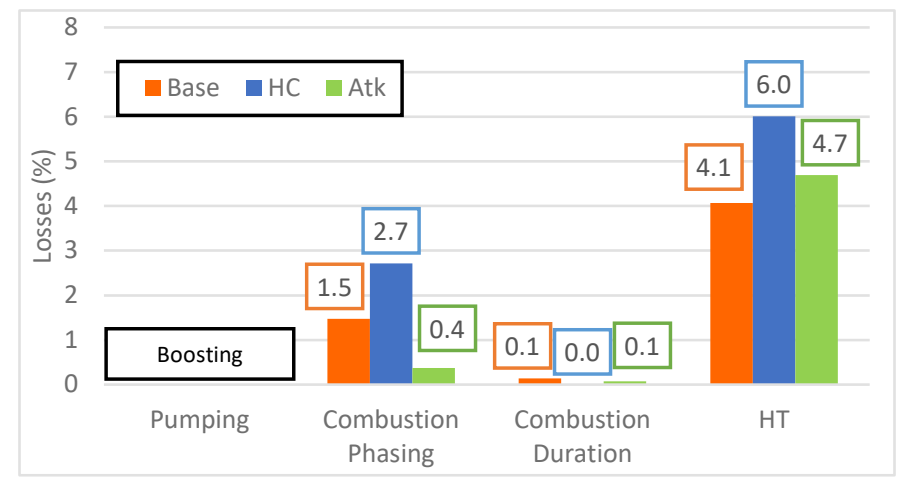

Figure 9.22. Efficiency losses of baseline engine, $\mathrm{HC}$ engine, and Atkinson cycle engine at $1500 \mathrm{rpm}, 1300 \mathrm{kPa}$ IMEPnet.

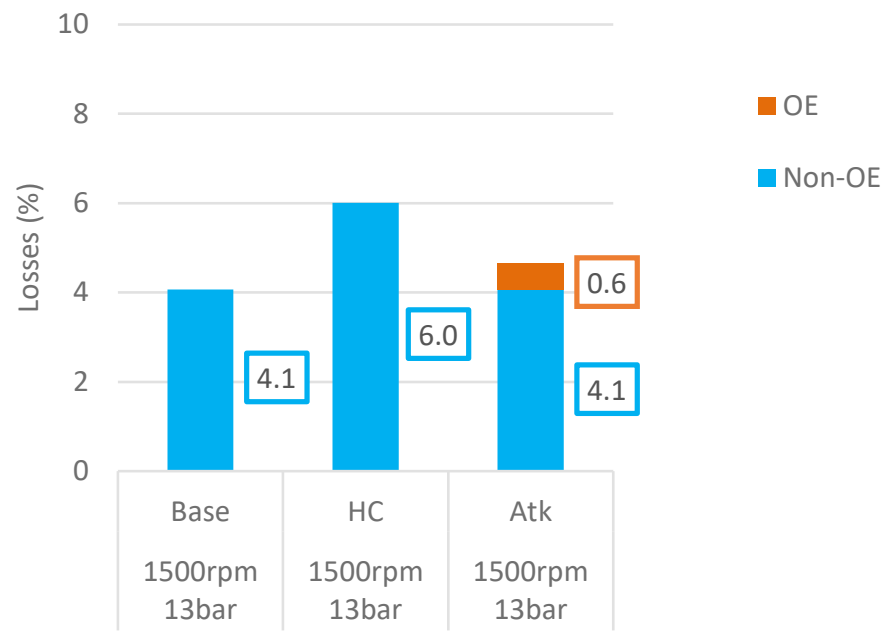

Figure 9.23 Heat transfer loss of baseline engine, $\mathrm{HC}$ engine, and Atkinson cycle engine at $1500 \mathrm{rpm}, 1300 \mathrm{kPa}$ IMEPnet.

At 1500rpm 1300kPa IMEPnet, combustion phasing loss had a significant impact on the net indicated efficiency difference between the three engines. The net indicated efficiency of the high compression engine was penalized by its high knock propensity due to its high compression ratio. Net indicated efficiency of the Atkinson cycle engine was benefited from lower knock propensity and the over-expansion. As load increases, the OE indicated efficiency of the Atkinson cycle engine at $1500 \mathrm{rpm} 1300 \mathrm{kPa}$ was $3.4 \%$ higher (absolute) than the operating condition at 1300rpm 330kPa IMEPnet. 


\subsubsection{Atkinson cycle engine at 2500rpm $1000 \mathrm{kPa}$ IMEPnet}

The third set of simulations was performed at 2500rpm 1000kPa IMEPnet with the 81point cam phasing sweep. This operating condition refers to the peak brake efficiency of the high compression engine from the study by Yamaji et. al. [33]. Net indicated efficiency as a function of intake and exhaust cam at 2500rpm 1000kPa IMEPnet are shown in Figure 9.24. The optimized cam timings at $2500 \mathrm{rpm} 1000 \mathrm{kPa}$ IMEPnet of three engines are at the cam timing with the highest net indicated efficiency. The optimized intake cam timing at $2500 \mathrm{rpm} 1000 \mathrm{kPa}$ IMEPnet was retarded compared to two previous studied operating conditions.

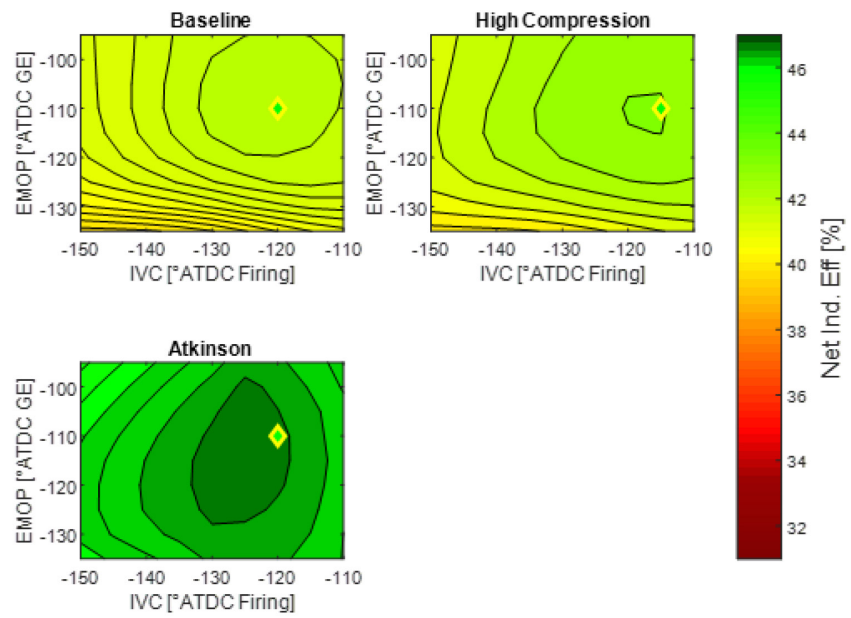

Figure 9.24. Net indicated efficiency as a function of IVC and EMOP, baseline engine, $\mathrm{HC}$ engine, and Atkinson cycle engine at 2500rpm 1000kPa IMEPnet

Figure 9.25 is the log-PV diagram of the three engines at 2500rpm 1000kPa IMEPnet with optimized cam timings. It is observed that the combustion phasing of the baseline engine and Atkinson cycle engine is similar, but the high compression engine is more retarded compared to the other two engines. 


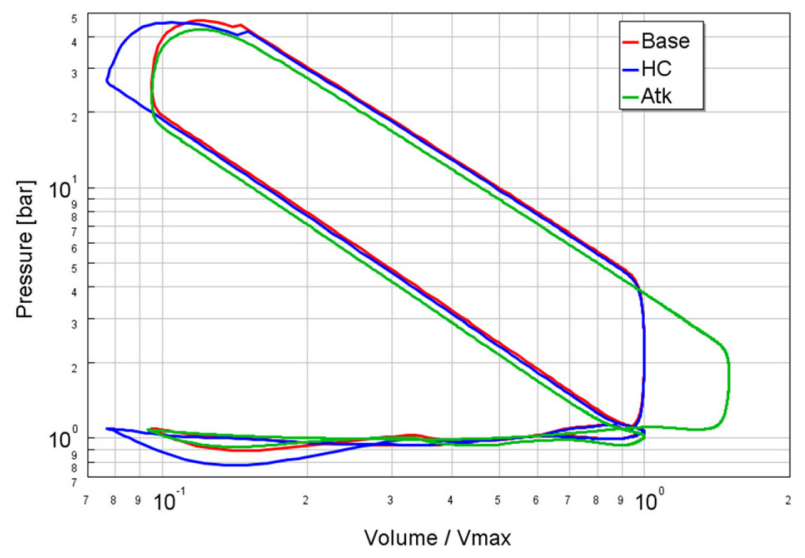

Figure 9.25. Log PV diagram of baseline engine, $\mathrm{HC}$ engine, and Atkinson cycle engine at $2500 \mathrm{rpm} 1000 \mathrm{kPa}$ IMEPnet, cam timing optimized (Vmax is the maximum in-cylinder volume at the end of intake stroke)

The optimized cases of three engines at 2500rpm 1000kPa IMEPnet were compared as shown in Table 9.12. The CA50 indicates that the baseline and Atkinson cycle engines were controlled at MBT spark timing. Only the high compression engine was controlled at KLSA. CA50 for the high compression engine was at $14.6^{\circ}$ aTDC. The unburned mass fraction fuel at knock onset depicts that the baseline engine was maintained at light knock conditions but lower than the knock constraints. Knock did not occur for the Atkinson cycle engine at $2500 \mathrm{rpm} 1000 \mathrm{kPa}$ IMEPnet. PMEP of three engines were all below $20 \mathrm{kPa}$.

Table 9.12. Results of baseline and Atkinson cycle engine of optimized cam timing, at 2500rpm, 1000kPa IMEPnet

\begin{tabular}{cccc}
\hline \hline & Baseline & HC & Atkinson \\
\hline IVC [ ${ }^{\circ}$ ATDC Firing] & -120 & -115 & -120 \\
IVO [ ${ }^{\circ}$ ATDC GE] & -14 & -9 & -14 \\
EMOP $\left[{ }^{\circ}\right.$ ATDC GE] & -110 & -110 & -110 \\
$\boldsymbol{\lambda}$ & 1.0 & 1.0 & 1.0 \\
Combustion Phasing [ ${ }^{\circ}$ ATDC of CA50] & 10.0 & 14.6 & 10.0 \\
Location of Knock Onset [ ${ }^{\circ}$ ATDC] & 22.8 & 27.5 & - \\
Unburned mass fraction of fuel @ $\mathbf{k n n o c k}$ onset [\%] & 7.7 & 10.0 & - \\
Total Net indicated efficiency [\%] & 41.9 & 43.0 & 46.7 \\
OE indicated efficiency [\%] & - & - & 4.5 \\
PMEP [kPa] & 9 & 16 & 7 \\
MAP [kPa] & 104 & 103 & 100 \\
\hline \hline
\end{tabular}


Figure 9.26 is the bar chart of the net indicated efficiency for the baseline engine, high compression engine, and Atkinson cycle engine with $41.9 \%, 43.0 \%$, and $46.7 \%$, respectively. The net indicated efficiency of the high compression and Atkinson cycle engine at $2500 \mathrm{rpm} 1000 \mathrm{kPa}$ is $2.6 \%$ and $11.5 \%$ higher (relative) than the baseline, respectively. Non-OE indicated efficiency of the Atkinson cycle engine is close to the net indicated efficiency baseline. OE indicated efficiency provided an additional $4.5 \%$ increase (absolute) compared to the baseline engine.

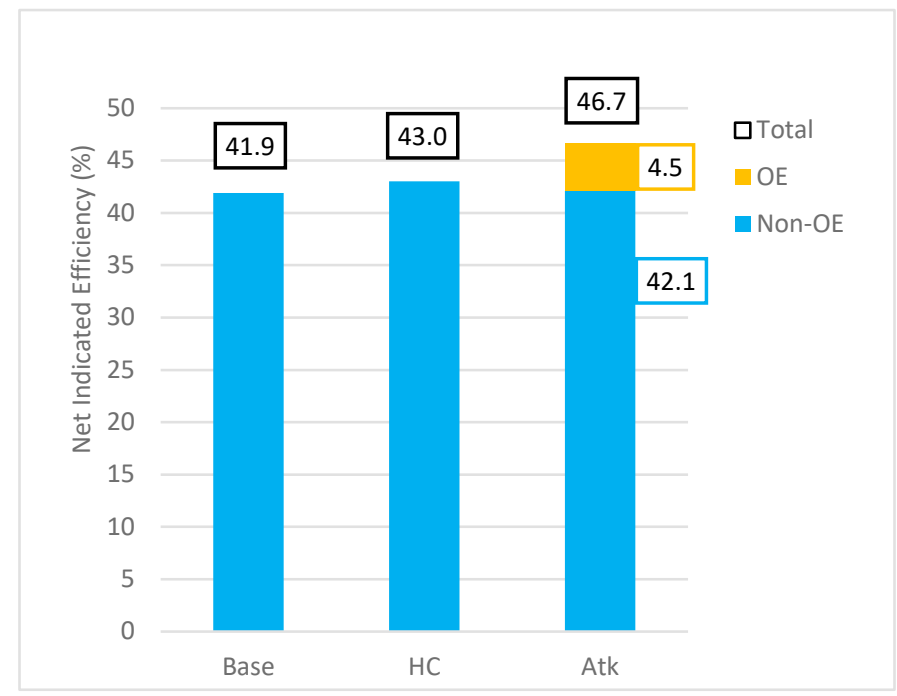

Figure 9.26. Net indicated efficiency of baseline engine, $\mathrm{HC}$ engine, and Atkinson cycle engine at $2500 \mathrm{rpm}, 1000 \mathrm{kPa}$ IMEPnet

Figure 9.27 compares the energy losses among the three engines. It was observed that pumping losses of the high compression engine were slightly higher at $0.3 \%$ (absolute) more than the baseline. Combustion phasing loss of the baseline and Atkinson cycle engine were similar. With the retarded CA50 of the high compression engine at KLSA, the combustion phasing loss of the high compression engine is $0.8 \%$ higher (absolute) than the two other engines due to its higher knock propensity. Heat transfer loss follows the trend observed in the 1300rpm 330kPa IMEPnet and 1500rpm 1300kPa IMEPnet. A heat transfer breakdown chart of Atkinson cycle engine is shown in Figure 9.28. The non-OE portion heat transfer of Atkinson cycle engine is approximately same as the baseline. The OE portion heat transfer of Atkinson cycle engine is $0.4 \%$. 


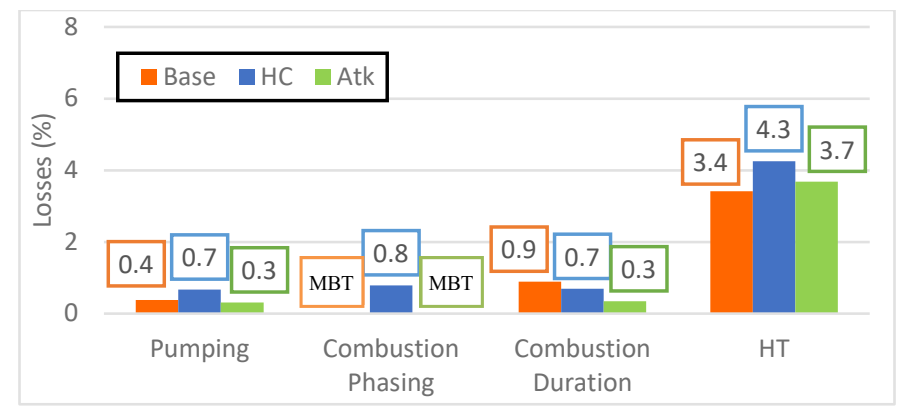

Figure 9.27. Efficiency losses of baseline engine, $\mathrm{HC}$ engine, and Atkinson cycle engine at $2500 \mathrm{rpm}, 1000 \mathrm{kPa}$ IMEPnet

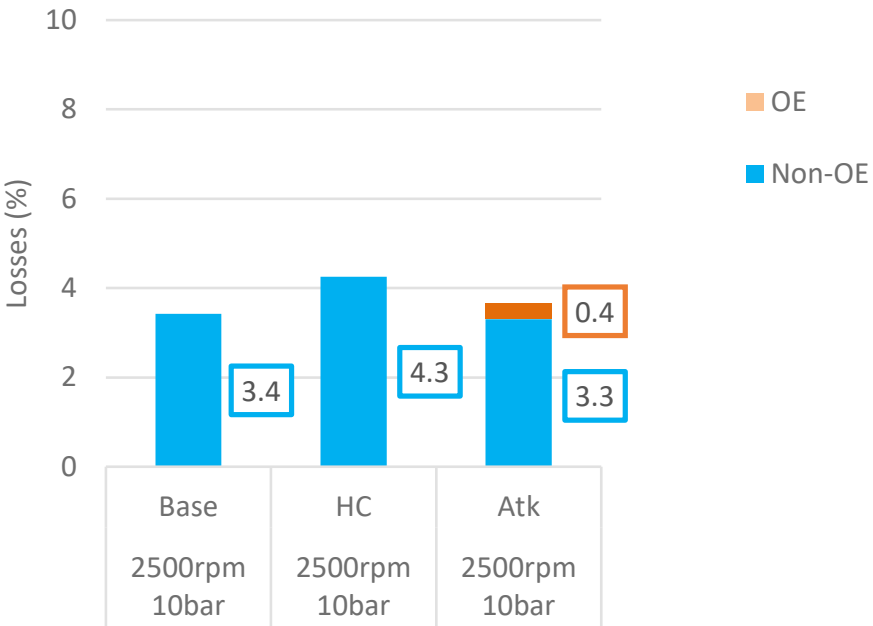

Figure 9.28 Heat transfer loss of baseline engine, $\mathrm{HC}$ engine, and Atkinson cycle engine at $2500 \mathrm{rpm}, 1000 \mathrm{kPa}$ IMEPnet

Figure 9.29 summarizes the net indicated efficiencies of three engines at three operating conditions. The non-OE and $\mathrm{OE}$ indicated efficiencies were labeled separately for the Atkinson cycle engine. At 1300rpm 330kPa IMEPnet, the high compression engine with LIVC was $8.7 \%$ higher (relative) than the baseline. The total net indicated efficiency of the Atkinson cycle engine was increased by $7.9 \%$ (relative) compared to the baseline engine. OE indicated efficiency of the Atkinson cycle engine contributes a 1.0\% increase (absolute) in the net indicated efficiency.

At $1500 \mathrm{rpm} 1300 \mathrm{kPa}$ IMEPnet, all three engines were maintained at KLSA. Net indicated efficiency of the high compression engine was increased by $0.5 \%$ (relative) compared to the baseline engine. High knock propensity of the high compression engine results in the efficiency penalty. Net indicated efficiency of the Atkinson cycle engine was $14.2 \%$ higher (relative) than the baseline engine due to the lower knock propensity with less combustion phasing loss. Non-OE indicated efficiency of the Atkinson cycle engine was $0.9 \%$ 
(absolute) higher than the baseline engine. OE indicated efficiency contributed a 4.9\% net indicated efficiency increase (absolute). Net indicated efficiency of the Atkinson cycle engine at $1500 \mathrm{rpm} 1300 \mathrm{kPa}$ IMEPnet was $13.7 \%$ higher (relative) than the high compression engine.

At 2500rpm 1000kPa IMEPnet, net indicated efficiency of the high compression engine and Atkinson cycle engine were $2.6 \%$ and $11.5 \%$ higher (relative) than the baseline engine, respectively. Non-OE indicated efficiency of the Atkinson cycle engine was close to the baseline engine as both engines were controlled at MBT condition. The net indicated efficiency increase of the Atkinson cycle engine was primarily contributed from the OEindicated efficiency of $4.5 \%$ (absolute). The net indicated efficiency of the Atkinson cycle engine was $8.6 \%$ higher (relative) than the high compression engine.

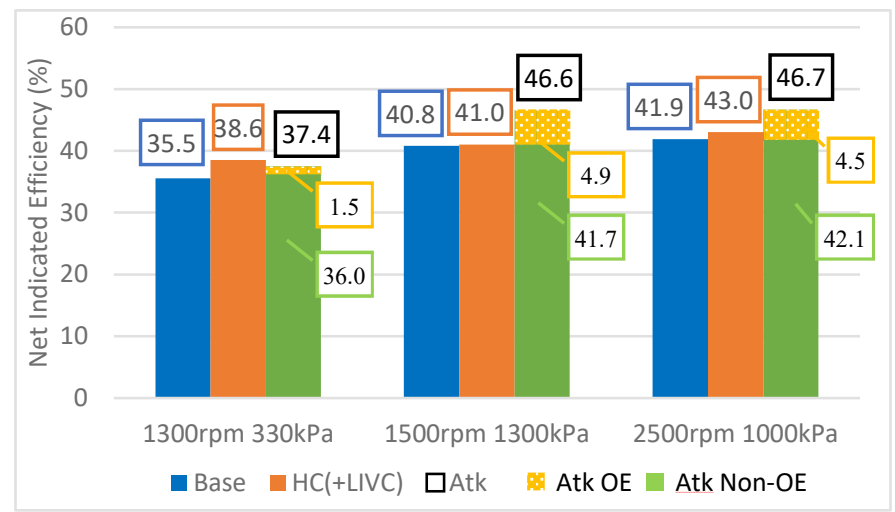

Figure 9.29. Net indicated efficiency of optimized baseline engine, optimized HC engine, and optimized Atkinson cycle engine, at 1300rpm, 330kPa IMEPnet, $1500 \mathrm{rpm}, 1300 \mathrm{kPa}$

IMEPnet, and 2500rpm 1000kPa IMEPnet

\subsection{Summary/Conclusions}

In this study, the calibration of the baseline model was based on the experimental results from a spark-ignited, direct-injected, boosted, 2-liter engine with compression ratio of 9.2:1. In the simulation, the baseline engine was modified to compression ratio of 10.5 to represent state-of-the-art of engine technology with respect to knock mitigation strategies. The compression ratio of the high compression engine was selected at 13:1 using the specification of Toyota's 2.0-liter high compression engine [33]. The Atkinson cycle engine was designed with the same compression ratio (10.5:1), bore, and intake stroke as the baseline engine. The over-expansion ratio of the Atkinson cycle engine was 1.5. The simulation results of three engines were obtained by switching the cranktrain of the 
baseline engine, high compression engine, and multi-link over-expanded engine, while keeping the same calibration.

In this research, the high compression engine was performed with late intake valve closing at light load conditions to realize an over-expanded cycle. The multi-link over-expanded engine (Atkinson cycle engine) also used the late intake valve closing strategy to optimize the intake cam timing and duration. The knock propensity of three engines was examined and compared at a high load condition by using the energy loss analysis. In addition, the baseline engine, high compression engine, and Atkinson cycle engine were compared at the peak efficiency point of the high compression engine. Energy losses normalized by fuel energy of the three engines were quantified including losses of pumping work, combustion phasing, combustion duration, and heat transfer. As most of the production engines with over-expanded cycle are realized by high compression ratio with LIVC, this comparison study depicts the advantage of a multi-link over-expanded engine over the high compression engine at various operating conditions, which can provide a reference for the future development of over-expanded engine.

Based upon the simulation results, the following observations were made:

- At 1300rpm 330kPa IMEPnet, all three engines were optimized at MBT spark timing within the constraint of $30 \%$ RGF. Both high compression engine and Atkinson cycle engine were optimized with late intake valve closing by extending the intake valve duration. With late intake valve closing, the high compression engine and Atkinson cycle engine can achieve the same residual gas fraction as the non late intake valve closing condition at higher manifold pressure resulting in a lower pumping loss and increased the net indicated efficiency by $5.2 \%$ and $2.4 \%$ (relative), respectively, compared to the non-LIVC condition of the same engine. The pumping loss of the high compression engine with late intake valve closing was $1.9 \%$ lower (absolute) than the baseline engine. The Atkinson cycle engine can further reduce the pumping loss by $0.9 \%$ (absolute) compared to the high compression engine with approximately fully overexpanded condition. The high compression and Atkinson cycle engines increased the indicated efficiency by $8.7 \%$ and $7.9 \%$ (relative) compared to the baseline, respectively.

- At 1500rpm 1300kPa IMEPnet, all three engines were optimized and simulated at knock limited spark advance with the constraint of trapping ratio (trapping ratio $\geq 99 \%$ ). At knock limited spark advance, CA50 of the baseline engine, high compression engine, and Atkinson cycle engine were $15.7^{\circ}, 21.4^{\circ}$, and $10.1^{\circ}$, respectively. Combustion phasing loss of the high compression was $1.2 \%$ higher (absolute) than the baseline engine. Conversely, combustion phasing loss of the Atkinson cycle engine was $1.1 \%$ lower (absolute) than the baseline engine. Net indicated efficiency of the high compression engine was only $0.5 \%$ (relative) higher compared to the baseline due to the higher knock propensity. The net indicated efficiency increase from the higher compression is compensated by the combustion phasing loss. With lower knock propensity and over-expansion, net indicated efficiency of Atkinson cycle engine was 
$14.2 \%$ higher (relative) than the baseline engine. The net indicated efficiency of the Atkinson cycle engine was $13.7 \%$ higher (relative) than the high compression engine.

- At 2500rpm 1000kPa IMEPnet, the high compression engine was controlled with knock limited spark advance. The baseline and Atkinson cycle engines were controlled at maximum brake torque spark timings. Pumping loss and combustion phasing loss of the baseline engine and Atkinson cycle engine were similar. The combustion phasing loss of the high compression engine was $0.8 \%$ higher (absolute) than the baseline engine. At $2500 \mathrm{rpm} 1000 \mathrm{kPa}$ IMEPnet, net indicated efficiency of the high compression and Atkinson cycle engine were $2.6 \%$ and $11.5 \%$ higher (relative) than the baseline engine, respectively. Net indicated efficiency of the Atkinson cycle engine was $8.6 \%$ higher (relative) than the high compression engine. The Atkinson cycle engine benefited from its lower knock propensity and over-expansion.

- At 2500rpm $1000 \mathrm{kPa}$ IMEPnet, the heat transfer losses of high compression and Atkinson cycle engine were $0.9 \%$ and $0.3 \%$ higher (absolute) than the baseline, respectively. Heat transfer loss at $1300 \mathrm{rpm} 330 \mathrm{kPa}$ IMEPnet and $1500 \mathrm{rpm} 1300 \mathrm{kPa}$ IMEPnet has the same trend as the $2500 \mathrm{rpm} 1000 \mathrm{kPa}$ IMEPnet conditions. Heat transfer loss of the high compression engine was higher than the baseline engine due to the higher compression ratio resulting in the higher peak temperature. A heat transfer breakdown was conducted to further separated the heat transfer loss into the portions of non-over-expansion and over-expansion. The portion of the non-over-expansion heat transfer is close to or lower than the baseline engine due to the faster piston movement speed and lower peak temperature of the Atkinson cycle engine. Higher heat transfer loss of the Atkinson cycle engine was mainly contributed by the portion of overexpansion due to the longer expansion stroke duration and larger in-cylinder surface area.

With the fully optimized cam phasing, the relation of net indicated efficiencies between three engines at three operating conditions are summarized in Table 9.13.

Table 9.13. Net indicate efficiency change between baseline engine, high compression engine, and Atkinson cycle engine

\begin{tabular}{|c|c|c|c|c|c|c|c|}
\hline \multirow[b]{2}{*}{$\begin{array}{l}\text { Speed } \\
{[\mathrm{rpm}]}\end{array}$} & \multirow[b]{2}{*}{$\begin{array}{c}\text { IMEPnet } \\
{[\mathrm{kPa}]}\end{array}$} & \multicolumn{3}{|c|}{$\begin{array}{c}\text { Net indicate efficiency relative } \\
\text { increase [\%] }\end{array}$} & \multicolumn{3}{|c|}{$\begin{array}{c}\text { Net indicate efficiency absolute } \\
\text { increase [\%] }\end{array}$} \\
\hline & & $\begin{array}{c}\mathrm{HC} \\
\text { compared } \\
\text { to } \\
\text { baseline }\end{array}$ & $\begin{array}{c}\text { Atkinson } \\
\text { compared } \\
\text { to } \\
\text { baseline }\end{array}$ & $\begin{array}{c}\text { Atkinson } \\
\text { compared } \\
\text { to HC }\end{array}$ & $\begin{array}{c}\mathrm{HC} \\
\text { compared } \\
\text { to } \\
\text { baseline }\end{array}$ & $\begin{array}{c}\text { Atkinson } \\
\text { compared } \\
\text { to } \\
\text { baseline }\end{array}$ & $\begin{array}{c}\text { Atkinson } \\
\text { compared } \\
\text { to } \mathrm{HC}\end{array}$ \\
\hline 1300 & 330 & 8.7 & 7.9 & -0.8 & 3.1 & 2.8 & -0.3 \\
\hline 1500 & 1300 & 0.5 & 14.2 & 13.7 & 0.2 & 5.8 & 5.6 \\
\hline 2500 & 1000 & 2.6 & 11.5 & 8.6 & 1.1 & 4.8 & 3.7 \\
\hline
\end{tabular}




\subsection{Future Work}

In this study, the compression ratio of the Atkinson cycle engine and baseline engine were same. A wide range of compression and expansion ratios Atkinson cycle engine can be designed and investigated. An Atkinson cycle engine with reduced CR can significantly reduce the knock propensity. The Atkinson cycle engine can also be investigated with the external cooled EGR. An Atkinson cycle engine can probably take more advantage of the cooled EGR than a conventional engine. This may further improve the overall efficiency of the Atkinson cycle engine. The other alternative fuel such as methanol blended gasoline or pure methanol could be compared based on the high compression or multilink over-expanded engine. As the cranktrain model is already developed in the model, the friction of the cranktrain is probable to be predicted based on the appropriate model calibration. These changes may warrant further study.

\subsection{Acknowledgments}

This work was supported by MTU Light Duty Consortium. The authors would like to thank the participating members of the MTU Light Duty Consortium and staff at MTU APS Labs for their support in the execution of this project.

The authors would also like to thank Nicolas Tuma for the contribution to this work.

\subsection{Appendix}

Knock Onset Prediction Model [66, 90]

$\tau_{i}=M_{1} a_{i}\left(\frac{O N}{100}\right)^{b_{i}}[\text { Fuel }]^{c_{i}}\left[O_{2}\right]^{d_{i}}[\text { Diluent }]^{e_{i}} \operatorname{Exp}\left(\frac{f_{i}}{M_{2} T}\right)$

$M_{1} \quad$ - Knock Induction Time Multiplier

ON - Fuel Octane Number

$M_{2} \quad$-Activation Energy Multiplier

Fuel, O2, and Diluent

-concentrations expressed in $\mathrm{mol} / \mathrm{m} 3$

-diluent concentration is the sum of concentrations of $\mathrm{N} 2, \mathrm{CO} 2$, and $\mathrm{H} 2 \mathrm{O}$.

$a_{i}$ through $f_{\mathrm{i}}$ are model constants shown in the table below [90]. 


\begin{tabular}{|c|c|c|c|c|c|c|}
\hline $\boldsymbol{i}$ & $\boldsymbol{a}$ & $\boldsymbol{b}$ & $\boldsymbol{c}$ & $\boldsymbol{d}$ & $\boldsymbol{e}$ & $\boldsymbol{f}$ \\
\hline $\mathbf{1}$ & $4.46 \mathrm{E}-07$ & 3.613 & -0.64 & -0.564 & 0.3978 & 12920 \\
\hline $\mathbf{2}$ & 11941.42 & 3.163 & -0.64 & -1.4596 & 0.4867 & -1957 \\
\hline $\mathbf{3}$ & $8.91 \mathrm{E}+07$ & 0 & -0.25 & -0.547 & 0 & 16856 \\
\hline
\end{tabular}




\section{Summary and Future Work}

Although the Atkinson cycle engine was originally patented in 1887 [42], the study of the over-expanded cycle engine is still incomplete. In the automotive industries, the Atkinson cycle is normally realized by LIVC with a high compression engine, e.g., Toyota, Ford, Mazda, and GM [32, 37, 53, 54]. The net indicated efficiency improvement by LIVC is promising, but the load capability is limited by the reduced effective displacement in the meantime. Utilizing a multi-link over-expanded mechanism is beneficial to achieve a higher over-expanded ratio without the penalty of load capability, which is counter to reduce the effective compression displacement. This study focuses on the over-expansion engine realized by the multi-link mechanism with comparison to other high efficiency engines. This developed model of multi-link over-expanded engine in this research is based on a conventional, four-cylinder, 2.0-liter, spark-ignited, boosted engine model calibrated by the experimental results. The research tasks include the optimization of the multi-link over-expanded engine at light load condition, where the previous study observed the efficiency penalty, and medium to high load conditions, where the baseline engine was performed at knock-limited and exhaust gas temperature-limited conditions. The comparison study between the multi-link over-expanded engine and state-of-the-art high compression engine is also included in this study.

\subsection{Observation and Findings}

\subsubsection{Light and medium load conditions without knock}

At 1300rpm 3.3bar IMEPnet, BD1090 followed the increasing trend of RGF (Figure 10.1 [68]) which is increased with the valve overlap with a maximum RGF limit of $30 \%$. The net indicated efficiency of multi-link over-expanded engine followed the trend of $\mathrm{OE}$ efficiency and PMEP. OE indicated efficiency (Figure 10.2 [68]) and PMEP (Figure 10.3 [68]) was $1.7 \%$ and $45 \mathrm{kPa}$, respectively, at the optimized cam timing.

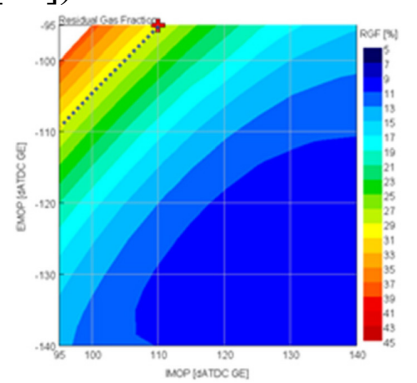

Figure 10.1. Residual gas fraction of intake and exhaust cam timing sweep at $1300 \mathrm{rpm}, 3.3 \mathrm{bar}$ IMEPnet [68]

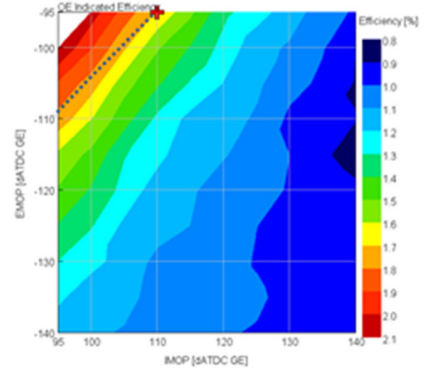

Figure 10.2. OE indicated Efficiency of intake and exhaust cam timing sweep at $1300 \mathrm{rpm}, 3.3 \mathrm{bar}$ IMEPnet [68]

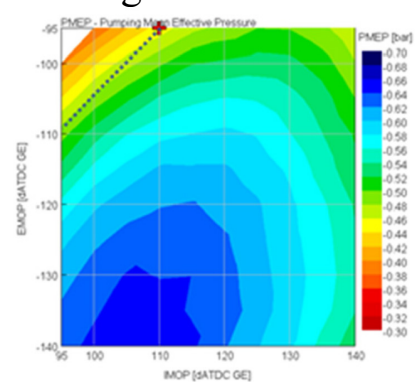

Figure 10.3. PMEP of intake and exhaust cam timing sweep at $\underline{1300 \mathrm{rpm}}$,

3.3bar IMEPnet [68] 
At 1750rpm 10.3bar IMEPnet, the multi-link over-expanded engine had a minor variation in burn duration due to the reduced RGF (less than 12\%). Two optimized cam timing was observed in the region of IMOP $95^{\circ}$ and $135^{\circ}$ aTDC GE, and EMOP $-105^{\circ}$ aTDC GE. At IMOP $95^{\circ}$ aTDC GE, the net indicated efficiency was primary dominated by the increase in the OE indicated efficiency (Figure 10.4 [68]). At IMOP $135^{\circ} \mathrm{aTDC}$ GE, the net indicated efficiency was primary dominated by reduced PMEP (Figure 10.5 [68]).

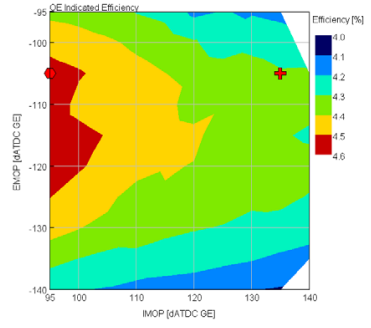

Figure 10.4. OE indicated efficiency of intake and exhaust cam timing sweep at 1750rpm, 10.3bar IMEPnet [68]

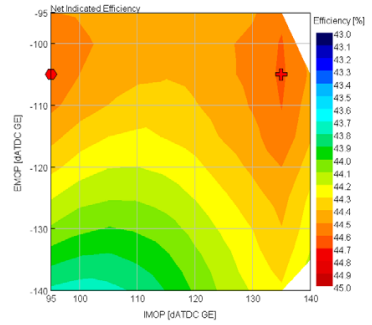

Figure 10.5. Net indicated efficiency of intake and exhaust cam timing sweep at 1750rpm, 10.3bar IMEPnet [68]

Figure 10.6 [68] summarized the net indicated efficiency of the baseline engine and multilink over-expanded engine (Atkinson cycle engine). It can be observed that at 1300rpm 3.3bar IMEPnet, the net indicated efficiency of multi-link over-expanded engine (not adjusted) was $1.8 \%$ lower (relative) than the optimized baseline engine. With the adjustment method, the net indicated efficiency of the over-expanded engine was increased by $5.9 \%$ (relative) compared to the baseline engine. At 1750rpm 10.3bar IMEPnet, the net indicated efficiency of the over-expanded engine was increased by $11.5 \%$ (relative) compared to the baseline engine.

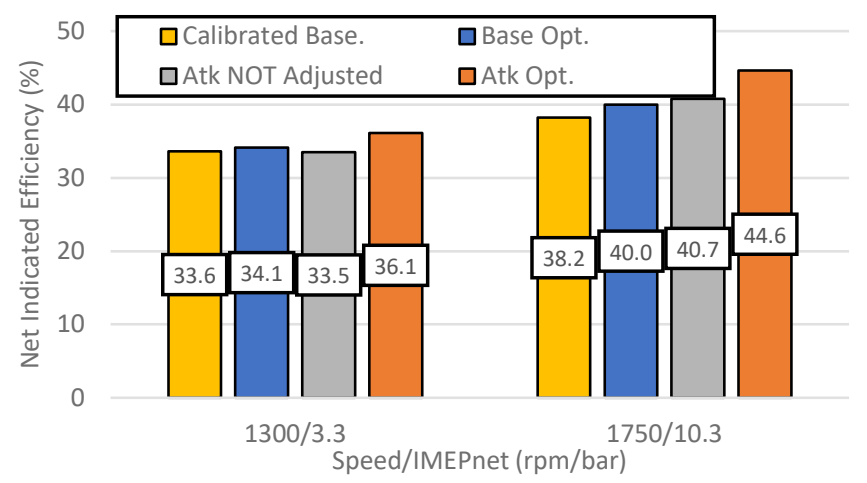

Figure 10.6 Net indicated efficiency of optimized baseline, Non-adjusted Atkinson cycle, and optimized Atkinson cycle engine, at 1300rpm, 3.3bar IMEPnet and 1750 rpm, 10.3bar IMEPnet [68] 


\subsubsection{Medium and high load conditions with the limit of knock and exhaust gas temperature}

At 1500rpm, 13bar IMEPnet, the simulation of baseline engine and multi-link overexpanded engine (Atkinson cycle engine) were compared at the same cam timing and spark timing. As Figure 10.7 shows, the piston speed of the multi-link over-expanded engine was higher from spark advanced to knock onset, which resulted in a lower residence time of unburned gas mixture. The knock onset of the multi-link over-expanded engine was retarded by $4.7^{\circ} \mathrm{CA}$ in comparison to the baseline engine. The mass fraction of unburned fuel at knock onset for the multi-link over-expanded engine was $8.1 \%$ lower than the baseline (Figure 10.8), which represents a lower knock level.

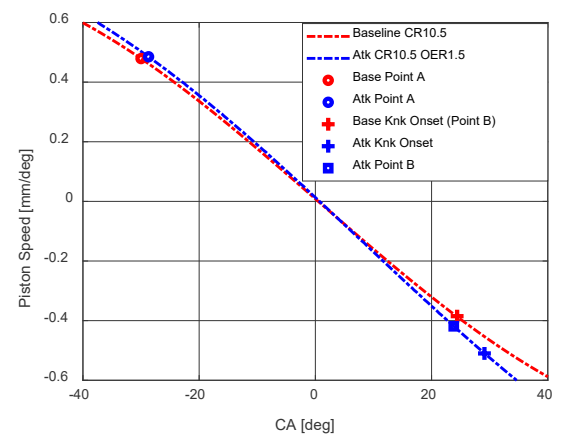

Figure 10.7. Piston speed as a function of crank angle of baseline and Atkinson cycle engine at

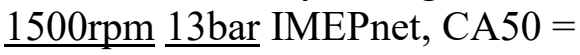
$14.8^{\circ} \mathrm{aTDC}$

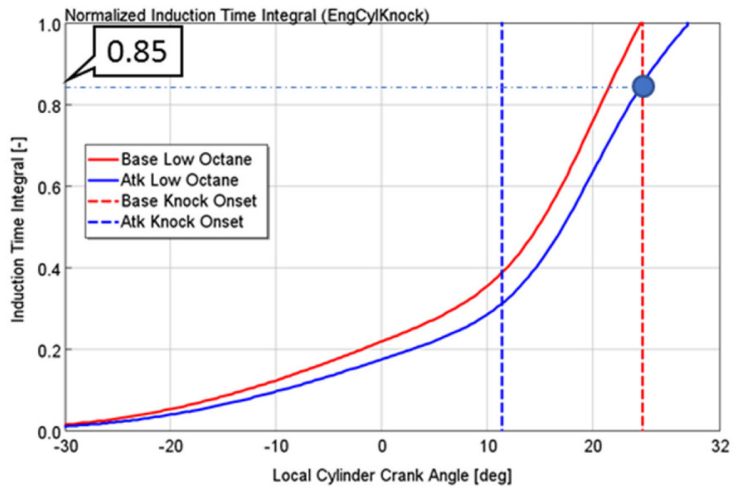

Figure 10.8. Overall $\tau$ ratio (baseline and Atkinson cycle engine) at $1500 \mathrm{rpm}, 13 \mathrm{bar}$ IMEPnet, $\mathrm{CA} 50=\underline{14.8^{\circ} \mathrm{aTDC}}$

At 1500rpm 13bar IMEPnet, combustion phasing loss of multi-link over-expanded engine was $0.8 \%$ lower than the baseline engine due to its lower knock propensity. CA50 of the multi-link over-expanded engine is at $12.3^{\circ} \mathrm{aTDC}$, which is $5.9^{\circ} \mathrm{CA}$ earlier than the baseline under the same knock constraint.

At 3500rpm 20bar IMEPnet, with the same constraint of turbine-inlet temperature, AFR of the baseline engine and multi-link over-expanded engine is 0.85 and 0.96 , respectively. The CA50 of the baseline engine and multi-link over-expanded engine is $12.3^{\circ}$ and $10.0^{\circ} \mathrm{aTDC}$, respectively, at the same KLSA. The AFR loss, combustion phasing, and combustion duration of the multi-link over-expanded engine were $4.4 \%, 0.6 \%$, and $0.2 \%$ lower (absolute value) than the baseline, respectively. 
At 1500rpm, 13bar IMEPnet and 3500rpm, 20bar IMEPnet, the heat transfer loss of multilink over-expanded engine was $1.4 \%$ and $0.6 \%$ higher (absolute) than the baseline engine, respectively. Higher heat transfer loss was caused by the increased duration of the power stroke $\left(22^{\circ}\right)$ and increased cylinder surface area ( $50 \%$ relatively increase) during the power stroke in comparison to the baseline engine, which is mainly contributed by the overexpansion.

With fully optimized cam phasing with the constraints of knock intensity and turbine-inlet temperature, the net indicated efficiencies of the multi-link over-expanded engine at 1500rpm, 13bar IMEPnet and 3500rpm, 20bar IMEPnet were increased by $15.7 \%$ (relative) and $27.3 \%$ (relative) compare to the baseline, respectively (Figure 10.9).

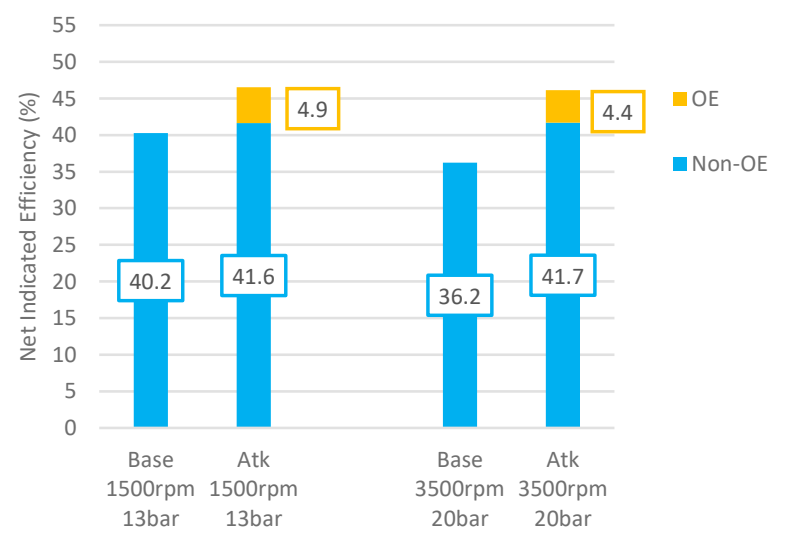

Figure 10.9. Summary of the optimized baseline and Atkinson cycle engine net indicated efficiency at optimized at 1500 rpm, 13bar IMEPnet and 3500rpm, 20bar IMEPnet

\subsubsection{Comparison study between multi-link over-expanded engine and high compression engine}

At 1300rpm 3.3bar IMEPnet, both high compression engine and multi-link over-expanded engine were optimized with LIVC by extending the intake valve duration. The pumping loss of the high compression engine was $1.9 \%$ lower (absolute) than the baseline engine. The multi-link over-expanded engine further reduces the pumping loss by $0.9 \%$ (absolute) compared to the high compression engine. The high compression and multi-link overexpanded engines increased the indicated efficiency by $8.7 \%$ and $7.9 \%$ (relative) compared to the baseline, respectively.

At 1500rpm 13bar IMEPnet, the three studied engines were optimized and simulated at KLSA with the constraint of trapping ratio (TR $\geq 99 \%$ ). The CA50 of the baseline engine, high compression engine, and multi-link over-expanded engine were $15.7^{\circ}, 21.4^{\circ}$, and $10.1^{\circ}$, respectively. Combustion phasing loss of the high compression was $1.2 \%$ higher 
(absolute) than the baseline engine. Conversely, combustion phasing loss of the multi-link over-expanded engine was $1.1 \%$ lower (absolute) than the baseline engine.

At 2500rpm 10bar IMEPnet, the pumping loss and combustion phasing loss of the baseline engine and multi-link over-expanded engine were similar. The combustion phasing loss of the high compression engine was $0.8 \%$ higher (absolute) than the baseline engine. This operating condition is the peak efficiency point of the high compression engine. The net indicated efficiency of multi-link over-expanded engine was $8.6 \%$ (relative) higher than the high compression engine.

At 2500rpm 10bar IMEPnet, the heat transfer losses of high compression and multi-link over-expanded engines were $0.9 \%$ and $0.3 \%$ higher (absolute) than the baseline, respectively. Heat transfer loss at 1300rpm 3.3bar IMEPnet and 1500rpm 13bar IMEPnet has the same trend as the 2500rpm 10bar IMEPnet conditions.

With the fully optimized cam phasing, the relation of net indicated efficiencies between three engines at three operating conditions are summarized in Table 10.1.

Table 10.1. Net indicate efficiency change between baseline engine, high compression engine, and Atkinson cycle engine

\begin{tabular}{|c|c|c|c|c|c|c|c|}
\hline \multirow[b]{2}{*}{$\begin{array}{l}\text { Speed } \\
{[\mathrm{rpm}]}\end{array}$} & \multirow[b]{2}{*}{$\begin{array}{l}\text { IMEPnet } \\
\text { [bar] }\end{array}$} & \multicolumn{3}{|c|}{$\begin{array}{c}\text { Net indicate efficiency relative } \\
\text { increase }[\%]\end{array}$} & \multicolumn{3}{|c|}{$\begin{array}{c}\text { Net indicate efficiency absolute } \\
\text { increase }[\%]\end{array}$} \\
\hline & & $\begin{array}{c}\mathrm{HC} \\
\text { compared } \\
\text { to } \\
\text { baseline }\end{array}$ & $\begin{array}{c}\text { Atkinson } \\
\text { compared } \\
\text { to } \\
\text { baseline }\end{array}$ & $\begin{array}{c}\text { Atkinson } \\
\text { compared } \\
\text { to } \\
\text { HC }\end{array}$ & $\begin{array}{c}\mathrm{HC} \\
\text { compared } \\
\text { to } \\
\text { baseline }\end{array}$ & $\begin{array}{c}\text { Atkinson } \\
\text { compared } \\
\text { to } \\
\text { baseline }\end{array}$ & $\begin{array}{c}\text { Atkinson } \\
\text { compared } \\
\text { to } \\
\text { HC }\end{array}$ \\
\hline 1300 & 3.3 & 8.7 & 7.9 & -0.8 & 3.1 & 2.8 & -0.3 \\
\hline 1500 & 13 & 0.5 & 14.2 & 13.7 & 0.2 & 5.8 & 5.6 \\
\hline 2500 & 10 & 2.6 & 11.5 & 8.6 & 1.1 & 4.8 & 3.7 \\
\hline
\end{tabular}

\subsection{Conclusion}

The piston movement of the multi-link over-expanded engine is different from a conventional engine. Utilizing the adjustment method including (spark advance, valve duration, cam timing) according to the mechanism characteristics can avoid the net indicated efficiency penalty and even slightly increase the net indicated efficiency at light load condition. At light to medium load conditions, the OE indicated efficiency and PMEP is the major factor in the total net indicated efficiency of multi-link over-expanded engine. 
The piston movement also affects the knock propensity of the multi-link over-expanded engine. At the same speed, load, cam timing, and spark timing, the overall induction time integral of the Atkinson cycle engine is lower than the baseline engine due to the faster piston movement during the period from spark timing to the knock onset.

With an increase of load, a higher improvement in net indicated efficiency over the baseline condition was observed due to the increased indicated work during the over expansion. At light to medium load conditions, the multi-link over-expanded engine only benefits from the indicated work of over-expansion. At high load conditions, the net indicated efficiency of the multi-link over-expanded engine combines the effect from the portion of non-overexpansion and over-expansion. The increase of the non-over-expansion is mainly due to the lower knock propensity and lower exhaust temperatures with air-fuel ratio approximately at stoichiometric condition.

The multi-link over-expanded engine also compared with the state-of-the-art high compression engine in this study. With the extended intake valve closing, the multi-link over-expanded engine and high compression engine is able to achieve the same residual gas fraction as the non-LIVC condition at higher MAP resulting in lower pumping loss compared to the baseline engine. Multi-link over-expanded engine can be fully expanded by utilizing the LIVC strategy. The pumping loss of multi-link over-expanded engine with LIVC can be further reduced compared to the high compression with LIVC. The lower pumping loss at light load condition results in a higher net indicated efficiency.

At the high load conditions, the multi-link over-expanded engine has lower knock propensity than the baseline engine. For the high compression engine, the net indicated efficiency increase from the compression change is compensated by the combustion phasing loss.

Heat transfer loss of the high compression engine and multi-link over-expanded engine are both higher than the baseline engine. Higher heat transfer loss of high compression engine is due to its compression ratio resulting in a higher peak temperature. Higher heat transfer loss of the multi-link over-expanded engine was due to the longer expansion stroke duration and larger in-cylinder surface area which is mainly contributed by the overexpansion portion.

At the peak brake efficiency point of high compression engine, the net indicated efficiency of the multi-link over-expanded engine is higher than the high compression engine. The multi-link over-expanded engine is beneficial from its lower knock propensity compared to the high compression engine and the over-expansion. 


\subsection{Future Work}

In this study, the knock propensity of the over-expanded engine was selected at one compression ratio based on the specification of the state-of-the-art high compression engine. As the CR is one of the main factors of knock propensity, it is worthwhile to extend the investigation of over-expanded engine with multiple CR and OER.

External cooled EGR helps to dilute the intake charge and de-throttle the engine by displacing air in the intake. With the over-expansion, an Atkinson cycle engine can probably take more advantage of the cooled EGR than a conventional engine. The investigation of over-expanded engine with cooled EGR is another topic to continue this study. These topics may further improve the overall efficiency of a multi-link overexpanded engine. These changes may warrant further study.

In this work, A multi-link over-expanded cranktrain model was developed and validated. The in-cylinder volume as a function of the crank angle is determined based on the cranktrain model. The engine friction can be calculated based on the multi-link mechanism model if the linkage and bearing property are defined appropriately. As the cranktrain model can be operated independent of the engine simulation, the optimization of the mechanism can be a separate topic.

Build a multi-link over-expanded engine for dynamometer testing is expected in the next stage of the over-expanded engine research. A further investigation of the over-expanded engine can be based on the collaborating the work of experimental study and simulation study with the feature of friction estimation. 


\section{Reference List}

1. "Annual Energy Outlook 2019 with projections to 2050" US Energy Information Administration, 2019. p. 117-130.

2. "2018 EPA Automotive Trends Report" US Environmental Protection Agency, 2018. p. 40.

3. Imtenan, S., Varman, M., Masjuki, H.H., Kalam, M.A., et al., "Impact of low temperature combustion attaining strategies on diesel engine emissions for diesel and biodiesels: A review". Energy Conversion and Management, 2014. 80: p. 329356, doi: 10.1016/j.enconman.2014.01.020.

4. Han, D., Ickes, A.M., Bohac, S.V., Huang, Z., et al., "Premixed low-temperature combustion of blends of diesel and gasoline in a high speed compression ignition engine". Proceedings of the Combustion Institute, 2011. 33(2): p. 3039-3046, doi: 10.1016/j.proci.2010.07.045.

5. $\quad$ LEV III and Tier 3 Exhaust Emission Control Technologies for Light-Duty Gasoline Vehicles" Manufacturers of Emission Controls Association, 2015. p. 1.

6. "EPA Sets Tier 3 Tailpipe and Evaporative Emission and Vehicle Fuel Standards" Environmental Protection Agency, 2014. p. 2.

7. An, F. and Sauer, A., "Comparison of passenger vehicle fuel economy and greenhouse gas emission standards around the world" Pew Center on Global Climate Change, 2004. p. 2.

8. "NHTSA and EPA Set Standards to Improve Fuel Economy and Reduce Greenhouse Gases for Passenger Cars and Light Trucks for Model Years 2017 and Beyond" NHTSA, 2011. p. 3.

9. "2017|2018 Worldwide Emissions Standards | Passenger Cars and Light Duty Vehicles" Delphi, 2017. p. 73.

10. "Midterm Evaluation of Light-Duty Vehicle Greenhouse Gas Emissions Standards for Model Years 2022-2025" Environmental Protection Agency, 2018. p. 16077.

11. Breda, S., Berni, F., d'Adamo, A., Testa, F., et al., "Effects on Knock Intensity and Specific Fuel Consumption of Port Water/Methanol Injection in a Turbocharged GDI Engine: Comparative Analysis". Energy Procedia, 2015. 82: p. 96-102, doi: 10.1016/j.egypro.2015.11.888. 
12. Chincholkar, S.P. and Suryawanshi, J.G., "Gasoline Direct Injection: An Efficient Technology". Energy Procedia, 2016. 90: p. 666-672, doi: 10.1016/j.egypro.2016.11.235.

13. Sellnau, M.C., Sinnamon, J., Hoyer, K. and Husted, H., "Full-Time Gasoline Direct-Injection Compression Ignition (GDCI) for High Efficiency and Low NOx and PM". SAE International Journal of Engines, 2012. 5(2): p. 300-314, doi: 10.4271/2012-01-0384.

14. Moore, W., Foster, M. and Hoyer, K. "Engine Efficiency Improvements Enabled by Ethanol Fuel Blends in a GDi VVA Flex Fuel Engine", 2011, doi:10.4271/201101-0900.

15. Iwamoto, Y., Noma, K., Nakayama, O., Yamauchi, T., et al. "Development of Gasoline Direct Injection Engine", SAE International 1997, doi:https://doi.org/10.4271/970541.

16. Park, C., Kim, S., Kim, H. and Moriyoshi, Y., "Stratified lean combustion characteristics of a spray-guided combustion system in a gasoline direct injection engine". Energy, 2012. 41(1): p. 401-407, doi: 10.1016/j.energy.2012.02.060.

17. Park, S.H., Kim, H.J., Suh, H.K. and Lee, C.S., "Atomization and spray characteristics of bioethanol and bioethanol blended gasoline fuel injected through a direct injection gasoline injector". International Journal of Heat and Fluid Flow, 2009. 30(6): p. 1183-1192, doi: 10.1016/j.ijheatfluidflow.2009.07.002.

18. Postrioti, L., Cavicchi, A., Brizi, G., Berni, F., et al. "Experimental and Numerical Analysis of Spray Evolution, Hydraulics and Atomization for a $60 \mathrm{MPa}$ Injection Pressure GDI System", SAE International 2018, doi:https://doi.org/10.4271/2018$\underline{01-0271 .}$.

19. Anbari Attar, M., Herfatmanesh, M.R., Zhao, H. and Cairns, A., "Experimental investigation of direct injection charge cooling in optical GDI engine using tracerbased PLIF technique". Experimental Thermal and Fluid Science, 2014. 59: p. 96108, doi: 10.1016/j.expthermflusci.2014.07.020.

20. Dietsche, K.-H., Reif, K., GmbH, S.D. and Robert Bosch Gmb, H., Automotive handbook. ed., ed. Vol. 2018.

21. Worm, J., Naber, J., Duncan, J., Barros, S., et al., "Water Injection as an Enabler for Increased Efficiency at High-Load in a Direct Injected, Boosted, SI Engine". SAE International Journal of Engines, 2017. 10(3): p. 951-958, doi: 10.4271/201701-0663. 
22. Heywood, J.B., Internal Combustion Engine Fundamentals 2E. ed., ed. Vol. 2018.

23. Çengel, Y.A., Boles, M.A. and Kanoglu, M., Thermodynamics : an engineering approach. ed., ed. Vol. 2020.

24. Hoppe, F., Thewes, M., Baumgarten, H. and Dohmen, J., "Water injection for gasoline engines: Potentials, challenges, and solutions". 2016. 17(1): p. 86-96, doi: $\underline{10.1177 / 1468087415599867 .}$.

25. Gray, C. "A Review of Variable Engine Valve Timing", SAE International 1988, doi:https://doi.org/10.4271/880386.

26. Fontana, G. and Galloni, E., "Variable valve timing for fuel economy improvement in a small spark-ignition engine". Applied Energy, 2009. 86(1): p. 96-105, doi: 10.1016/j.apenergy.2008.04.009.

27. Ma, T.H. "Effect of Variable Engine Valve Timing on Fuel Economy", SAE International 1988, doi:https://doi.org/10.4271/880390.

28. Bohac, S.V. and Assanis, D.N. "Effect of Exhaust Valve Timing on Gasoline Engine Performance and Hydrocarbon Emissions", SAE International 2004, doi:https://doi.org/10.4271/2004-01-3058.

29. Leroy, T., Alix, G., Chauvin, J., Duparchy, A., et al., "Modeling Fresh Air Charge and Residual Gas Fraction on a Dual Independent Variable Valve Timing SI Engine". 2008, SAE International. p., doi: https://doi.org/10.4271/2008-01-0983.

30. Dresner, T. and Barkan, P. "A Review and Classification of Variable Valve Timing Mechanisms", SAE International 1989, doi:https://doi.org/10.4271/890674.

31. Sellnau, M. and Rask, E. "Two-Step Variable Valve Actuation for Fuel Economy, Emissions, and Performance", SAE International 2003, doi:https://doi.org/10.4271/2003-01-0029.

32. Jocsak, J., White, D., Armand, C. and Davis, R.S., "Development of the Combustion System for General Motors' High-Efficiency Range Extender Ecotec Small Gas Engine". SAE International Journal of Engines, 2015. 8(4): p. 15871601, doi: https://doi.org/10.4271/2015-01-1272.

33. Yamaji, K., Tomimatsu, M., Takagi, I., Higuchi, A., et al. "New 2.0L I4 Gasoline Direct Injection Engine with Toyota New Global Architecture Concept", SAE International 2018, doi:https://doi.org/10.4271/2018-01-0370. 
34. Kumano, K. and Yamaoka, S. "Analysis of Knocking Suppression Effect of Cooled EGR in Turbo-Charged Gasoline Engine", 2014, doi:10.4271/2014-01-1217.

35. Kargul, J., Stuhldreher, M., Barba, D., Schenk, C., et al. "Benchmarking a 2018 Toyota Camry 2.5-Liter Atkinson Cycle Engine with Cooled-EGR", 2019, doi:10.4271/2019-01-0249.

36. Phlips, P. and Scholl, D., "Characterization of Powertrain Technology Benefits Using Normalized Engine and Vehicle Fuel Consumption Data". SAE International Journal of Fuels and Lubricants, 2018. 11(4): p. 517-531, doi: 10.4271/2018-01$\underline{0318}$.

37. Ellies, B., Schenk, C. and Dekraker, P. "Benchmarking and Hardware-in-the-Loop Operation of a 2014 MAZDA SkyActiv 2.0L 13:1 Compression Ratio Engine", 2016, doi:10.4271/2016-01-1007.

38. Watanabe, S., Koga, H. and Kono, S. "Research on Extended Expansion GeneralPurpose Engine Theoretical Analysis of Multiple Linkage System and Improvement of Thermal Efficiency", SAE International 2006, doi:https://doi.org/10.4271/2006-32-0101.

39. Pertl, P., Trattner, A., Abis, A., Schmidt, S., et al. "Expansion to Higher Efficiency - Investigations of the Atkinson Cycle in Small Combustion Engines", SAE International 2012, doi:https://doi.org/10.4271/2012-32-0059.

40. Anandhan, M. and Cheng, W.K. "Performance Assessment of Extended Stroke Spark Ignition Engine", SAE International 2018-01-0893, 2018, doi: $10.4271 / 2018-01-0893$.

41. Brendel, M.K., Realisierung eines variablen Kurbeltriebs für einen aufgeladenen Ottomotor. ed. Audi-Dissertationsreihe, Audi AG, ed. Vol. 74. 2013: Cuvillier Verlag. 174.

42. Atkinson, J. "Gas Engine", U.S. Patent

43. Ikeya, K., Takazawa, M., Yamada, T., Park, S., et al., "Thermal Efficiency Enhancement of a Gasoline Engine". 2015, SAE International. p., doi: https://doi.org/10.4271/2015-01-1263.

44. Turner, J.W.G., Popplewell, A., Patel, R., Johnson, T.R., et al., "Ultra Boost for Economy: Extending the Limits of Extreme Engine Downsizing". SAE International Journal of Engines, 2014. 7(1): p. 387-417, doi: 10.4271/2014-01$\underline{1185}$. 
45. Leduc, P., Dubar, B., Ranini, A. and Monnier, G., "Downsizing of Gasoline Engine: an Efficient Way to Reduce CO2 Emissions". Oil \& Gas Science and Technology, 2006. 58(1): p. 115-127, doi: 10.2516/ogst:2003008.

46. Caton, J.A. "A Review of Investigations Using the Second Law of Thermodynamics to Study Internal-Combustion Engines", SAE International 200001-1081, 2000, doi:10.4271/2000-01-1081.

47. Atkinson, J. "Gas Engine", U.S. Patent No.367496, August 1887

48. Kentfield, J.A.C. "Diesel Engines with Extended Expansion Strokes", SAE International 1989, doi:https://doi.org/10.4271/891866.

49. Kentfield, J.A.C. "Alternative Mechanical Arrangements for Diesel and SparkIgnition Engines Employing Extended Expansion Strokes", SAE International 1992, doi:https://doi.org/10.4271/929060.

50. Anderson, M.K., Assanis, D.N. and Filipi, Z. "First and Second Law Analyses of a Naturally-Aspirated, Miller Cycle, SI Engine with Late Intake Valve Closure", SAE International 1998, doi:https://doi.org/10.4271/980889.

51. Feng, R., Li, Y., Yang, J., FU, J., et al. "Investigations of Atkinson Cycle Converted from Conventional Otto Cycle Gasoline Engine", SAE International 2016, doi:https://doi.org/10.4271/2016-01-0680.

52. SAKATA, Y., YAMANA, K., NISHIDA, K., SHIMIZU, T., et al. "A Study on Optimization of an Over-Expansion Cycle Gasoline Engine with Late-Closing of Intake Valves", Consiglio Nazionale delle Ricerche 2007, doi:https://doi.org/10.4271/2007-24-0089.

53. hakariya, M., Toda, T. and Sakai, M. "The New Toyota Inline 4-Cylinder 2.5L Gasoline Engine", 2017, doi:10.4271/2017-01-1021.

54. Jung, H.H., Stein, R.A. and Leone, T.G. "Comparison of Dual Retard VCT to Continuously Variable Event Valvetrain", SAE International 2004, doi:https://doi.org/10.4271/2004-01-1268.

55. Gonca, G., Sahin, B., Parlak, A., Ust, Y., et al., "Theoretical and experimental investigation of the Miller cycle diesel engine in terms of performance and emission parameters". Applied Energy, 2015. 138: p. 11-20, doi: 10.1016/j.apenergy.2014.10.043.

56. Austin, W. "Variable-stroke internal-combustion engine.", U.S. Patent No.1278563A, September 1918. 
57. Wang, C., Daniel, R. and Xu, H. "Research of the Atkinson Cycle in the Spark Ignition Engine", SAE International 2012, doi:https://doi.org/10.4271/2012-01$\underline{0390 .}$.

58. Zhao, J., Li, Y. and $\mathrm{Xu}, \mathrm{F}$. ., "The effects of the engine design and operation parameters on the performance of an Atkinson engine considering heat-transfer, friction, combustion efficiency and variable specific-heat". Energy Conversion and Management, 2017. 151: p. 11-22, doi: 10.1016/j.enconman.2017.08.066.

59. Zhao, J., Xi, Q., Wang, S. and Wang, S., "Improving the partial-load fuel economy of 4-cylinder SI engines by combining variable valve timing and cylinderdeactivation through double intake manifolds". Applied Thermal Engineering, 2018. 141: p. 245-256, doi: 10.1016/j.applthermaleng.2018.05.087.

60. Zhao, J. and Xu, M., "Fuel economy optimization of an Atkinson cycle engine using genetic algorithm". Applied Energy, 2013. 105: p. 335-348, doi: https://doi.org/10.1016/j.apenergy.2012.12.061.

61. KOGA, H. and WATANABE, S. "Research on Extended Expansion GeneralPurpose Engine - Heat Release and Friction", Society of Automotive Engineers of Japan 2007,

62. Takita, Y., Kono, S. and Naoi, A. "Study of Methods to Enhance Energy Utilization Efficiency of Micro Combined Heat and Power Generation Unit-Equipped with an Extended Expansion Linkage Engine and Reduction of Waste Energy", Society of Automotive Engineers of Japan 2011, doi:https://doi.org/10.4271/2011-32-0574.

63. Anandhan, M.M., "Study of extended stroke gasoline engines: a thermodynamic system modelling and analysis of improvement in fuel consumption". 2017, Massachusetts Institute of Technology. p., doi: http://hdl.handle.net/1721.1/114085.

64. Boretti, A. and Scalzo, J. "Exploring the Advantages of Atkinson Effects in Variable Compression Ratio Turbo GDI Engines", 2011, doi:10.4271/2011-01$\underline{0367}$.

65. Pertl, P., Trattner, A., Stelzl, R., Lang, M., et al. "Expansion to Higher Efficiency Experimental Investigations of the Atkinson Cycle in Small Combustion Engines", Society of Automotive Engineers of Japan 2015,

66. Ra, Y. and Reitz, R.D., "A combustion model for IC engine combustion simulations with multi-component fuels". Combustion and flame, 2011. 158(1): p. 69-90, doi: $\underline{10.1016 / j . c o m b u s t f l a m e .2010 .07 .019}$. 
67. Chun, K.M. and Heywood, J.B. "Characterization of Knock in a Spark-Ignition Engine", SAE International 1989, doi:https://doi.org/10.4271/890156.

68. Yang, Z., Miganakallu Narasimhamurthy, N., Miller, T. and Naber, J., "Investigation and Optimization of Cam Actuation of an Over-Expanded Atkinson Cycle Spark-Ignited Engine". SAE International Journal of Advances and Current Practices in Mobility, 2019. 2(1): p. 639-653, doi: 10.4271/2019-01-0250.

69. Amann, M., Alger, T. and Mehta, D., "The Effect of EGR on Low-Speed PreIgnition in Boosted SI Engines". SAE International Journal of Engines, 2011. 4(1): p. 235-245, doi: 10.4271/2011-01-0339.

70. Zhen, X., Wang, Y., Xu, S., Zhu, Y., et al., "The engine knock analysis - An overview". Applied Energy, 2012. 92: p. 628-636, doi: 10.1016/j.apenergy.2011.11.079.

71. Potteau, S., Lutz, P., Leroux, S., Moroz, S., et al. "Cooled EGR for a Turbo SI Engine to Reduce Knocking and Fuel Consumption", SAE International 2007, doi:https://doi.org/10.4271/2007-01-3978.

72. Grandin, B. and Ångström, H.-E. "Replacing Fuel Enrichment in a Turbo Charged SI Engine: Lean Burn or Cooled EGR", SAE International 1999, doi:https://doi.org/10.4271/1999-01-3505.

73. Hudson, C., Gao, X. and Stone, R., "Knock measurement for fuel evaluation in spark ignition engines". Fuel, 2001. 80(3): p. 395-407, doi: https://doi.org/10.1016/S0016-2361(00)00080-6.

74. Bozza, F., De Bellis, V. and Teodosio, L., "Potentials of cooled EGR and water injection for knock resistance and fuel consumption improvements of gasoline engines". Applied Energy, 2016. 169: p. 112-125, doi: 10.1016/j.apenergy.2016.01.129.

75. Wang, Y., Conway, G. and Chadwell, C. "Combined Benefits of Variable Valve Actuation and Low-Pressure EGR on SI Engine Efficiency Part 2: High Load", SAE International 2019, doi:10.4271/2019-01-0237.

76. Alger, T., Gingrich, J., Roberts, C. and Mangold, B., "Cooled exhaust-gas recirculation for fuel economy and emissions improvement in gasoline engines". International Journal of Engine Research, 2011. 12(3): p. 252-264, doi: $\underline{10.1177 / 1468087411402442 .}$. 
77. Wei, H., Zhu, T., Shu, G., Tan, L., et al., "Gasoline engine exhaust gas recirculation - A review". Applied Energy, 2012. 99: p. 534-544, doi: 10.1016/j.apenergy.2012.05.011.

78. Boretti, A., "Water injection in directly injected turbocharged spark ignition engines". Applied Thermal Engineering, 2013. 52(1): p. 62-68, doi: 10.1016/j.applthermaleng.2012.11.016.

79. Miganakallu, N., Naber, J.D., Rao, S., Atkinson, W., et al., "Experimental Investigation of Water Injection Technique in Gasoline Direct Injection Engine". 2017. (58318): p. V001T03A013, doi: 10.1115/ICEF2017-3619.

80. Cordier, M., Lecompte, M., Malbec, L.-M., Reveille, B., et al. "Water Injection to Improve Direct Injection Spark Ignition Engine Efficiency", 2019, doi: $10.4271 / 2019-01-1139$.

81. Zhu, S., Hu, B., Akehurst, S., Copeland, C., et al., "A review of water injection applied on the internal combustion engine". Energy Conversion and Management, 2019. 184: p. 139-158, doi: 10.1016/j.enconman.2019.01.042.

82. Zhao, J., "Research and application of over-expansion cycle (Atkinson and Miller) engines - A review". Applied Energy, 2017. 185: p. 300-319, doi: 10.1016/j.apenergy.2016.10.063.

83. Kutlar, O.A., Arslan, H. and Calik, A.T., "Methods to improve efficiency of four stroke, spark ignition engines at part load". Energy Conversion and Management, 2005. 46(20): p. 3202-3220, doi: 10.1016/j.enconman.2005.03.008.

84. Li, T., Gao, Y., Wang, J. and Chen, Z., "The Miller cycle effects on improvement of fuel economy in a highly boosted, high compression ratio, direct-injection gasoline engine: EIVC vs. LIVC". Energy Conversion and Management, 2014. 79: p. 59-65, doi: $10.1016 /$ j.enconman.2013.12.022.

85. Wan, Y. and Du, A., "Reducing Part Load Pumping Loss and Improving Thermal Efficiency through High Compression Ratio Over-Expanded Cycle". 2013. 1: p., doi: $\underline{10.4271 / 2013-01-1744 .}$.

86. Luisi, S., Doria, V., Stroppiana, A., Millo, F., et al. "Experimental Investigation on Early and Late Intake Valve Closures for Knock Mitigation through Miller Cycle in a Downsized Turbocharged Engine", 2015, doi:10.4271/2015-01-0760.

87. Pertl, P., Lang, M., Schmidt, S. and Kirchberger, R., "Mass Balancing Measures of a Linkage-Based Extended Expansion Engine". SAE International Journal of Engines, 2016. 9(4): p. 2498-2507, doi: https://doi.org/10.4271/2016-32-0096. 
88. Kojima, S., Kiga, S., Moteki, K., Takahashi, E., et al. "Development of a New 2L Gasoline VC-Turbo Engine with the World's First Variable Compression Ratio Technology", SAE International 2018, doi:https://doi.org/10.4271/2018-01-0371.

89. Woschni, G. "A universally applicable equation for the instantaneous heat transfer coefficient in the internal combustion engine", 1967 , doi:https://doi.org/10.4271/670931.

90. Gamma Technologies Inc. GT-Suite User's Manual version ed. Gamma Technologies Inc, ed. Vol. 2016.

91. Wang, Y., Conway, G. and Chadwell, C. "Combined Benefits of Variable Valve Actuation and Low-Pressure EGR on SI Engine Efficiency Part 1: Part Load", SAE International 2019, doi:https://doi.org/10.4271/2019-01-0241.

92. Zhao, H., Advanced Direct Injection Combustion Engine Technologies and Development: Gasoline and Gas Engines. ed., ed. Vol. 1. 2009: Woodhead Publishing.

93. Costa, R.C. and Sodré, J.R., "Compression ratio effects on an ethanol/gasoline fuelled engine performance". Applied Thermal Engineering, 2011. 31(2-3): p. 278283, doi: 10.1016/j.applthermaleng.2010.09.007.

94. Crabb, D., Fleiss, M., Larsson, J.-E. and Somhorst, J., "New Modular Engine Platform from Volvo". MTZ worldwide, 2013. 74(9): p. 4-11, doi: 10.1007/s38313013-0081-9.

95. Sagñay Aucancela, R.D., "Determinar las características del motor 3.71 v6 TI-VCT DOHC de la camioneta FORD F 150 y su rendimiento con el uso de biocombustible en el periodo 2014-2015". 2016, Riobamba, UNACH 2016. p., doi: http://dspace.unach.edu.ec/handle/51000/2869.

96. Mittal, V., Revier, B.M. and Heywood, J.B. "Phenomena that Determine Knock Onset in Spark-Ignition Engines", SAE International 2007, doi:https://doi.org/10.4271/2007-01-0007.

97. Kojima, S. "Development of High-Performance and Low-Emission Gasoline Engine", SAE International 2008, doi:https://doi.org/10.4271/2008-01-0608. 


\section{Appendix}

\section{A Mechanism Geometric Specification}

\begin{tabular}{ccc}
\hline \hline CR & CR 9.2 OER1.5 & CR 10.5 OER1.5 \\
\hline ER & 9.2 & 10.5 \\
OER & 13.8 & 15.8 \\
Bore & 1.5 & 1.50 \\
Compression Stroke & $86 \mathrm{~mm}$ & $86 \mathrm{~mm}$ \\
Intake Stroke & $86 \mathrm{~mm}$ & $86 \mathrm{~mm}$ \\
$\mathbf{l}_{\mathbf{4}}$ & $86 \mathrm{~mm}$ & $86 \mathrm{~mm}$ \\
$\mathbf{l}_{\mathbf{2}}$ & $221.4 \mathrm{~mm}$ & $221.4 \mathrm{~mm}$ \\
$\mathbf{l}_{\mathbf{1}}$ & $83.1 \mathrm{~mm}$ & $83.1 \mathrm{~mm}$ \\
$\mathbf{l}_{3}$ & $161.0 \mathrm{~mm}$ & $164.6 \mathrm{~mm}$ \\
$\mathbf{r}_{\mathbf{c}}$ & $165.0 \mathrm{~mm}$ & $165.0 \mathrm{~mm}$ \\
$\mathbf{r}_{\mathbf{p}}$ & $35.2 \mathrm{~mm}$ & $35.2 \mathrm{~mm}$ \\
$\boldsymbol{\delta}$ & $5.1 \mathrm{~mm}$ & $51.1 \mathrm{~mm}$ \\
$\boldsymbol{\alpha}$ & $60 \mathrm{~mm}$ & $60 \mathrm{~mm}$ \\
\hline \hline
\end{tabular}




\section{B Fuel Report}

Workorder: 187593 MICH TECH-021413

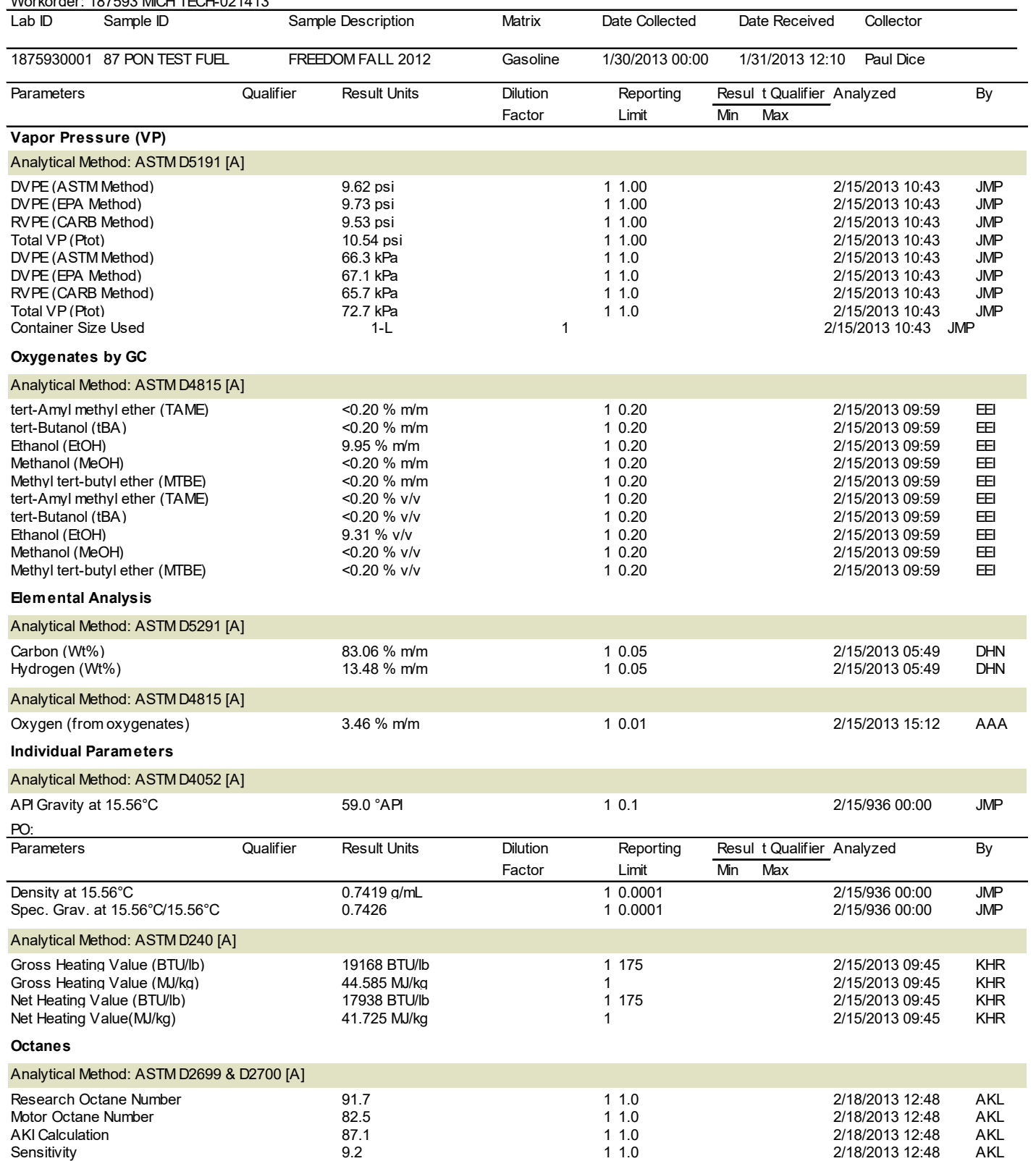




\section{Copyright documentation}

SAE International Journal of Advances and Current Practices in Mobility, 2019-01-0250

${ }_{0}^{\substack{\text { Copyright } \\ \text { Center }}}$ Marketplace

\section{SAE International - License Terms and Conditions}

$\begin{array}{ll}\text { Order Date } & 31-\text { Oct-2019 } \\ \text { Order license ID } & 1001622-1 \\ \text { ISSN } & 0148-7191 \\ \text { Type of Use } & \text { Republish in a thesis/dissertation } \\ \text { Publisher } & \text { SOCIETY OF AUTOMOTIVE ENGINEERS, } \\ \text { Portion } & \text { Chapter/article }\end{array}$

\section{LICENSED CONTENT}

Publication Title

Author/Editor

Date

Language
SAE technical paper series SOCIETY OF AUTOMOTIVE ENGINEERS.

01/01/1970

English
Country

Rightsholder

Publication Type
United States of America

SAE International

Monographic Series

\section{REQUEST DETAILS}

Portion Type
Page range(s)
Total number of pages
Format (select all that
apply)
Who will republish the
content?
Duration of Use
Lifetime Unit Quantity

NEW WORK DETAILS

\section{Chapter/article}

639-653

15

Print, Electronic

Author of requested content

Life of current edition

More than 2,000,000
Rights Requested

Distribution

Translation

Copies for the disabled?

Minor editing privileges?

Incidental promotional

use?

Currency

\section{Main product}

Worldwide

Original language of publication

Yes

No

No

USD
Title

Instructor name
Investigation and Optimization of Cam Actuation of an OverExpanded Atkinson Cycle Spark-Ignited Engine

Jeffrey D. Naber
Institution name

Expected presentation

date
Michigan Technological University

2019-11-20

ADDITIONAL DETAILS

Order reference number

SAE 2019-01-0250

The requesting person /
organization to appear

Zhuyong Yang 


\begin{tabular}{|c|c|c|c|}
\hline $\begin{array}{l}\text { Title, description or } \\
\text { numeric reference of the } \\
\text { portion(s) }\end{array}$ & $\begin{array}{l}\text { SAE International Journal } \\
\text { of Advances and Current } \\
\text { Practices in Mobility }\end{array}$ & $\begin{array}{l}\text { Title of the } \\
\text { article/chapter the } \\
\text { portion is from }\end{array}$ & $\begin{array}{l}\text { SAE International Journal } \\
\text { of Advances and Current } \\
\text { Practices in Mobility }\end{array}$ \\
\hline Editor of portion(s) & Mohamed El-Sayed & \multirow[t]{2}{*}{ Author of portion(s) } & SOCIETY OF AUTOMOTIVE \\
\hline Volume of serial or & $1(2)$ & & ENGINEERS. \\
\hline monograph & & \multirow{2}{*}{$\begin{array}{l}\text { Issue, if republishing an } \\
\text { article from a serial }\end{array}$} & \multirow[t]{2}{*}{$\mathrm{N} / \mathrm{A}$} \\
\hline Page or page range of & $639-653$ & & \\
\hline portion & & $\begin{array}{l}\text { Publication date of } \\
\text { portion }\end{array}$ & 1970-01-01 \\
\hline
\end{tabular}

\section{Republication Terms and Conditions}

1. Description of Service; Defined Terms. This Republication License enables the User to obtain licenses for republication of one or more copyrighted works as described in detail on the relevant Order Confirmation (the "Work(s)"). Copyright Clearance Center, Inc. ("CCC") grants licenses through the Service on behalf of the rightsholder identified on the Order Confirmation (the "Rightsholder"). "Republication", as used herein, generally means the inclusion of a Work, in whole or in part, in a new work or works, also as described on the Order Confirmation. "User", as used herein, means the person or entity making such republication.

2. The terms set forth in the relevant Order Confirmation, and any terms set by the Rightsholder with respect to a particular Work, govern the terms of use of Works in connection with the Service. By using the Service, the person transacting for a republication license on behalf of the User represents and warrants that he/she/it (a) has been duly authorized by the User to accept, and hereby does accept, all such terms and conditions on behalf of User, and (b) shall inform User of all such terms and conditions. In the event such person is a "freelancer" or other thirc party independent of User and CCC, such party shall be deemed jointly a "User" for purposes of these terms and conditions. In any event, User shall be deemed to have accepted and agreed to all such terms and conditions if User republishes the Work in any fashion.

3. Scope of License; Limitations and Obligations.

3.1. All Works and all rights therein, including copyright rights, remain the sole and exclusive property of the Rightsholder. The license created by the exchange of an Order Confirmation (and/or any invoice) and payment by User of the full amount set forth on that document includes only those rights expressly set forth in the Order Confirmation and in these terms and conditions, and conveys no other rights in the Work(s) to User. All rights not expressly granted are hereby reserved.

3.2. General Payment Terms: You may pay by credit card or through an account with us payable at the end of the month. If you and we agree that you may establish a standing account with CCC, then the following terms apply: Remit Payment to: Copyright Clearance Center, 29118 Network Place, Chicago, IL 60673-1291. Payments Due: Invoices are payable upon their delivery to you (or upon our notice to you that they are available to you for downloading). After 30 days, outstanding amounts will be subject to a service charge of $1-1 / 2 \%$ per month or, if less, the maximum rate allowed by applicable law. Unless otherwise specifically set forth in the Order Confirmation or in a separate written agreement signed by CCC, invoices are due and payable on "net 30" terms. While User may exercise the rights licensed immediately upon issuance of the Order Confirmation, the license is automatically revoked and is null and void, as if it had never been issued, if complete payment for the license is not received on a timely basis either from User directly or through a payment agent, such as a credit card company.

3.3 .

Unless otherwise provided in the Order Confirmation, any grant of rights to User (i) is "one-time" (including the editions and product family specified in the license), (ii) is non-exclusive and non-transferable and (iii) is subject to any and all limitations and restrictions (such as, but not limited to, limitations on duration of use or circulation) included in the Order Confirmation or invoice and/or in these terms and conditions. Upon completion of the licensed use, User shall either secure a new permission for further use of the Work(s) or immediately cease any new use of the Work(s) and shall render inaccessible (such as by 
deleting or by removing or severing links or other locators) any further copies of the Work (except for copies printed on paper in accordance with this license and still in User's stock at the end of such period).

3.4. In the event that the material for which a republication license is sought includes third party materials (such as photographs, illustrations, graphs, inserts and similar materials) which are identified in such material as having been used by permission, User is responsible for identifying, and seeking separate licenses (under this Senvice or otherwise) for, any of such third party materials; without a separate license, such third party materials may not be used.

3.5. Use of proper copyright notice for a Work is required as a condition of any license granted under the Service. Unless otherwise provided in the Order Confirmation, a proper copyright notice will read substantially as follows: "Republished with permission of [Rightsholder's name], from [Work's title, author, volume, edition number and year of copyright]; permission conveyed through Copyright Clearance Center, Inc. " Such notice must be provided in a reasonably legible font size and must be placed either immediately adjacent to the Work as used (for example, as part of a by-line or footnote but not as a separate electronic link) or in the place where substantially all other credits or notices for the new work containing the republished Work are located. Failure to include the required notice results in loss to the Rightsholder and CCC, and the User shall be liable to pay liquidated damages for each such failure equal to twice the use fee specified in the Order Confirmation, in addition to the use fee itself and any other fees and charges specified.

3.6. User may only make alterations to the Work if and as expressly set forth in the Order Confirmation. No Work may be used in any way that is defamatory, violates the rights of third parties (including such third parties' rights of copyright, privacy, publicity, or other tangible or intangible property), or is otherwise illegal, sexually explicit or obscene. In addition, User may not conjoin a Work with any other material that may result in damage to the reputation of the Rightsholder. User agrees to inform CCC if it becomes aware of any infringement of any rights in a Work and to cooperate with any reasonable request of CCC or the Rightsholder in connection therewith.

4. Indemnity. User hereby indemnifies and agrees to defend the Rightsholder and CCC, and their respective employees and directors, against all claims, liability, damages, costs and expenses, including legal fees and expenses, arising out of any use of a Work beyond the scope of the rights granted herein, or any use of a Work which has been altered in any unauthorized way by User, including claims of defamation or infringement of rights of copyright, publicity, privacy or other tangible or intangible property.

5. Limitation of Liability. UNDER NO CIRCUMSTANCES WILL CCC OR THE RIGHTSHOLDER BE LIABLE FOR ANY DIRECT, INDIRECT, CONSEQUENTIAL OR INCIDENTAL DAMAGES (INCLUDING WITHOUT LIMITATION DAMAGES FOR LOSS OF BUSINESS PROFITS OR INFORMATION, OR FOR BUSINESS INTERRUPTION) ARISING OUT OF THE USE OR INABILITY TO USE A WORK, EVEN IF ONE OF THEM HAS BEEN ADVISED OF THE POSSIBILITY OF SUCH DAMAGES. In any event, the total liability of the Rightsholder and CCC (including their respective employees and directors) shall not exceed the total amount actually paid by User for this license. User assumes full liability for the actions and omissions of its principals, employees, agents, affiliates, successors and assigns.

6. Limited Warranties. THE WORK(S) AND RIGHT(S) ARE PROVIDED "AS IS". CCC HAS THE RIGHT TO GRANT TO USER THE RIGHTS GRANTED IN THE ORDER CONFIRMATION DOCUMENT, CCC AND THE RIGHTSHOLDER DISCLAIM ALL OTHER WARRANTIES RELATING TO THE WORK(S) AND RIGHT(S), EITHER EXPRESS OR IMPLIED, INCLUDING WITHOUT LIMITATION IMPLIED WARRANTIES OF MERCHANTABILITY OR FITNESS FOR A PARTICULAR PURPOSE. ADDITIONAL RIGHTS MAY BE REQUIRED TO USE ILLUSTRATIONS, GRAPHS, PHOTOGRAPHS, ABSTRACTS, INSERTS OR OTHER PORTIONS OF THE WORK (AS OPPOSED TO THE ENTIRE WORK) IN A MANNER CONTEMPLATED BY USER; USER UNDERSTANDS AND AGREES THAT NEITHER CCC NOR THE RIGHTSHOLDER MAY HAVE SUCH ADDITIONAL RIGHTS TO GRANT.

Effect of Breach. Any failure by User to pay any amount when due, or any use by User of a Work beyond the scope of the license set forth in the Order Confirmation and/or these terms and conditions, shall be a material breach of the license created by the Order Confirmation and these terms and conditions. Any breach not cured within 30 
days of written notice thereof shall result in immediate termination of such license without further notice. Any unauthorized (but licensable) use of a Work that is terminated immediately upon notice thereof may be liquidated by payment of the Rightsholder's ordinary license price therefor; any unauthorized (and unlicensable) use that is not terminated immediately for any reason (including, for example, because materials containing the Work cannot reasonably be recalled) will be subject to all remedies available at law or in equity, but in no event to a payment of less than three times the Rightsholder's ordinary license price for the most closely analogous licensable use plus Rightsholder's and/or CCC's costs and expenses incurred in collecting such payment.

8. Miscellaneous.

8.1. User acknowledges that CCC may, from time to time, make changes or additions to the Service or to these terms and conditions, and CCC reserves the right to send notice to the User by electronic mail or otherwise for the purposes of notifying User of such changes or additions; provided that any such changes or additions shall not apply to permissions already secured and paid for.

8.2. Use of User-related information collected through the Service is governed by CCC's privacy policy, available online here: https://marketplace.copyright.com/rs-ui-web/mp/privacy-policy

8.3. The licensing transaction described in the Order Confirmation is personal to User. Therefore, User may not assign or transfer to any other person (whether a natural person or an organization of any kind) the license created by the Order Confirmation and these terms and conditions or any rights granted hereunder; provided, however, that User may assign such license in its entirety on written notice to CCC in the event of a transfer of all or substantially all of User's rights in the new material which includes the Work(s) licensed under this Service.

8.4. No amendment or waiver of any terms is binding unless set forth in writing and signed by the parties. The Rightsholder and CCC hereby object to any terms contained in any writing prepared by the User or its principals, employees, agents or affiliates and purporting to govern or otherwise relate to the licensing transaction described in the Order Confirmation, which terms are in any way inconsistent with any terms set forth in the Order Confirmation and/or in these terms and conditions or CCC's standard operating procedures, whether such writing is prepared prior to, simultaneously with or subsequent to the Order Confirmation, and whether such writing appears on a copy of the Order Confirmation or in a separate instrument.

8.5. The licensing transaction described in the Order Confirmation document shall be governed by and construed under the law of the State of New York, USA, without regard to the principles thereof of conflicts of law. Any case, controversy, suit, action, or proceeding arising out of, in connection with, or related to such licensing transaction shall be brought, at CCC's sole discretion, in any federal or state court located in the County of New York, State of New York, USA, or in any federal or state court whose geographical jurisdiction covers the location of the Rightsholder set forth in the Order Confirmation. The parties expressly submit to the personal jurisdiction and venue of each such federal or state court.If you have any comments or questions about the Service or Copyright Clearance Center, please contact us at 978-750 8400 or send an e-mail to info@copyright.com. 